
FIRING MEMBRANES 


\section{Promotiecommissie:}

prof. dr. ir. J.W.M. Hilgenkamp (Voorzitter) Universiteit Twente

prof. dr. ir. Arian Nijmeijer (Promotor) Universiteit Twente

prof. dr. ir. Nieck E. Benes (Promotor) Universiteit Twente

prof. dr.-ing. habil. Roland Dittmeyer Karlsruhe Institute of Technology

dr. Anne Julbe Institut Européen des Membranes

dr. Wilhelm A. Meulenberg Forschungszentrum Jülich

prof. dr. ir. Freek Kapteijn Technische Universiteit Delft

prof. dr. Guido Mul Universiteit Twente

prof. dr. ir. André ten Elshof Universiteit Twente

Omslagontwerp door Ton en Jolien Kappert \& Karin Platenkamp

Firing membranes

ISBN: 978-90-365-3819-0

DOI: $10.3990 / 1.9789036538190$

URL: http://dx.doi.org/10.3990/1.9789036538190

Printed by: Ipskamps Drukkers, Enschede

C Copyright 2015 Emiel J. Kappert 


\title{
FIRING MEMBRANES
}

\author{
PROEFSCHRIFT
}

ter verkrijging van

de graad van doctor aan de Universiteit Twente, op gezag van de rector magnificus,

prof. dr. H. Brinksma,

volgens besluit van het College voor Promoties

in het openbaar te verdedigen

op vrijdag 13 februari 2015 om 14:45 uur

door

\author{
Emiel Jan Kappert \\ geboren op 10 maart 1986 \\ te Hellendoorn, Nederland
}


Dit proefschrift is goedgekeurd door de promotoren:

prof. dr. ir. Arian Nijmeijer (Promotor)

prof. dr. ir. Nieck E. Benes (Promotor) 

This work is financially supported by the University of Twente, Inorganic Membranes Chair, and the Helmholtz Alliance MEM-BRAIN, funded by the Initiative and Networking Fund of the Helmholtz Association. 


\section{Table of contents}

Table of contents...............................................................................

Summary ......................................................................................11

Samenvatting ...................................................................................... 15

Chapter 1 Introduction to the thermal processing of inorganic, hybrid, and organic membrane materials.......................................19

1.1. On membranes \& heat …………………………………………....... 20

1.2. Thermally stimulated processes........................................................2

1.3. Thermodynamics and kinetics.........................................................32

1.4. Analysis and characterization techniques.......................................32

1.5. Thesis outline …………………………………………………......... 34

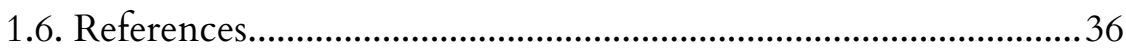

Chapter 2 Formation and prevention of fractures in sol-gel-derived thin films ................................................................................... 41

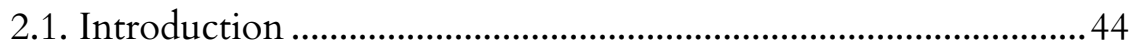

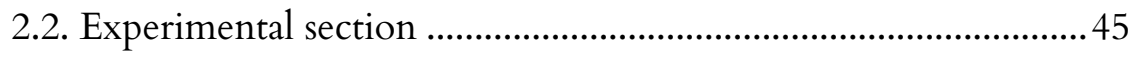

2.3. Results and discussion ................................................................. 48

2.4. Conclusions .................................................................................. 58

2.5. Acknowledgments ......................................................................5

2.6. Appendices …………………………………………………..... 59

2.7. References..................................................................................63

Chapter 3 Expeditious calcination of inorganic membranes by an instant temperature increment .......................................................67

3.1. Introduction …………………………………………………......

3.2. Experimental section ………………………………………….... 72 


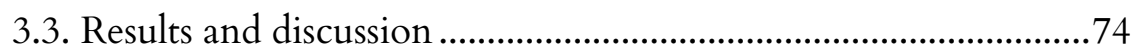

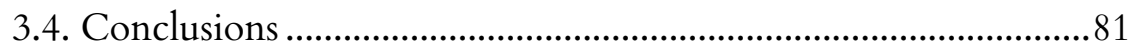

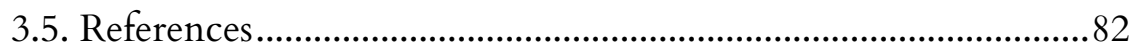

Chapter 4 Kinetic analysis of the thermal processing of silica and organosilica ..............................................................................85

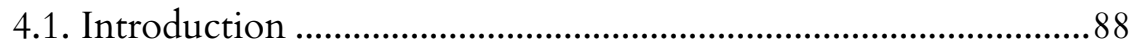

4.2. Experimental section...................................................................90

4.3. Results and discussion .............................................................93

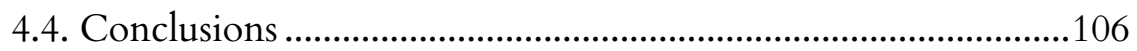

4.5. Acknowledgements ....................................................................108

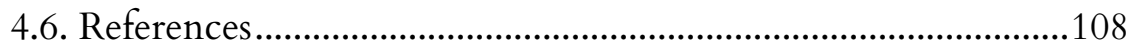

Chapter 5 Temperature calibration procedure for thin film substrates for thermo-ellipsometric analysis using melting point standards113

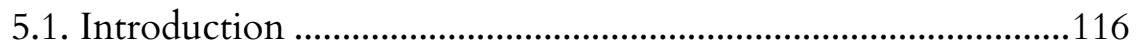

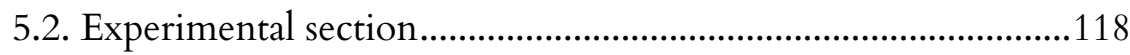

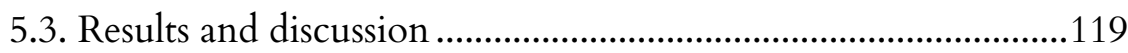

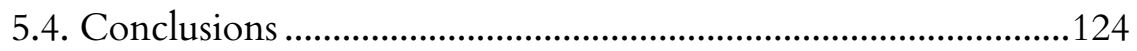

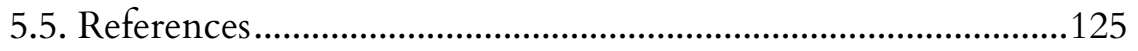

Chapter 6 Thermal stability of sulfonated poly(ether ether ketone): on the role of protodesulfonation ...............................................127

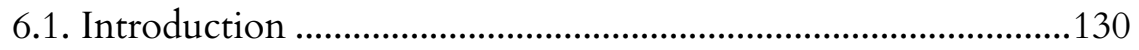

6.2. Experimental section..................................................................131

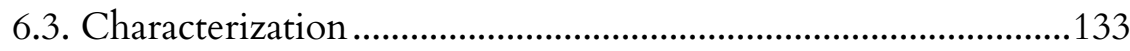

6.4. Results and discussion ..................................................................136

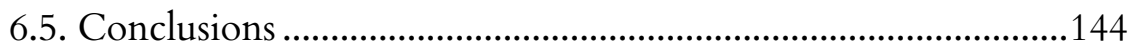

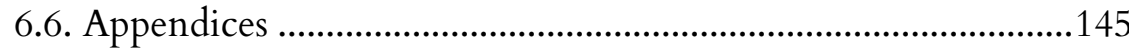


6.7. References.

Chapter 7 Thermal imidization kinetics of ultrathin films of hybrid poly(POSS-imide)s

7.1. Introduction 156

7.2. Experimental section 158

7.3. Results and discussion 163

7.4. Conclusion 175

7.5. Appendices 176

7.6. References. 178

Chapter 8 Highly permeable and mechanically robust silicon carbide hollow fiber membranes. 183

8.1. Introduction 186

8.2. Experimental section 186

8.3. Results and discussion. 191

8.4. Conclusions 202

8.5. Acknowledgements 202

8.6. References. 203

Chapter 9 Reflections \& Perspectives.........................................207

9.1. Reflections 209

9.2. Perspectives 213

9.3. References. 220

Epilogue: Turn it on again? 225

Dankwoord 227

Curriculum Vitae 233

List of publications 235 


\section{Summary}

Thermal processing is commonly employed to alter the chemistry and microstructure of membrane layers. It can shape, strengthen, and give functionality to a membrane. A good understanding of the processes taking place during the thermal processing of a membrane material allows for optimization and tuning of the membrane properties.

The introductory Chapter 1 presents a broad overview of the processes that can take place upon heating a membrane. The thermal processing of inorganic, organic, and hybrid materials is considered, and where possible, the related similarities and differences are explained. The chapter briefly reviews the thermodynamics and kinetics of thermally stimulated processes, and provides a short overview of the common thermal analysis methods.

Chapter 2 describes the mechanisms behind the fracturing of ultrathin solgel-derived films during drying. The resistance to fracturing is explained in terms of the critical thickness $h_{c}$, above which the stresses that accumulate in a material are released through the formation of propagating cracks. The development of an image analysis algorithm allows for the detection of these cracks in optical micrographs and for the calculation of the crack density and inter-crack spacing. The thickness dependency of the crack density shows that silica films, with $h_{\mathrm{c}}=300 \mathrm{~nm}$, are more prone to fracturing than organosilica films, for which $h_{\mathrm{c}}$ is found to be $>1250 \mathrm{~nm}$. These results confirm that ultrathin organosilica coatings can be used as a robust silica substitute for a wide range of applications.

The fact that silica is resistant to fracturing as long as drying cracks are avoided is exploited in Chapter 3, in which the expedited thermal processing of mesoporous and microporous membrane layers is reported. Calcinations have been performed by exposing the samples to an instant temperature increment. This approach requires only $3 \%$ of the conventional processing time. The performance of the $\gamma$-alumina and silica membranes, obtained by an instantaneous increase in temperature to 
$600{ }^{\circ} \mathrm{C}$, is comparable to those synthesized via the conventional calcination steps. Although the prevention of defect formation needs continuous attention, the developed method is easily scalable to larger surface areas and other membrane geometries.

In Chapter 4, the kinetics of the thermal processing of silica and organosilica are studied in detail. At elevated temperatures, the following reactions take place in the material: dehydration, dehydroxylation, and decomposition of the organic moiety (only for organosilica). The dehydroxylation step is desired for synthesizing high-performance (organo)silica membranes, whereas the decomposition step should typically be avoided. The developed kinetic model allows for a full prediction of the reaction kinetics. For silica, it is found that dehydration and dehydroxylation can be performed under either air or nitrogen atmosphere, and under a wide variety of thermal programs. For organosilica, even under inert atmosphere, full thermal dehydroxylation cannot be achieved without affecting the organic moiety in the material. This indicates that prudence in designing a heat-treatment program for hybrid materials is required.

Chapter 5 proposes a simple and generic method for the temperature calibration of a substrate-film interface temperature by spectroscopic ellipsometry. The method is adapted from temperature calibration methods that are well developed for conventional thermal analysis instruments, and is based on detecting the melting point of metals. Detecting a change in $\Psi$ or signal intensity by ellipsometry allows for the detection of the phase transition temperature, which can be used for construction of a linear calibration curve with an accuracy of $1.3{ }^{\circ} \mathrm{C}$ over the full temperature range.

This temperature calibration is required for Chapter 6, where the stability of sulfonated poly(ether ether ketone) (SPEEK) films at moderate temperatures is studied. Undesired reactions of the sulfonic acid groups in SPEEK can be avoided by exchanging the sulfonate proton by a sodium 
counter ion. Without this exchange, prolonged exposure to temperatures as low as $160{ }^{\circ} \mathrm{C}$ induces irreversible changes to thin films of SPEEK. If not stabilized by $\mathrm{Na}^{+}$, higher temperatures $\left(>195{ }^{\circ} \mathrm{C}\right)$ lead to a secondary reaction, causing degradation of the material and removal of sulfur dioxide from the polymer. Because sulfuric acid and solvents can be excluded as the sulfur source in our experiments, the findings directly relate to the thermal stability of SPEEK. The findings in the present study have strong implications for the thermal processing of SPEEK, and the same reaction mechanisms may potentially be found in other sulfonated polymers.

Chapter 7 provides new insights in the thermal imidization of alternating hybrid inorganic-organic network polymers. Here, the hybrid material consists of polyhedral oligomeric silsesquioxane (POSS) cages that are covalently bridged by (amic acid) groups. In addition to the thermal imidization, a thermally stimulated silanol condensation is detected, resulting from partially opened POSS-cages. During the imidization step, the shrinkage of the material shows an inverse relation with the length of the organic bridging group. Whereas a comparable mass loss is recorded for the five different bridging groups with different lengths, shorter organic linkers hamper the network mobility, resulting in a lower shrinkage than that recorded for the longer organic bridging groups. The thermal imidization, which sets on at $150{ }^{\circ} \mathrm{C}$, follows a decelerating reaction mechanism and shows a higher activation energy than the imidization of purely organic polyimides. The distinct imidization kinetics underline the strongly different characteristics of the hyper-cross-linked hybrid materials.

Chapter 8 details the thermal processing steps required to obtain silicon carbide ( $\mathrm{SiC}$ ) hollow fiber membranes with sufficient mechanical strength for membrane applications. Relatively strong fibers have been obtained after thermal processing at $1500{ }^{\circ} \mathrm{C}$, but these fibers still contain considerable amount of residual carbon from the polymer binder. Treatment at $1790{ }^{\circ} \mathrm{C}$ removes the carbon, but results in a decreased 
mechanical strength; only after treatment at very high temperatures of $2075{ }^{\circ} \mathrm{C}$, the $\mathrm{SiC}$ particles sinter together, resulting in fibers with mechanical strengths of 30-40 $\mathrm{MPa}$ and exceptionally high water permeabilities of $50,000 \mathrm{~L} \mathrm{~m}^{-2} \mathrm{~h}^{-1} \mathrm{bar}^{-1}$. Combined with the unique chemical and thermal resistance of silicon carbide, these properties make the fibers suitable for application as a microfiltration membrane or as a membrane support for application under demanding conditions.

The final Chapter 9 reflects on the results obtained in this thesis, synthesizes the knowledge obtained in this thesis, and offers guidance on the different approaches that can be followed to study thermal processing of membrane materials. 


\section{Samenvatting}

Membraanlagen kunnen een warmtebehandeling ondergaan om de samenstelling en microstructuur van de laag te veranderen. Deze warmtebehandeling kan worden toegepast om het membraan vorm te geven, te versterken of van functionaliteit te voorzien. Als de processen die tijdens de warmtebehandeling van het membraanmateriaal plaatsvinden goed worden begrepen, dan kan de kennis hiervan worden toegepast voor het optimaliseren van membraaneigenschappen.

Hoofdstuk 1 geeft een overzicht van de processen die plaats kunnen vinden wanneer een membraan verwarmd wordt. De warmtebehandeling van anorganische, organische en hybride materialen wordt besproken en waar mogelijk worden de overeenkomsten en verschillen tussen de behandeling van deze verschillende materialen aangegeven. De thermodynamica en kinetiek van thermisch geactiveerde processen wordt kort besproken en een bondig overzicht van standaardmethoden voor thermische analyse wordt gegeven.

Hoofdstuk 2 beschrijft het mechanisme dat verantwoordelijk is voor het breken van ultradunne, via sol-gelchemie verkregen lagen gedurende het drogen. De weerstand tegen breuk wordt verklaard vanuit de kritische dikte $h_{c}$, boven welke de spanningen die zich opbouwen in het materiaal zich loslaten door de formering van een voortplantende breuk. Door middel van een beeldanalysealgoritme kunnen breuken gedetecteerd worden in optischemicroscopiefoto's en kunnen de breukdichtheid en de interbreukafstand berekend worden. De dikteafhankelijkheid van de breukdichtheid laat zien dat silicalagen, met $h_{\mathrm{c}}=300 \mathrm{~nm}$, vatbaarder zijn voor breuk dan organosilicalagen, waarvoor $h_{\mathrm{c}}$ bepaald is op >1250 nm. Deze resultaten bevestigen dat ultradunne organosilicalagen een robuust alternatief voor silica zijn in een brede reeks toepassingen.

Het feit dat silica een hoge breukweerstand heeft zo lang droogbreuken vermeden worden, wordt benut in Hoofdstuk 3, waarin de snelle 
warmtebehandeling van meso- en microporeuze lagen wordt gerapporteerd. De membraanlagen zijn gecalcineerd door ze bloot te stellen aan een instantane temperatuurverhoging. Door deze aanpak is slechts $3 \%$ van de tijd van conventionele warmtebehandelingen nodig. De prestatie van de $\gamma$-alumina- en silicamembranen die zijn verkregen door een plotse blootstelling aan $600{ }^{\circ} \mathrm{C}$, is vergelijkbaar met membranen die via de conventionele procedure verkregen zijn. Ofschoon het voorkomen van defectvorming continue aandacht vraagt, kan deze methode eenvoudig opgeschaald worden naar grotere oppervlakten en andere membraangeometrieën.

In Hoofdstuk 4 wordt de kinetiek van de warmtebehandeling van silica en organosilica tot in detail bestudeerd. Bij verhoogde temperaturen kunnen dehydratie-, dehydroxylering- en ontledingsreacties plaatsvinden in het materiaal. De dehydroxyleringstap is gewenst voor het maken van hoogwaardige (organo)silicamembranen, maar de decompositie van het organisch gedeelte dient over het algemeen te worden voorkomen. Het ontwikkelde kinetische model kan gebruikt worden om de reactiekinetiek volledig te voorspellen. De warmtebehandeling van silica blijkt zowel onder lucht als stikstof te kunnen worden uitgevoerd onder een grote verscheidenheid van temperatuurprogramma's. Voor organosilica kan zelfs onder een inerte atmosfeer geen volledige dehydroxylering bereikt worden zonder de organische brug aan te tasten. Dit geeft aan dat voorzichtigheid geboden is bij het ontwikkelen van een warmtebehandelingsprogramma van hybride materialen.

In Hoofdstuk 5 wordt een simpele en algemene methode voor de kalibratie van de substraat-laaggrensvlaktemperatuur door middel van spectroscopische ellipsometrie voorgesteld. Deze methode is afgeleid van temperatuurkalibratiemethoden die doorontwikkeld zijn voor traditionele thermische-analyse-apparatuur en is gebaseerd op het detecteren van het smeltpunt van metalen. Het detecteren van een verandering in $\Psi$ of in de meetsignaalintensiteit door middel van ellipsometriemetingen kan gebruikt 
worden voor de detectie van een faseovergangstemperatuur. Deze temperaturen worden dan gebruikt voor het construeren van een lineaire ijklijn met een nauwkeurigheid van $1.3{ }^{\circ} \mathrm{C}$ over het gehele temperatuurbereik.

Deze temperatuurkalibratie wordt toegepast in Hoofdstuk 6, waarin de stabiliteit van gesulfoneerde poly(etheretherketon)lagen (SPEEK) op gematigde temperatuur wordt bestudeerd. Ongewenste reacties van de sulfonzuurgroep in SPEEK kunnen voorkomen worden door het uitwisselen van het sulfonaatproton door een natriumion. Zonder deze uitwisseling leidt langdurige blootstelling aan temperaturen boven $160{ }^{\circ} \mathrm{C}$ al tot een onomkeerbare verandering in dunne lagen van SPEEK en leiden hogere temperaturen $\left(>195{ }^{\circ} \mathrm{C}\right)$ tot een verdere degradatie van het polymeer, die gepaard gaat met de verwijdering van zwaveldioxide. Omdat zwavelzuur en oplosmiddelen uitgesloten konden worden als de zwavelbron in onze experimenten, slaan deze constateringen direct terug op de thermische stabiliteit van SPEEK. De bevindingen in dit onderzoek hebben belangrijke implicaties voor het thermisch behandelen van SPEEK; voorts kunnen dezelfde reactiemechanismen waarschijnlijk teruggevonden worden in andere gesulfoneerde polymeren.

Hoodstuk 7 biedt nieuw inzicht in het thermisch imidiseren van alternerend anorganisch-organisch hybride netwerkpolymeren. In deze studie bestaat het hybride materiaal uit polyedrischoligomerisch-silsesquioxaan (POSS) kooien die covalent gebrugd zijn door amidocarbonzuurgroepen. Tijdens de imidiseringstap houdt de krimp van het materiaal een invers verband met de lengte van de organische bruggroep. Naast de thermische imidisering werd een thermisch geactiveerde silanolcondensatie ten gevolge van partieel geopende POSSkooien waargenomen. Hoewel een vergelijkbaar massaverlies gemeten wordt voor de vijf verschillende bruggroepen, belemmeren korte organische bruggen de netwerkmobiliteit, hetgeen resulteert in een lagere krimp dan gemeten wordt voor de langere organische bruggroepen. De 
thermische imidisering, die begint op $150{ }^{\circ} \mathrm{C}$, laat een afremmende reactiesnelheid zien en heeft een hogere activeringsenergie dan de imidisering van een puur organisch polyimide. De verschillen tussen de imidiseringkinetiek onderstreept de sterk afwijkende eigenschappen van het hyperverknoopte hybride netwerkmateriaal ten opzichte van haar organische tegenhanger.

Hoofdstuk 8 beschrijft de verschillende warmtebehandelingen die nodig zijn om siliciumcarbide $(\mathrm{SiC})$ hollevezelmembranen te verkrijgen met voldoende mechanische sterkte voor membraantoepassingen. Relatief sterke vezels werden verkregen na het thermisch behandelen op $1500{ }^{\circ} \mathrm{C}$, maar deze vezels bevatten nog steeds een behoorlijke hoeveelheid achterblijvend koolstof uit de polymeer binder. Bij behandeling op $1790{ }^{\circ} \mathrm{C}$ wordt het koolstof verwijderd, maar heeft een verminderde mechanische sterkte ten gevolg; pas na behandeling op een erg hoge temperatuur van $2075^{\circ} \mathrm{C}$ sinteren de SiC-deeltjes samen en leidt de behandeling tot een sterkte van 30-40 MPa en een exceptioneel hoge schoonwaterpermeabiliteit van $50.000 \mathrm{~L} \mathrm{~m}^{-2} \mathrm{~h}^{-1} \mathrm{bar}^{-1}$. In combinatie met de unieke chemische en thermische stabiliteit van siliciumcarbide maken deze eigenschappen de vezels geschikt voor toepassing als een microfiltratiemembraan of als een membraandrager voor toepassing onder veeleisende omstandigheden.

Het laatste hoofdstuk 9 reflecteert op de resultaten die in dit proefschrift behaald zijn, brengt de kennis die opgedaan is samen, en biedt een leidraad voor verschillende benaderingen die gevolgd kunnen worden bij het bestuderen van warmtebehandelingen van membraanmaterialen. 
Chapter 1

Introduction to the thermal processing of inorganic, hybrid, and organic membrane materials 


\subsection{On membranes \& heat}

A membrane is a selective barrier material that allows for the separation of one or more compounds from a mixture. Large-scale applications of membranes are currently found in water purification and medical applications. In these fields, the mature membrane separations include microfiltration, ultrafiltration, reverse osmosis, hemodialysis, and blood oxygenation [1]. New developments for these applications can either be expected to be incremental improvements or tailored to highly specific separations. Due to the large scale of the applications, small optimizations can still result in major benefits. Considerable developments can still be expected in the fields of gas separation, (organic solvent) nanofiltration, and pervaporation [1]. These fields have a large market potential, and plenteous research on suitable, novel membranes materials is performed [2-4].

Membrane technologies can be applied for the separation of many different mixtures. As a result, membranes with many different structures and properties exist. All these membranes have in common their property of being a barrier layer that selectively impedes the transport rate of specific components in a mixture, while other specific components are allowed to pass the layer with a relatively higher rate. For an optimal performance, a membrane needs to combine a high retention for a part of the mixture with as little resistance as possible for the other components. The permeation rates through a membrane can be tuned by altering the microstructure of the membranes. To produce high-quality membranes, precise control over the microstructure of the material is essential.

During the fabrication of membranes, thermal processing is commonly employed to shape, stabilize, or functionalize membrane layers. The focus of this thesis will be on visualizing, understanding, explaining, and predicting the effects of these thermal treatments on the structure and properties of the materials. The membranes studied include inorganic, hybrid, and organic materials, are amorphous, and possess pores or free 
volume that affects the molecular selectivity. As the term thermal processing will be used frequently throughout this thesis, but is ill defined in the field of membrane research, I here postulate the definition for the 'thermal processing of membranes' to be used in this thesis as:

\section{Thermal processing of membranes:}

\section{The use of thermal energy to alter the chemistry and microstructure of a membrane layer}

The present definition takes into account that thermal processing of membranes needs to take place on the $\mathrm{m}^{2}$-scale, and that defects or fractures in the membrane layers are to be avoided. Where possible, the effects of the thermal processing are explained in terms of the changes to the material's structure. The properties that are displayed by a membrane, such as the permeance and the selectivity, can then be considered as directly resulting from a specific structure. Figure 1-1 shows an overview of the wide variety of processes that can occur when a membrane is exposed to elevated temperatures. All these processes will be briefly introduced in section 1.2. Many of the conclusions that will be drawn for the thermal processing of membranes will be equally valid for other fields in which porous materials are applied (e.g., coatings, catalysts, absorbents, filters, and dielectrics).

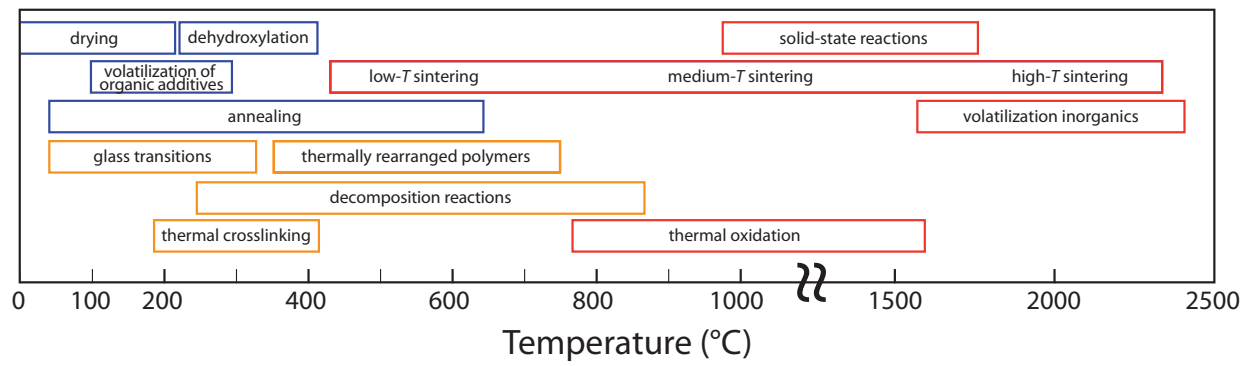

Figure 1-1: Overview of thermally stimulated processes that can occur in amorphous, porous membranes and their typical temperature ranges. Frame colors are used to indicate processes that are specific to inorganics (red) or polymers (orange), or both materials (blue). Hybrid materials typically undergo the same thermal processes as polymers. 


\subsection{Thermally stimulated processes}

\subsubsection{Drying}

A majority of all membranes is formed through solution processing. A drying step follows on the formation of the membrane layer to remove all the solvent from the material. For membranes, the drying rate and the stresses that develop during the drying step are important. The drying rate governs the time required to dry the material; the stresses that develop during the drying can influence the microstructure and the integrity of the membrane layers.

\section{Bulk Solvent}

First, we will focus on the drying of macro- and mesoporous materials, where the solvent can initially be considered as a continuous, percolating phase in the layer. The drying of these materials is well document and studied in many disciplines, such as the food industry [5], for sol-gel materials [6], and for ceramics in general [7]. Typically, the drying process of porous materials is classified into four stages [6,7]: (1) an initial stage, (2) a constant-rate period, during which drying takes place from the surface, and for which the rate is close to the evaporation rate from an open container; (3) a first falling-rate period, in which the solvent-gas interface recedes into the pores, but where most of evaporation still takes place at the surface; and (4) a second falling-rate period, in which the solvent-gas interface is receded so far into the pores that the characteristics of the drying mechanism change.

The drying rate of the material is most easily influenced during stage 2, where the drying is sensitive to external conditions such as the flow rate of a gas over the drying body. It is also during this stage, that the strong capillary forces in the liquid introduce stresses in the drying material. These stresses can result in shrinkage of the material, particularly when high surface tension liquids such as water are used. If the membrane network is not strong enough to resist these stresses, the network may yield under the induced stress, resulting in (partial) pore collapse [1]. To avoid this pore 22 
collapse, the solvent can be exchanged with a solvent that has a lower surface tension [8].

A special case of drying is encountered when the membrane film is bound to a substrate. As the shrinkage is now restraint to two dimensions, the total stresses that develop in the layer can be so high that the film cannot respond elastically [9]. In this case, (macroscopic) cracks will form in the layer, reducing the functionality of the membrane. This is especially the case in gas separation, where the transport through a defect will be many times faster than the transport through the selective material, and hence, small defects may ruin the total membrane performance [10].

\section{Physisorbed solvent}

As a result of the attractive forces exerted by the surface of a material, it can be energetically favourable for an adsorbate to physisorb to a material's surface. The physisorption enthalpy is in the order of a few times the condensation enthalpy of the vapor, and is typically found to be $<20 \mathrm{~kJ} \mathrm{~mol}^{-1}$ [11], water being a notable exception with a high condensation enthalpy of $44 \mathrm{~kJ} \mathrm{~mol}^{-1}$ at room temperature [12]. Although physisorption can be reversed by using low partial pressures of the absorbed vapor, as a result of pronounced diffusion limitations the desorption rate can be very low at room temperature.

For materials with small mesopores and for microporous materials, a significant part of the solvent can be physisorbed. Especially the removal of water from hydrophilic microporous materials may require high temperatures. Removal of water from mesoporous ceramic oxides may already require temperatures up to $120^{\circ} \mathrm{C}$, and temperatures up to $180{ }^{\circ} \mathrm{C}$ are given for microporous silica [13]. In some cases, temperatures up to even $300{ }^{\circ} \mathrm{C}$ are reported [14]. The required temperature depends strongly on the materials microstructure. Many of these materials readily reabsorb moisture from the atmosphere. This is the reason that for microporous 
membranes, heating steps of up to $200{ }^{\circ} \mathrm{C}$ are required to remove all the water from the pores before starting a permeation experiment [15].

\subsubsection{Dehydroxylation}

Hydroxyl-terminated surfaces are found on most ceramic oxides, on many polymers, and on some metals. In some cases, these hydroxyl groups are a direct result of the presence of hydroxyl groups in the precursor of the material; in other cases, the hydroxyl groups form by reactions with moisture from the atmosphere. Hydroxyl groups can be present closely together or isolated, and may or may not be bonded together through hydrogen bonds. Properties such as the hydrophilicity of the surface can strongly depend on coverage [16]. Figure 1-2 gives an overview of the various hydroxyl-groups on a silica surface [17]. The figure provides an example of the heterogeneity that a surface can have. As a result of this heterogeneity, dehydroxylation for a single material can take place over very broad temperature ranges.

The removal of hydroxyl-groups often takes place through a condensation reaction, in which two $\mathrm{M}(\mathrm{OH})$ groups react to a $\mathrm{M}-\mathrm{O}-\mathrm{M}$ group, and water is released. Through this reaction, the level of cross-linking of the network is increased.

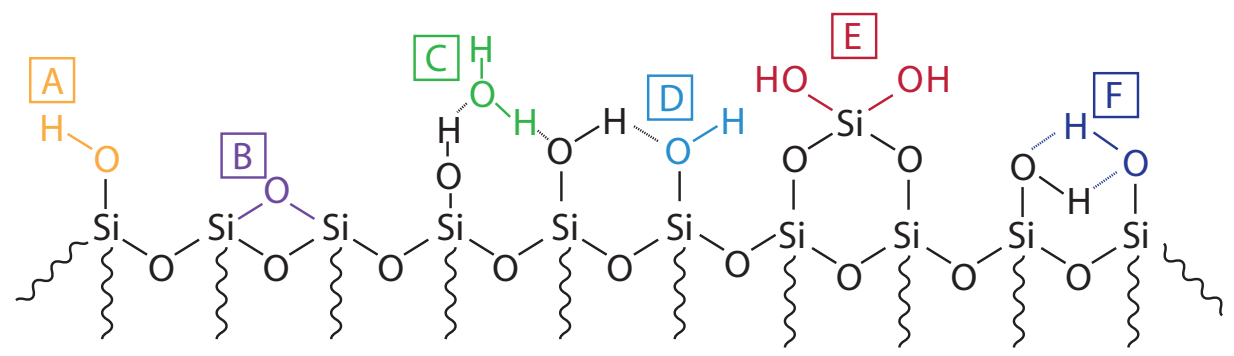

Figure 1-2: Overview of the different types of silanol groups on a silica surface, postulated by Iler: A, isolated; B, siloxane, dehydrated; C, vicinal, hydrated; D, vicinal, anhydrous; E, geminal; G, vicinal, hydrogen bond. Modified after R.K. Iler [17] 


\subsubsection{Volatilization of low-molecular-weight additives}

During the synthesis of many membrane materials, low molecular weight additives (i.e., non-polymeric additives) are used. Typical examples are surfactants (although often for non-amorphous membranes) or acid and base catalysts. At moderate temperatures, some of these compounds can evaporate without decomposition [18], others decompose without residue (e.g., $\mathrm{HNO}_{3} \rightarrow \mathrm{H}_{2} \mathrm{O}+\mathrm{NO}_{2}$ ), whereas others, mainly bases with metal counter ions, will leave a residue behind [19]. In some cases, these residues can be incorporated in the material as a functional group [20].

\subsubsection{Glass transitions}

Glasses are amorphous solids that are in a hard and brittle state. Upon heating, these solid can pass through a glass-liquid transition (= glass transition), upon which the polymer attains the characteristics of a liquid. Even though the glass transition is not a phase transition, it brings about dramatic changes in the properties of the material. Below the glass transition temperature $\left(T_{\mathrm{g}}\right)$, polymer chain segments have limited mobility; as a result, any deviation from thermodynamic equilibrium, such as the presence of excess free volume, is arrested into the structure. The time scale on which these deviations relax toward their equilibrium state can be extremely long, even in the order of years. Above the $T_{\mathrm{g}}$ the polymer chains have a significantly higher mobility, and the relaxations tend to be fast.

Technically, the $T_{\mathrm{g}}$ is not a phase transition, and as such, not a thermodynamic parameter. Rather, it is defined by the rate in which the material was cooled from its rubbery state, and as such, it is a kinetic property [21]. In practical applications, however, the shift in the $T_{\mathrm{g}}$ with different cooling rates is low, and it can be considered a materials property. The $T_{\mathrm{g}}$ of a polymer is a function of the molecular weight of the polymer and the degree of crosslinking. 
The $T_{\mathrm{g}}$ of a polymer can have a strong influence on the properties of a membrane. In operandi, the difference between operating a membrane below or above the $T_{\mathrm{g}}$ can have strong effects on the performance [22,23]. However, the effect of the change in properties upon passing the $T_{\mathrm{g}}$ is also exploited in numerous ways during the preparation of membranes. The most common example found in the preparation of gas separation membranes, in which the polymer is heated above the $T_{\mathrm{g}}$ followed by a quench to low temperatures. Due to the fast cooling rate, below the $T_{\mathrm{g}}$ the chains do not have the time to rearrange, and excess free volume (EFV) gets arrested in the polymer [24], enhancing the polymer permeability [25].

In a completely different application, the reduced polymer viscosity upon transition through the $T_{\mathrm{g}}$ is exploited to reduce the diameter of inorganic hollow fibers [26]. By heating the fibers around the $T_{\mathrm{g}}$, the macrovoids in the fiber collapse, resulting in a strong radial shrinkage of the fiber.

The glass transition temperature is a parameter that allows for drawing similarities between inorganic and organic polymers. Silica can be thought of as an inorganic polymer, especially when it is synthesized in long strands [27]. During heating, silanol groups in the polymer can condensate (see: Dehydroxylation), and result in an increase in crosslinking in the silica network. In order to reach a glass transition in silica, rearrangement of the siloxane bonds is required. This implies that breakage of a Si-O bond is necessary, and explains why the $T_{\mathrm{g}}$ of silica is so much higher than that of polymers, in which hydrogen bonds need to be broken, or Van der Waalsforces need to be overcome. For membranes, silica can be considered as a polymer with an extremely high $T_{\mathrm{g}}$ and, as a result, a high free volume.

\subsubsection{Thermal crosslinking}

Membrane materials are often crosslinked to improve their resistance to solvents, to suppress plasticization or swelling, or to add functionalization [28]. Crosslinking can be performed via auto-crosslinking, in which 
crosslinks form on groups that are already present inside the material, or by adding a crosslinking agent. Both processes can be thermally induced, but the term 'thermal crosslinking' is typically reserved for thermal autocrosslinking.

Discerning auto-crosslinking from reactions by a crosslinking agent is not always straightforward. For instance, in the case of sulfonated polymers, crosslinking can take place by the condensation of a sulfonic acid moiety on a phenyl ring, forming a $-\mathrm{SO}_{2}-$ group [29], but it can also take place via residual solvent (DMSO) still present in the matrix [30]. As both reactions are thermally stimulated and involve the same reacting groups, it can be difficult to discern between the two reactions.

\subsubsection{Polymer decomposition}

Polymer decomposition is an extremely broad term encompassing all irreversible polymer degradation processes that involve a loss of weight from the material. The chemical changes that occur during degradation can be classified as chain depolymerization (alias end-chain scission, unzipping), random-chain scission and chain stripping (alias substituent reactions) [21]. In turn, these processes can lead to changes to the material that are classified as volatilization, cross-linking and charring [31].

If only reactions that involve the main chain of the polymer are considered, thermochemical reactions can be classified into two main groups: chain depolymerization (alias end-chain scission, unzipping) and random scission [21,31]. In the chain depolymerization process, heating results in the removal of monomer units from the polymer backbone. The monomeric groups will volatilize to the gas phase, and the polymer will be 'unzipped' until stripped down to the last monomeric unit. This process typically results in very high monomer yields, and only minor char formation [31]. This process is in contrast to random chain scission, in which the polymer chain is cut at random points, resulting in formation of oligomeric and monomeric units. 
The study of polymer decomposition is of interest in membrane synthesis as well as during membrane application. For polymeric membranes, the goal is typically to avoid polymer decomposition completely. For lowtemperature applications, this is straightforward, and a broad range of polymers will be stable. Since polymers break at the weakest link, replacing it by a stronger group will increase the thermal stability of the polymer. Typically, this involves including aromatic groups in the polymer main chain, possibly combined with nitrogen, oxygen, and sulfur-substituents. These types of groups have an inherent higher thermal stability than, e.g., aliphatic groups [21]. In turn, these groups also tend to raise the $T_{\mathrm{g}}$ of the polymer, and thus also increase the operational stability.

For inorganic membranes, polymers are often used as a binder or additive. Here, the goal is opposite to that for polymer membranes, and use a polymer with lower thermal stability. However, a more important consideration is the (carbon) residue that the polymer can leave behind [32]. To avoid residues, a polymer with a low charring tendency can be sought [33]. Although the charring tendency of polymers has been well studied and documented [21], the 'spinnability' of polymers limits widespread adoption of binders other than PES [33].

For a third class of membranes, the carbon membranes, the decomposition process is actually tuned to create membranes $[34,35]$. Carbon membranes are known for their high stability and selectivity, but hitherto developed membranes often lack the mechanical integrity to be employed in a membrane process. Typically, carbon membranes are formed by the pyrolysis and carbonization of a polymeric precursor. The pyrolysis stage is the most important stage in the formation of the pore structure of the material. Typically, thermosetting polymers such as polyimides are used, and carbonization takes place at high temperatures $\left(>500{ }^{\circ} \mathrm{C}\right)[35]$. 


\section{Volatilization of heavies from the char}

At temperatures in excess of $\sim 550{ }^{\circ} \mathrm{C}$, the char that is formed at lower temperatures can undergo a second decomposition step [21]. In this step, secondary char is formed, while mostly hydrogen and methane are released. Unless when going to the extremely high temperatures where carbon can be volatilized (see: Volatilization of inorganics), the presence of hydrogen in the char is required for the volatilization.

\section{Decomposition in the presence of oxygen or other reactive gases}

If the polymer decomposition is not performed under an inert atmosphere, the decomposition can be influenced by the reactive gas in the atmosphere. As many processes are performed under an air atmosphere, oxygen is the most commonly encountered reactive gas. Strongly exothermic reactions with oxygen can provide the heat to further drive the decomposition process of the polymer. Whether the presence of oxygen influence the decomposition process is strongly dependent on the reaction mechanism, and the presence may result in a different reaction model for the decomposition [31]. In rare cases, the presence of oxygen may introduce an initial stabilizing effect on thermal decomposition, due to the prevention of depolymerisation reactions [36].

\subsubsection{Thermally rearranged polymers}

Benzene rings with an adjacent heteronuclear ring, such as a benzoxazole, benzimidazole, or phtalimide group are among the thermally most stable groups [21]. However, many polymers containing these groups suffer from lack of solubility, making liquid phase processing difficult. Recently, it has been shown that these highly stable groups can be formed through the thermal rearrangement of poly(hydroxyimide)s [37]. In addition, the thus obtained polymers show very high free volumes with a narrow size distribution, resulting in membranes combining high permeances and selectivities [38]. 


\subsubsection{Sintering}

Sintering is a high-temperature densification process occurring in inorganic materials. An inorganic material that is not yet thermally treated (referred to as a green compact), is usually porous, and will consist of grains or domains with specific sizes. The material in the grains is under a concave surface, and therefore has a higher chemical potential than it would have in a continuous phase. This creates the driving force for the reduction in curvature that results in the filling of the pores inside the material. The process is mainly limited by the low diffusion rate of the atoms at low temperatures. To create sufficiently high diffusion rates, a temperature of $\approx 2 / 3 T_{\text {melt }}$ is typically required.

The sintering behaviour can be grouped into three stages [39]: (1) an initial stage, starting when the atoms get enough mobility, and resulting in neck formation between the particles with little densification, (2) the intermediate stage, in which the curvatures are already lower, and the pore radii shrink further, and (3) the final stage, in which pores become isolated and no percolative paths exist anymore. Obviously, this latter stage has to be avoided in the sintering of porous membranes.

Pores are typically present at the point where multiple grains touch. It has been shown that, dependent on the dihedral angle between the grains and the number of grains that surround a pore, pores will either shrink or grow [39]. Pore growth is further encountered when surface diffusion is the predominant mechanism [40]. In ceramic membranes, this type of sintering is for instance encountered in $\gamma$-alumina membranes, where pore sizes are seen to increase with increasing sintering temperature [41].

\subsubsection{Inorganic (solid state) reactions}

Most solid-state reactions only take place at very high temperatures (an exception are the highly exothermic self-propagating high-temperature synthesis and solid-state metathesis reactions that supply their own heat to propagate reactions, such as the thermite reaction [42]). The main reason 
for this is the high diffusivity that is required to bring the solid-state reaction species into contact with each other on a molecular level [43]. Solid-state reactions are not often encountered in the formation of porous membranes. One of the few exceptions is the removal of excess carbon from a silicon carbide body by reactions with silica.

\subsubsection{Volatilization of inorganics}

At the very high temperatures encountered in sintering and inorganic solid-state reactions, inorganic components can have a non-negligible vapor pressure. Evaporation of carbon is noticeable at temperature higher than $2000{ }^{\circ} \mathrm{C}$ [44]; disproportionation and vaporization of silicon monoxide is already recorded at temperatures higher than $1000{ }^{\circ} \mathrm{C}$ [45]; based on the melting point of silica of $\sim 1700{ }^{\circ} \mathrm{C}$, a strong increase in the vapor pressure can be expected at temperatures above $1700{ }^{\circ} \mathrm{C}$ [12]. These temperatures are not often encountered for porous membranes, where sintering is conducted at relatively low temperatures to keep porosity (see: Sintering of Inorganics), for some high-temperature sintering materials, such as silicon carbide, these processes may play an important role, and have to be taken into account.

\subsubsection{Annealing and quenching}

Annealing and quenching are two processes that follow a different classification. For both processes, the cooling rate is an important parameter in the process. Quenching is defined across many different fields as the very fast cooling of a material, with the purpose of arresting the structure in a specific non-equilibrium state. Although relaxing into an equilibrium-state is thermodynamically favored, the low temperature results in kinetics that are so slow that the material does not achieve the equilibrium state in the time scales of the experiment. The opposite of quenching is annealing, where a material is heated to a state in which stresses are removed easily, and is subsequently cooled very slowly to avoid that the material attains a non-equilibrium status. This procedure is applied to both metals and polymers, for reducing stresses inside the material. The 
term annealing is used both for the process of bringing a material to a specific temperature (e.g., just above the glass transition temperature) as well as for the slow cooling down that follows the heating step. When performed below the $T_{\mathrm{g}}$ of a glassy polymer, annealing may have the effect of accelerated ageing of the polymer.

\subsection{Thermodynamics and kinetics}

Two questions are central to thermally stimulated reactions:

1. Can it happen?

2. Will it happen?

The answer to the first question is thermodynamics, and the answer to the second question is kinetics. For a process to occur, it has to be thermodynamically favorable: the Gibbs energy $\Delta G$ of the change has to be lower than zero. In thermochemical reactions, the Gibbs energy typically decreases for endothermic reactions, and for reactions that cause an increase in entropy.

Even if a change can occur, it may be that the rate of the change is too low for it to occur in the timescale of the experiment. If the reaction can occur, but does not take place fast enough, the reaction is said to be kinetically inhibited.

Typically, the rate of a reaction is dependent on three parameters: the preexponential constant $A$, the activation energy $E_{\mathrm{a}}$, and the reaction model $f(\alpha)$, where $\alpha$ denotes the degree of conversion:

$$
\frac{\mathrm{d} \alpha}{\mathrm{d} t}=A \exp \left(\frac{-E_{\mathrm{a}}}{R T}\right) f(\alpha)
$$

As the activation energy is positive, it is evident from equation 1-1 that the reaction rate will increase with increasing temperature.

\subsection{Analysis and characterization techniques}

The classical characterization techniques for the analysis of thermochemical processes are thermogravimetric analysis (TGA), and differential scanning 
calorimetry (DSC) or differential thermal analysis (DTA). In TGA, the weight of a sample is studied as a function of temperature, and can therefore be used for reactions that involve a change in weight, such as volatilization or oxidation. DSC and DTA are employed to measure the changes in heat flow or temperature to the sample. These techniques give insight into the energies associated with processes, and can be used to track any reaction that consumes or releases heat - mass loss is not required. One of the major differences between these techniques is the fact that TGA measures the cumulative mass loss, and, hence, the conversion of a process, whereas DSC and DTA measure the heat flow per time, and, hence, the derivative of the conversion to time.

To gain more insight in the products that evolve from the thermal analysis apparatus, the evolved gases can be analyzed. This process, called Evolved Gas Analysis (EGA), can be carried out by, for instance, mass spectrometry (MS) and infrared analysis (IR). The combination of the techniques is then, e.g., TGA-MS. By performing EGA, it is often easier to couple certain mass loss steps to specific groups in a compound; as such, it gives insight in which groups are thermally labile, and which reactions occur.

Thermochemical analysis is not limited to these techniques. In fact, any technique that can track a structure or property of a material as a function of temperature can be used to study the changes in the material. However, as the sample temperature must be controlled during the measurement, the technique needs to be fitted to a furnace, heating plate, or other means of temperature control. Optical techniques often have the advantage that they can be easily fitted into a temperature-controlled environment, and as a result, techniques such as (spectroscopic) ellipsometry [46], attenuated total reflection-infrared analysis [47], and Raman spectroscopy [48] are used.

In yet a broader sense, one could say that any analysis or characterization technique can be used to study thermochemical processes. A furnace can be used to thermally process a sample, and the properties of the material can be studied ex situ. This opens the way to a wide variety of analysis 
techniques. However, as the processes cannot be tracked as a function of temperature, results are typically reported as a function of a specific dwell time at a certain temperature. Whereas it allows for getting a rough estimate of the optimal treatment, it may be prone to overlooking certain processes that can occur during the heat treatment.

In this thesis, the use of in-situ techniques was preferred where possible.

\subsection{Thesis outline}

In this thesis, the thermal processing of a broad range of materials in a broad range of temperatures is described.

In Chapter 2, the fracturing characteristics of thin films of silica and organosilica are compared. The organosilica films exhibited a higher resistance to fracturing, conceivably because of lower residual stresses in these films. The fractured films demonstrated high crack spacing, indicating that the elastic-fracturing model is too simplistic to describe the fracturing of (organo)silica materials.

In Chapter 3, a proof-of-concept of the rapid thermal processing of microporous silica membranes is given. The results invalidate the common belief that high heating rates lead to defects in ultrathin membrane films, and open up the way to new processing techniques.

In Chapter 4, the thermal processing of silica and organosilica is analyzed from a kinetic perspective. The dehydration, dehydroxylation, and decomposition reactions that take place upon heating the material are studied, and the rates of the different steps are compared. With the developed kinetic model, the conversion of the individual reactions under a generic temperature program can be predicted.

In Chapter 5, a simple technique for the temperature calibration of substrates on a hot stage is presented. It is shown than thin films of metals can be used as melting point standards. The melting point can be detected model-free from changes in the measurement signal or the signal intensity. 
In Chapter 6, the thermal processing of bulk sulfonated poly(ether ether ketone) is examined. The increased thermal stability after replacing the sulfonate proton by a sodium ion is studied in detail. Although the protonated SPEEK is apparently stable up to temperatures of $\sim 180^{\circ} \mathrm{C}$ based on bulk measurements, it is shown that long-term exposure of thin films to temperatures as low as $160{ }^{\circ} \mathrm{C}$ causes irreversible changes in the material.

In Chapter 7, the imidization of a novel class of hybrid imides, the poly(POSS-imides), is studied. The influence of the length of the organic group that links the POSS-cages together on the imidization is studied.

In Chapter 8, the high-temperature thermal treatment of silicon carbide is reported. It is shown that high temperatures of at least $1800{ }^{\circ} \mathrm{C}$, but preferably $>2000{ }^{\circ} \mathrm{C}$, is required to obtain fibers with a mechanical strength that is sufficient for industrial applications.

In Chapter 9, the results obtained in this thesis are placed in the perspective of the development of inorganic supports, sol-gel-derived membranes, and thin-film membranes in general. The thesis finishes with general considerations on the thermal processing of membranes. 


\subsection{References}

1. Baker, R.W., 2012, Membrane technology and applications. 3rd edn. Chichester, United Kingdom: John Wiley \& Sons. ISBN: 9780470743720(doi:10.1016/S09582118(96)90133-0)

2. Vandezande, P., Gevers, L.E.M. \& Vankelecom, I.F.J., 2008, Solvent resistant nanofiltration: separating on a molecular level. Chem. Soc. Rev. 37, pp. 365-405. (doi:10.1039/b610848m)

3. Merkel, T.C., Lin, H., Wei, X. \& Baker, R., 2010, Power plant post-combustion carbon dioxide capture: An opportunity for membranes. J. Membr. Sci. 359, pp. 126-139. (doi:10.1016/j.memsci.2009.10.041)

4. Chapman, P.D., Oliveira, T., Livingston, A.G. \& Li, K., 2008, Membranes for the dehydration of solvents by pervaporation. J. Membr. Sci. 318, pp. 5-37. (doi:10.1016/j.memsci.2008.02.061)

5. Vega-Mercado, H., Marcela Góngora-Nieto, M. \& Barbosa-Cánovas, G. V., 2001, Advances in dehydration of foods. J. Food Eng. 49, pp. 271-289. (doi:10.1016/S0260-8774(00)00224-7)

6. Brinker, C.J. \& Scherer, G.W., 1990, Sol-gel Science: The Physics and Chemistry of Sol-Gel Processing. 1st ed. San Diego, CA, USA: Academic Press. ISBN: 9780121349707

7. Brosnan, D.A. \& Robinson, G.C., 2003, Introduction to drying of ceramics: with laboratory excersises. 1st ed. Ohio: The American Ceramic Society. ISBN: 978-157498-046-2

8. Yu Wang, K., Chung, T.-S. \& Gryta, M., 2008, Hydrophobic PVDF hollow fiber membranes with narrow pore size distribution and ultra-thin skin for the fresh water production through membrane distillation. Chem. Eng. Sci. 63, pp. 25872594. (doi:10.1016/j.ces.2008.02.020)

9. Hu, M.S., Thouless, M.D. \& Evans, A.G., 1988, The decohesion of thin films from brittle substrates. Acta Metall. 36, pp. 1301-1307. (doi:10.1016/00016160(88)90282-9)

10. Henis, J.M.S. \& Tripodi, M.K., 1980, A novel approach to gas separations using composite hollow fiber membranes. Sep. Sci. Technol. 15, pp. 1059-1063. (doi:10.1080/01496398008076287)

11. Barnes, G.T. \& Gentle, I.R., 2005, Interfacial Science: an introduction. 1st ed. New York: Oxford University Press. ISBN: 978-0-19-927882-4

12. Lide, D., 2007, CRC Handbook of Chemistry and Phsysics. 87th ed. Boca Raton, FL: Taylor \& Francis. 
13. Zhuravlev, L.T., 2000, The surface chemistry of amorphous silica. Zhuravlev model. Colloids Surfaces A Physicochem. Eng. Asp. 173, pp. 1-38. (doi:10.1016/S0927-7757(00)00556-2)

14. Jackson, P. \& Parfitt, G.D., 1971, Infrared Study of the Surface Properties of Rutile. Trans. Faraday Soc. 67, pp. 2469-2483. (doi:10.1039/TF9716702469)

15. De Vos, R.M. \& Verweij, H., 1998, High-Selectivity, High-Flux Silica Membranes for Gas Separation. Science 279, pp. 1710-1711. (doi:10.1126/science.279.5357.1710)

16. Bolis, V., Fubini, B., Marchese, L., Martra, G. \& Costat, D., 1991, Hydrophilic and Hydrophobic Sites on Dehydrated Crystalline and Amorphous Silicas. J. Chem. Soc. Faraday Trans. 87, pp. 497-505. (doi:10.1039/FT9918700497)

17. Iler, R.K., 1979, The chemistry of silica: Solubility, Polymerization, Colloid and Surface Properties, and Biochemistry. New York: John Wiley \& Sons.

18. Kumar, P., Ida, J., Kim, S., Guliants, V.V. \& Lin, J.Y.S., 2006, Ordered mesoporous membranes: Effects of support and surfactant removal conditions on membrane quality. J. Membr. Sci. 279, pp. 539-547. (doi:10.1016/j.memsci.2005.12.053)

19. Raaijmakers, M.J.T., Wessling, M., Nijmeijer, A. \& Benes, N.E., 2014, Hybrid polyhedral oligomeric silsesquioxanes-imides with tailored intercage spacing for sieving of hot gases. Chem. Mater. 26, pp. 3660-3664. (doi:10.1021/cm500691e)

20. De Wit, M.A.T., 2011, The influence of different acid catalysts used in silica sol synthesis on the performance and microstructure of silica membranes. Master thesis, Enschede, The Netherlands: University of Twente.

21. Van Krevelen, D.W.W. \& Te Nijenhuis, K., 2009, Properties of Polymers: their correlation with chemical structure; their numerical estimation and prediction from additive group contributions. 4th ed. Amsterdam: Elsevier. ISBN: 9780080548197(doi:10.1016/B978-0-08-054819-7.00004-2)

22. Meares, P., 1954, The diffusion of gases through polyvinyl acetate. J. Am. Chem. Soc. 482, pp. 3415-3422. (doi:10.1021/ja01642a015)

23. Freeman, B.D., 1999, Basis of Permeability/Selectivity Tradeoff Relations in Polymeric Gas Separation Membranes. Macromolecules 32, pp. 375-380. (doi:10.1021/ma9814548)

24. Van den Beukel, A. \& Sietsma, J., 1990, The glass transition as a free volume related kinetic phenomenon. Acta Metall. Mater. 38, pp. 383-389. (doi:10.1016/0956-7151(90)90142-4)

25. Koros, W.J. \& Fleming, G.K., 1993, Membrane-based gas separation. J. Membr. Sci. 83, pp. 1-80. (doi:10.1016/0376-7388(93)80013-N)

26. Luiten-Olieman, M.W.J., Raaijmakers, M.J.T., Winnubst, L., Wessling, M., Nijmeijer, A. \& Benes, N.E., 2011, Porous stainless steel hollow fibers with 
shrinkage-controlled small radial dimensions. Scr. Mater. 65, pp. 25-28. (doi:10.1016/j.scriptamat.2011.03.023)

27. Brinker, C.J., Ward, T.L., Sehgal, R., Raman, N.K., Hietala, S.L., Smith, D.M. \& Hua, D., 1993, "Ultramicroporous" silica-based supported inorganic membranes. J. Membr. Sci. 77, pp. 165-179. (doi:10.1016/0926-860X(93)80011-E)

28. Vanherck, K., Koeckelberghs, G. \& Vankelecom, I.F.J., 2013, Crosslinking polyimides for membrane applications: A review. Prog. Polym. Sci. 38, pp. 874896. (doi:10.1016/j.progpolymsci.2012.11.001)

29. Hou, H., Di Vona, M.L. \& Knauth, P., 2012, Building bridges: Crosslinking of sulfonated aromatic polymers-A review. J. Membr. Sci. 423-424, pp. 113-127. (doi:10.1016/j.memsci.2012.07.038)

30. Maranesi, B., Hou, H., Polini, R., Sgreccia, E., Alberti, G., Narducci, R., Knauth, P. \& Di Vona, M.L., 2013, Cross-Linking of Sulfonated Poly(ether ether ketone) by Thermal Treatment: How Does the Reaction Occur? Fuel Cells 13, pp. 107117. (doi:10.1002/fuce.201200010)

31. Beyler, C.L. \& Hirschler, M.M., 2002, Thermal Decomposition of Polymers. In SFPE Handbook of Fire Protection Engineering, pp. 110-131.

32. Wu, Z., Faiz, R., Li, T., Kingsbury, B.F.K. \& Li, K., 2013, A controlled sintering process for more permeable ceramic hollow fibre membranes. J. Membr. Sci. 446, pp. 286-293. (doi:10.1016/j.memsci.2013.05.040)

33. Luiten-Olieman, M.W.J., 2012, Inorganic porous hollow fiber membranes with tunable small radial dimensions. PhD Thesis, Enschede, The Netherlands: University of Twente. ISBN: 10.3990/1.9789036533270. (doi:10.3990/1.9789036533270)

34. Ismail, A.F. \& David, L.I.B., 2001, A review on the latest development of carbon membranes for gas separation. J. Membr. Sci. 193, pp. 1-18. (doi:10.1016/S03767388(01)00510-5)

35. Saufi, S.. \& Ismail, A.F., 2004, Fabrication of carbon membranes for gas separation - a review. Carbon N. Y. 42, pp. 241-259. (doi:10.1016/j.carbon.2003.10.022)

36. Peterson, J.D., Vyazovkin, S. \& Wight, C.A., 1999, Kinetic study of stabilizing effect of oxygen on thermal degradation of poly(methyl methacrylate). J. Phys. Chem. B 103, pp. 8087-8092. (doi:10.1021/jp991582d)

37. Park, H.B., Han, S.H., Jung, C.H., Lee, Y.M. \& Hill, A.J., 2010, Thermally rearranged (TR) polymer membranes for $\mathrm{CO}_{2}$ separation. J. Membr. Sci. 359, pp. 11-24. (doi:10.1016/j.memsci.2009.09.037)

38. Sanders, D.F., Smith, Z.P., Guo, R., Robeson, L.M., McGrath, J.E., Paul, D.R. \& Freeman, B.D., 2013, Energy-efficient polymeric gas separation membranes for a sustainable future: A review. Polymer (Guildf). 54, pp. 4729-4761. (doi:10.1016/j.polymer.2013.05.075) 
39. Rahaman, M.N., 2007, Ceramic Processing. 1st ed. Boca Raton, FL: CRC Press.

40. Whittemore Jr., O.J. \& Sipe, J.J., 1974, Pore Growth during the Initial Stages of Sintering Ceramics. Powder Technol. 9, pp. 159-164.

41. Leenaars, A.F.M., Keizer, K. \& Burggraaf, A.J., 1984, The preparation and characterization of alumina membranes with ultra-fine pores. 1. Microstructural investigations on non-supported membranes. J. Mater. Sci. 19, pp. 1077-1088. (doi:10.1007/bf01120016)

42. Meyer, H.-J., 2010, Solid state metathesis reactions as a conceptual tool in the synthesis of new materials. Dalt. Trans. 39, pp. 5949-64. (doi:10.1039/b927026d)

43. West, A.R., 2014, Solid State Chemistry and its applications. 2nd ed. Chichester, United Kingdom: Wiley. ISBN: 9781119942948

44. Marshall, A.L. \& Norton, F.J., 1950, Carbon Vapor Pressure and Heat of Vaporization. J. Am. Chem. Soc. 72, pp. 2166-2171. (doi:10.1021/ja01161a081)

45. Hertl, W. \& Pultz, W.W., 1967, Disproportionation and vaporization of solid silicon monoxide. J. Am. Ceram. Soc. 50, pp. 378-381. (doi:10.1111/j.11512916.1967.tb15135.x)

46. Kawana, S. \& Jones, R., 2001, Character of the glass transition in thin supported polymer films. Phys. Rev. E 63, pp. 021501. (doi:10.1103/PhysRevE.63.021501)

47. Karabudak, E., Kas, R., Ogieglo, W., Rafieian, D., Schlautmann, S., Lammertink, R.G.H., Gardeniers, H.J.G.E. \& Mul, G., 2013, Disposable attenuated total reflection-infrared crystals from silicon wafer: a versatile approach to surface infrared spectroscopy. Anal. Chem. 85, pp. 33-8. (doi:10.1021/ac302299g)

48. McMillan, P.F., Poe, B.T., Gillett, P. \& Reynard, B., 1994, A study of $\mathrm{SiO}_{2}$ glass and supercooled liquid to $1950 \mathrm{~K}$ via high-temperature Raman spectroscopy. Geochim. Cosmochim. Acta 58, pp. 3653-3664. (doi:10.1016/00167037(94)90156-2) 



\section{Chapter 2 \\ Formation and prevention of fractures in sol-gel-derived thin films}

This chapter had been adapted from:

Kappert, E.J., D. Pavlenko, J. Malzbender, A. Nijmeijer, N.E. Benes, P.A. Tsai, 2015, Formation and prevention of fractures in sol-gel-derived thin films, Soft Matter, accepted for publication, doi: 10.1039/C4SM02085E 

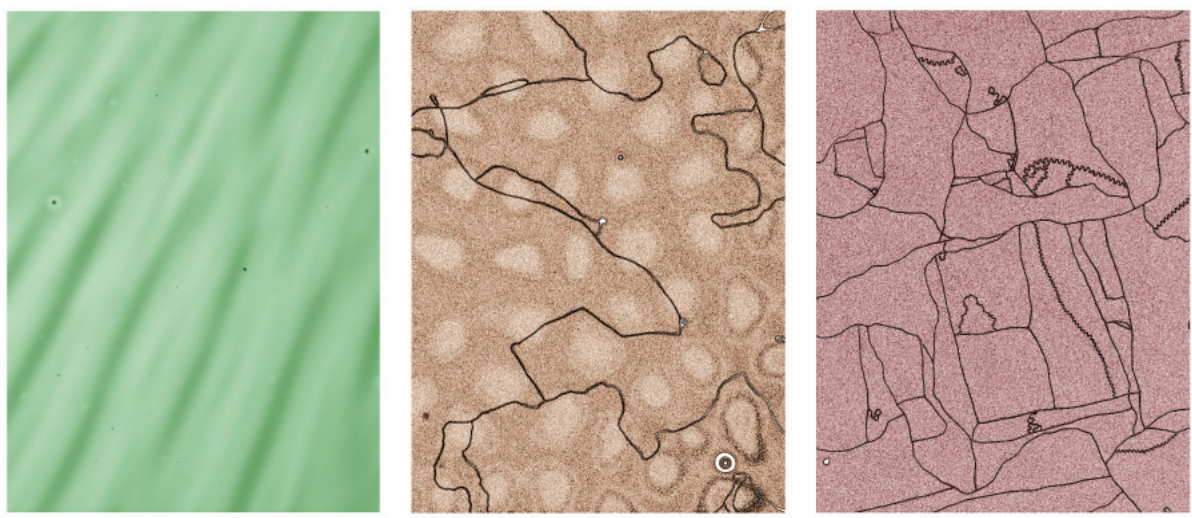

\title{
silica $h_{c}=300 \mathrm{~nm}$
}

\section{Crack density increasing with thickness}

\section{organosilica $h_{c} \geq 1250 \mathrm{~nm}$}

\begin{abstract}
Sol-gel-derived thin films play an important role as the functional coatings for various applications that require crack-free films to function fully. However, the fast drying process of a standard sol-gel coating often induces mechanical stresses, which may fracture the thin films. An experimental study on the crack formation in sol-gel-derived silica and organosilica ultrathin (sub-micron) films is presented. The relationships among the crack density, inter-crack spacing, and film thickness were investigated by combining direct micrograph analysis with spectroscopic ellipsometry. It is found that silica thin films are more fragile than organosilica films and have a critical film thickness of $300 \mathrm{~nm}$, above which the film fractures. In contrast, the organosilica films can be formed without cracks in the experimentally explored thickness regime up to at least $1250 \mathrm{~nm}$. These results confirm that ultrathin organosilica coatings are a robust silica substitute for a wide range of applications.
\end{abstract}




\subsection{Introduction}

Sol-gel thin films are widely used as functional finishing layers for various applications. For instance, as common materials, silica and organosilica have been widely used and studied for the applications of anti-reflective coatings [1], membranes for gas separation [2], alcohol dehydration [3], and low-k dielectrics [4]. For these applications, it is imperative to fabricate thin layers without forming cracks during the drying process in a sol-gel chemistry-based method [5]. This requirement has been challenging because cracks form during the drying process when the built-up mechanical stress exceeds the material ability to respond elastically. In the current work, an experimental study of crack formation in thin films is presented, and we derived the conditions under which the synthesized thin layer remained crack-free, which is beneficial for designing high-quality coatings.

In the literature, crack formation upon drying has been widely studied (see, e.g., refs. [6-11]); however, these studies were mainly with experimental systems of colloid suspensions and micron-thick films [7,12-17]. Theoretically, by considering the energy release rate for a steady-state film cracking, one can estimate the so-called critical thickness $h_{\mathrm{c}}$, below which a drying layer remains crack-free. A commonly used derivation $[18,19]$ leads to the equation:

$$
h_{c}=\frac{E G_{f}}{C \pi \sigma^{2}}
$$

with the elastic modulus $E\left(\mathrm{~N} / \mathrm{m}^{2}\right)$, critical strain energy release rate $G_{\mathrm{f}}$ $\left(\mathrm{J} / \mathrm{m}^{2}\right)$, a function $C(-)$ that indicates the difference in elastic properties between the films and the substrates $[20]$ and residual stress $\sigma\left(\mathrm{N} / \mathrm{m}^{2}\right)$ in the film. One key implication here is that for a given material, $E$ and $G_{\mathrm{f}}$ are essentially material properties, although they are affected by the porosity [2123]; thus, a larger critical thickness can be achieved by decreasing the residual stress $\sigma$ in the layer. Decreasing $\sigma$ is particularly challenging for ultrathin layers because the stress is largely accumulated during the fast drying step, which instantaneously follows on the spin or dip coating deposition. 

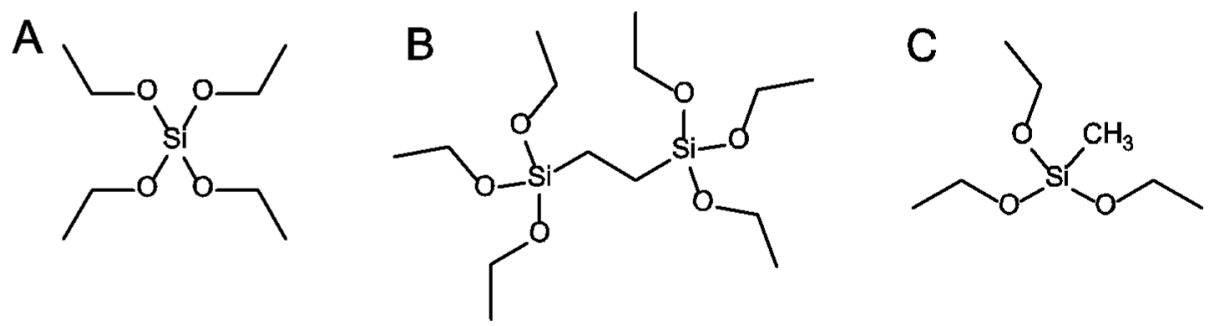

Figure 2-1: Molecular structure of the precursors of (A) silica (TEOS),

(B) bridged organosilica (BTESE), and (C) terminated organosilica (MTES).

We explored the fracturing of ultra-thin submicron films coated from polymeric sols and compared our results with previous experiments on crack formation in thin films or colloidal suspensions during drying. We systematically studied the formation of cracks in submicron-thick films of tetraethyl orthosilicate (TEOS)-derived silica and 1,2-bis(triethoxysilyl)ethane (BTESE), zirconium-doped BTESE (Zr-BTESE), and methyltriethoxysilane (MTES)-derived organosilica. The chemical structures of these materials are shown in Figure 2-1. Until now, only a few systematic studies have been performed to determine the critical thickness of these materials directly, and the data are particularly lacking for organosilica. Our results demonstrate that organosilica films have much larger critical thickness than silica. Moreover, our results corroborate the findings for bulk organosilica, which indicates that a higher fracture energy and possibly a lower residual stress in the applied coatings can prevent thin films from fracturing during fast drying.

\subsection{Experimental section}

\subsubsection{Experimental procedure}

The experimental procedure in this study was as follows: first, a sol synthesis was performed following the recipe provided in Sol Synthesis below. The (organo)silica layers were spin-coated on silicon wafers, where the layer thickness was tuned by adjusting the sol dilution with ethanol. Subsequently, the layers were dried for 1 day, the thickness was 
subsequently determined using Spectroscopic Ellipsometry. In addition, optical micrographs were again taken at 9 random spots of the sample after one week, after three weeks, and after the calcination of the layer. The optical micrographs were used to analyze the cracking morphology of the layers, as provided in Data Analysis. In total, 75 films were prepared for the experiments using TEOS, BTESE, Zr-BTESE, and MTES precursors.

\subsubsection{Film preparation}

Tetraethyl orthosilicate (TEOS) (for synthesis, Merck), methyltriethoxysilane (MTES) (pur. 99\%, Sigma-Aldrich), 1,2-bis(triethoxysilyl)ethane (BTESE) (pur. 97\%, ABCR Germany), zirconyl nitrate $\left(\mathrm{ZrO}\left(\mathrm{NO}_{3}\right)_{2}\right.$, solution, $35 \mathrm{wt}-\%$ in dilute nitric acid, Sigma-Aldrich), dried ethanol (max $0.01 \% \mathrm{H}_{2} \mathrm{O}$, SeccoSolv ${ }^{\circledR}$,Merck), ethanol (absolute for analysis, EMSURE ${ }^{\circledR}$, Merck), nitric acid (1 M, Titrisol ${ }^{\circledR}$, Merck and $\geq 65 \%$ (T), Sigma-Aldrich), sulfuric acid ( $98 \%$ p.a., Merck) and hydrogen peroxide (35\%, SigmaAldrich) were used as received. Water was deionized to $18.2 \mathrm{M} \Omega \mathrm{cm}^{-1}$ using a Milli-Q Advantage A10 ${ }^{\circledR}$ system (Millipore). Silicon wafers (100, Silchem, Germany) were cleaned using a 3:1 $\mathrm{H}_{2} \mathrm{SO}_{4}: \mathrm{H}_{2} \mathrm{O}_{2}$ piranha solution.

(Organo)silica sols were prepared using the acid-catalyzed sol-gel route, which follows the experimental procedures described in the literature for the precursors TEOS [24], BTESE [25], Zr-BTESE (16\% Zr) [26] and MTES/TEOS 50/50 mixture [27]. These recipes lead to sols with a slightly branched, chainlike structure [28-30] which results in microporous materials with similar particle sizes of the sol [24,25,27].

The obtained sols were diluted 1-20 times to control the film thickness. The diluted sols were spin-coated onto the piranha-cleaned silicon wafers using a spin-coater (WS-400B-6NPP/LITE, Laurell Technologies Corporation) with a $5 \mathrm{sec}$ spin at $500 \mathrm{rpm}$, followed by a $30 \mathrm{sec}$ spin at $2000 \mathrm{rpm}$. The films gelled during spin-coating. The spin-coated wafers were stored in a storage box in nitrogen until measurement. 
To synthesize sols with thicknesses higher than those attainable with the undiluted sols at $2000 \mathrm{rpm}$, lower spinning speeds down to $250 \mathrm{rpm}$ were used. The films gelled during the spin coating. The films obtained at the lower spinning speeds display a strong non-uniformity, resulting in larger error bars in the thickness determination for thicker films [31].

\subsubsection{Data analysis}

The submicron-scale film thickness values were accurately determined using Spectroscopic Ellipsometry. The $\Psi$ and $\Delta$-spectra were measured with an M-2000X spectroscopic ellipsometer (J.A. Woollam) using the CompleteEase software v4.86 (J.A. Woollam). The well-established optical model $\mathrm{Si}$ (bulk)- $\mathrm{SiO}_{2}(2 \mathrm{~nm})$-Cauchy(fit) was used, where the optical parameters for the silicon and native oxide were obtained from the software, and the optical constants for the top layer were fitted using the Cauchy $A$ and $B$ parameters [32]. For thicker films (>1000 nm), the higher-order $C$ and an Urbach absorption terms were necessary to model the layers. A depolarization due to the presence of cracks was found not to influence the optical modeling for the films. To study the crack patterns, the thin films were examined using optical microscopy (Axiovert $40 \mathrm{MAT}$ ) with an HAL 100 illuminator (Zeiss) at $5 \times$ magnification. Micrographs were taken after 1 day, 1 week, and 3 weeks of drying. After 3 weeks of drying, the films were treated at $400{ }^{\circ} \mathrm{C}$ in nitrogen (organosilica) or $600{ }^{\circ} \mathrm{C}$ in air (silica) for 3 hours with heating and cooling rates of $0.5^{\circ} \mathrm{C} \mathrm{min}{ }^{-1}$, and optical micrographs were also taken for these treated layers. Two silica and two organosilica films were not thermally treated, but they were examined for their mechanical properties by nanoindentation using a CSM indentation system. The mechanical properties from the load- displacement data were evaluated using the procedures outlined in the references [33,34]. For the nano-indentation measurements, a substrate-correction method can be performed to minimize the substrate effect [35]. Our nano-indentation experiments of the thin films were performed at a low load of $0.1 \mathrm{mN}$. Therefore, the thin films do not 
possess sufficient depth range to carry out the modeling of the data for the substrate-correction method.

The micrographs were analyzed using MATLAB $^{\circ}$ to obtain statistical information of the crack patterns on the thin films. The algorithm is summarized here, and full details can be found in the Appendix. The cracks were first detected using a built-in edge-detection algorithm of $\operatorname{MATLAB}^{\circ}$ with the Laplacian of Gaussian edge detection filter. The edge detection results in two outlines of the cracks. A series of morphological operations was applied to convert the crack outlines to a single line. These operations result in a binary matrix that has zero values except for the crack lines, which are assigned a value of 1 . All connected pixels with value 1 are considered a region. Noise filtering was performed using a heuristically optimized approach, which removed all small regions and regions of which the ratio of cracked pixels versus the crack bounding-box was too high. The crack density was determined from the ratio of crack area to the total area of the image. To calculate the crack spacing, a watershed segregation was used to identify all pixels in the image that fall exactly between two cracks. For these pixels, the Euclidian distance to the nearest crack was calculated. Then, the crack spacing was calculated as two times the average Euclidian distance.

\subsection{Results and discussion}

\subsubsection{Visualization of cracks and thin films}

The drying of sufficiently thick sol-gel coatings makes the material fracture. For thicker films, the presence of such channeling cracks can be directly verified after spin-coating by the naked eye. Figure 2-2 shows the representative cracking patterns of a $575-\mathrm{nm}$ silica layer at random spots on the sample after 1 day (A) and 3 weeks (B). The cracking in these layers was solely induced by the drying process, which occurred for the first minute in the controlled nitrogen atmosphere of the spin-coater followed by an exposure to a gentle flow of nitrogen $\left(\sim 0.05 \mathrm{~mm} \mathrm{~s}^{-1}\right)$. The micro- 
graphs show that no significant change in the amount or type of cracks was found during the drying time of 3 weeks. The striped pattern, which is always oriented from the center to the edge of the wafer, is a local inhomogeneity in the refractive index or thickness of the film, which was induced by the spin-coating process. No preferential alignment of the cracks with this pattern could be detected in any micrograph. The color change between the layer after 1 day and 1 week of drying is the result of progressive shrinkage of the layer during the initial days of drying.
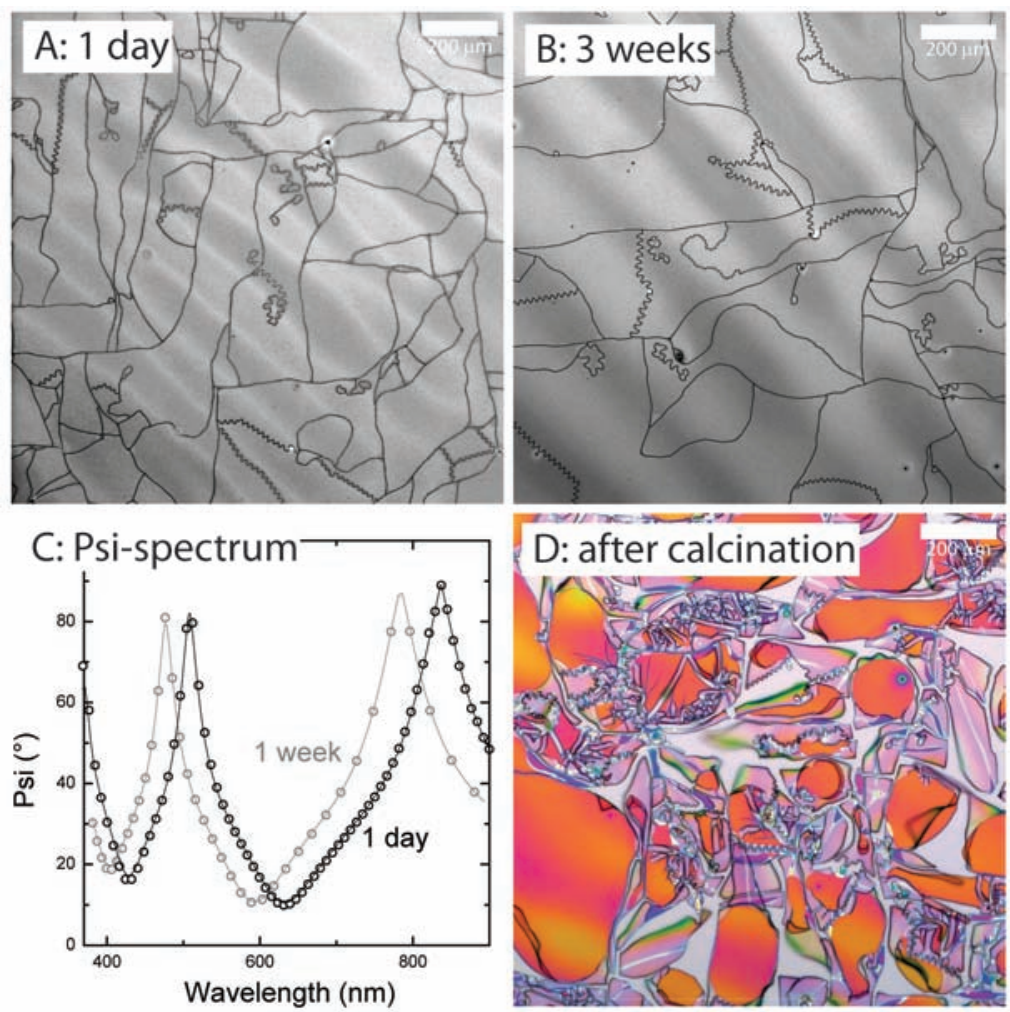

Figure 2-2: Optical micrographs of cracks in a representative spot of a $575 \mathrm{~nm}$ silica layer after 1 day of drying (A) and after 3 weeks of drying (B); the psi-spectrum obtained using spectroscopic ellipsometry after 1 day and 1 week (symbols: experimental data, solid line: fit from optical model) (C); and an optical micrograph of the layer after calcination (D). The tonal range and color balance of the micrographs were adjusted for visualization purposes. 
The thickness of the dried layers was accurately measured using spectroscopic ellipsometry. Figure $2-2 \mathrm{C}$ presents the psi-spectrum obtained from a silica layer after 1 day and 1 week of drying. Optical modeling with a Cauchy optical dispersion shows that in this time frame, the film thickness decreased from 575 to $543 \mathrm{~nm}( \pm 10 \mathrm{~nm})$. Larger stresses can be introduced in the layer upon calcination and cause delamination. Figure $2-2 \mathrm{D}$ is a micrograph of the layer after calcination at $600{ }^{\circ} \mathrm{C}$ in air. As can be observed, the induced stresses during calcination result in the delamination of the layer from the substrate.

In the micrographs of the fractured layers, different types of cracks are observed. The two most abundant crack geometries are straight-line and wavy cracks (also called: crescent periodic cracks). The formation of these different crack geometries is the result of a complex interplay between the fracturing in the film and (partial) delamination of the film from the substrate. Without delamination, straight cracks are formed. In the presence of partial delamination, the film can form wavy cracks [36] that tend to occur as a result of the maximization of the energy-release rate of the cracks [37]. By comparing the residual, fracturing, and adhesion energies, a recent study has shown that the wavy, spiral and self-replicating cracking patterns have a characteristic, periodic length scale of the pattern that is approximately 30 times the film thickness [11]. Consistent with this theoretical prediction, the periodic wavy patterns observed in our experiments have a similar characteristic length scale of approximately 35 times the film thickness (see the Appendix, Figure 2-A7). This agreement supports the collaborative model of the interplay between layer delamination and cracking propagation as the main mechanism for producing such periodic wavy cracks [11].

\subsubsection{Quantitative analysis of drying cracks and the critical thickness}

Figure 2-3B illustrates the results of the crack detection algorithm (see Experimental) based on a representative optical micrograph (Figure 2-3A). 

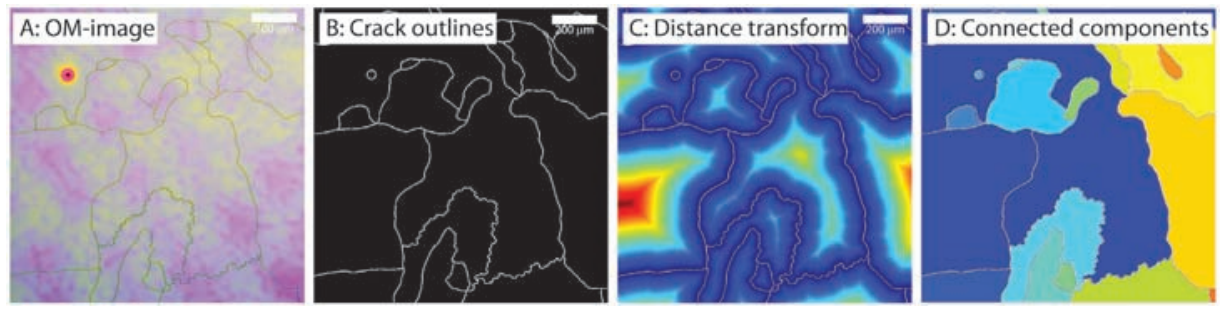

Figure 2-3: Illustrations of image analysis of the cracking patterns: (A) optical micrograph; (B) outlines of the cracks in A, where the white pixels refer to a crack pattern; (C) Euclidian distance transform of the image (B), where the color corresponds to the distance away from the nearest crack (blue for small distances, red for large distances); (D) different regions in image $B$ that can be used to calculate the region properties (e.g., area), where each color refers to an individual region. The thickness of the cracks in figure (B) was increased for visualization purposes, and the scale bars were added after the image analysis.

As can be observed in the figure, the algorithm can capture the outlines of nearly all cracks without introducing many artifacts. On some samples, the algorithm omitted some of the less pronounced cracks, where the contrast to the background was insufficient. Therefore, on all samples that contain cracks, nine spots were measured to statistically analyze the images.

For this analysis, the crack density was determined on every micrograph by dividing the amount of white pixels by the total surface area (in px2) of the image, and a 95\% confidence interval on the crack density was determined. Figure 2-3C and D were constructed to calculate the average spacing between the cracks. Figure 2-3C shows the Euclidian distance transform, where the pixel color indicates the distance to the nearest crack (from blue for small distances to red for larger distances). The crack spacing can be calculated by averaging the distances at the points precisely between two cracks. As an alternative metric, the square root of the area of a flake surround by the cracks could be used. However, as observed in Figure $2-3 \mathrm{D}$, this approach is highly sensitive to minor deviations in the crack detection algorithm. If a small part of the crack is not properly 
detected, two regions will be interpreted as directly connected, which results in a large overestimated crack spacing.

In Figure 2-4 and Figure 2-5, the crack density in silica and organosilica is plotted as a function of the sample thickness. This method of plotting allows for a direct inspection of the critical thickness. For silica, the critical thickness is evident at $300 \pm 30 \mathrm{~nm}$, which is consistent with the observed critical thickness for the fracturing of silica layers from polymeric sols in different drying conditions $[12,31,36]$. This consistency is attributed to the rapid initial drying, which results in an accumulation of stress and subsequent cracking before the layers can be transferred to another environment to mitigate the drying rate. Therefore, the drying time does not affect the critical thickness in the measured regime. For thicknesses larger than the critical thickness, the crack density first increases with the thickness before reaching a constant value for thicknesses larger than $400 \mathrm{~nm}$.

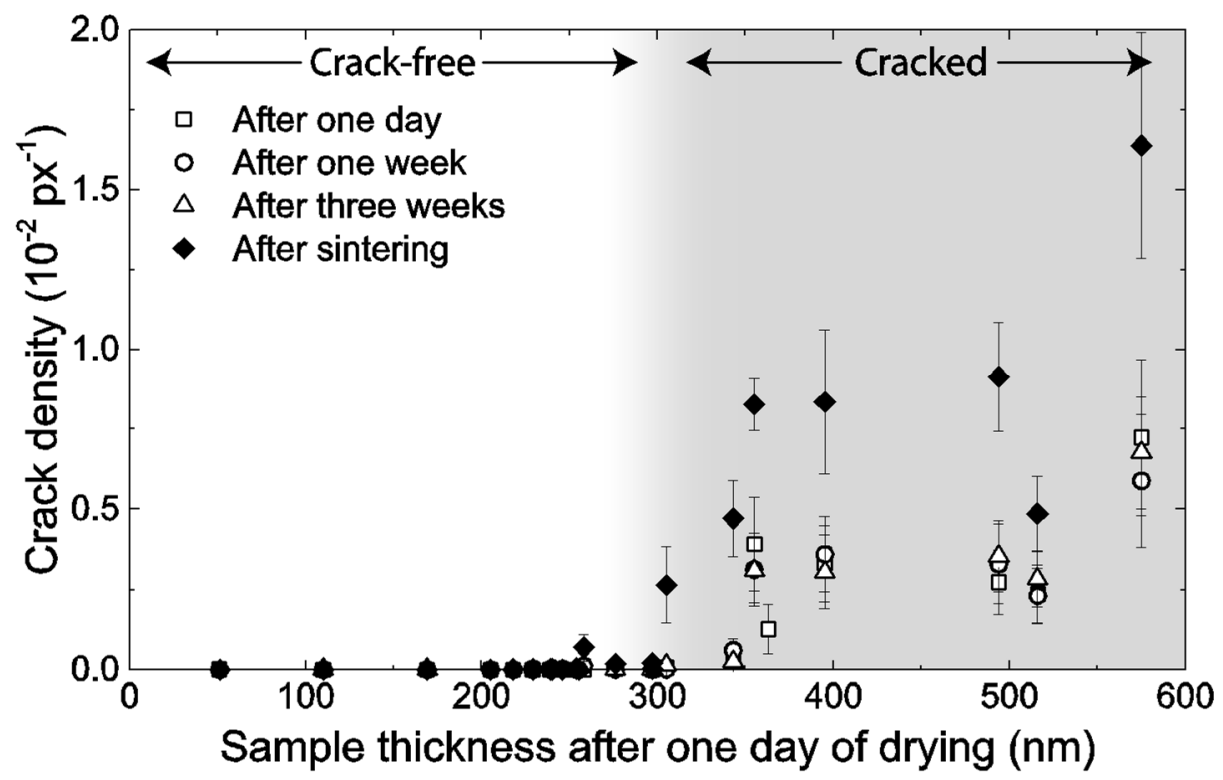

Figure 2-4: Dependence of the cracked area on the sample thickness for silica films after drying and calcination. Error bars denote the $95 \%$ confidence intervals. 


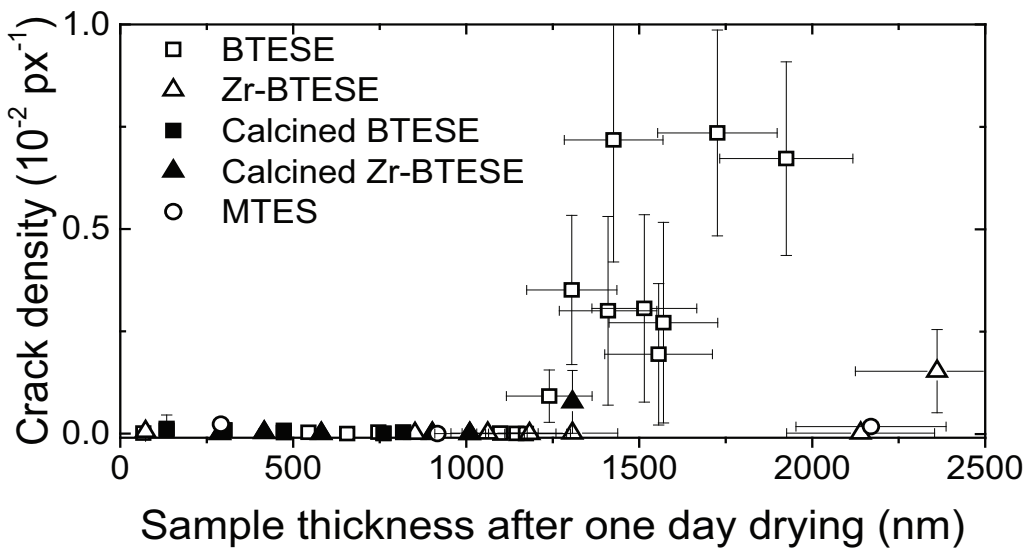

Figure 2-5: Crack density as a function of the film thickness for BTESE, Zr-BTESE, and MTES after one day of drying and after calcination.

Consistent with the direct observation from the optical micrographs (Figure 2-2D), the thermal treatment significantly increased the crack density of the samples. However, as we noticed from the experiments, the observed cracks originated from the cracks that formed during the drying step, which may suggest that the delamination originates from cracks that naturally formed during drying upon the spin-coating processes instead of the commonly attributed thermally-induced fracturing [38,39].

For the different organosilica materials (Figure 2-5), the critical thickness was substantially higher than that of silica. As a result of the experimental procedure required to synthesize thick layers, these layers exhibit a high thickness nonuniformity [31], resulting in a slightly lower accuracy for the determined critical thickness. For BTESE-derived organosilica, the critical thickness was determined at $1250 \pm 200 \mathrm{~nm}$. Incorporation of zirconium into the coating solution leads to a defect-free film at $2150 \mathrm{~nm}$. For MTES-derived organosilica, the critical thickness could not be determined accurately; a crack-free film of $2200 \mathrm{~nm}$ was synthesized. 
Our nano-indentation measurements (given in Table 2-A1 in the Appendix) demonstrate that the E-modulus of the organosilica films is of the same order of magnitude as that of the silica films. The E-modulus could not be exactly determined because of the limited thickness of the films, which made the results biased by the underlying silicon substrate (see the Appendix). Assuming that the critical thickness can be derived from equation 1-1, a comparable E-modulus implies that the difference in critical thickness results from a difference in the combining factor of $G_{f} / \sigma^{2}$, affected by the critical strain energy release rate $G_{\mathrm{f}}$ or/and the residual stress $\sigma$. Compared to silica, $G_{\mathrm{f}}$ was demonstrated to be higher for bridged organosilicas but lower for methyl-terminated organosilicas [21,40]. Based on these literature values of $G_{\mathrm{f}}$, despite the lower strain-energy release rate, the methyl-terminated organosilica has a larger critical thickness for fracturing than silica; thus, methyl-terminated silica may have lower residual stress. In semi-bulk materials, stress is a result of the strain introduced by the condensation of silanol groups [41] and cannot relax in a pure silica material; however, in a terminated organosilica, the material relaxes over the course of days [41]. For thin layers, such relaxations manifest themselves on shorter timescales. This mechanism suggests that the lower network connectivity of terminated organosilicas results in a lower $G_{f}[40]$ and a lower residual stress, which may explain the larger critical thickness of terminated organosilica observed in the experiments. It would be insightful to determine the residual stress of the ultra-thin films in independent experiments to understand the fracturing mechanism. There are many different techniques to determine the residual stress in thin films [42], such as measurement of the curvature in the substrate induced by contraction of the thin film; measurement of the strain in a crystalline material from the change in the interplanar spacing obtained by diffraction methods (X-ray or neutron); or measurement of stress-induced optical anisotropy or stressinduced anisotropy of the ultrasonic speed in the materials. However, many of these are not applicable to amorphous materials, such as our films. From our results, no interference fringes could be detected on optical 
micrographs of the synthesized layers. Applying the beam-bending technique on our films, with $625 \mu \mathrm{m}$ thick wafer as the substrate, the resulted curvatures are below the detection limit, yielding the estimation of the residual stress in the layer lower than $100 \mathrm{MPa}$. Lower stresses could not be determined accurately with the substrates used, as the film thickness cannot be increased further because of fracturing. To accurately measure the residual stress to a high resolution, one could use alternative substrates. As the measurable stress scales with the square of the substrate thickness, lower stresses may be determined on ultra-thin silicon wafers of $50 \mu \mathrm{m}$ or thinner. Alternatively, using different substrates of lower stiffness can be a method, but this could change the film-solid interaction as well.

\subsubsection{Crack spacing}

To compare the results of silica and organosilica to other systems, the crack spacing is plotted as a function of the film thickness (as obtained in many past studies) in Figure 2-6. It is clearly observed that the crack spacing data of various materials display different trends. For the colloidal materials such as silica [7] or polystyrene [15] spheres, the log-log plot of crack spacing versus layer thickness (of these micron-sized films) indicates an approximately linear trend. The ceria sol [43] may also be a colloidal suspension based on the original recipe [44]. For the polymeric (organo)silica sols of this study and Malzbender and de With [45] a different trend is observed, where the crack spacing actually increases with decreasing thickness until it reaches an asymptote at the critical thickness. This trend is consistent with the expected behavior for an elastically relaxing material $[10,43,45]$ which is given by

$$
l \cong \frac{8 h}{\ln \left(h / h_{\mathrm{c}}\right)}
$$

in which 1 is the crack spacing, and $\mathrm{h}$ is the film thickness. However, the predicted crack spacing of the model is not consistent with the determined value from the micrographs because the predicted crack spacing appears to 
be a factor 10 to 100 too low. This deviation can partially be the result of the crack spacing determination method, which depends on the definition of crack spacing and the used algorithm. However, using a different method that always underestimates the crack spacing, the calculated value of crack spacing will only change by a maximum factor of 2-3. This change still shows that the crack spacing is much larger than the value predicted by the elastic interaction of cracks, by a factor of 3 to 30 [46].

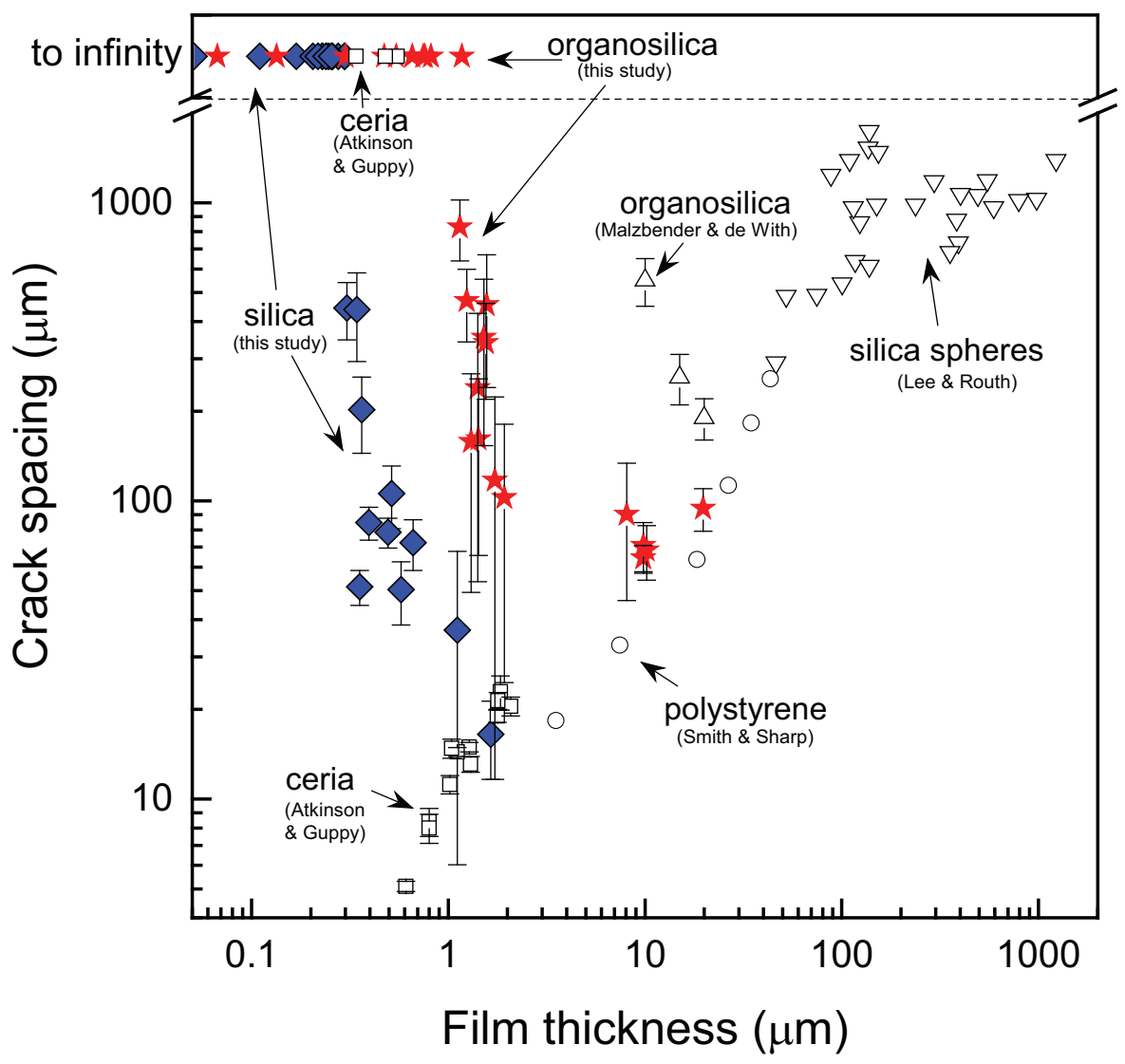

Figure 2-6: Crack spacing as a function of thickness for multiple studies $[7,15,43,45]$ using different submicron- and micron-thick films. Here, the organosilica films are BTESE-derived. 
In other words, the formation of cracks here is likely not governed by their elastic interaction. Instead, the crack formation may be generated by the nucleation of new cracks, for which the crack spacing does not only depend on film thickness, but also on drying rate and initial defect concentration [47-50]. This quantitative deviation between the data and the results predicted by equation 1-2 indicates that the elastic fracturing model is too simplistic to adequately capture the behavior of the (organo)silica thin films in a broad range of regimes. Thus, a new, unified theory is required to explain these different data for diverse systems.

These results also imply that the formation of cracks in the silica-based layers can be sensitive to crack nucleation. Nucleation can take place as a result of stress built-up in the layer, and is likely to take place at weak spots in the material, such as pinhole defects. Paying extra attention to the prevention of defects, e.g., by coating under clean room conditions, is then a path that is likely to succeed in decreasing the fracturing of the (organo)silica layers.

For the organosilica, the crack spacing saturates to a nearly constant value for the thickest films. Examination of the optical micrographs of these data shows that for the films $>1.5 \mu \mathrm{m}$, partial delamination of the layer is visible. In addition, for the thickest films of $>10 \mu \mathrm{m}$, some of the areas that were completely encircled by cracks, fully delaminated. Delamination of the layer leads to a stress release in the film. Consequently, there is no driving force for further crack formation, resulting in the plateau in the crack spacing and density seen for the thickest films.

A difference between the polymeric and colloidal materials appears to arise from the origin of the cracking. In colloidal sols, the cracks appear to nucleate in many different spots without progressing throughout the layer, which steadily increases the crack spacing when minor cracks become connected. In silica-based materials, a nucleating crack immediately propagates through the layer, which decreases the crack spacing when more cracks are formed. 


\subsection{Conclusions}

In summary, the fracturing tendency of sol-gel derived silica and organosilica coatings was compared using systematic experimental investigations. The critical thickness of silica was determined to be $300 \pm 30$ $\mathrm{nm}$, below which the films remain crack-free. With a sol-synthesis recipe that is targeted towards obtaining a final material with a comparable microstructure, the results for silica and organosilica were directly compared. Organosilica materials have much larger critical thicknesses than silica. For BTESE-derived organosilica, the critical thickness was determined to be $1250 \pm 200 \mathrm{~nm}$. For Zr-BTESE- and MTES-derived films, crack-free films were synthesized up to, approximately, 2150 and $2200 \mathrm{~nm}$, respectively. For the cracked silica and organosilica layers, the crack spacing was determined and compared to the values in the literature. Although the decreasing trend of crack spacing with increasing layer thickness is consistent with the predictions based on the elastic fracture model, the crack spacing was in a different order of magnitude than predicted. Based on these results, the elastic fracturing model may be too simplistic to capture the fracturing behavior of the studied films. Because the fracturing of silica coatings cannot be easily avoided when the thickness is above $300 \mathrm{~nm}$, substituting an organosilica for purely inorganic silica should be considered to obtain crack-free layers, which is beneficial for various sol-gel derived functional coatings.

\subsection{Acknowledgments}

The authors would like to thank Chris Hecker and Wim Bakker for suggesting the Laplacian of Gaussian edge detection algorithm and Bart Zaalberg for performing part of the optical microscopy experiments. Marcel ten Hove is acknowledged for kindly supplying the Zr-BTESE sol. The funding by the Helmholtz Alliance MEM-BRAIN through the Initiative and Networking Fund is gratefully acknowledged. 


\subsection{Appendices}

\subsubsection{Details on the algorithm used to determine the crack densities}

The following sequence of steps was taken for the image anal ysis of the crack edge, with Matlab built-in functions:

1. Edge detection with the Laplacian of Gaussian filter on the grayscale image. The edge detection results in a binary matrix, where the $1 \mathrm{~s}$ represent the outlines of the cracks and the 0s represent the space in between.

2. Removal of regions (regions of 1 s that are connected) with less than 30 pixels from the matrix obtained in step 1 , as these regions with only a few pixels were heuristically determined to constitute noise;

3. Removal of regions for which the extent (the ratio of $1 \mathrm{~s}$ to the number of total pixels in the bounding box) is higher than 0.05, as these regions with a bounding box that is comparatively small to the amount of pixels were heuristically determined to constitute noise;

4. To convert the outlines of the cracks to a single-pixel crack line, the following morphological operations were used: a. Filling of the isolated interior pixels; b. Dilation with a $3 \times 3$ matrix of ones; c. Bridging, setting 0s with at least two non-zero non-connected neighbours to 1; d. Dilation with a $3 \times 3$ matrix of ones; e. Setting 0s to 1 if 5 or more of its $3 \times 3$ neighbours are 1 ; f. Thinning with $n=$ Inf, shrinking objects down to lines; g. Filling of theisolated interior pixels;

This sequence was heuristically determined to result in an accurate representation of the cracks by a single line.

\subsubsection{Details on determining the crack spacing}

The image obtained in step $4 \mathrm{~g}$ above was used as a starting point for the determination of the crack spacing. Crack spacing was determined via two individual approaches. Both approaches involve the determination of the Euclidian distance transform of the binary image. The distance to the 
nearest white pixel is determined by: $\sqrt{\left(x_{1}-x_{2}\right)^{2}+\left(y_{1}-y_{2}\right)^{2}}$. A plot of this distance transform is given in Figure 2-3C, where blue colors indicate regions close to cracks and red colors regions far away from cracks.

\section{Method 1}

In the first method to determine the crack spacing, the average value of the Euclidian distance transform was taken as a measure for the crack spacing. This method will always underestimate the crack spacing because it averages over the pixels close to the cracks as well.

\section{Method 2}

In the second method, the midpoint between two lines was determined by performing a watershed analysis, where the different cracks were used as catchment basins. The result of this analysis are watershed lines, i.e., lines that are at exactly in between two cracks. In this method, the crack distance was taken as the average distance to the cracks on the watershed lines.

Method 2 represents a more accurate calculation of the crack distance, but may omit the crack spacing of regions that are enclosed by a single crack. Therefore, the results of method 2 were checked against the results of method 1, and confirmed to give the similar results. Therefore, the results of method 2 were taken as a representative value for the average crack spacing in an image.

\subsubsection{Nanoindentation measurements}

Table 2-A1 lists the mechanical properties for silica-derived and BTESEderived films as determined by nanoindentation measurements performed in this study. The layers used for the nanoindentation measurements needed to stay (well) below the critical thickness, requiring low layer thicknesses. However, a lower layer thickness results in increased effect of the substrate properties on the measurement results. 
Table 2-A1: Mechanical properties for silica and BTESE after drying and after annealing, measured by nanoindentation on layers supported on a silicon wafer. The error bars denote the $95 \%$ confidence intervals over a large amount of indentations in a single sample. Because of the low layer thicknesses, cautiousness is required upon interpreting the data (see text). Explanation of symbols: $E^{\star}$, plane-strain modulus; $H_{\max }$, maximum creep during holding for 20 seconds at maximum force; $\mu \mathrm{IT}$, elastic contribution to the total work.

\begin{tabular}{llllllll}
\hline & $\begin{array}{l}\text { Layer } \\
\text { thickness } \\
(\mathbf{n m})\end{array}$ & $\begin{array}{l}\text { Indentation } \\
\text { hardness } \\
\left(\mathbf{N} / \mathbf{m m}^{2}\right)\end{array}$ & $\begin{array}{l}\text { Vickers } \\
\text { hardness } \\
\mathbf{( H V )}\end{array}$ & $\begin{array}{l}\mathbf{E}^{*} \\
\mathbf{( G P a )}\end{array}$ & $\begin{array}{l}\boldsymbol{H}_{\max } \\
\mathbf{( n m )}\end{array}$ & $\begin{array}{l}\text { CIT } \\
\mathbf{( \% )}\end{array}$ & $\begin{array}{l}\boldsymbol{\mu I T} \\
(\%)\end{array}$ \\
\hline Silica & 194 & $415 \pm 29$ & $39 \pm 3$ & $6.1 \pm 0.7$ & $134 \pm 5$ & $12 \pm 2$ & $35 \pm 4$ \\
Silica & 153 & $606 \pm 76$ & $56 \pm 7$ & $10.9 \pm 1.2$ & $111 \pm 8$ & $9 \pm 1$ & $28 \pm 4$ \\
Silica (calcined) & 191 & $447 \pm 26$ & $41 \pm 2$ & $6.5 \pm 0.4$ & $128 \pm 5$ & $12 \pm 1$ & $39 \pm 3$ \\
Silica (calcined) & 76 & $532 \pm 37$ & $49 \pm 3$ & $7.1 \pm 0.4$ & $112 \pm 7$ & $14 \pm 2$ & $39 \pm 2$ \\
BTESE & 1182 & $476 \pm 49$ & $39 \pm 4$ & $7.6 \pm 1.1$ & $136 \pm 8$ & $9 \pm 1$ & $27 \pm 5$ \\
BTESE (calcined) & 946 & $426 \pm 43$ & $43 \pm 3$ & $5.8 \pm 0.5$ & $135 \pm 7$ & $12 \pm 1$ & $39 \pm 5$ \\
\hline
\end{tabular}

Typically, for measuring the elastic properties, the indentation depth $H_{\max }$ should be smaller than $10 \%$ of the layer thickness. For measuring the layer hardness, a deeper indentation is allowed. Especially in the case of the silica layers, the indentation depths over the layer are significantly above half of the layer thicknesses $(69 \%, 73 \%, 67 \%$, and 147\%). The values obtained for silica should therefore be used as an estimate of the order of magnitude only.

In Figure 2-A7, we show the characteristic length scale, $l$, for periodic cracks in three films of different thicknesses. One of the films is silica, the other two films are made of BTESE-derived organosilica. A recent study [11] identified a relationship between the crack replicating distance $W_{1}$ and the film thickness h. For multiple orders of magnitude of film thicknesses, the ratio $l / h$ was found to be approximately 30 . 


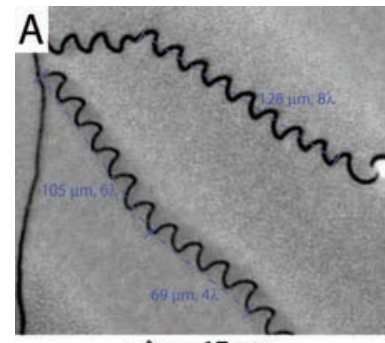

$<\lambda>=17 \mu \mathrm{m}$

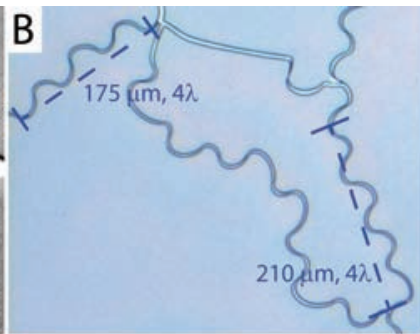

$<\lambda>=48 \mu \mathrm{m}$

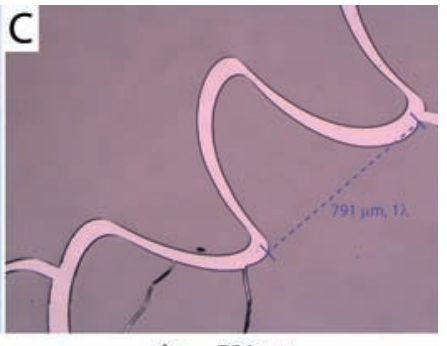

$<\lambda>=791 \mu \mathrm{m}$

Figure 2-A7: Determination of the characteristic length scale for periodic cracks for three films of different thicknesses: A: a $575 \pm 10 \mathrm{~nm}$ silica film; B: a 1430 $\pm 140 \mathrm{~nm}$ BTESE-derived organosilica film; and C: a $20 \pm 2 \mu \mathrm{m}$ BTESE-derived organosilica film.

From our data, we calculate the ratio $W_{1}=l / h$ and find the average of $l / h$ of 34, which is consistent with a recent theoretical prediction [11]. The agreement suggests that such periodic, wavy cracks stems from the interplay between layer delimitation and cracking propagation, quantitatively predicted by the collaborative model [11]. 


\subsection{References}

1. Manca, M., Cannavale, A., De Marco, L., Aricò, A.S., Cingolani, R. \& Gigli, G., 2009, Durable superhydrophobic and antireflective surfaces by trimethylsilanized silica nanoparticles-based sol-gel processing. Langmuir 25, pp. 6357-62. (doi:10.1021/la804166t)

2. Tsai, C.Y., Tam, S.Y., Lu, Y. \& Brinker, C.J., 2000, Dual-layer asymmetric microporous silica membranes. J. Membr. Sci. 169, pp. 255-268. (doi:10.1016/S0376-7388(99)00343-9)

3. Agirre, I., Arias, P.L., Castricum, H.L., Creatore, M., ten Elshof, J.E., Paradis, G.G., Ngamou, P.H.T., van Veen, H.M. \& Vente, J.F., 2014, Hybrid organosilica membranes and processes: Status and outlook. Sep. Purif. Technol. 121, pp. 2-12. (doi:10.1016/j.seppur.2013.08.003)

4. Volksen, W., Lionti, K., Magbitang, T. \& Dubois, G., 2014, Hybrid low dielectric constant thin films for microelectronics. Scr. Mater. 74, pp. 19-24. (doi:10.1016/j.scriptamat.2013.05.025)

5. Brinker, C.J. \& Scherer, G.W., 1990, Sol-gel Science: The Physics and Chemistry of Sol-Gel Processing. 1st ed. San Diego, CA, USA: Academic Press. ISBN: 9780121349707

6. $\quad$ Routh, A.F., 2013, Drying of thin colloidal films. Rep. Prog. Phys. 76, pp. 046603. (doi:10.1088/0034-4885/76/4/046603)

7. Lee, W.P. \& Routh, A.F., 2004, Why do drying films crack? Langmuir 20, pp. 9885-8. (doi:10.1021/la049020v)

8. Bohn, S., Pauchard, L. \& Couder, Y., 2005, Hierarchical crack pattern as formed by successive domain divisions. Phys. Rev. E 71, pp. 046214. (doi:10.1103/PhysRevE.71.046214)

9. Xia, Z. \& Hutchinson, J., 2000, Crack patterns in thin films. J. Mech. Phys. Solids 48, pp. 1107-1131. (doi:10.1016/S0022-5096(99)00081-2)

10. Grosskreutz, J.C. \& McNeil, M.B., 1969, The Fracture of Surface Coatings on a Strained Substrate. J. Appl. Phys. 40, pp. 355. (doi:10.1063/1.1657059)

11. Marthelot, J., Roman, B., Bico, J., Teisseire, J., Dalmas, D. \& Melo, F., 2014, SelfReplicating Cracks: A Collaborative Fracture Mode in Thin Films. Phys. Rev. Lett. 113, pp. 085502. (doi:10.1103/PhysRevLett.113.085502)

12. Prosser, J.H., Brugarolas, T., Lee, S., Nolte, A.J. \& Lee, D., 2012, Avoiding cracks in nanoparticle films. Nano Lett. 12, pp. 5287-91. (doi:10.1021/nl302555k)

13. Boulogne, F., Giorgiutti-Dauphiné, F. \& Pauchard, L., 2013, How to reduce the crack density in drying colloidal material? Oil Gas Sci. Technol. - Rev. IFP Energies Nouv. 69, pp. 397-404. (doi:http://dx.doi.org/10.2516/ogst/2013119) 
14. Xu, Y., German, G.K., Mertz, A.F. \& Dufresne, E.R., 2013, Imaging stress and strain in the fracture of drying colloidal films. Soft Matter 9, pp. 3735. (doi:10.1039/c3sm27912j)

15. Smith, M.I. \& Sharp, J.S., 2011, Effects of substrate constraint on crack pattern formation in thin films of colloidal polystyrene particles. Langmuir 27, pp. 800917. (doi:10.1021/la2000624)

16. Lazarus, V. \& Pauchard, L., 2011, From craquelures to spiral crack patterns: influence of layer thickness on the crack patterns induced by desiccation. Soft Matter 7, pp. 2552. (doi:10.1039/c0sm00900h)

17. Singh, K. \& Tirumkudulu, M., 2007, Cracking in Drying Colloidal Films. Phys. Rev. Lett. 98, pp. 218302. (doi:10.1103/PhysRevLett.98.218302)

18. Hu, M.S. \& Evans, A.G., 1989, The cracking and decohesion of thin films on ductile substrates. Acta Metall. 37, pp. 917-925. (doi:10.1016/00016160(89)90018-7)

19. Beuth, J.L., 1992, Cracking of thin bonded films residual tension. Int. J. Solids Struct. 2, pp. 1657-1675. (doi:10.1016/0020-7683(92)90015-L)

20. Dundurs, J., 1969, Edge-Bonded Dissimilar Orthogonal Elastic Wedges Under Normal and Shear Loading. J. Appl. Mech. 36, pp. 650-652. (doi:10.1115/1.3564739)

21. Dubois, G., Volksen, W., Magbitang, T., Miller, R.D., Gage, D.M. \& Dauskardt, R.H., 2007, Molecular network reinforcement of sol-gel glasses. Adv. Mater. 19, pp. 3989-3994. (doi:10.1002/adma.200701193)

22. Dubois, G., Volksen, W., Magbitang, T., Sherwood, M.H., Miller, R.D., Gage, D.M. \& Dauskardt, R.H., 2008, Superior mechanical properties of dense and porous organic/inorganic hybrid thin films. J. Sol-Gel Sci. Technol. 48, pp. 187193. (doi:10.1007/s10971-008-1776-2)

23. Kayaba, Y., Nishiyama, F., Seino, Y. \& Kikkawa, T., 2011, Molecular Bonding Structure of Alkylene-Bridged Organosilicate Glass Films. J. Phys. Chem. C 115, pp. 12981-12989. (doi:10.1021/jp202957f)

24. De Lange, R.S.A., Hekkink, J.H.A., Keizer, K. \& Burggraaf, A.J., 1995, Formation and characterization of supported microporous ceramic membranes prepared by sol-gel modification techniques. J. Membr. Sci. 99, pp. 57-75. (doi:10.1016/03767388(94)00206-E)

25. Qureshi, H.F., Nijmeijer, A. \& Winnubst, L., 2013, Influence of sol-gel process parameters on the micro-structure and performance of hybrid silica membranes. J. Membr. Sci. 446, pp. 19-25. (doi:10.1016/j.memsci.2013.06.024)

26. Ten Hove, M., Nijmeijer, A. \& Winnubst, A.J.A., 2014, Facile synthesis of zirconia doped hybrid organic inorganic silica membranes. Presented at the International Conference on Inorganic Membranes, Brisbane, Australia. 
27. Castricum, H.L., Sah, A., Mittelmeijer-Hazeleger, M.C., Huiskes, C. \& Ten Elshof, J.E., 2007, Microporous structure and enhanced hydrophobicity in methylated $\mathrm{SiO}_{2}$ for molecular separation. J. Mater. Chem. 17, pp. 1509-1517. (doi:10.1039/B610311A)

28. Brinker, C.J., Ward, T.L., Sehgal, R., Raman, N.K., Hietala, S.L., Smith, D.M. \& Hua, D., 1993, "Ultramicroporous" silica-based supported inorganic membranes. J. Membr. Sci. 77, pp. 165-179. (doi:10.1016/0926-860X(93)80011-E)

29. Nair, B.N., Elferink, W.J., Keizer, K. \& Verweij, H., 1996, Sol-Gel Synthesis and Characterization of Microporous Silica Membranes I: SAXS Study on the Growth of Polymeric Structures. J. Colloid Interface Sci. 178, pp. 565-570. (doi:10.1006/jcis.1996.0152)

30. Castricum, H.L., Paradis, G.G., Mittelmeijer-Hazeleger, M.C., Bras, W., Eeckhaut, G., Vente, J.F., Rothenberg, G. \& ten Elshof, J.E., 2014, Tuning the nanopore structure and separation behavior of hybrid organosilica membranes. Microporous Mesoporous Mater. 185, pp. 224-234. (doi:10.1016/j.micromeso.2013.11.005)

31. Huang, Y.-Y. \& Chou, K.-S., 2003, Studies on the spin coating process of silica films. Ceram. Int. 29, pp. 485-493. (doi:10.1016/S0272-8842(02)00191-8)

32. Woollam, J.A., Johs, B., Herzinger, C.M., Hilfiker, J., Synowicki, R. \& Bungay, C.L., 1999, Overview of Variable Angle Spectroscopic Ellipsometry (VASE), Part I: Basic Theory and Typical Applications. In Optical Metrology (ed G. A. AlJumaily), pp. 3-28. Bellingham, Washington: SPIE.

33. Malzbender, J., de With, G. de \& den Toonder, J., 2000, Determination of the elastic modulus and hardness of sol-gel coatings on glass: influence of indenter geometry. Thin Solid Films 372, pp. 134-143. (doi:10.1016/S00406090(00)01025-7)

34. Malzbender, J., 2003, Comment on hardness definitions. J. Eur. Ceram. Soc. 23, pp. 1355-1359. (doi:10.1016/S0955-2219(02)00354-0)

35. Hay, J. \& Crawford, B., 2011, Measuring substrate-independent modulus of thin films. J. Mater. Res. 26, pp. 727-738. (doi:10.1557/jmr.2011.8)

36. Wan, N., Xu, J., Lin, T., Xu, L. \& Chen, K., 2009, Observation and model of highly ordered wavy cracks due to coupling of in-plane stress and interface debonding in silica thin films. Phys. Rev. B 80, pp. 014121. (doi:10.1103/PhysRevB.80.014121)

37. Goehring, L., Clegg, W.J. \& Routh, A.F., 2011, Wavy cracks in drying colloidal films. Soft Matter 7, pp. 7984-7987. (doi:10.1039/c1sm05979c)

38. Elma, M., Yacou, C., Wang, D., Smart, S. \& Costa, J.C.D. da, 2012, Microporous silica based membranes for desalination. Water 4, pp. 629-649. (doi:10.3390/w4030629) 
39. Leenaars, A.F.M. \& Burggraaf, A.J., 1985, The preparation and characterization of alumina membranes with ultrafine pores. 2. The formation of supported membranes. J. Colloid Interface Sci. 105, pp. 27-40. (doi:10.1016/00219797(85)90343-1)

40. Oliver, M.S., Dubois, G., Sherwood, M., Gage, D.M. \& Dauskardt, R.H., 2010, Molecular origins of the mechanical behavior of hybrid glasses. Adv. Funct. Mater. 20, pp. 2884-2892. (doi:10.1002/adfm.201000558)

41. Scherer, G.W., 1996, Influence of Viscoelasticity and Permeability on the Stress Response of Silica Gel. Langmuir 12, pp. 1109-1116. (doi:10.1021/la9503111)

42. Withers, P.J. \& Bhadeshia, H.K.D.H., 2001, Residual stress Part 1 - Measurement techniques. Mater. Sci. Technol. 17, pp. 355-365. (doi:10.1179/026708301101509980)

43. Atkinson, A. \& Guppy, R.M., 1991, Mechanical stability of sol-gel films. J. Mater. Sci. 26, pp. 3869-3873. (doi:10.1007/BF01184984)

44. Woodhead, J.L., 1974, Improvement in or relating to the production of ceria. UK1342893.

45. Malzbender, J. \& de With, G., 2000, Cracking and residual stress in hybrid coatings on float glass. Thin Solid Films 359, pp. 210-214. (doi:10.1016/S00406090(99)00885-8)

46. Thouless, M.D., 1990, Crack spacing in brittle films on elastic substrates. J. Am. Ceram. Soc. 73, pp. 2144-2146. (doi:10.1111/j.1151-2916.1990.tb05290.x)

47. Yamamura, M., Ono, H., Uchinomiya, T., Mawatari, Y. \& Kage, H., 2009, Multiple crack nucleation in drying nanoparticle-polymer coatings. Colloids Surfaces A Physicochem. Eng. Asp. 342, pp. 65-69. (doi:10.1016/j.colsurfa.2009.04.008)

48. Yamamura, M., Ono, H. \& Uchinomiya, T., 2010, Suppressed Cracking in Drying Coatings at High Peclet Numbers. J. Chem. Eng. Japan 43, pp. 209-213.

49. Tirumkudulu, M.S. \& Russel, W.B., 2005, Cracking in Drying Latex Films. Langmuir 15, pp. 4938-4948. (doi:10.1021/la048298k)

50. Jagla, E., 2002, Stable propagation of an ordered array of cracks during directional drying. Phys. Rev. E 65, pp. 046147. (doi:10.1103/PhysRevE.65.046147) 


\section{Chapter 3 \\ Expeditious calcination of inorganic membranes by an instant temperature increment}

This chapter had been adapted from:

Kappert, E.J., A. Nijmeijer, N.E. Benes, 2012, Expeditious calcination of inorganic membranes by an instant temperature increment, Micropor. Mesopor. Mater., 151, pp. 211-215, doi: 10.1016/j.micromeso.2011.10.034 


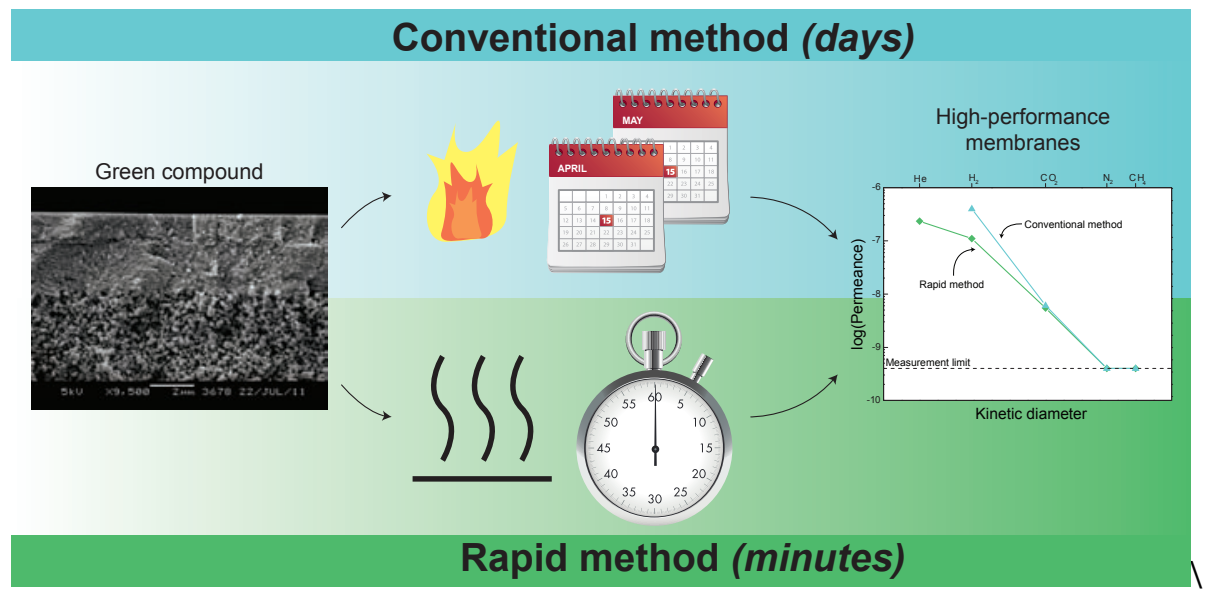

\section{Abstract}

Rapid thermal treatments potentially allow for a significant reduction in the production time of ceramic multilayered membranes, in turn aiding the increased industrial application of these membranes and accelerating research on their development. Two methods are proposed for the rapid thermal treatment of thin supported inorganic membrane films. Both methods involve an instant increment in temperature imposed on the membrane. In the first method, the instant temperature step is enforced by placing the membrane in a preheated environment; in the second method, the membrane is placed directly onto a hot plate. The proposed methods can be used for a diverse range of materials. Mesoporous $\gamma$-alumina and microporous silica were selected as model membrane materials. Both rapid heating methods require $\sim 20 \mathrm{~min}$ to yield mesoporous $\gamma$-alumina membranes that are comparable to membranes made via conventional calcination ( $\sim 1$ day). Selective silica membranes were obtained after 1 hour exposure to an environment of 400 or $600{ }^{\circ} \mathrm{C}$, and after 1 hour contact with a hot plate of $550{ }^{\circ} \mathrm{C}$ (compared to up to 2 days for conventional calcination). The results indicate that, although prevention of contaminations needs continuous attention, both methods proposed for rapid heat treatment can reduce cost and time in ceramic membrane production. 


\subsection{Introduction}

Sol-gel deposition is a versatile method for the production of thin, inorganic membrane layers with a broad range of properties and competitive permeances and selectivities [1-7]. Sol-gel derived layers are coated on a porous support that provides mechanical strength. Multiple membrane layers are sequentially coated onto the support, rendering the production process of the membranes laborious and expensive [8]. Especially the thermal treatment step is time-consuming and energyintensive. Typically, each layer is calcined at temperatures around $600{ }^{\circ} \mathrm{C}$ for 3 hours, with heating and cooling rates in the order of $1{ }^{\circ} \mathrm{C}$ per minute $[4-7,9]$. For a full heating and cooling cycle from and to room temperature, this results in a total residence time in the furnace of 22 hours. For a membrane comprising multiple layers, the processing time may add up to over a week. By minimizing the time required for thermal treatment, production costs of ceramic membranes can be decreased, in turn boosting opportunities for application and research for rapid material screening.

Recently, rapid thermal processing (RTP) was applied to inorganic membranes in the prevention of grain-boundary defect formation in the zeolite silicate-1 [10] and for the significant reduction in calcination time of $\gamma$-alumina membranes [11]. In both cases, the application of RTP led to an improvement in the material microstructure. While not yet commonly applied in membrane production, RTP is common in especially the semiconductor industry. Using an infrared lamp array, heating rates over $100{ }^{\circ} \mathrm{C}$ per second are applied in combination with dwell times shorter than ten minutes [12]. Apart from decreasing the processing time, there are several other reasons to choose for RTP over conventional processing, including the prevention of dopant diffusion [13], the improvement of crystallization behavior [14, 15], and the ability to rapidly fabricate multilayered films of micrometer thickness [16]. The high heating rate and controlled atmosphere give RTP an advantage over conventional furnace 
processing, especially for nanoscale systems that are sensitive to particles (e.g. dust, aerosols).

Although thin membrane layers are known to be prone to defects, they may be less susceptible to contamination than, e.g., integrated circuits, where one small particle can damage the whole system. As classical RTP techniques have been developed for single wafers they may even be unsuited and too expensive for the production of membranes on industrial scales, where surface areas in the order of hundreds of square meters need to be treated thermally. In addition, RTP techniques seem inapt for thermal treatment of desired non-flat geometries like tubes and hollow fibers that are required for industrial up-scaling.

As an alternative to classic RTP methods, we demonstrate two generic rapid thermal treatment methods for the calcination of inorganic membranes. In both methods, an instant change in temperature is imposed onto the membrane. In the first method, hereafter referred to as Hot Environment (HE), the membrane is suddenly exposed to a preheated environment. In the second method, referred to as Hot Plate (HP), the membrane is placed directly onto a hot surface. Two model membranes were selected to explore the heating methods: supported thin film mesoporous $\gamma$-alumina, synthesized from a boehmite precursor that contains an organic binder, and supported thin film microporous silica, synthesized from a polymeric sol in ethanol.

Silica membranes have arbitrarily been defined as 'high-quality' if the selectivity for helium/methane is at least 100. From experience, it is known that such selectivities are only found on homogeneous $\gamma$-alumina intermediate layers with defect-free silica layers. Hence, by demonstrating the successful synthesis of high-quality, rapidly calcined $\gamma$-alumina and silica layers it is proven that rapid thermal treatments can be applied for the calcination of membrane layers without compromising their quality. 


\subsection{Experimental section}

\subsubsection{Materials}

AKP-30 $\alpha$-alumina powder (Sumitomo) was used for supports; aluminium tri-sec-butylate (Merck) and poly(vinyl alcohol) (86.7-88.7 mol-\% hydrolysis, $\mathrm{M}_{\mathrm{W}} \sim 67,000$, Sigma-Aldrich) were used for boehmite sol synthesis and preparation of the coating solution; and tetraethyl orthosilicate (Merck) was used for silica sol synthesis. $\alpha$-alumina supports, made via a process identical to that of the homemade supports (described below), were purchased from Pervatech (Netherlands).

\subsubsection{Support and sol-synthesis}

Synthesis of flat $\alpha$-alumina supports, and synthesis of and coating with boehmite colloidal sol and silica sol was all carried out following the procedures described elsewhere [5]. Coating was carried out in a controlled environment (corresponding to clean room class 6).

\subsubsection{Calcination procedure}

Supported $\gamma$-alumina membranes were dried for three hours in a climate chamber (Heraeus Vötsch) at $40{ }^{\circ} \mathrm{C}$ and $60 \%$ relative humidity prior to thermal treatment. Thermal treatments were categorized into three groups: conventional calcination, hot environment calcination, and hot plate calcination. Conventional calcination was carried out in a furnace (Carbolite CWF with Eurotherm 3504 temperature controller) for three hours at the desired temperature with heating and cooling rates of $1{ }^{\circ} \mathrm{C}$ ( $\gamma$-alumina) or $0.5{ }^{\circ} \mathrm{C}$ (silica), resulting in total calcination times of 22 and 41 hours, respectively. Hot environment calcination was carried out in the same furnace that was preheated to $400{ }^{\circ} \mathrm{C}$ or $600{ }^{\circ} \mathrm{C}$. Membranes were loaded onto a wafer and placed inside the furnace for the desired time. After removal, the wafer was placed on a thick alumina plate at room temperature to cool down. Hot plating was performed by placing membranes for a desired time on a hot plate (Schott, SLK 1) at maximum power (corresponding to a surface temperature of approximately $550{ }^{\circ} \mathrm{C}$ ). 


\section{Support ring}

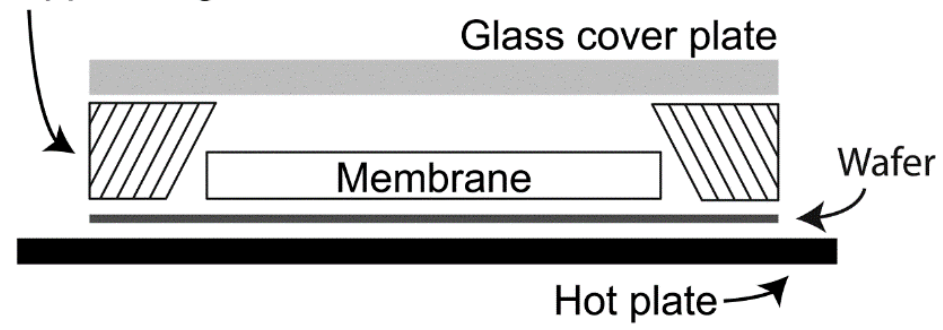

Figure 3-1: Covering of a membrane during hot plate experiments. The membrane is placed on a wafer and shielded by a quartz glass plate supported by an alumina ring.

During the hot plate experiment, the membrane was covered by a quartz glass plate to prevent contamination from the environment (Figure 3-1).

\subsubsection{Nomenclature}

Conventionally calcined (CC) samples are indicated by materialtemperature-CC; hot environment (HE) samples are named materialtemperature-time; and hot plating (HP) samples are named materialtemperature-time-HP. Materials are indicated by $\gamma$ ( $\gamma$-alumina $)$ and $\mathrm{Si}$ (silica), temperature and time are in ${ }^{\circ} \mathrm{C}$ and minutes, respectively.

\subsubsection{Characterization}

The pore size of the $\gamma$-alumina membranes was determined using permporometry. Measurements were carried out on an in-house designed apparatus using cyclohexane as the pore-filling liquid and an oxygen sensor to determine oxygen concentration, following the procedure described by Cao et al. [17].

Silica membranes were characterized by single-gas permeation in dead-end mode without backpressure. The standard measurement carried out for every membrane consisted of measuring the permeances of a selection of $\mathrm{He}, \mathrm{H}_{2}, \mathrm{~N}_{2}, \mathrm{CO}_{2}, \mathrm{CH}_{4}$, and $\mathrm{SF}_{6}$ at $200{ }^{\circ} \mathrm{C}$ and a pressure difference of 2 bar. 
The single-gas permeance $F$ was determined by:

$$
F_{i}=\frac{N_{i}}{\Delta P}
$$

in which $N_{i}$ is the molar flux of species $i$ through the membrane. The permselectivity $F_{\alpha}$ between a gas $i$ and a gas $j$ was determined by taking the ratio of the permeation of the two single gases.

To follow the debinding of organics from the $\gamma$-alumina precursors, video recordings of the membrane color in time were made with a Canon PowerShot A530 at $640 \times 480$ resolution and a frame rate of $10 \mathrm{~s}^{-1}$. The movie was cropped to a $15 \times 15$ pixel spot on the membrane. Using Matlab (version 2010a, Mathworks), RGB color data was extracted from the video and converted to $L^{\star} a^{\star} b^{\star}$ color space (applying the makecform('srgb2lab') and applycform commands), after which the $L^{\star} a^{\star} b^{\star}$ colors were averaged over the selected area. The color was compared to white $\left(L^{\star}=100, a^{\star}=0, b^{\star}=0\right)$ by taking the Euclidean distance between white and the measured color:

$$
\Delta E=\sqrt{\left(\Delta L^{*}\right)^{2}+\left(\Delta a^{*}\right)^{2}+\left(\Delta b^{*}\right)^{2}}
$$

\subsection{Results and discussion}

\subsection{1. $\gamma$-alumina membranes}

The obtained oxygen permeance through the different membranes was plotted as a function of the relative cyclohexane pressure in the gas in Figure 3-2A. For a non-cured $(\gamma-0)$ layer, no permeance was detected for the complete range of cyclohexane pressures, indicating a non-porous or microporous layer. For membranes rapidly calcined at increasing times, the cumulative oxygen permeance as well as the onset cyclohexane pressure at which permeance starts were found to increase. 

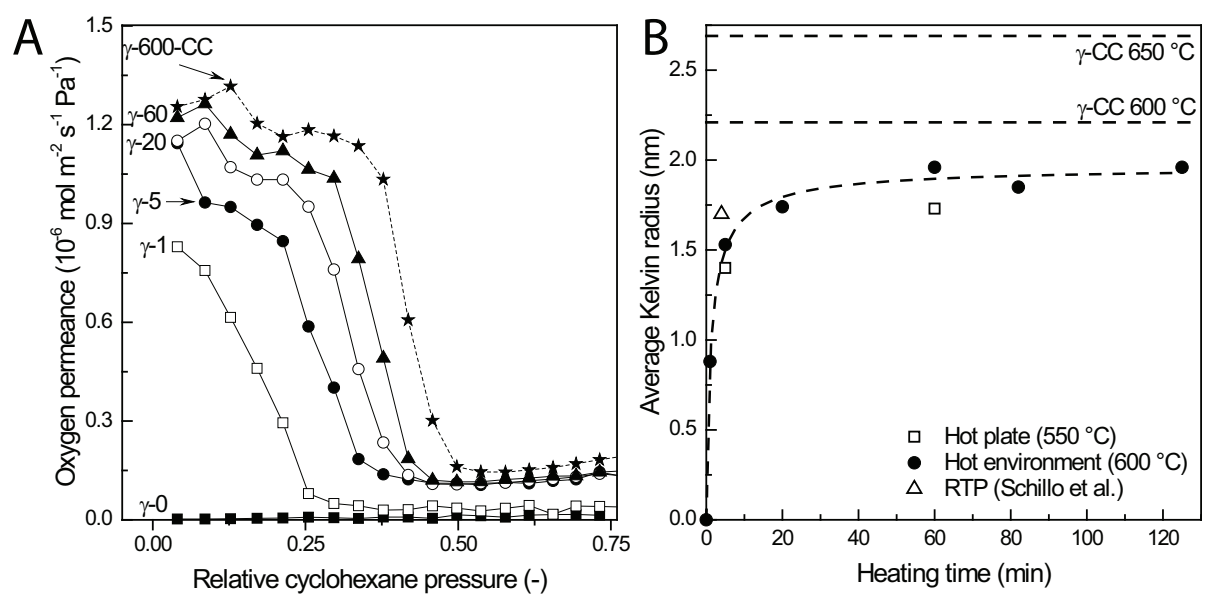

Figure 3-2: A. Oxygen permeance through rapidly calcined $\gamma$-alumina membrane layers as a function of relative cyclohexane pressure. B. Calculated average Kelvin radii for $\gamma$-alumina membranes after rapid treatment. The triangle indicates a $\gamma$-alumina layer after 3 minutes of RTP treatment as reported by Schillo et al. [11]

From the relative cyclohexane pressure, the corresponding Kelvin radius was calculated [17]. Figure 3-2B shows the progress of the average Kelvin radius of rapidly calcined $\gamma$-alumina membranes as a function of their thermal-treatment time. The radius steeply increases in the first 5 minutes, after which the pore size slowly increases further to reach an asymptotic value of $2.0 \mathrm{~nm}$. The asymptotic Kelvin radius of $2.0 \mathrm{~nm}$ compares well to literature [18] and is only slightly lower than the average pore radius of conventionally calcined membranes (2.3 nm for $\gamma$-600-CC). Analysis of layers of boehmite/PVA on wafers by ATR-FTIR, given in the Supporting Information in reference [21], show that no PVA remains in the structure after calcination. The results of this study also agree well to the results that were obtained by Schillo et al., whom used rapid thermal processing by a tungsten-halogen-lamp array [11]. 
The steep pore size increase in the first five minutes of calcination is attributed to the debinding of poly(vinyl alcohol) from the membrane layer, which takes place in two steps. First, the alcohol groups are removed from the polymer backbone by chain stripping [19], resulting in a conjugated polyene with a brown-orange color. Secondly, at higher temperatures, the polyene is decomposed into volatiles via a chain-scission mechanism. In oxygen, this decomposition will not leave any residues behind if the temperature becomes higher than $700 \mathrm{~K}$ [20]. Hence, to verify whether the fast increase in Kelvin radius in the first minutes indeed corresponds to the debinding of the poly(vinyl alcohol) binder from the green boehmite, the change in membrane color was recorded by performing the calcination step on a hot plate and recording it on video. The derived $L^{\star} a^{\star} b^{\star}$ color is plotted in Figure 3-3.

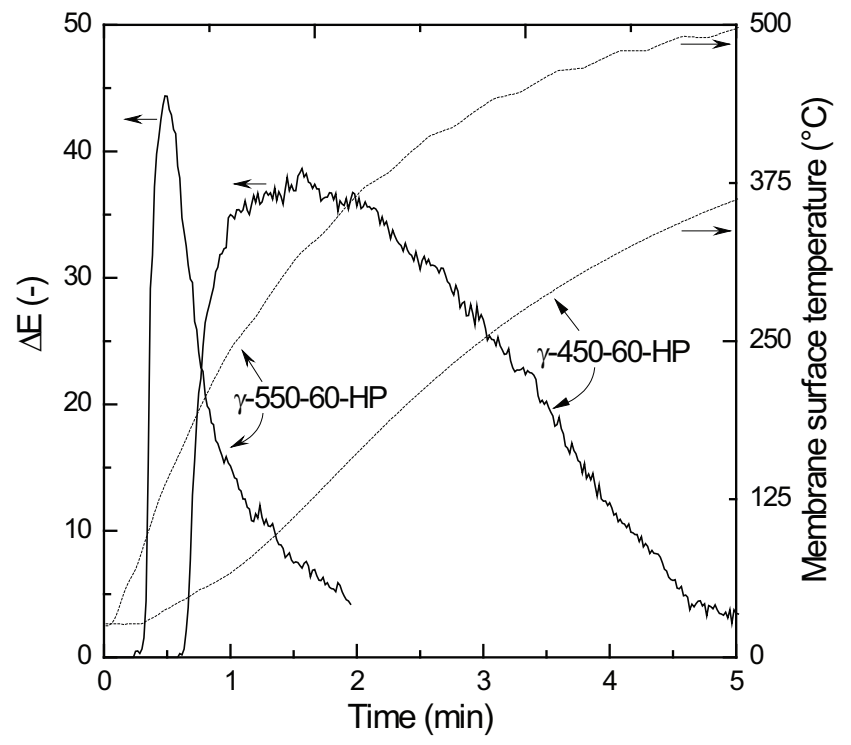

Figure 3-3: Membrane surface color (solid line) and temperature (dotted line) as a function of the time on the hot plate. The color is given as the deviation from white as determined by equation 1-4 
The progress of color and temperature in time is visualized for two membranes: $\gamma-550-60-\mathrm{HP}$ and $\gamma-450-60-\mathrm{HP}$, where a $2 \mathrm{~mm}$ copper plate was inserted as a thermal barrier between the hot plate and the membrane in the latter case. In both cases, a temperature-color correlation is evident, since the darkest color is observed as the membrane surface reaches a temperature of $150{ }^{\circ} \mathrm{C}$ and the membrane returns to its initial color at roughly $400{ }^{\circ} \mathrm{C}$.

\subsubsection{Rapidly calcined silica layers}

The permeance of multiple gases through Si-400-60 and Si-600-60 membranes at $200{ }^{\circ} \mathrm{C}$ is given in Figure 3-4 and Figure 3-5, respectively. Regardless of the temperature, the membranes treated for 60 minutes show comparable helium permeances, averaging $3.13 \pm 0.75 \cdot 10^{-7} \mathrm{~mol} \mathrm{~m}^{-2} \mathrm{~s}^{-1} \mathrm{~Pa}^{-1}$.

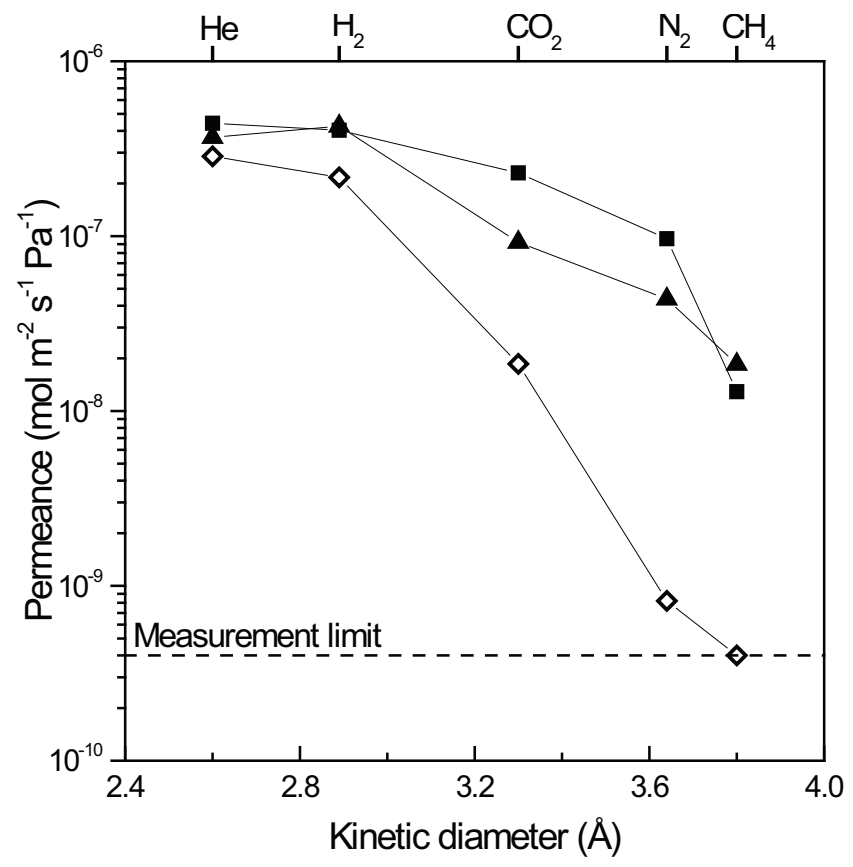

Figure 3-4: Permeance through silica layers rapidly calcined in a hot environment at $400{ }^{\circ} \mathrm{C}$ for 60 minutes (Si-400-60). The three lines indicate distinct membranes that were made through identical procedures. 


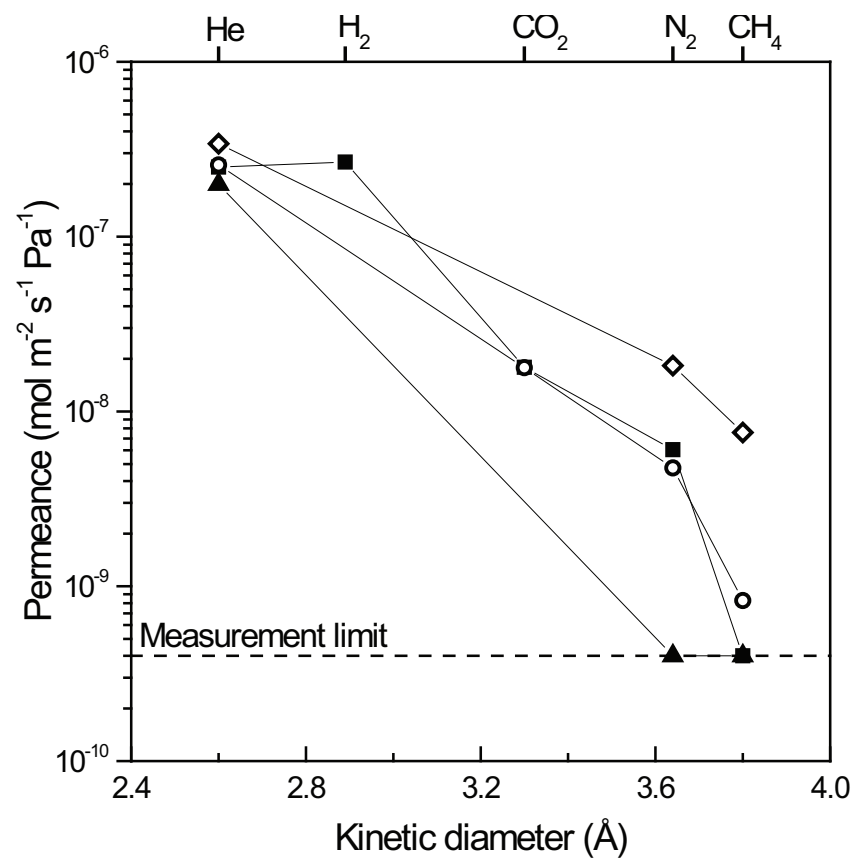

Figure 3-5: Permeance through silica layers rapidly calcined in a hot environment at $600{ }^{\circ} \mathrm{C}$ for 60 minutes $(\mathrm{Si}-600-60)$. The four lines indicate distinct membranes that were made through identical procedures.

This value compares well to literature, indicating that applying an instant temperature step did not result in significant network densification. The high permselectivity of the silica layers $\left(\mathrm{He} / \mathrm{CH}_{4}>100\right)$ indicates a defectfree layer and thus demonstrates the viability of the hot environment technique.

On the other hand, as can be seen in Figure 3-4 and Figure 3-5, approximately $50 \%$ of the membranes only show moderate selectivities $\left(\mathrm{He} / \mathrm{CH}_{4}<100\right.$, henceforth called defect), whereas for conventionally processed membranes, a defect rate of approximately $15 \%$ is stated [7]. This increased defect rate for the HE method can be explained by the increased exposure to particles present in the environment (e.g., dust, aerosols) that damage the thin membrane layer. 
Whereas this contamination is easily prevented in the conventional process by shielding the membranes until placement in the furnace, the shielding requires more attention in the case of a preheated furnace. As we focused on delivering a proof-of-concept, no effort was taken to optimize the shielding for the hot environment concept.

Figure 3-6 shows the permeances of a batch of membranes calcined for only 10 minutes at $600{ }^{\circ} \mathrm{C}(\mathrm{Si}-600-10)$. Although the helium permeance of these membranes equals that of the membranes calcined for 60 minutes, the selectivity of helium over nitrogen and methane is low as compared to conventional membranes [6] and the membranes calcined for 60 minutes. Apparently, the desired membrane microstructure has not yet been fully developed after 10 minutes.

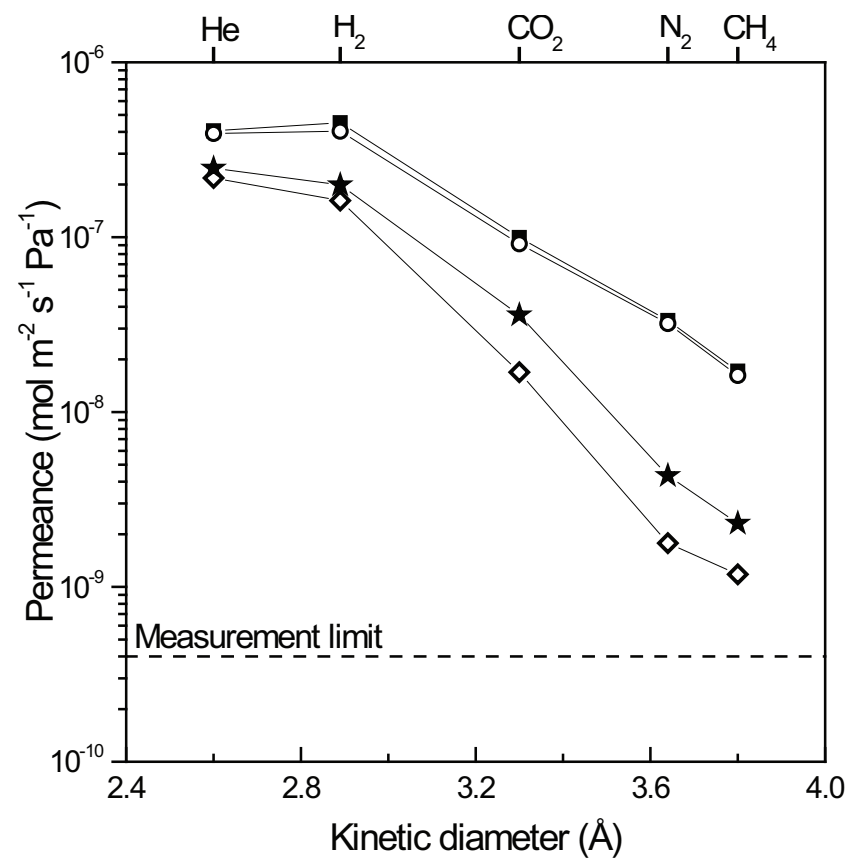

Figure 3-6: Permeance through silica layers rapidly calcined in a hot environment at $600{ }^{\circ} \mathrm{C}$ for 10 minutes (Si-600-10). The four lines indicate distinct membranes that were made through identical procedures. 
Figure 3-7 shows the permeance data of a membrane obtained after 1 hour calcination on a hot plate temperature of $550{ }^{\circ} \mathrm{C}$. The helium permeance is comparable to that of the other membranes. The measured selectivity of $\mathrm{He} / \mathrm{CO}_{2}$ is 43 , and the selectivities of $\mathrm{He} / \mathrm{N}_{2}$ and $\mathrm{He} / \mathrm{CH}_{4}$ are well above 500. These values show that rapid calcination using the hot plate can result in high-performance membranes. It has to be noted that continuous attention needs to be paid to the prevention of contamination; any calcination performed without the shielding device (Figure 3-1) resulted in membranes showing only Knudsen selectivity (even for sulfur hexafluoride, $d_{\mathrm{k}}=5.5 \AA$ ), which indicates pores with sizes larger than nanometers, or in this case, defects.

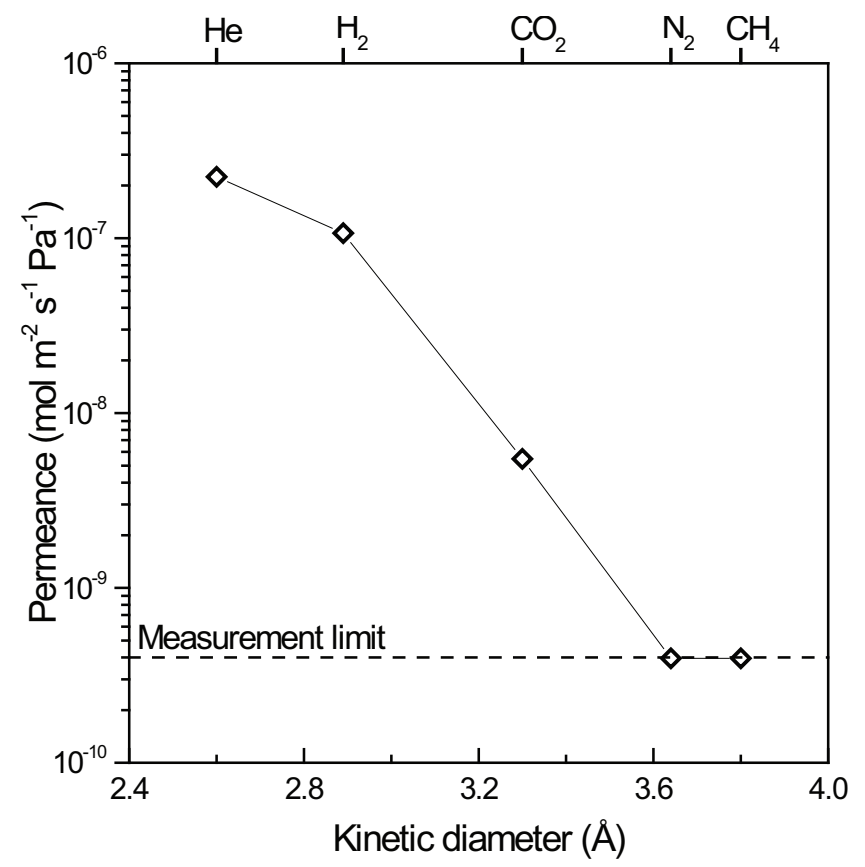

Figure 3-7: Gas permeance data obtained on the hot plate at $550{ }^{\circ} \mathrm{C}$ for 1 hour (Si-550-60-HP) using the cover mechanism. 


\subsection{Conclusions}

Rapid thermal treatments are employed successfully for the calcination of $\gamma$-alumina and silica membranes. The membranes obtained by the proposed methods are comparable to conventionally calcined membranes; however, the calcination time is reduced from 22 hours to 30 minutes for $\gamma$-alumina, and from 41 hours to at most 1 hour for silica. This is a reduction to less than $3 \%$.

For both methods, a decrease in repeatability of the experiments was found, presumably caused by defects in the membrane layers that originate from an increased exposure time to the environment at the insertion and removal of the membranes from the furnace. Likely, this defect rate can be decreased in an optimized configuration, where the shielding of the membrane from the environment is further improved.

$\gamma$-alumina and silica are regarded representative for meso- and microporous membrane layers, respectively. Since both types of materials were successfully calcined rapidly, the developed rapid thermal treatment methods can probably be extended to a wide class of inorganic materials, like titania and hybrid organic-inorganic membranes. Employing rapid thermal treatments encourages the rapid screening of materials for research purposes. Above all, on industrial scale, both methods offer an advantage over classical RTP, as they can be scaled to larger areas and applied to nonplanar geometries, potentially decreasing costs and production time. The results confirm the viability of rapid thermal treatments, and give reason to continue the research into a wider range of materials and further optimized configuration for hot plate experiments. 


\subsection{References}

1. Leenaars, A.F.M. \& Burggraaf, A.J., 1985, The preparation and characterization of alumina membranes with ultrafine pores. 2. The formation of supported membranes. J. Colloid Interface Sci. 105, pp. 27-40. (doi:10.1016/00219797(85)90343-1)

2. Julbe, A., Guizard, C., Larbot, A., Cot, L. \& Giroir-Fendler, A., 1993, The sol-gel approach to prepare candidate microporous inorganic membranes for membrane reactors. J. Membr. Sci.77, pp. 137-153. (doi:10.1016/0376-7388(93)85065-5)

3. Van Gestel, T., Vandecasteele, C., Buekenhoudt, A., Dotremont, C., Luyten, J., Leysen, R., Van der Bruggen, B. \& Maes, G., 2002, Alumina and titania multilayer membranes for nanofiltration: preparation, characterization and chemical stability. J. Membr. Sci. 207, pp. 73-89. (doi:10.1016/S0376-7388(02)00053-4)

4. Uhlhorn, R.J.R., Huis In 't Veld, M.H.B.J., Keizer, K. \& Burggraaf, A.J., 1989, High permselectivities of microporous silica-modified g-alumina membranes. $J$. Mater. Sci. Lett. 8, pp. 1135-1138. (doi:10.1007/bf01730047)

5. Benes, N.E., Nijmeijer, A. \& Verweij, H., 2000, Microporous silica membranes. In Recent advances in gas separation by microporous ceramic membranes (ed N. K. Kanellopoulos), Amsterdam: Elsevier.

6. Lin, Y.S., Kumakiri, I., Nair, B.N. \& Alsyouri, H., 2002, Microporous Inorganic Membranes. Sep. Purif. Rev. 31, pp. 229-379. (doi:10.1081/spm-120017009)

7. De Vos, R.M. \& Verweij, H., 1998, High-Selectivity, High-Flux Silica Membranes for Gas Separation. Science 279, pp. 1710-1711. (doi:10.1126/science.279.5357.1710)

8. Gopalakrishnan, S., Nair, B.N. \& Nakao, S.-I., 2006, High performance hydrogen selective membranes prepared using rapid processing method. In International Conference on Nanoscience and Nanotechnology, (doi:10.1109/ICONN.2006.340665)

9. Uhlmann, D., Liu, S., Ladewig, B.P. \& Diniz da Costa, J.C., 2009, Cobalt-doped silica membranes for gas separation. J. Membr. Sci. 326, pp. 316-321. (doi:10.1016/j.memsci.2008.10.015)

10. Choi, J., Jeong, H.-K., Snyder, M.A., Stoeger, J.A., Masel, R.I. \& Tsapatsis, M., 2009, Grain Boundary Defect Elimination in a Zeolite Membrane by Rapid Thermal Processing. Science 325, pp. 590-593. (doi:10.1126/science.1176095)

11. Schillo, M.C., Park, I.S., Chiu, W. V \& Verweij, H., 2010, Rapid thermal processing of inorganic membranes. J. Membr. Sci. 362, pp. 127-133. (doi:10.1016/j.memsci.2010.06.030)

12. Timans, P.J., 2008, Rapid Thermal Processing. In Handbook of semiconductor manufacturing technology (eds R. Doering \& Y. Nishi), Boca Raton: CRC Press. 
13. Fair, R.B., 1990, Challenges to manufacturing submicron, ultra-large scale integrated circuits. Proc. IEEE 78, pp. 1687-1705. (doi:10.1109/5.63298)

14. Motemani, Y., Tan, M.J., White, T.J. \& Banas, A., 2011, Evolution of structural, surfacial and mechanical properties of titanium-nickel-copper thin films during rapid thermal annealing. Surf. Coatings Technol. 205, pp. 3147-3157. (doi:10.1016/j.surfcoat.2010.11.033)

15. Siemer, K., Klaer, J., Luck, I., Bruns, J., Klenk, R. \& Bräunig, D., 2001, Efficient $\mathrm{CuInS}_{2}$ solar cells from a rapid thermal process (RTP). Sol. Energy Mater. Sol. Cells 67, pp. 159-166. (doi:10.1016/S0927-0248(00)00276-2)

16. Jeong, H.-K., Chandrasekharan, R., Chu, K.-L., Shannon, M.A. \& Masel, R.I., 2005, Rapid Thermal Processing of Mesoporous Silica Films: A Simple Method to Fabricate Films Micrometers Thick for Microelectromechanical Systems (MEMS) Applications. Ind. Eng. Chem. Res. 44, pp. 8933-8937. (doi:10.1021/ie050809q)

17. Cao, G.Z., Meijerink, J., Brinkman, H.W. \& Burggraaf, A.J., 1993, Permporometry study on the size distribution of active pores in porous ceramic membranes. J. Membr. Sci. 83, pp. 221-235. (doi:10.1016/0376-7388(93)85269-3)

18. Cuperus, F.P., Bargeman, D. \& Smolders, C.A., 1992, Permporometry: the determination of the size distribution of active pores in UF membranes. J. Membr. Sci. 71, pp. 57-67. (doi:10.1016/0376-7388(92)85006-5)

19. Gilman, J.W., VanderHart, D.L. \& Kashiwagi, T., 1994, Thermal Decomposition Chemistry of Poly(vinyl alcohol). In Fire and Polymers II: Materials and Test for Hazards Prevention, Washington, DC: The American Chemical Society.

20. Beyler, C.L. \& Hirschler, M.M., 2002, Thermal Decomposition of Polymers. In SFPE Handbook of Fire Protection Engineering, pp. 110-131.

21. Supporting information for the paper Kappert, E.J., A. Nijmeijer \& N.E. Benes, 2012, Expeditious calcination of inorganic membranes by an instant temperature increment, Micropor. Mesopor. Mater., 151, pp. 211-215. (doi:10.1016/j.micromeso.2011.10.034) 



\section{Chapter 4 \\ Kinetic analysis of the thermal processing of silica and organosilica}

This chapter had been adapted from:

Kappert, E.J., H.J.M. Bouwmeester, N.E. Benes, A. Nijmeijer Kinetic analysis of the thermal processing of silica and organosilica, J. Phys. Chem. $B$, 118, pp. 5270-5277, doi: 10.1021/jp502344k 


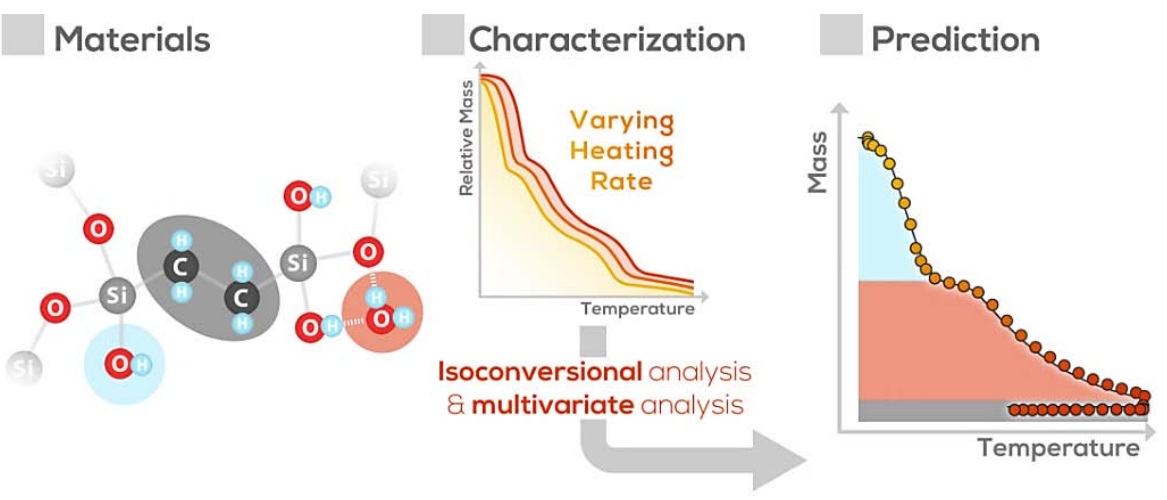

\section{Abstract}

The incorporation of an organic group into sol-gel-derived silica causes significant changes in the structure and properties of these materials. Therefore, the thermal treatment of organosilica materials may require a different approach. In this chapter, kinetic parameters (activation energy, pre-exponential constant, and reaction models) have been determined from mass loss data for the dehydration, dehydroxylation, and decomposition reactions that take place upon heating silica and organosilica. Parameters were obtained by employing model-free isoconversional methods to data obtained under multiple heating rates as well as by multivariate analysis of the kinetics using a multistep reaction model with distributed activation energy. For silica, it can be concluded that the reaction atmosphere (i.e., inert or thermo-oxidative) has no influence on the reaction rate of the dehydration and dehydroxylation reactions that are responsible for the densification of the material. For organosilica, full dehydration can be reached without affecting the organic moiety under inert atmospheres. Achieving complete dehydroxylation of the organosilica is practically impossible as decomposition does manifest itself under commonly employed calcination temperatures. This indicates that prudence is required in designing a heat treatment program for these hybrid materials. To aid in optimizing the thermal treatment, a predictive model was developed, which can be used to forecast the extent of dehydration, dehydroxylation, and decomposition reactions under a multitude of temperature programs. 


\subsection{Introduction}

Organosilica layers are used in a multitude of applications, including membranes [1-3], low- $\kappa$ dielectrics [4,5], and optical coatings [6,7]. The properties of these layers can be tailored by a thermal treatment, in which temperature and duration can be changed to obtain the desired properties. Densification of pure silica is classically achieved by using high temperatures $\left(>300{ }^{\circ} \mathrm{C}\right)$ and long treatment times $(>1 \mathrm{~h})$. However, lower treatment temperatures and shorter treatment times are desired to prevent decomposition of the organic moiety in organosilicas [8,9], to decrease energy use during calcination, or to allow for application of the layer on a supporting substrate with a limited thermal stability [10-13]. Researchers have investigated several strategies to limit the treatment temperature or duration for hybrid and inorganic systems: a long-term treatment at low temperatures [14], flash heating at high temperatures [15-19], or a treatment with acids that renders thermal treatment unnecessary [2].

To obtain a material with a targeted microstructure, one is preferably able to predict and steer the thermal processing. Detailed information on the kinetics of the thermally activated processes that occur during the calcination of organosilica is required to predict the influence of the thermal treatment. This kinetic data is commonly displayed in the form of the kinetic triplet: the activation energy, pre-exponential constant, and reaction model. In the case of a hybrid material such as organosilica, a number of reactions can occur during heating, including dehydration, sintering, and decomposition. With each of these reactions, specific kinetics are associated. The study of these reactions kinetics requires a model capable of treating multistep reaction mechanisms. Such models have been developed for several inorganic materials, e.g., for cement [20], boehmite [21], and a hydride silica [22]. To study the effects of a thermal treatment on organosilica materials we take a BTESE-derived organosilica as a model system and compare it to purely inorganic, TEOS-derived silica. The thermal dehydration of silica has been studied extensively in the past. 
Zhuravlev has presented an overview of the different steps during the dehydration process for silica gels, including activation energies and reaction orders [23]. In this study, the work of Zhuravlev is expanded by comparing silica with organosilica, thus demonstrating the influence of an organic moiety on the thermal properties of these materials.

Determination of the kinetic triplet for solid-state reactions can be done in various ways. For an overview of these methods, the reader is referred to the excellent overview on kinetics of solid-state reactions that has been drafted based on the recommendations of the ICTAC Kinetics Committee [24]. Kinetic models typically consider the reaction rate to be a function of only two variables, the temperature $T$ and the conversion $\alpha$ :

$$
\frac{d \alpha}{d t}=A \exp \left(\frac{-E_{\alpha}}{R T}\right) f(\alpha)
$$

in which $A$ is the pre-exponential constant (min-1), $E_{\alpha}$ the activation energy $\left(\mathrm{J} \mathrm{mol}^{-1}\right), R$ the gas constant $\left(8.3145 \mathrm{~J} \mathrm{~mol}^{-1} \mathrm{~K}^{-1}\right)$, and $f(\alpha)$ a reaction model as a function of the conversion. Here, we determine the effective activation energy via a model-free isoconversional method [25-27] and estimate the corresponding pre-exponential constant via the compensation effect [24]. The obtained parameters are called "effective" parameters, as they do not necessarily refer to an intrinsic, individual reaction step [24]. For the sake of readability, we refer to the activation energy without the adjective "effective" from here on. The full reaction model is determined by a multivariate fitting to the experimental data. A complete description of the used models is given in Theoretical Calculations. The thus obtained fitting parameters are used to comprehend the thermal treatment process of organosilica materials and can be used in further studies to predict thermal stability of the hybrid and inorganic materials. 


\subsection{Experimental section}

\subsubsection{Materials}

TEOS (for synthesis, Merck), BTESE (pur. 97\%, ABCR Germany), dried ethanol ( $\max 0.01 \% \mathrm{H} 2 \mathrm{O}$, SeccoSolv, Merck), ethanol (absolute for analysis, EMSURE, Merck), and nitric acid (1 M, Titrisol, Merck and $\geq 65 \%$ (T), Sigma-Aldrich) were used as received. Water was deionized to 18.2 $\mathrm{M} \Omega \mathrm{cm}^{-1}$ using a Milli-Q Advantage A10 system (Millipore). Oxygen and nitrogen used for TGA-MS were dried with molecular sieve water absorbers. Oxygen was removed from the nitrogen using an oxygen trap (outlet concentration $<1 \mathrm{ppb} \mathrm{O}_{2}$ ).

\subsubsection{Synthesis}

Silica and organosilica sols were prepared via the acid-catalyzed hydrolysis and condensation of TEOS and BTESE, respectively. In a glovebox under nitrogen, the silicon precursor was mixed with dried ethanol in a conical flask that was subsequently transferred outside the glovebox to an ice bath for cooling. A mixture of $\mathrm{HNO}_{3}$ and water was added dropwise to the flask in the ice bath, under vigorous stirring. The thus obtained mixture was heated under reflux at $60{ }^{\circ} \mathrm{C}$ for $180 \mathrm{~min}$ (TEOS) or $90 \mathrm{~min}$ (BTESE). After the refluxing of the mixture, the sol was quenched in an ice bath to prevent further reaction. The obtained sols had a molar ratio of 1:3.8:6.4:0.085 (TEOS/ethanol/water/acid) and 1:10.7:6:0.21 (BTESE/ethanol/water/acid). To obtain powders, the solution was poured into a Petri dish and the ethanol was allowed to evaporate overnight. The obtained flakes were ground to a powder and were placed in a stove at $80{ }^{\circ} \mathrm{C}$ for $60 \mathrm{~min}$. The samples were mixed thoroughly with a spatula after $30 \mathrm{~min}$. The powders were stored at room temperature in glass vials until further use.

\subsubsection{TGA-MS}

Thermogravimetric analysis (TGA) was performed on a STA 449 F3 Jupiter (Netzch) fitted with a TG- only sample holder. Measurements were 
performed under $70 \mathrm{~mL} \mathrm{~min}^{-1}$ synthetic air $\left(20 \% \mathrm{O}_{2}\right.$ in $\left.\mathrm{N}_{2}\right)$ or $70 \mathrm{~mL} \mathrm{~min}^{-1}$ nitrogen with heating rates $\beta$ of $5,10,15$, and $20{ }^{\circ} \mathrm{C} \mathrm{min}{ }^{-1}$, from room temperature to $1000^{\circ} \mathrm{C}$. Temperature calibration was done using melting standards; measurements were run sample-temperature controlled. Blank corrections with an empty cup were carried out at every different heating rate. Sample masses were determined in situ, exactly $30 \mathrm{~min}$ after starting purge gas flow rate. Using a consistent residence time in the purge gas prior to measurement was found to be a crucial parameter to obtain reproducible TGA graphs.

Gases evolving during the thermogravimetric analysis were transferred to a mass spectrometer (MS, QMS 403 D Aëolos, Netzch). TGA and MS start times were synchronized, but no correction was applied for the time offset caused by the transfer line time (estimated $<30$ s, systematic offset). First, a bar graph scan for $m / z=1-60 \mathrm{amu}$ was recorded for both silica and organosilica under both nitrogen and air to determine the evolving $\mathrm{m} / \mathrm{z}$ numbers (data not included here). The detected $\mathrm{m} / \mathrm{z}$ numbers $(2,12-19$, $25,26,28-32,40-46)$ were selected and recorded more accurately in multiple-ion-detection mode, with a dwell of $0.5 \mathrm{~s}$ per $\mathrm{m} / z$ value and a resolution of 50 .

\subsubsection{Theoretical Calculations}

\section{Analysis of TGA Data Using Advanced Isoconversional Analysis.}

The mass loss as a function of time and temperature was determined using TGA under multiple different heating rate programs. The mass change was converted to conversion $\alpha$ and normalized between 0 and 1. From the data, activation energies were determined following the integral isoconversional method proposed by Vyazovkin and Dollimore [25], using the modified integral for nonlinear temperature programs [27] and variation of the activation energy as a function of conversion [26]. 
The activation energy is obtained by minimizing the function $\Phi\left(E_{\mathrm{\alpha}}\right)$ :

$$
\Phi\left(E_{\alpha}\right)=\sum_{i=1}^{n} \sum_{j \neq i}^{n} \frac{J\left[E_{a}, T_{i}\left(t_{\alpha}\right)\right]}{J\left[E_{a}, T_{j}\left(t_{\alpha}\right)\right]}
$$

in which $i=1 \ldots n$ and $j=1 \ldots n$ indicate measurements under different heating programs. In this formula, the integral $J$ is given by

$$
J\left[E_{\alpha}, T_{i}\left(t_{\alpha}\right)\right] \equiv \int_{t_{\alpha-\Delta \alpha}}^{t_{\alpha}} \exp \left[\frac{-E_{\alpha}}{R T_{i}(t)}\right] \mathrm{d} t
$$

The integral in Equation 1-7 cannot be solved analytically and was therefore approximated numerically; the minimization of Equation 1-6 was done using MATLAB's fminsearch algorithm [28].

\section{Overall Data Fitting Using Multivariate Analysis of the Kinetics}

A multivariate analysis of the kinetics was used to fit the different heating rate curves obtained by TGA with a multistep parallel reaction model represented by [29]

$$
\frac{\mathrm{d} \alpha_{i}}{\mathrm{~d} t}=A_{i} \exp \left[\frac{-E_{\alpha, i}}{R T(t)}\right] f_{i}\left(\alpha_{i}\right)
$$

in which $i$ denotes the $i$ th reaction with weighing factor $w_{i}$, where the total conversion is given by

$$
\alpha=\sum_{i}^{n} w_{i} \alpha_{i} \quad \text { and } \quad \sum_{i}^{n} w_{i}=1
$$

To obtain physically realistic values for the kinetic triplet, the risk of overfitting needs to be avoided [24]. To this end, we took the following approach: the number of reaction steps was determined by evaluating the main steps in TGA and MS data; steps with only a small impact on the mass loss were disregarded for the model fit. Initial values for the multistep mechanism were taken from the previously determined model-free 
activation energy and the corresponding pre-exponential constant as determined via the compensation effect that is manifested in the method of invariant kinetic parameters [24]. The truncated Sestak-Berggren model, $f(\alpha)=\alpha^{m}(1-\alpha)^{n}$, was used to represent the reaction model. MATLAB's built-in ode23-solver was used to integrate Equation 1-8 [28]. Instead of using a single activation energy, the activation energy was modeled as a Weibull distribution [30], in which all the activation energies are associated with independent parallel reactions satisfying Equation 1-9. Minimization of the residual sum of squares (RSS) was performed using MATLAB's patternsearch algorithm to detect the global minimum RSS, followed by a run of fminsearch to detect the exact position of the minimum. ${ }^{28}$

\subsection{Results and discussion}

\subsubsection{Thermogravimetric analysis and mass spectrometry}

Figure 4-1 and Figure 4-2 display the mass loss curve and the primary evolved gases during the thermal treatment of silica under nitrogen and air, respectively (an overview of all MS-peaks is given in the Supporting Information in reference [37]). The evolution of the mass of silica is similar under inert (nitrogen) and oxidative (air) atmosphere, with the bulk of the mass loss coming to pass below $250{ }^{\circ} \mathrm{C}$ and a second mass loss step between 250 and $375^{\circ} \mathrm{C}$. Above $375^{\circ} \mathrm{C}$, further mass loss occurs gradually and individual steps cannot be identified. Analysis of the evolved gases associates the mass loss steps with the release of specific compounds. The primary mass loss is mainly caused by dehydration. Other, minor compounds that are released are $\mathrm{NO}_{x}$ (from $\mathrm{HNO}_{3}$ catalyst), ethoxy groups (from reactant and/or solvent), and $m / z=44$, assigned to either $\mathrm{CH}_{2} \mathrm{CH}(\mathrm{OH})$ or $\mathrm{CO}_{2}$ (from reactant and/or solvent). Under an inert atmosphere, $\mathrm{CH}_{2} \mathrm{CH}(\mathrm{OH})$ can be formed by the catalytic conversion of ethanol (or ethoxy groups) to acetaldehyde and derivatives thereof $[31,32]$. Under air, further oxidation to $\mathrm{CO}_{2}$ is the most probable explanation for the $m / z=44$ signal. The peak shape of the evolved gases under an inert 
atmosphere is slightly different than under air, indicating a thermooxidative influence under air. However, the impact of this effect is not high enough to cause significant visible differences in the mass loss. At 325 ${ }^{\circ} \mathrm{C}$, the peak in the mass loss rate is caused by dehydroxylation of (mainly vicinal) silanol groups [23]. The removal of hydroxyl groups continues gradually up to $1000{ }^{\circ} \mathrm{C}$. Because of an increase in isolation of the silanol groups, the rate keeps decreasing.

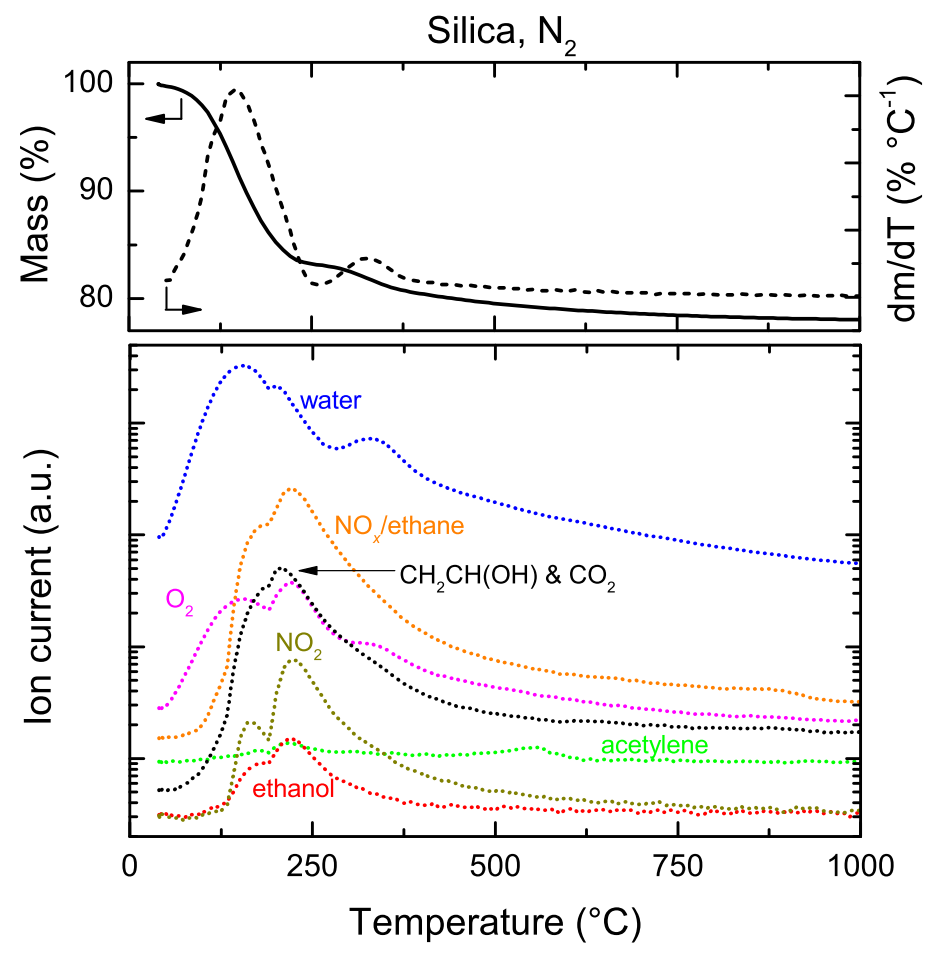

Figure 4-1: Mass loss and first derivative thereof (top panel) and evolved gases (bottom panel) as a function of temperature for silica, heated under nitrogen at $20{ }^{\circ} \mathrm{C} \mathrm{min}{ }^{-1}$. The assigned $\mathrm{m} / z$ signals are oxygen 16 , water 18 , acetylene $26, \mathrm{NO}_{x} 30$, ethanol $31, \mathrm{CH}_{2} \mathrm{CH}(\mathrm{OH})$ and/or $\mathrm{CO}_{2} 44$, and $\mathrm{NO} 46$. 


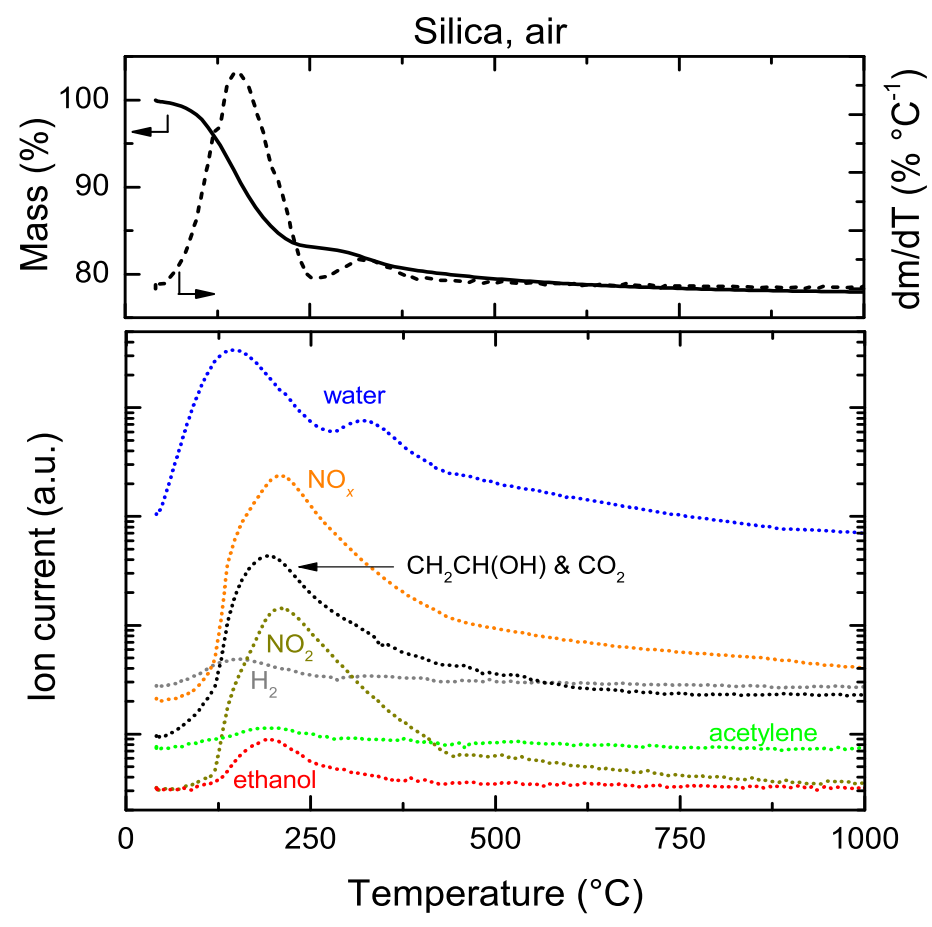

Figure 4-2: Mass loss and first derivative thereof (top panel) and evolved gases (bottom panel) as a function of temperature for silica, heated under air at $20{ }^{\circ} \mathrm{C} \mathrm{min}{ }^{-1}$. The assigned $\mathrm{m} / \mathrm{z}$ signals are hydrogen 2, water 18, acetylene $26, \mathrm{NO}_{x} 30$, ethanol $31, \mathrm{CH}_{2} \mathrm{CH}(\mathrm{OH})$ and/or $\mathrm{CO}_{2} 44$, and $\mathrm{NO}_{2} 46$.

Figure 4-3 and Figure 4-4 display the weight loss curve and the primary evolved gases during the thermal treatment of organosilica under nitrogen and air, respectively (an overview of all MS-peaks is given in in the Supporting Information in reference [37]). The differential mass loss curves reveal four dominating mass loss processes. Two of these processes appear similar under both atmospheres: a dehydration step and a sharp decomposition step in which mainly $\mathrm{NO}_{x}$ is released, taking place in the range of $25-250{ }^{\circ} \mathrm{C}$. These results agree with the processes occurring for the thermal treatment of silica, although the extent of the weight loss is different, which is caused by the different $\mathrm{Si}-$ precursor $/ \mathrm{HNO}_{3} /$ water ratio used in the synthesis of both materials. 
Under inert atmosphere, a third mass loss step takes place between 250 and $375{ }^{\circ} \mathrm{C}$. As with silica, this weight loss originates mainly from dehydroxylation of the material. The organic moiety remains intact until $500{ }^{\circ} \mathrm{C}$, at which temperature the onset of a release of methane and hydrogen indicate its decomposition. The presence of methane in the evolved gases reveals that the decomposition of the ethyl-bridge takes place through scission of the carbon-carbon bond. The continuous release of hydrogen up to $1000{ }^{\circ} \mathrm{C}$ indicates that hydrogen-containing organic material is still present at these temperatures. The carbonous residue that would result from this dehydrogenation is confirmed by the black appearance of the organosilica after the TGA experiment.

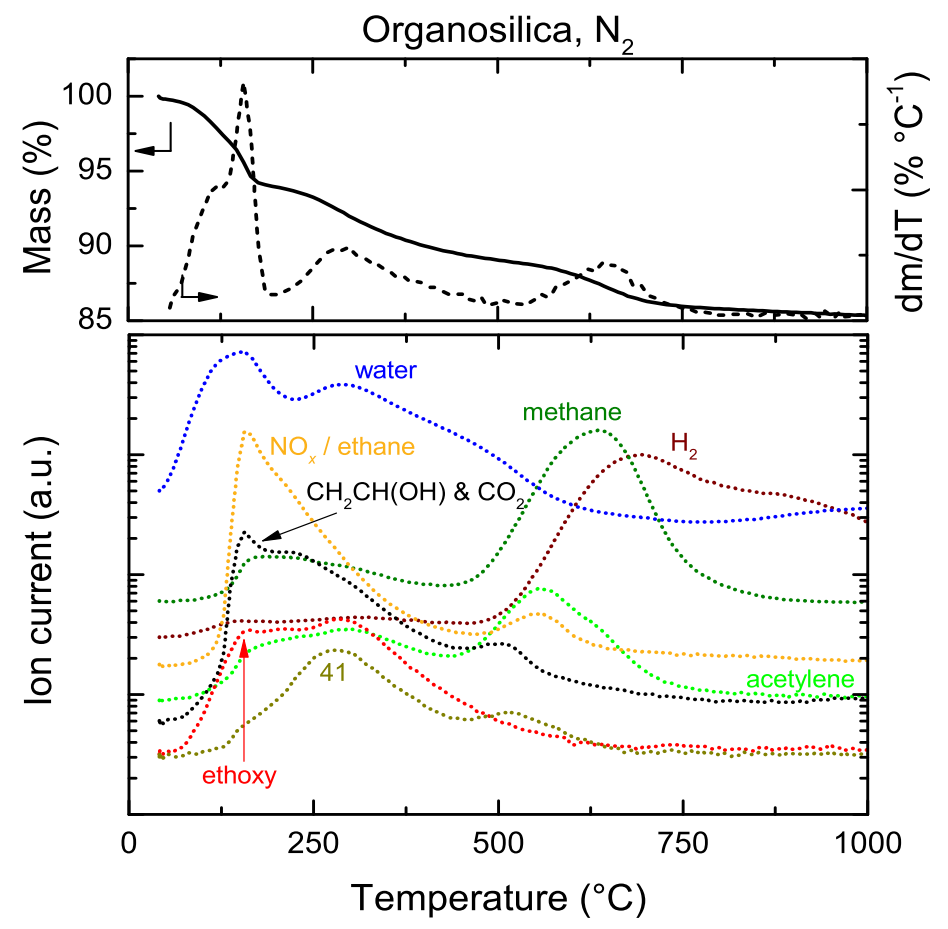

Figure 4-3: Mass loss and first derivative thereof (top panel) and evolved gases (bottom panel) as a function of temperature for organosilica, heated under nitrogen at $20{ }^{\circ} \mathrm{C} \mathrm{min}^{-1}$. The assigned $\mathrm{m} / z$ signals are hydrogen 2 , methane 15 , water 18 , acetylene $26, \mathrm{NO}_{x} 30$, unknown 41, $\mathrm{CH}_{2} \mathrm{CH}(\mathrm{OH})$ and/or $\mathrm{CO}_{2} 44$, and ethoxy 45. 
Under an oxidative atmosphere, the gradual decomposition of the organic moiety initiates at $250{ }^{\circ} \mathrm{C}$. Here, gas release takes place in the form of methane, acetaldehyde, and $\mathrm{CH}_{2} \mathrm{CH}(\mathrm{OH}) / \mathrm{CO}_{2}$, indicating that the majority of the decomposition takes place via a thermo-oxidative pathway.

The different ratios of the evolved gases with respect to temperature show that the decomposition takes place via a complex multistep mechanism. The apparent drop in the methane release at $625^{\circ} \mathrm{C}$ can be assigned to the thermo-oxidation of the methane [33]. The weight loss rate goes down to zero only at temperatures approaching $1000{ }^{\circ} \mathrm{C}$.

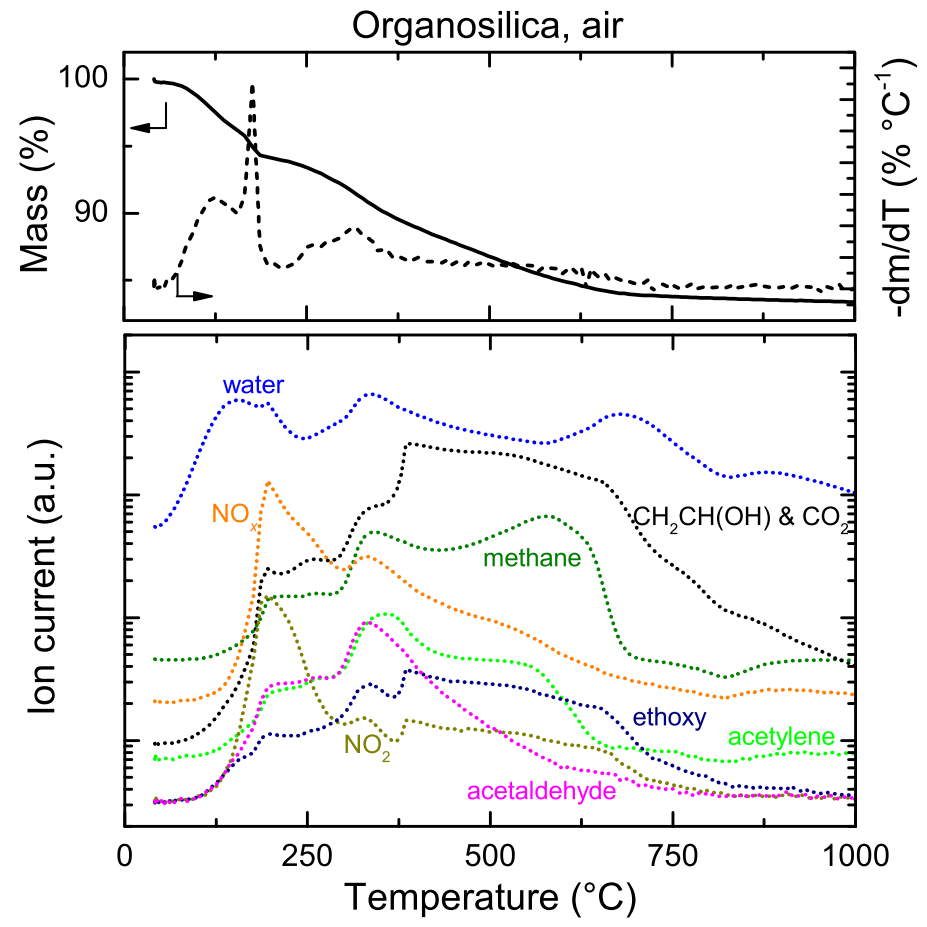

Figure 4-4: Mass loss and first derivative thereof (top panel) and evolved gases (bottom panel) as a function of temperature for organosilica, heated under air at $20{ }^{\circ} \mathrm{C} \mathrm{min}{ }^{-1}$. The assigned $\mathrm{m} / z$ signals are methane 15 , water 18 , acetylene $26, \mathrm{NO}_{x} 30, \mathrm{CH}_{2} \mathrm{CH}(\mathrm{OH})$ and/or $\mathrm{CO}_{2} 44$, ethoxy $45, \mathrm{NO}_{2} 46$. 


\subsubsection{Determination of activation energies via isoconversional analysis}

Figure 4-5 shows the apparent activation energy as a function of conversion for silica and organosilica, as obtained from the advanced isoconversional method (Equation 1-6), calculated from the data presented in the Supporting Information in reference [37]. Data is given for treatment under nitrogen (open circles) and under air (closed squares). The calculated activation energy is an effective average over the individual reactions that occur at a given degree of conversion. Based on the TGA-MS results (see Thermogravimetric Analysis and Mass Spectrometry), the major reaction steps can be assigned as shown in Table 4-1.

The TGA-MS reveals two major steps in the mass loss. The first is a dehydration step, for which the activation energy for both atmospheres lies within the margins of error. A constant value of the activation energy typically implies that a single reaction dominates the mass loss process [24]. The activation energy reported for this step by Zhuravlev [23], 25-42 $\mathrm{kJ} \mathrm{mol}^{-1}$, is a factor 2-3 lower than the value calculated here. This difference can be caused by the different microstructure (this study, microporous; Zhuravlev's study, mesoporous) if the activation energy is associated with the diffusion process of the water out of the silica network. It has been demonstrated that decreasing pore sizes lead to higher activation energies for diffusion of several gases [34], and for water in particular [35]. Alternatively, this difference may be a result of the use of a single heating rate mass loss curve by Zhuravlev, a method that was later judged unreliable for determining activation energies [24].

The first mass loss step is shouldered by the decomposition of the ethoxy groups and the $\mathrm{HNO}_{3}$ catalyst. In this part, the activation energy is an effective average over the dehydration and decomposition reactions. The second step is associated with the dehydroxylation of the material. As the amount of vicinal silanol groups decreases, more silanol groups become isolated. 

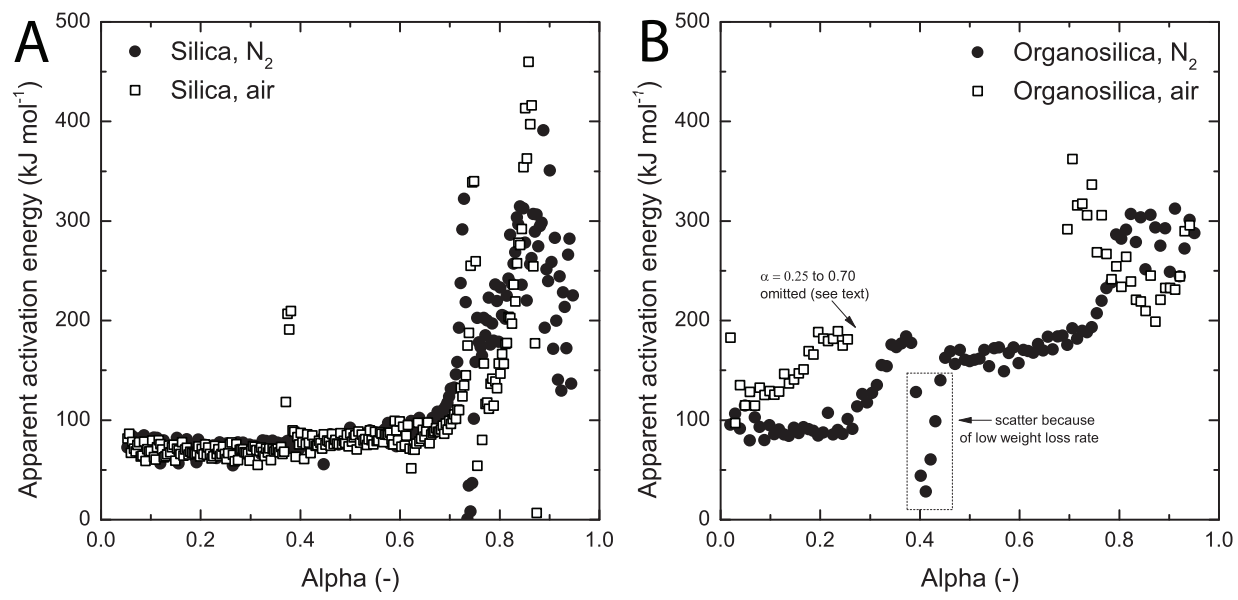

Figure 4-5: Apparent activation energy determined by the isoconversional analysis of TGA-data for the thermal treatment of silica (a) and organosilica (b) under nitrogen ( $\bullet$ ) and under air ( $\square$ ). Data for organosilica under air is shown only for $\alpha=0-0.25$ and $\alpha=$ $0.7-1$ because of nonphysical values for the data in this region (see text). The full version of the graph can be in the Supporting Information in reference [37].

Table 4-1: Assignment of occurring processes to the mass loss of silica, under both inert atmosphere and air

\begin{tabular}{|c|c|c|}
\hline Conversion & Process & $E_{\mathrm{a}}\left(\mathrm{kJ} \mathrm{\textrm {mol } ^ { - 1 } )}\right.$ \\
\hline $0-0.6$ & Dehydration & $76 \pm 3$ \\
\hline \multirow[t]{3}{*}{$0.6-0.75$} & Dehydration & $76-300$ \\
\hline & $\mathrm{HNO}_{3}$ catalyst decomposition & \\
\hline & Solvent/ethoxy-group & \\
\hline $0.75-0.90$ & Dehydroxylation & $150-300$ \\
\hline $0.90-1$ & $\begin{array}{l}\text { Dehydroxylation (thermodynamically } \\
\text { limited) }\end{array}$ & $\begin{array}{l}\text { Accurate determination not } \\
\text { possible }\end{array}$ \\
\hline
\end{tabular}


Table 4-2: Assignment of specific processes to the mass loss conversion of organosilica, both under inert atmosphere and air

\begin{tabular}{|c|c|c|c|c|}
\hline$\alpha$ & Under $\mathbf{N}_{2}$ & $E_{\mathrm{a}}\left(\mathrm{kJ} \mathrm{mol}^{-1}\right)$ & Under air & $E_{\mathrm{a}}\left(\mathrm{kJ} \mathrm{mol}^{-1}\right)$ \\
\hline $0-0.25$ & Dehydration & $91.7 \pm 3.9$ & Dehydration & $130-180$ \\
\hline \multirow[t]{5}{*}{$0.25-0.45$} & Dehydration & $90-180$ & Dehydration & * \\
\hline & Catalyst & & Catalyst decomposition & \\
\hline & decomposition & & Solvent/ethoxy-groups & \\
\hline & Solvent/ethoxy- & & & \\
\hline & groups & & & \\
\hline \multirow[t]{3}{*}{$0.45-0.70$} & Dehydroxylation & $160-190$ & Many reactions, mainly & * \\
\hline & & & decomposition or organic & \\
\hline & & & moiety & \\
\hline \multirow[t]{3}{*}{$0.75-0.95$} & Decomposition & $190-300$ & Many reactions, mainly & * \\
\hline & organic moiety & & decomposition or organic & \\
\hline & & & moiety & \\
\hline
\end{tabular}

However, two silanol groups are required for the condensation reaction with the release of water. Because of their isolation, the convergence of silanol groups becomes less frequent, and the activation energy for dehydroxylation rises [23].

With increasing conversion, the mass loss rate decreases, and the relative error in the conversion decreases, leading to scatter in the activation energy data. Above $90 \%$ conversion, the low mass loss rate causes the different heating rate curves to lie close together; because the error in the mass loss becomes similar to the magnitude of the shift in the curves, it is impossible to determine the activation energy in this heating rate range.

Describing the kinetics of dehydration, dehydroxylation, and decomposition is more complex for organosilica because the decompositions of the organic bridging group overlaps (part of) the other processes. Table 4-2 gives an overview of the specific processes responsible for the mass loss as a function of conversion (see Thermogravimetric Analysis and Mass Spectrometry for the assignments). The TGA-MS under $\mathrm{N}_{2}$ reveals four major mass loss steps. The first two steps, responsible for the $40 \%$ conversion, are a dehydration step $(\alpha=0-0.25)$ and a decomposition step of the 
solvents/ethoxy groups and the $\mathrm{HNO}_{3}$ combined with further dehydration $(\alpha=0.25-0.40)$. The slightly higher activation energy for the dehydration of the organosilica, as compared to that of silica, may indicate a difference in the physisorption energy for the two materials, which can be a result of the difference in the pore morphology and/or surface chemistry of the materials.

At $\alpha=0.40$, the activation energy shows an apparent drop. This drop is an artifact of the analysis and is physically not realistic: because the mass loss curves are positioned closely together, small errors in the mass cause the curves to crossover, which manifests itself in lower or even negative values for the activation energy. The third step is assigned to the dehydroxylation of the organosilica. Although a small increase in the activation energy is observed, this increase is less strong than that of silica. We hypothesize that the organic linking group in the material provides more dynamics for the silanol group and stabilizes the partial positive charge on the silicon atom by electron donation, thus effectively decreasing the energy barrier for dehydroxylation. In the fourth step ( $\alpha=0.75-0.95)$, decomposition of the organic groups take place.

Under air, the thermal treatment of the organosilica forms a complex mixture of a multitude of decomposition reactions. The only step that can be identified is the dehydration reaction $(\alpha=0-0.25)$. At $\alpha$-values higher than 0.25 , the calculated values for the activation energies are strongly scattered (between -200 and $800 \mathrm{~kJ} \mathrm{~mol}^{-1}$ ) because of a crossover of the mass loss curves (see Figure S12 in the Supporting Information in reference [37]). Surprisingly, this crossover is caused by a significant acceleration in the mass loss at higher heating rates. This accelerated mass loss has been observed consistently in triplicate when measurements were repeated (results not shown here). For conversion values higher than 0.70 , the values of the activation energy are physically realistic. However, the unexpected dependence of the mass loss rate on the heating rate indicates that any interpretation should be performed with caution. We have therefore 
limited the determination of kinetic parameters for organosilica to those obtained under inert atmospheres.

\subsubsection{Multivariate analysis of the kinetics}

Figure 4-6 shows the results of the multivariate analysis fit to the data acquired for the thermal treatment of silica under nitrogen. Equation 1-8 was used for the fitting; the constraints are given in 1-9. The mass ratios of the different steps were determined from the vertical asymptote in the model-free activation energy data (in this case, $w_{1}=0.75$ and $w_{2}=0.15$ ). Both reaction steps were modeled with a Weibull-distributed activation energy for independent parallel reactions. Conversion values larger than 0.9 were omitted because the magnitude of the shift in the curves was equal to the magnitude of the error. The fit parameters are given in Table 4-3, and the resulting fit is given in Figure 6.

An identical approach was chosen for the data obtained for organosilica under nitrogen. The mass ratios of the different steps were determined from the vertical asymptote in the model-free activation energy data (in this case, $w_{1}=0.42, w_{2}=0.37$, and $w_{3}=0.15$ ). All reaction steps were modeled with a Weibull-distributed activation energy for independent parallel reactions. Conversion values larger than 0.95 were omitted because the magnitude of the shift in the curves was equal to the magnitude of the error. The fit parameters are given in Table 4-4. 


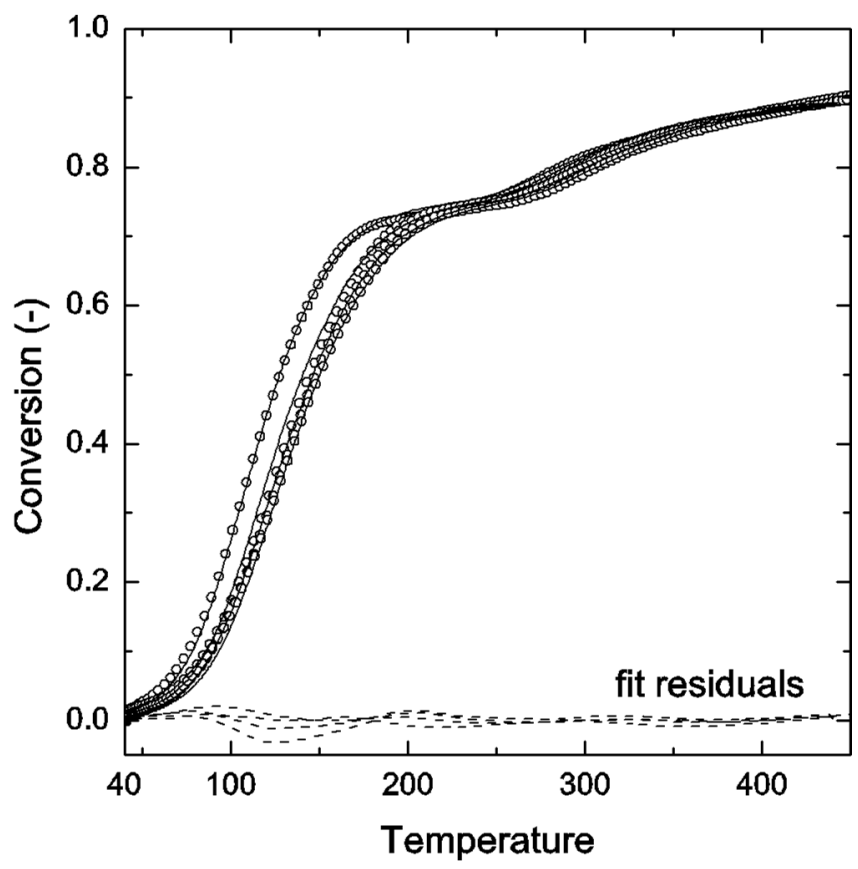

Figure 4-6: Multivariate fit for the thermal treatment of silica under $\mathbf{N}_{2}$. Symbols depict the experimental data, and solid lines represent the fit; dashed lines show the fit residuals.

Table 4-3: Kinetic parameters for the thermal treatment of silica under nitrogen, fitted with a Weibull-distributed activation energy

\begin{tabular}{|c|c|c|c|c|}
\hline Conversion & $\begin{array}{l}\text { Step } 1(w=0.75) \\
\text { Nitrogen }\end{array}$ & $\begin{array}{l}\text { Step } 2(w=0.15) \\
\text { Nitrogen }\end{array}$ & $\begin{array}{l}\text { Step } 1(w=0.75) \\
\text { Air }\end{array}$ & $\begin{array}{l}\text { Step } 2(w=0.15) \\
\text { Air }\end{array}$ \\
\hline$A\left(\mathrm{~min}^{-1}\right)$ & $2.65 \cdot 10^{10}$ & $2.56 \cdot 10^{16}$ & $3.03 \cdot 10^{10}$ & $2.47 \cdot 10^{16}$ \\
\hline 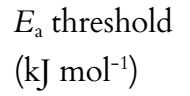 & 70.6 & 164.1 & 69.2 & 153.4 \\
\hline$\beta(-)$ & 1.52 & 1.39 & 1.98 & 2.08 \\
\hline$\eta\left(\mathrm{kJ} \mathrm{mol}{ }^{-1}\right)$ & 11.4 & 30.1 & 13.9 & 37.3 \\
\hline $\begin{array}{l}E_{a} \text { average } \\
\left(\mathrm{kJ} \mathrm{mol}{ }^{-1}\right)\end{array}$ & 81.0 & 191.5 & 81.5 & 186.4 \\
\hline$m(-)^{\star}$ & 0 & 0 & 0 & 0 \\
\hline$n(-)^{\star}$ & 1 & 1 & 1 & 1 \\
\hline
\end{tabular}

${ }^{a}$ Variable not fitted because it is convoluted with Ea. For nitrogen: RSS $=0.0081$, $n_{\text {datapoints }}=9604, p=8$, variance $=8.4 \times 10^{-7}$. For air: $\mathrm{RSS}=4.6 \times 10-7, n_{\text {datapoints }}=9604, p=8$, variance $=4.6 \times 10^{-7}$. 
Table 4-4: Kinetic parameters for the thermal treatment of silica under nitrogen, fitted with a Weibull-distributed activation energy

\begin{tabular}{llll}
\hline Conversion & Step 1 $(\boldsymbol{w}=0.43)$ & Step 2 $(\boldsymbol{w}=0.37)$ & Step 2 $(\boldsymbol{w}=0.15)$ \\
\hline$A\left(\mathrm{~min}^{-1}\right)$ & $3.63 \cdot 10^{10}$ & $2.75 \cdot 10^{16}$ & $1 \cdot 10^{18}$ \\
$E_{\mathrm{a}}$ threshold $\left(\mathrm{kJ} \mathrm{mol}^{-1}\right)$ & 68.6 & 156.7 & 302.7 \\
$\beta(-)$ & 2.52 & 1.16 & 0.77 \\
$\eta(\mathrm{kJ} \mathrm{mol}$ & $-1)$ & 48.3 & 27.6 \\
$E_{a}$ average $\left(\mathrm{kJ} \mathrm{mol}^{-1}\right)$ & 14.7 & 202.6 & 335.1 \\
$m(-)^{\mathrm{a}}$ & 0 & 0 & 0 \\
$n(-)^{\mathrm{a}}$ & 1 & 1 & 1 \\
\hline
\end{tabular}

${ }^{a}$ Variable not fitted because it is convoluted with $E_{\mathrm{a}} . \mathrm{RSS}=0.0129, n_{\text {datapoints }}=7206, p=12$, variance $=1.79 \times 10^{-6}$.

For silica, the results of the model fit show good agreement with the data obtained using the model-free isoconversional analysis. The fit matches the data closely and seems to deviate only slightly for the first and final parts of the dehydration reaction. For the organosilica, the results deviate from those obtained using the model-free methods, especially in the case of the activation energy of the dehydration reaction, which is $10 \mathrm{~kJ} \mathrm{~mol}^{-1}$ lower when determined via the multivariate analysis of the kinetics. Here, this may be caused by a correlation of the activation energy with $n$, as a pseudo- $n$-th order reaction is mathematically identical to a -distribution or a Weibull distribution (with shape parameter 1) in the activation energy [30].

\subsubsection{Model simulations}

The obtained model parameters can be used to predict the conversion of the reaction steps under any chosen heating program. It should be noted that predictions at temperatures, times, and/or heating rates outside of the measurement range have an inherent inaccuracy because of the propagation of errors in the kinetic predictions. The model returns good results within the original measurement range $(\beta$ between 5 and $20{ }^{\circ} \mathrm{C} \mathrm{min}^{-1}$ ). 


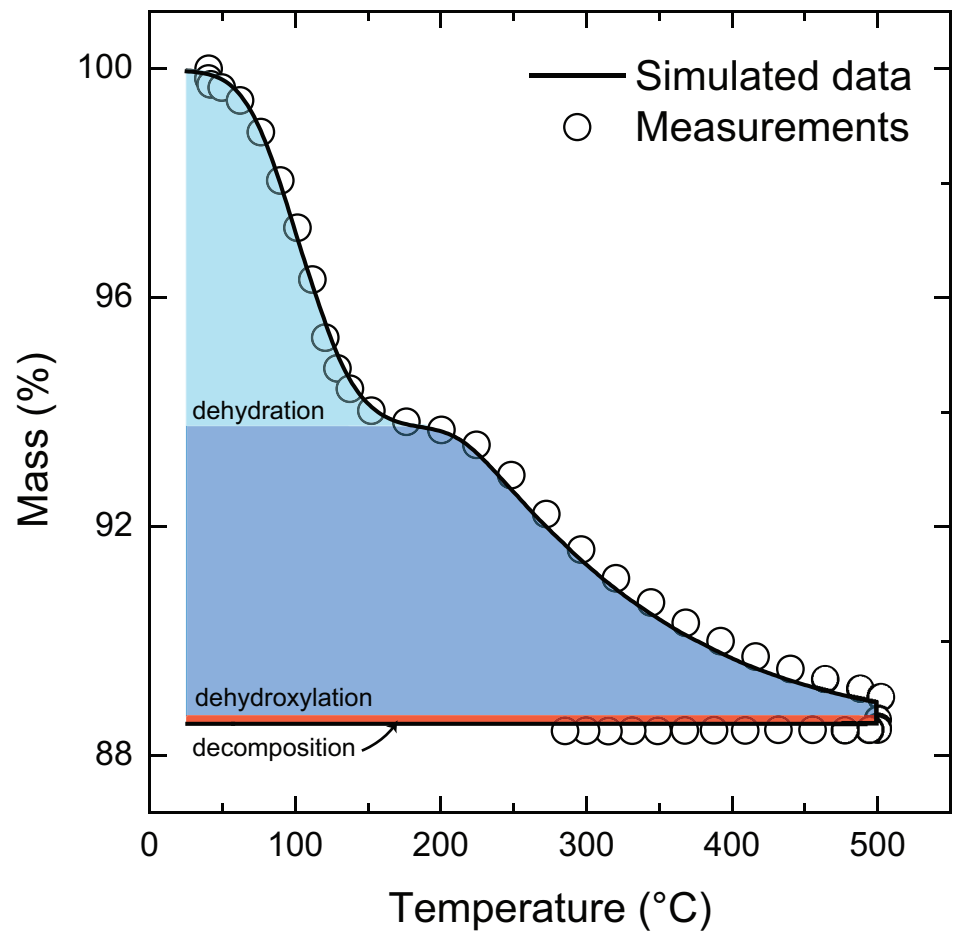

Figure 4-7: Simulated data (solid line) and measured data (0) for the thermal treatment of organosilica under $\mathrm{N}_{2}$ at a heating rate of $3{ }^{\circ} \mathrm{C}$ min $^{-1}$ including a $2 \mathrm{~h} \mathrm{dwell} \mathrm{at} 500{ }^{\circ} \mathrm{C}$. The different steps are indicated by the colored area under the graph: dehydration (teal), dehydroxylation (blue), and decomposition (red).

To further illustrate the model accuracy, data was simulated for the thermal treatment of organosilica under $\mathrm{N}_{2}$ under extrapolated conditions: a linear heating rate of $3{ }^{\circ} \mathrm{C} \min ^{-1}$ to $500{ }^{\circ} \mathrm{C}$, followed by a $2 \mathrm{~h}$ dwell. Figure $4-7$ shows that the experimental data closely follows the model simulation. Furthermore, the model allows for deconvolution of the data for dehydration, dehydroxylation, and decomposition processes, creating the possibility for fine-tuning of the thermal treatment program, e.g., to avoid decomposition of the organic moiety. 
Table 4-5: Temperature Ranges in Which the Studied Processes Take Place, for Silica and Organosilica under Nitrogen for Three Different Linear Heating Rates ${ }^{a}$

\begin{tabular}{|c|c|c|c|}
\hline & \multicolumn{3}{|c|}{$\begin{array}{c}\text { Temperature range for designated process }\left({ }^{\circ} \mathrm{C}\right) \text { for heating } \\
\text { rates of: }\end{array}$} \\
\hline & $1^{\circ} \mathrm{C} \min ^{-1 b}$ & $10^{\circ} \mathrm{C} \mathrm{min}^{-1}$ & $100{ }^{\circ} \mathrm{C} \min ^{-1 b}$ \\
\hline \multicolumn{4}{|c|}{ Silica } \\
\hline Dehydration & $33-187$ & $52-228$ & $79-276$ \\
\hline Dehydroxylation & $204-482$ & $230-525$ & $258-573$ \\
\hline Decomposition & - & - & - \\
\hline \multicolumn{4}{|c|}{ Organosilica } \\
\hline Dehydration & $34-159$ & 53-197 & $80-242$ \\
\hline Dehydroxylation & $185-714$ & $209-770$ & $237-832$ \\
\hline Decomposition & $500-1071$ & $537-1139$ & $578-1216$ \\
\hline
\end{tabular}

${ }^{a}$ Temperature ranges are given as $T_{\text {start }}-T_{\text {end }}$, where $T_{\text {start }}$ is defined as $\alpha=0.01$ and $T_{\text {end }}$ is defined as $\alpha=0.99 .{ }^{b}$ These heating rates are an extrapolation of the measured data.

To give guidelines for the thermal processing, Table 4-5 lists the temperature ranges in which the three identified processes (dehydration, dehydroxylation, and decomposition) occur under three relevant temperature programs: $1{ }^{\circ} \mathrm{C} \mathrm{min}^{-1}$ and $10{ }^{\circ} \mathrm{C} \mathrm{min}^{-1}$ as the bounds for commonly used heating ranges, and $100{ }^{\circ} \mathrm{C} \mathrm{min}^{-1}$ as an identifier for flashheating process.

\subsection{Conclusions}

The first step in the thermal treatment of silica-based materials is the removal of physisorbed water from the material. By isoconversional analysis, an effective activation energy of $76 \pm 3 \mathrm{~kJ} \mathrm{~mol}^{-1}$ was calculated for the dehydration of silica, irrespective of the atmosphere in which the material was treated, and an effective activation energy of $91.7 \pm 3.9 \mathrm{~kJ} \mathrm{~mol}^{-1}$ was calculated for the dehydration of the organosilica under inert atmosphere; under air atmosphere, it was impossible to determine a single activation energy for the dehydration of the organosilica. The activation energy for dehydration of the organosilica was roughly $20 \%$ higher than that for plain silica; we hypothesize that this is 106 
caused by a difference in the binding of the water to the material as a result of the organic bridging group. In both cases, the activation energy is significantly higher than the activation energy for evaporating water, $40-43 \mathrm{~kJ} \mathrm{~mol}^{-1}$ [36], suggesting that the water is strongly bound.

The second process that is manifested through the loss of water is the dehydroxylation of the material. For silica, the dehydroxylation reaction had an effective activation energy of $150-300 \mathrm{~kJ} \mathrm{~mol}^{-1}$ and was strongly dependent on the degree of conversion. The strong increase in activation energy is attributed to the increasing spatial separation of the silanol groups, which makes dehydroxylation more difficult. For organosilica, this activation energy was fairly constant at $160-190 \mathrm{~kJ} \mathrm{~mol}^{-1}$; it is hypothesized that this is a result of the enhanced mobility of the organosilica framework that is provided by the organic bridging group.

The third process that is encountered is the decomposition of the organic moiety for organosilica. Under nitrogen, the effective activation energy of this process could be determined to range from 190 to $300 \mathrm{~kJ} \mathrm{~mol}^{-1}$. Under air, dehydroxylation and decomposition reactions take place simultaneously, rendering it impossible to accurately determine the kinetics of this reaction step. For organosilica the kinetics of the dehydration, dehydroxylation, and decomposition of the organic moiety could be modeled via a multivariate analysis. The developed model allows for a prediction of the conversion of the different reactions as a function of temperature and time. Model simulations for extrapolated heating rates are in excellent agreement with experimentally obtained data. Model simulations for linear heating rates show that full dehydroxylation is always accompanied by a certain extent of decomposition.

Mass loss may not be the sole predictor for the micro- structure of a material, as reactions without or with minor mass loss can be decisive in the formation process. Nonetheless, important steps such as dehydration, dehydroxylation, and decomposition of organic moieties can be tracked through their mass loss, especially when the evolved gases are analyzed. 
The determination of reaction kinetics on the basis of TGA/MS data can form an important addition to the trial-and-error optimization of thermal treatment schemes and can be used to predict the thermal stability of the synthesized materials.

\subsection{Acknowledgements}

The authors acknowledge the funding of this work by the Helmholtz Alliance MEM-BRAIN, funded by the Initiative and Networking Fund of the Helmholtz Association. The authors acknowledge the help of Cindy Huiskes with setting up the TGA-measurements.

\subsection{References}

1. Agirre, I., Arias, P.L., Castricum, H.L., Creatore, M., ten Elshof, J.E., Paradis, G.G., Ngamou, P.H.T., van Veen, H.M. \& Vente, J.F., 2014, Hybrid organosilica membranes and processes: Status and outlook. Sep. Purif. Technol. 121, pp. 2-12. (doi:10.1016/j.seppur.2013.08.003)

2. Wang, J., Gong, G., Kanezashi, M., Yoshioka, T., Ito, K. \& Tsuru, T., 2012, Pore-size Tuning of Highly Selective Organic-Inorganic Hybrid Silica Membranes by Solid-phase Post-treatment at Low Temperature. Chem. Lett. 41, pp. 1663-1665. (doi:10.1246/cl.2012.1663)

3. Elma, M., Yacou, C., Wang, D., Smart, S. \& Costa, J.C.D. da, 2012, Microporous silica based membranes for desalination. Water 4, pp. 629-649. (doi:10.3390/w4030629)

4. Chaudhari, M. \& Du, J., 2012, Reaction mechanisms of oxygen plasma interaction with organosilicate low-k materials containing organic crosslinking groups. J. Vac. Sci. Technol. A 30, pp. 61302-61307. (doi:10.1116/1.4755898)

5. Rathore, J.S., Interrante, L. V \& Dubois, G., 2008, Ultra low-k films derived from hyperbranched polycarbosilanes (HBPCS). Adv. Funct. Mater. 18, pp. 4022-4028. (doi:10.1002/adfm.200801197)

6. Loy, D.A. \& Shea, K.J., 1995, Bridged polysilsesquioxanes. Highly porous hybrid organic-inorganic materials. Chem. Rev. 95, pp. 1431-1442. (doi:10.1021/cr00037a013)

7. Manca, M., Cannavale, A., De Marco, L., Aricò, A.S., Cingolani, R. \& Gigli, G., 2009, Durable superhydrophobic and antireflective surfaces by trimethylsilanized silica nanoparticles-based sol-gel processing. Langmuir 25, pp. 6357-62. (doi:10.1021/la804166t) 
8. Wang, J., Kanezashi, M., Yoshioka, T. \& Tsuru, T., 2012, Effect of calcination temperature on the PV dehydration performance of alcohol aqueous solutions through BTESE-derived silica membranes. J. Membr. Sci. 415-416, pp. 810-815. (doi:http://dx.doi.org/10.1016/j.memsci.2012.05.073)

9. Kanezashi, M., Shazwani, W.N., Yoshioka, T. \& Tsuru, T., 2012, Separation of propylene/propane binary mixtures by bis(triethoxysilyl) methane (BTESM)derived silica membranes fabricated at different calcination temperatures. J. Membr. Sci. 415-416, pp. 478-485. (doi:10.1016/j.memsci.2012.05.034)

10. Kreiter, R., Creatore, M., Cuperus, F.P., Vente, J.F., Herve, T.N.P. \& Tchoua Ngamou, P.H., 2012, Supported Polysilsesquioxane membrane and production thereof. WO2013066184A1.

11. Ngamou, P.H.T., Overbeek, J.P., Kreiter, R., van Veen, H.M., Vente, J.F., Wienk, I.M., Cuperus, P.F. \& Creatore, M., 2013, Plasma-deposited hybrid silica membranes with a controlled retention of organic bridges. J. Mater. Chem. A 1, pp. 5567-5576. (doi:10.1039/c3ta00120b)

12. Jang, K.-S., Kim, H.-J., Johnson, J.R., Kim, W., Koros, W.J., Jones, C.W. \& Nair, S., 2011, Modified Mesoporous Silica Gas Separation Membranes on Polymeric Hollow Fibers. Chem. Mater. 23, pp. 3025-3028. (doi:10.1021/cm200939d)

13. Nair, S., Jang, K.-S., Jones, C., Koros, W. \& Johnson, J., 2012, Mesoporous silica membrane on polymeric hollow fibers. U.S. Patent 20120108418.

14. Wang, J.-S. \& Huang, S.-Y., 12AD, Potential of low-temperature post processing of silica gel for high-temperature stable LED encapsulant. J. Sol-Gel Sci. Technol. (doi:10.1007/s10971-012-2889-1)

15. Schillo, M.C., Park, I.S., Chiu, W. V \& Verweij, H., 2010, Rapid thermal processing of inorganic membranes. J. Membr. Sci. 362, pp. 127-133. (doi:10.1016/j.memsci.2010.06.030)

16. Kappert, E.J., Nijmeijer, A. \& Benes, N.E., 2012, Expeditious calcination of inorganic membranes by an instant temperature increment. Microporous Mesoporous Mater. 151, pp. 211-215. (doi:10.1016/j.micromeso.2011.10.034)

17. Wang, D.K., Motuzas, J., Costa, J.C.D. da \& Smart, S., 2013, Rapid thermal processing of tubular cobalt oxide silica membranes. Int.J. Hydrogen Energy 38, pp. 7394-7399. (doi:10.1016/j.ijhydene.2013.04.052)

18. Wang, D.K., Diniz da Costa, J.C. \& Smart, S., 2014, Development of rapid thermal processing of tubular cobalt oxide silica membranes for gas separations. $J$. Membr. Sci. 456, pp. 192-201. (doi:10.1016/j.memsci.2014.01.014)

19. Van Gestel, T., Hauler, F., Bram, M., Meulenberg, W.A. \& Buchkremer, H.P., 2014, Synthesis and characterization of hydrogen-selective sol-gel SiO2 membranes supported on ceramic and stainless steel supports. Sep. Purif. Technol. 121, pp. 20-29. (doi:10.1016/j.seppur.2013.10.035) 
20. Zhang, Q. \& Ye, G., 2012, Dehydration kinetics of Portland cement paste at high temperature. J. Therm. Anal. Calorim. 110, pp. 153-158. (doi:10.1007/s10973-0122303-9)

21. Xu, B. \& Smith, P., 2012, Dehydration kinetics of boehmite in the temperature range 723-873 K. Thermochim. Acta 531, pp. 46-53. (doi:10.1016/j.tca.2011.12.025)

22. Campostrini, R., Sicurelli, A., Ischia, M. \& Carturan, G., 2007, Pyrolysis study of a hydride sol-gel silica: Part II. Kinetic aspects. J. Therm. Anal. Calorim. 90, pp. 179184. (doi:10.1007/s10973-006-7624-0)

23. Zhuravlev, L.T., 2000, The surface chemistry of amorphous silica. Zhuravlev model. Colloids Surfaces A Physicochem. Eng. Asp. 173, pp. 1-38. (doi:10.1016/S0927-7757(00)00556-2)

24. Vyazovkin, S., Burnham, A.K., Criado, J.M., Pérez-Maqueda, L.A., Popescu, C. \& Sbirrazzuoli, N., 2011, ICTAC Kinetics Committee recommendations for performing kinetic computations on thermal analysis data. Thermochim. Acta 520, pp. 1-19. (doi:10.1016/j.tca.2011.03.034)

25. Vyazovkin, S. \& Dollimore, D., 1996, Linear and Nonlinear Procedures in Isoconversional Computations of the Activation Energy of Nonisothermal Reactions in Solids. J. Chem. Inf. Comput. Sci. 36, pp. 42-45. (doi:10.1021/ci950062m)

26. Vyazovkin, S., 2001, Modification of the integral isoconversional method to account for variation in the activation energy. J. Comput. Chem. 22, pp. 178-183. (doi:10.1002/1096-987x(20010130)22:2<178::aid-jcc5>3.0.co;2-\%23)

27. Vyazovkin, S., 1997, Evaluation of activation energy of thermally stimulated solid-state reactions under arbitrary variation of temperature. J. Comput. Chem. 18, pp. 393-402. (doi:10.1002/(sici)1096-987x(199702)18:3<393::aid-jcc9>3.0.co;2-p)

28. MATLAB and Optimization Toolbox, Release 2012b. Natick, Massachusetts, USA: The MathWorks.

29. Cai, J., Wu, W. \& Liu, R., 2012, Isoconversional kinetic analysis of complex solidstate processes: parallel and successive reactions. Ind. Eng. Chem. Res. 51, pp. 16157-16161. (doi:10.1021/ie302160d)

30. Burnham, A.K. \& Braun, R.L., 1999, Global Kinetic Analysis of Complex Materials. Energy \& Fuels 13, pp. 1-22. (doi:10.1021/ef9800765)

31. Matsumura, Y., Hashimoto, K. \& Yoshida, S., 1989, Selective Dehydrogenation of Ethanol over Highly Dehydrated Silica. J. Catal. 117, pp. 135-143. (doi:10.1016/0021-9517(89)90226-1)

32. Hao, Y., Tao, L. \& Zheng, L., 1994, Ethanol dehydrogenation on silica pillared rectorite. Appl. Catal. A Gen. 115, pp. 219-228. (doi:10.1016/0926$860 \mathrm{X}(94) 80354-4)$ 
33. Chen, Q., Hoebink, J.H.B.J. \& Marin, G.B., 1991, Kinetics of the oxidative coupling of methane at atmospheric pressure in the absence of catalyst. Ind. Eng. Chem. Res. 30, pp. 2088-2097. (doi:10.1021/ie00057a006)

34. De Lange, R.S. a., Keizer, K. \& Burggraaf, a. J., 1995, Analysis and theory of gas transport in microporous sol-gel derived ceramic membranes. J. Membr. Sci. 104, pp. 81-100. (doi:10.1016/0376-7388(95)00014-4)

35. Li, X., Li, Z., Xia, Q. \& Xi, H., 2007, Effects of pore sizes of porous silica gels on desorption activation energy of water vapour. Appl. Therm. Eng. 27, pp. 869-876. (doi:10.1016/j.applthermaleng.2006.09.010)

36. Prado, J.R. \& Vyazovkin, S., 2011, Activation energies of water vaporization from the bulk and from laponite, montmorillonite, and chitosan powders. Thermochim. Acta 524, pp. 197-201. (doi:10.1016/j.tca.2011.06.005)

37. Online Supporting Information for: Kappert, E.J., Bouwmeester, H.J.M., Benes, N.E., Nijmeijer, A., Kinetic analysis of the thermal processing of silica and organosilica, J. Phys. Chem. B, 118, pp. 5270-5277 (doi: 10.1021/jp502344k) 



\section{Chapter 5}

Temperature calibration procedure for thin film substrates for thermo-ellipsometric analysis using melting point standards

This chapter has been published:

Kappert, E.J., M.J.T. Raaijmakers, W. Ogieglo, A. Nijmeijer, C. Huiskes, N.E. Benes, Temperature calibration procedure for thin film substrates for ellipsometry using melting point standards, Thermochim. Acta, 601, pp. 29-32, doi: 10.1016/j.tca.2014.12.017 


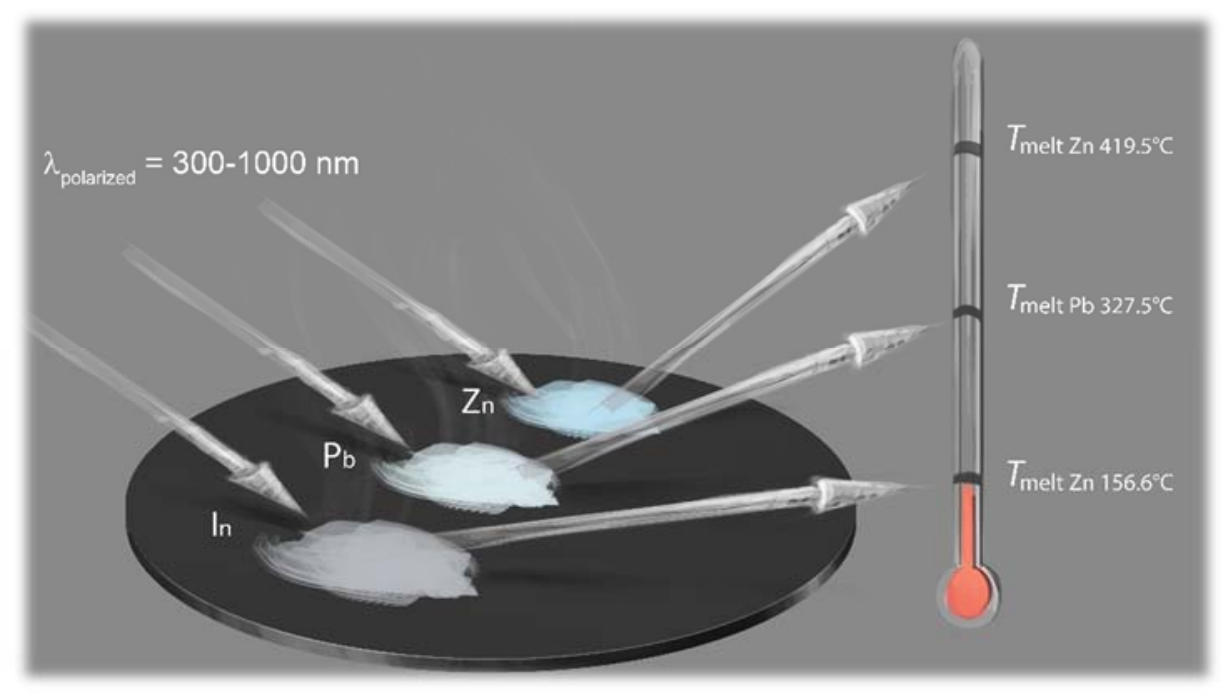

\section{Abstract}

Precise and accurate temperature control is pertinent to studying thermally activated processes in thin films. Here, we present a calibration method for the substrate-film interface temperature using spectroscopic ellipsometry. The method is adapted from temperature calibration methods that are well developed for thermogravimetric analysis and differential scanning calorimetry instruments, and is based on probing a transition temperature. Indium, lead, and zinc could be spread on a substrate, and the phase transition of these metals could be detected by a change in the $\Psi$ signal of the ellipsometer. For water, the phase transition could be detected by a loss of signal intensity as a result of light scattering by the ice crystals. The combined approach allowed for construction of a linear calibration curve with an accuracy of $1.3{ }^{\circ} \mathrm{C}$ or lower over the full temperature range. 


\subsection{Introduction}

Precise control of the sample temperature is essential for studying thermally activated processes [1,2]. Even minor errors in the recorded sample temperature potentially lead to large errors, if derivative calculations on the data are performed [3]. The behavior of thin films may be systematically different from that of bulk materials [4-7]. For the thermal analysis of thin films it is imperative to know the temperature at the substrate-film interface. In such experiments, the properties of the thin film are typically probed by optical techniques, and heating is performed substrate-sided to leave the film open to the light beam. As a result, heat losses may occur from the topside of the sample, or a time-lag may be introduced in the sample heating. The extent of the heat losses can strongly depend on the thickness and thermal conductivity of the substrate. Contrary to the analysis of (semi)bulk samples by, e.g., thermogravimetry or calorimetry $[3,8,9]$, no standardized temperature calibration strategies exist for these type of measurements. In this paper, we will shortly review the existing techniques for probing the temperature of a substrate-film interface. Subsequently, we will demonstrate a simple method to calibrate the substrate-film interface temperature using melting point standards. This simple method is applicable for different types of substrates.

The state-of-the-art temperature calibrations for flat substrates are found in rapid thermal processing (RTP)-environments in the semiconductor industry, where accurate control over the temperature of silicon wafers is achieved. For these systems, pyrometry is the commonly employed technique. The drawback of this technique is the fact that below $\sim 600{ }^{\circ} \mathrm{C}$ lightly-doped wafers are partially transparent at the pyrometer's wavelength [10].

Plainly placing a thermocouple on top of the sample suffers from imperfect thermal bonding [10]. Embedding of a thermocouple or optical sensor into a wafer would circumvent this problem, but is not straightforward [11,12]; moreover, this technique is not generically available for different substrates. 
Other techniques such as ellipsometry, Raman spectroscopy, or ultrasonic measurements, require knowledge on the change in the (optical) properties of the substrate as function of temperature [10]. Measurement of the thermal changes and matching it to reference data requires extensive knowledge on the technique and the substrate studied.

Precise temperature calibration is a problem that has been extensively addressed in the thermal analysis community. For standard thermal analysis methods, such as thermogravimetric analysis (TG/TGA), differential scanning calorimetry (DSC), and differential thermal analysis (DTA), several temperature calibration methods are available. Typically, calibration involves measuring a transition temperature of a standard, and comparing it with the known value of this transition temperature. The melting point of metals is typically used for DSC and DTA-capable instruments [1]. This method is also recorded in the current ASTM-standard for DSC calibration [8]. For TG-apparatuses, the state-of-the-art technique involves the placement of a magnet above or under the apparatus, and recording the apparent mass change in a ferromagnetic material when it loses its magnetic properties, as it passes through the Curie temperature [9]. An alternative method involves the use of a dropping weight that hangs from a fusible link made from a melting point temperature standard [13]. Other options include recording the decomposition point of a material [14] or the difference between sample and set temperature that occurs as a result of sample self-heating or cooling (this technique is named calculated DTA and is the technique behind Netzsch's c-DTA ${ }^{\oplus}$ ).

The use of melting point standards is an attractive technique for the calibration of wafer temperatures. In the past, this technique has been performed by visual observation of the phase transition [15]. In our experience, visual observations of the phase transition of a thin film are inaccurate because of the small changes in the film properties. Moreover, if a calibration needs to be performed in a closed chamber, visual observation will not be possible. 
Here, we report the use of metal melting point standards for simple and fast temperature calibration of temperature-controlled ellipsometry. Because of the light absorbance by the thin metal films, the layers are optically semiinfinite when thicker than $\sim 100 \mathrm{~nm}$, and the substrate can be considered optically invisible. The method relies on the change in the amplitude ratio of the polarized light, $\Psi$, that takes place upon melting of a thin metal film. Upon heating without a phase change $\Psi$ is relatively constant [16]. Melting induces a step change in $\Psi$ that is a result of an abrupt change in the roughness, the material's density, the films alignment angle or light intensity. The melting temperature of the film is a good indication for the substrate-film interface temperature, because of the large thermal conductivity of the thin metal films. The versatility of the presented method is demonstrated by determining the temperature on silicon wafers and porous alumina substrates.

\subsection{Experimental section}

In, Sn, Bi, and $\mathrm{Zn}$ melting standards ( $>99.99 \%$ purity) were obtained from Netsch. Pb melting standard $(99.999 \%$ purity) was obtained from Chempur. Silicon wafers $((100)$-oriented $\mathrm{p}$-type, thickness $=508 \mu \mathrm{m}$, front side polished, abbreviated by $\mathrm{Si}$ ) were obtained from Silchem. Porous $\alpha$-alumina disks (thickness $=2 \mathrm{~mm}, d_{\text {pore }} \approx 80 \mathrm{~nm}$, porosity $\approx 40 \%$ ) were obtained from Pervatech.

DTA and TGA measurements were carried out on a STA 449 F3 Jupiter (Netsch) fitted with a TGA-DTA-holder (DTA measurement) or a TGonly holder (TGA experiments). Experiments were carried out with $\sim 20 \mathrm{mg}$ of metal, at heating rates of $5-20{ }^{\circ} \mathrm{C} \mathrm{min}^{-1}$, under nitrogen. For the TGA measurement, the melting onset was determined using the calculated DTA signal $\left(T_{\text {set }}-T_{\text {exp }}\right)$.

Spectroscopic ellipsometry measurements were recorded on an M2000X spectroscopic ellipsometer (J.A. Woollam) equipped with a heating stage with quartz windows at $70^{\circ}$ incident angle (HCS622, INSTEC) and 
focusing probes. $\Psi$ was measured at an interval of 5 seconds over the full wavelength range of $210-1000 \mathrm{~nm}$. The measurements were performed under a blanket of nitrogen with negligible flow rate.

To obtain a measurable signal without scattering, a small piece of metal was placed on top of the substrate. Then, the temperature was increased to above the melting point of the metal, and the metal was spread over the surface using a flat spatula. Next, the sample and/or the light beam were aligned to achieve maximum light intensity. The wavelength that displayed the best signal-to-noise ratio was selected for the evaluation of the phase transition. Typically, multiple wavelengths could be selected with identical results. The melting and solidification steps were subsequently studied at different heating rates.

\subsection{Results and discussion}

Figure 5-1 shows the melting curves of zinc using three different methods. The figure displays a clear difference between the instantaneous melting of the thin film in the ellipsometry, and the time-dependent melting of the metal in the DTA and calculated DTA measurements. Because heating and cooling are both initiated from the wafer-film interface, the absence of hysteresis between the heating and cooling cycle indicates the homogeneous temperature distribution throughout the thin film. The (extrapolated) onset of the curve is the indication for the melting point, as the shape and maximum are heating-rate and sample-mass dependent [1]. As can be expected for a dedicated thermal analysis device, the DTA and TGA measurements displayed the least deviation from the true melting point, with a difference between experimental and known melting temperature of only $0.4{ }^{\circ} \mathrm{C}$ for DTA, and a difference of $1.8{ }^{\circ} \mathrm{C}$ for TGA (where melting was determined via calculated DTA). For the hot stage of the ellipsometer, a temperature difference of $12.8{ }^{\circ} \mathrm{C}$ was determined. 


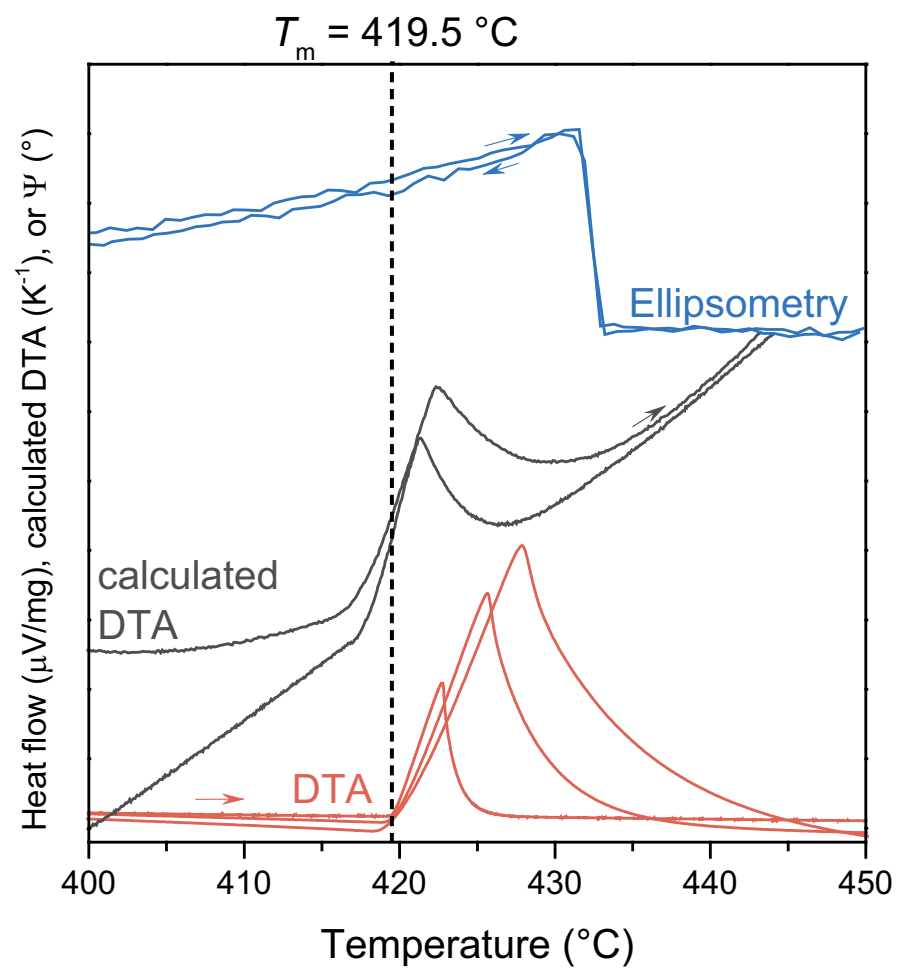

Figure 5-1: Melting curves of zinc obtained by DTA, TGA (via calculated DTA), and ellipsometry. For DTA and calculated DTA, the onset of the melting step indicates the melting point. The difference between the known melting point of zinc $\left(419.5{ }^{\circ} \mathrm{C}\right)$ and the recorded melting point indicates the temperature offset that needs to be corrected for.

During the ellipsometry measurements, the phase transition fully occurs between two temperature values. The melting points can be determined as the average of these two temperature values, the accuracy of the ellipsometry temperature calibration depends on the data spacing. Shorter measurements intervals therefore lead to a more accurate determination of the melting point; however, at the expense of increased noise in the data, making the transition less pronounced. A measurement time of 5 seconds was heuristically determined to give optimal results. For the DTA and TGA, the accuracy depends on the precision of the extrapolated onset. 
Although the onset is theoretically not dependent on heating rate, the extrapolated onset in practice is, and the accuracy can be different for different heating rates.

Similar to the data given in Figure 5-1, the melting point could be determined for other metals and water. Figure 5-2 shows the melting curves of indium, water, and lead on silicon wafers, and that of lead on a porous $\alpha$-alumina substrate. The melting curves of tin and bismuth were recorded as well. During the experiment, these metals showed a strong color change that is indicative for the oxidation of the metal. Hence, these measurements were discarded.

The melting curves for indium, lead, and zinc show a strongly reproducible melting point. Contrary to the results obtained for indium and zinc, a small offset of $\sim 2{ }^{\circ} \mathrm{C}$ was detected between heating and cooling cycles for the lead sample. This offset is attributed to the fact that the layer thickness for lead is larger than what could be achieved for indium and zinc, in combination with the lower thermal conductivity of the lead.

For water, upon freezing the ice crystals scatter the incoming light. As a result, the large noise in $\Psi$ prevents the detection of the phase change. However, the scattering upon freezing can be tracked by recording the step change in the light intensity that is detected when freezing occurs. The temperature corresponding to this step change can be used for the temperature calibration. For the metal samples, a step change in the light intensity indicative for the phase transition was found as well. However, determining the onset of melting or solidification from the melting temperature proved less accurate. Therefore, for these samples $\Psi$ was chosen as the indicator for the phase change.

The calibration data, such as given in Figure 5-2, can be used to construct a calibration curve, see Figure 5-3. The proximity of the several data points for one melting point standard demonstrates the precision of the data. 

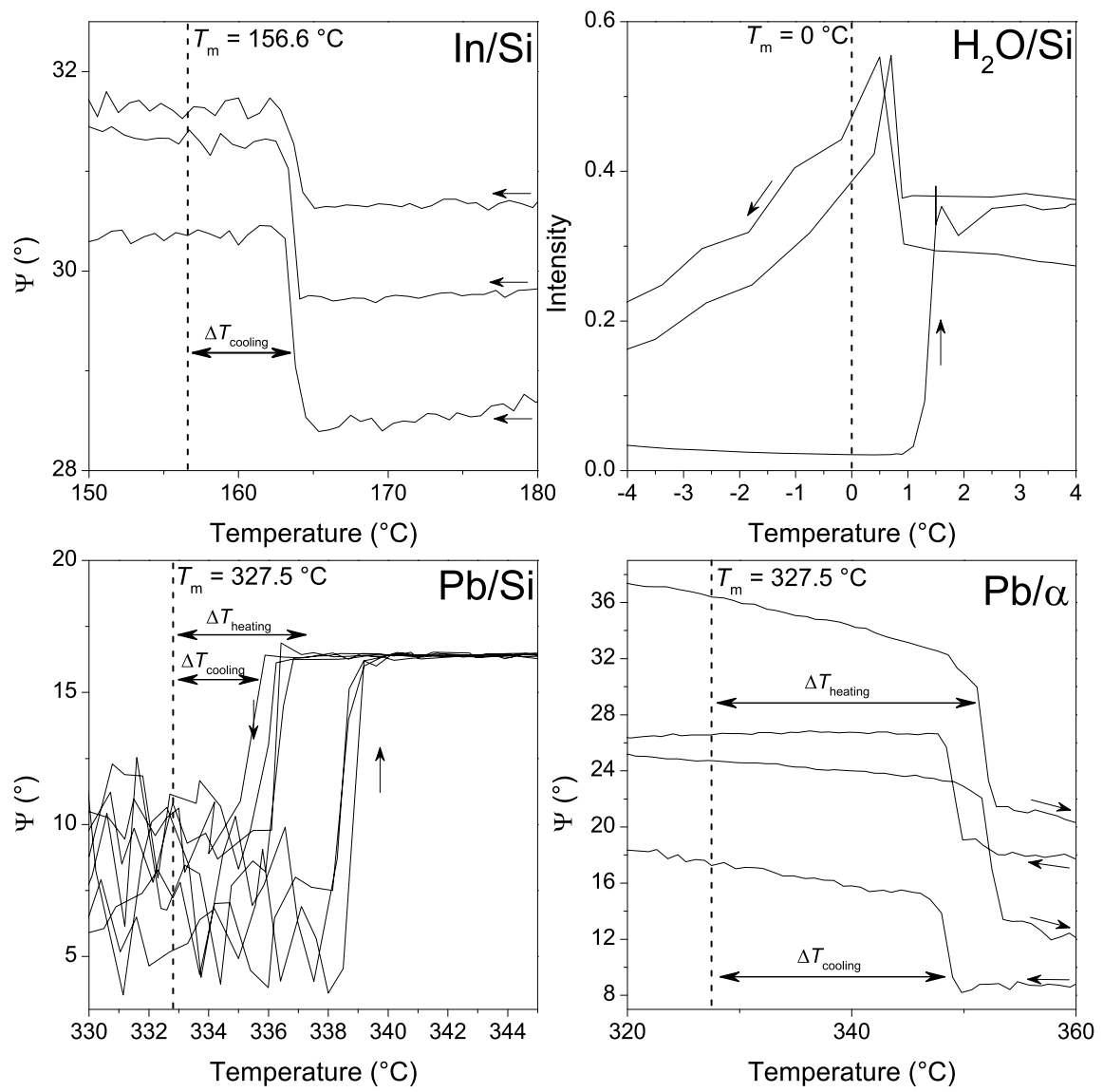

Figure 5-2: Melting curves of indium, water, and lead on silicon, and lead on $\alpha$-alumina, obtained by ellipsometry. The wavelengths at which $\Psi$ was recorded were $500 \mathrm{~nm}, 300 \mathrm{~nm}$, and $900 \mathrm{~nm}$ for In/Si, $\mathrm{Pb} / \mathrm{Si}$, and $\mathrm{Pb} / \mathrm{\alpha}$-alumina, respectively. For water, freezing leads to the formation of crystals that scatter all the incoming light, rendering measurements of $\Psi$ impossible. Here, the light intensity was used as an alternative metric. The data demonstrates the accuracy and reproducibility of the melting points, irrespective of noise in the data, or hysteresis in $\Psi$. 

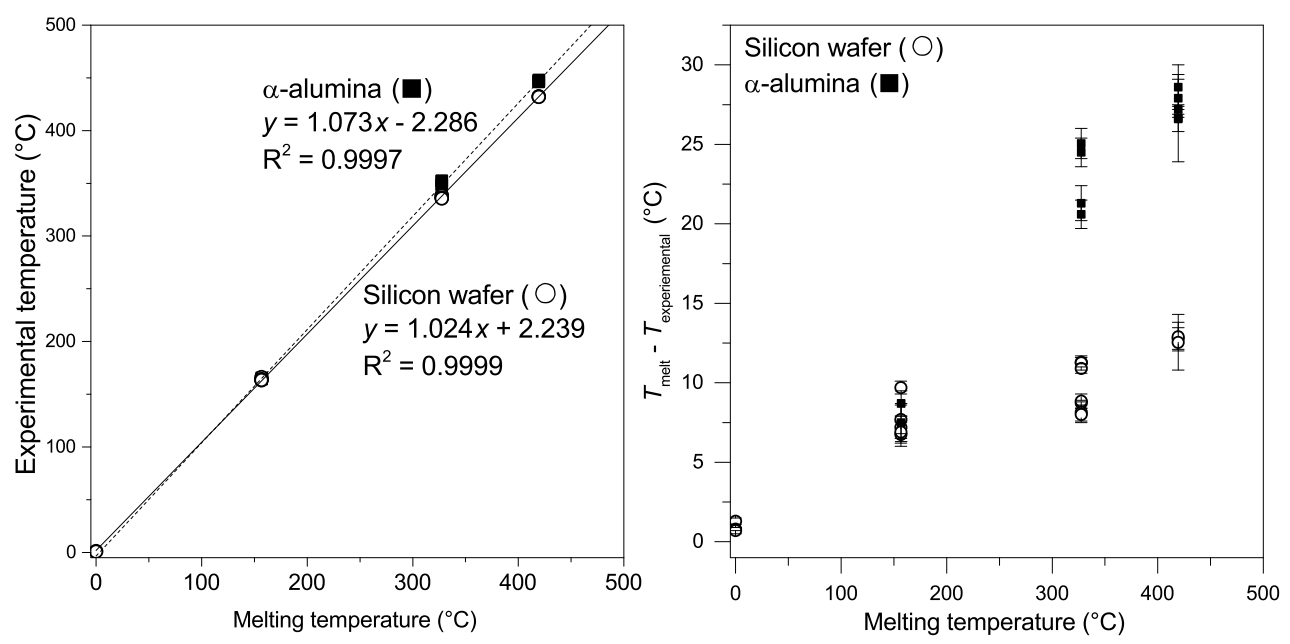

Figure 5-3: Calibration curve (left) and deviation between experimentally determined melting points and literature values (right).

Over the full temperature range studied, the deviation between the recorded and actual temperatures follows a linear relation. For the $\alpha$-alumina substrate, the temperature offsets are higher, as is expected based on the larger sample thickness, lower thermal conductivity of alumina versus silicon, and porosity inside the alumina substrate. Experiments in which a thermocouple was placed onto the silicon wafer, with thermal conductivity paste applied to improve the thermal contact, at $200{ }^{\circ} \mathrm{C}$ already resulted in deviations of over $20^{\circ} \mathrm{C}$ from the melting point curve.

The accuracy of the calibration curve can be calculated from the 95\% confidence interval of the data. Over the whole temperature range, the 95\% confidence interval for the silicon wafer temperature is smaller than $1.3{ }^{\circ} \mathrm{C}$, and therefore within the typical limits set for temperature calibration [8]. Because water was not measured for the $\alpha$-alumina support, the deviations for this support are slightly higher $\left(\max 3.3^{\circ} \mathrm{C}\right)$ at lower temperatures. To predict the difference during a single experiment, a prediction interval needs to be constructed. Because of the abundance of 
measurement data, the maximum deviation for the silicon wafer is within $3{ }^{\circ} \mathrm{C}$ over the full temperature range studied.

For all calibration measurements, the recorded temperature of the substrate is higher than the known value for the melting point, as a result of heat losses of the sample at the topside. For indium, these heat losses were studied in more detail by performing experiments with different gas flow rates impinging on the sample. The experiments show an increasing difference between the recorded temperature and the theoretical value because of the increased cooling of the sample. This difference can be up to $20{ }^{\circ} \mathrm{C}$ at flow rates of $0.5 \mathrm{~L} \mathrm{~min}^{-1}$. More specifically, the melting temperature increased with the square root of the gas flow, thus following the expected trend of the temperature to approximately scale with the gas velocity of the impinging jet [17]. To take into account such temperature variations, temperature calibration is preferably performed in the exact same setting as the actual experiments, i.e., using the same substrate, experimental cell, and flow rates.

\subsection{Conclusions}

Temperature calibration of the substrate-film interface was performed by spectroscopic ellipsometry on a sample heated by a hot stage. Indium, lead, and zinc are recommended as melting point standards. The use of tin and bismuth is discouraged due to the strong tendency of these metals to oxidize. Detecting the phase transition using the polarized light beam allows for temperature calibration of a variety of substrates under the experimental conditions, e.g., for the use of gas flows in a purged experimental chamber. 


\subsection{References}

1. Vyazovkin, S., Chrissafis, K., Di Lorenzo, M.L., Koga, N., Pijolat, M., Roduit, B., Sbirrazzuoli, N. \& Suñol, J.J., 2014, ICTAC Kinetics Committee recommendations for collecting experimental thermal analysis data for kinetic computations. Thermochim. Acta 590, pp. 1-23. (doi:10.1016/j.tca.2014.05.036)

2. Pfohl, O., Hino, T. \& Prausnitz, J.M., 1995, On the temperature calibration of a thermo-optical apparatus. Fluid Phase Equilib. 112, pp. 157-162. (doi:10.1016/0378-3812(93)02609-Q)

3. Vyazovkin, S., Burnham, A.K., Criado, J.M., Pérez-Maqueda, L.A., Popescu, C. \& Sbirrazzuoli, N., 2011, ICTAC Kinetics Committee recommendations for performing kinetic computations on thermal analysis data. Thermochim. Acta 520, pp. 1-19. (doi:10.1016/j.tca.2011.03.034)

4. Huang, Y. \& Paul, D.R., 2005, Effect of Temperature on Physical Aging of Thin Glassy Polymer Films. Macromolecules 38, pp. 10148-10154. (doi:10.1021/ma051284g)

5. Fakhraai, Z. \& Forrest, J.A., 2008, Measuring the Surface Dynamics of Glassy Polymers. Science 319, pp. 600-604. (doi:10.1126/science.1151205)

6. Keddie, J.L., Jones, R.A.L. \& Cory, R.A., 1994, Interface and Surface Effects on the Glass-transition Temperature in Thin Polymer Films. Farady Discuss. 98, pp. 219-230. (doi:10.1039/FD9949800219)

7. Napolitano, S. \& Wübbenhorst, M., 2010, Structural relaxation and dynamic fragility of freely standing polymer films. Polymer (Guildf). 51, pp. 5309-5312. (doi:10.1016/j.polymer.2010.09.060)

8. ASTM Standard E967-08, 2014, Standard Test Method for Temperature Calibration of Differential Scanning Calorimeters and Differential Thermal Analyzers. , pp. 1-4. (doi:10.1520/E0967-08R14.2)

9. Gallagher, P.K., Blaine, R., Charsley, E.L., Koga, N., Ozao, R., Sato, H., Sauerbrunn, S., Schultze, D. \& Yoshida, H., 2003, Magnetic temperature standars for TG. J. Therm. Anal. Calorim. 72, pp. 1109-1116. (doi:10.1023/A:1025032013135)

10. Timans, P.J., 2008, Rapid Thermal Processing. In Handbook of semiconductor manufacturing technology (eds R. Doering \& Y. Nishi), Boca Raton: CRC Press.

11. Renken, W.G., Sun, M.H., Miller, P., Gordon, R. \& Vandenabeele, P.M.N., 2001, Integrated wafer temperature sensors. US6325536B1.

12. Iuchi, T. \& Gogami, A., 2009, Uncertainty of a hybrid surface temperature sensor for silicon wafers and comparison with an embedded thermocouple. Rev. Sci. Instrum. 80, pp. 126109. (doi:10.1063/1.3274676) 
13. McGhie, A.R., Chiu, J., Fair, P.G. \& Blaine, R.L., 1983, Thermogravimetric apparatus temperature calibration using melting point standards. Thermochim. Acta 67, pp. 241-250. (doi:10.1016/0040-6031(83)80104-X)

14. Slager, T.L. \& Prozonic, F.M., 2005, Simple methods for calibrating IR in TGA/IR analyses. Thermochim. Acta 426, pp. 93-99. (doi:10.1016/j.tca.2004.07.022)

15. Fryer, D.S., Nealey, P.F. \& de Pablo, J.J., 2000, Thermal Probe Measurements of the Glass Transition Temperature for Ultrathin Polymer Films as a Function of Thickness. Macromolecules 33, pp. 6439-6447. (doi:10.1021/ma0003349)

16. Aster, A.K., 1922, The optical properties of molten metals. Phys. Rev. 20, pp. 349357. (doi:10.1103/PhysRev.20.349)

17. Viskanta, R., 1993, Heat Transfer to Impinging Isothermal Gas and Flame Jets. Experimental Therm. Fluid Sci. 6, pp. 111-134. (doi:10.1016/0894-1777(93)90022B) 


\section{Chapter 6 \\ Thermal stability of sulfonated poly(ether ether ketone): on the role of protodesulfonation}

This chapter has been submitted for publication:

B. Koziara, E.J. Kappert, W. Ogieglo, D.C. Nijmeijer, M.A. Hempenius, N.E. Benes, Thermal stability of sulfonated poly(ether ether ketone): on the role of protodesulfonation, submitted for publication 


\section{H-SPEEK}

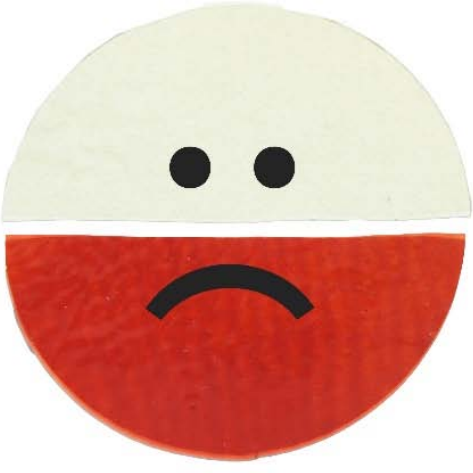

+NaCl Na-SPEEK

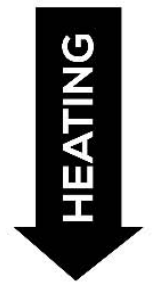

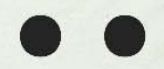

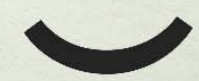

\section{Abstract}

Sulfonated poly(ether ether ketone) (SPEEK) is a highly charged and stable polymer membrane material. For many membrane applications thermal processing of this polymer is required, during which desulfonation can occur. Such removal of the sulfonic acid groups in SPEEK can be avoided by exchanging the sulfonate proton by a sodium counter ion. Without this exchange, prolonged exposure to temperatures as low as $160{ }^{\circ} \mathrm{C}$ induces irreversible changes to thin films of SPEEK. At higher temperatures $\left(>195{ }^{\circ} \mathrm{C}\right.$ ), a secondary reaction leads to further changes in the material and removal of $\mathrm{SO}_{2}$ from the polymer. Because sulfuric acid and solvents could be excluded as the sulfur source in our experiments, the findings directly relate to the thermal stability of SPEEK. Although it has been recognized that the sulfonate proton plays a major role in desulfonation reactions, the implications on the thermal stability of sulfonated polymers of exchanging the protons with other cations have, to the best of our knowledge, not been systematically assessed. Our study demonstrates that such an ion exchange has very important consequences for the thermal processing of SPEEK membranes. The findings of this study may be extended to other membranes consisting of sulfonated polymers. 


\subsection{Introduction}

Sulfonated poly(ether ether ketone) (SPEEK, Figure 6-1) is a negatively charged polymer that finds wide use as membrane material. It can be applied in water purification [1-3], in proton exchange membrane (PEM) fuel cells [4-6], and in dehydration of industrial gases [7-9].

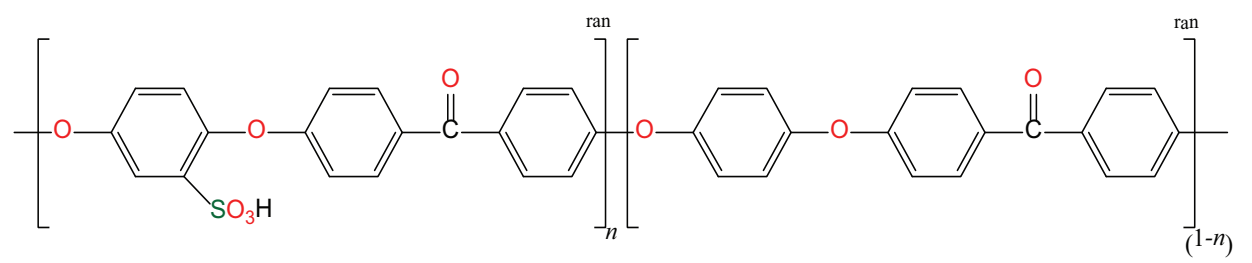

Figure 6-1: Structural formula of SPEEK with degree of sulfonation $n$

For multiple reasons, SPEEK membranes may be exposed to higher temperatures. In PEM fuel cells, higher temperatures hold advantages during operation [10,11]. Alternatively, high temperatures are used to remove residual high boiling point solvents after membrane formation [12], bring the material above its glass transition temperature to remove its history [4], or to perform temperature-promoted crosslinking [13,14]. Although temperatures up to $200{ }^{\circ} \mathrm{C}$ are not uncommon in these procedures [15], they can have detrimental effects on the integrity of SPEEK [16].

Generally, thermal changes to SPEEK are reported to occur via three separate processes $[17,18]$ : the removal of absorbed water and solvent $\left(T=50-150{ }^{\circ} \mathrm{C}\right)$; temperature-promoted crosslinking and/or removal of the sulfonic acid group $\left(T=150-400{ }^{\circ} \mathrm{C}\right)$; and backbone decomposition $\left(T>400{ }^{\circ} \mathrm{C}\right)$. Especially the second temperature range is of interest, as the reactions that take place at this temperature can all involve the sulfonate $\left(\mathrm{SO}_{3}{ }^{-}\right)$group. Because desulfonation typically takes place through a protodesulfonation reaction, the thermal stability of a sulfonate group is strongly dependent on the counter ion of the sulfonate group [19]. Without the presence of a proton to take the place of the sulfonate group when it leaves the aromatic ring, desulfonation cannot occur. During performance studies, experiments in which the sulfonate proton was 
exchanged by a sodium ion showed indications of an enhanced stability $[12,15]$. Decades ago, TGA-experiments on the sodium-exchanged form indeed showed a higher thermal stability [16]. Since then, the effect of exchanging the sulfonate proton by a different counter-ion on the thermal processing of SPEEK membranes has not been studied systematically.

In this study, we assessed the thermal stability of SPEEK, both in the bulk and in thin films, over a time scale of 15 hours at moderate temperatures. First, the differences between the thermal stability of SPEEK in the protonform (H-SPEEK) and the sodium form (Na-SPEEK) were analyzed. Based on the obtained results, a temperature range $\left(160-250{ }^{\circ} \mathrm{C}\right)$ was selected in which the thermal stability of thin films was studied for 15 hours. The results indicate that temperatures already as low as $160{ }^{\circ} \mathrm{C}$ can induce changes into $\mathrm{H}$-SPEEK. Exchanging the proton by a sodium ion significantly enhances the thermal stability of the SPEEK, allowing for treatment at higher temperatures without adverse effects.

\subsection{Experimental section}

\subsubsection{Materials}

Poly(ether ether ketone) (PEEK) was purchased from Victrex. $\mathrm{CaF}_{2}$ pellets were obtained from Crystran. $\mathrm{NaCl}$ (99.5\% for analysis) was obtained from Acros Organics. Methanol (Emsure ${ }^{\circledR}$ ) and sulfuric acid 95-98\% $\left(\right.$ EMPROVE $\left.^{\circledR}\right)$ were purchased from Merck. DMSO-d6 (99.5\% atom D) for H-NMR measurements was obtained from Sigma-Aldrich. Silicon wafers (100-oriented) were obtained from Okmetic. Water was deionized to $18.2 \mathrm{M} \Omega \mathrm{cm}^{-1}$ using a Milli-Q Advantave A10 system (Millipore). Nitrogen was dried with molecular sieve water absorbents, followed by removal of oxygen using an oxygen trap (outlet concentration $<1 \mathrm{ppb}_{2}$ ).

\subsubsection{PEEK sulfonation}

Sulfonated poly(ether ether)ketone was obtained by sulfonation of PEEK in sulfuric acid following the procedure described by Shibuya and Porter [20]. The obtained SPEEK was in the acidic form, where $\mathrm{H}^{+}$is the 
counter ion; from hereon, it will be referred to as H-SPEEK. The degree of sulfonation was determined by $\mathrm{H}-\mathrm{NMR}$ to be $84 \%$ following the procedure in literature [21] (see section ${ }^{1} \mathrm{H}-\mathrm{NMR}$ for the details on the calculation).

\subsubsection{SPEEK conversion to sodium form}

SPEEK with sodium as the counter ion, referred to as Na-SPEEK, was made by immersing $\mathrm{H}$-SPEEK in a $2 \mathrm{M} \mathrm{NaCl}$ solution. Each hour, the $\mathrm{NaCl}$ solution was substituted by a fresh solution. After three hours, the $\mathrm{Na}$-SPEEK was rinsed with deionized water and dried for 48 hours at 30 ${ }^{\circ} \mathrm{C}$ under vacuum. Part of the Na-SPEEK was back-converted to the proton form. This back-converted SPEEK will be referred to as $\mathrm{H}^{\star}$-SPEEK to distinguish it from $\mathrm{H}$-SPEEK. $\mathrm{H}^{\star}$-SPEEK was made by immersing $\mathrm{Na}$ SPEEK in a stirred $1 \mathrm{M} \mathrm{HCl}$ solution for 17 hours. Afterwards, $\mathrm{H}^{\star}$-SPEEK was rinsed with deionized water multiple times and dried for 48 hours at $30{ }^{\circ} \mathrm{C}$ under vacuum.

\subsubsection{Preparation of freestanding H-SPEEK and Na-SPEEK films}

A $10 \mathrm{wt}-\%$ solution of $\mathrm{H}-\mathrm{SPEEK}$ in methanol was cast onto a glass plate. After methanol evaporation under atmospheric conditions for 24 hours, the membranes were detached from the glass plate by immersing them into deionized water. Subsequently, the membranes were dried for 48 hours at $30{ }^{\circ} \mathrm{C}$ under vacuum. Na-SPEEK membranes were obtained by immersing $\mathrm{H}$-SPEEK membranes in a $2 \mathrm{M} \mathrm{NaCl}$ solution according, following the same procedure as described above for the SPEEK powder.

\subsubsection{Preparation of H-SPEEK and Na-SPEEK thin films on silicon substrates}

A 5 wt- $\%$ solution of H-SPEEK or Na-SPEEK in methanol was spincoated onto $2 \times 2 \mathrm{~cm}$ silicon wafers at $2000 \mathrm{rpm}$ for 50 seconds. The spincoated thin films were dried for 48 hours at $30{ }^{\circ} \mathrm{C}$ under vacuum. 


\subsection{Characterization}

\subsubsection{Thermogravimetric analysis}

Thermogravimetric analysis (TGA) was performed on a STA 449 F3 Jupiter $^{\circledR}$ (Netzch) fitted with a TG-only sample holder. Measurements were performed under $70 \mathrm{~mL} \mathrm{~min}^{-1}$ nitrogen at a heating rate of $20{ }^{\circ} \mathrm{C}$ $\mathrm{min}^{-1}$ from room temperature to $1200{ }^{\circ} \mathrm{C}$. A temperature correction by melting standards and a blank correction with an empty cup were carried out prior to the measurements. A sample mass of $\sim 50 \mathrm{mg}$ was used, the exact mass being determined accurately by an external balance.

Gases evolving during the thermogravimetric analysis were transferred to a mass spectrometer (MS, QMS 403 D Aëolos ${ }^{\circledR}$, Netzch). TGA and MS start times were synchronised, but no correction was applied for the time offset caused by the transfer line time (estimated $<30 \mathrm{sec}$, systematic offset). First, a bar graph scan for mass-to-charge ratio $(\mathrm{m} / \mathrm{z})$ 1-100 amu was performed to determine the evolving $m / z$-numbers. The detected $m / z$-numbers were selected and recorded more accurately in multiple-ion-detection mode, with a dwell time of $0.5 \mathrm{sec}$ per $\mathrm{m} / z$-value and a resolution of 50 .

\subsubsection{Photographs of heated SPEEK}

Photographs of SPEEK were taken of fresh, freestanding films of H-SPEEK and Na-SPEEK, and of freestanding films of H-SPEEK and $\mathrm{Na}$-SPEEK that were heated for 15 hours at $190 \pm 10{ }^{\circ} \mathrm{C}$ in a furnace under ultrapure nitrogen.

\subsubsection{H-NMR}

The ${ }^{1} \mathrm{H}-\mathrm{NMR}$ spectra were recorded on a Ascend ${ }^{\mathrm{TM}} 400$ (Bruker) at a resonance frequency of $400 \mathrm{MHz}$. For each analysis, $5 \mathrm{mg}$ of polymer was dissolved in $1 \mathrm{ml}$ of DMSO-d6. NMR data were acquired for 16 scans. From the ${ }^{1} \mathrm{H}-\mathrm{NMR}$ spectra, the degree of sulfonation was calculated following the procedure outlined in literature.[18] In this method, the degree of sulfonation is calculated as the ratio of the surface areas of the 
peaks stemming from the proton neighbouring the sulfonic acid to that of the other protons.

\subsubsection{UV-VIS}

UV-VIS spectra were recorded on a Cary 300 Spectrophotometer (Varian) with a spectral range of $200-800 \mathrm{~nm}$, a resolution of $1 \mathrm{~nm}$ and a scan rate of $600 \mathrm{~nm} / \mathrm{min}$, on a solution of SPEEK in ethanol in a quartz cuvette.

\subsubsection{Ellipsometry}

Spectroscopic ellipsometry measurements were conducted on a M2000X ellipsometer (J.A. Woollam Co.) in the full wavelength range of 210-1000 nm. For measurements using the $\mathrm{CaF}_{2}$-substrate, the ellipsometer was used in transmission mode, and the background was taken in air. For room temperature measurements using silicon wafers as substrate, measurements were performed at $70^{\circ}$ angle of incidence. Temperaturecontrolled experiments were performed on layers on silicon wafers. For these measurements, the M2000X was equipped with a HTC200 HeatCell ${ }^{\mathrm{TM}}$ accessory. Measurements were performed at a $70^{\circ}$ angle of incidence. During experiments, the hot stage was continuously purged with nitrogen. The thermal treatment program consisted of a two hour dwell at room temperature, followed by heating the material to the desired temperature with a heating rate of $2.5{ }^{\circ} \mathrm{C} \mathrm{min}^{-1}$. The dwell time was 15 hours, and after the dwell the sample was cooled to room temperature at $2.5^{\circ} \mathrm{C} \min ^{-1}$.

\subsubsection{Analysis of ellipsometry data}

Analysis of the obtained optical spectra was performed using CompleteEase $^{\circledR}$ (version 4.86, J.A. Woollam Co.). The used optical constants for silicon were taken from the built-in library, and the thickness of the native oxide was fixed at $2 \mathrm{~nm}$. 


\section{Parameterization of the optical dispersion by Kramers-Kronig consistent B-splines}

Parameterization of the optical dispersion of SPEEK was performed using Kramers-Kronig consistent B-Splines [22]. In order to obtain the optical dispersion reproducibly, the following steps were taken. First, the layer thickness was determined by fitting a Cauchy optical dispersion in the transparent range $(\lambda=500-1000 \mathrm{~nm})$. Taking into account optical anisotropy in the layers was not required to accurately model the absorption spectra. With fixed thickness, the layer was parameterized by BSplines, with the node resolution set to $0.15 \mathrm{eV}$, the B-Splines forced to be Kramers-Kronig consistent, and $\varepsilon_{2}$ forced to be a positive number. Subsequently, the wavelength range of the B-Spline was expanded with increments of $0.15 \mathrm{eV}$, until it spanned the full wavelength range of the measurement. The node tie-offs at 0.640 and $0.840 \mathrm{eV}$ were then forced to zero. This last step was performed to be able to output the nodes of the BSpline in such a way that the optical dispersions could be reconstructed from the output data, using Matlab ${ }^{\circledR}$ software and the approach outlined by Johs and Hale [22]. Finally, all parameters, i.e. thickness and optical dispersion, were fit using the B-Spline function.

For the temperature-controlled measurements, exactly the same approach was followed, with the exception that the temperature-dependent optical model for silicon was selected.

\subsubsection{Conversion of extinction coefficient to absorption coefficient}

In order to be able to directly compare the results of spectroscopic ellipsometry, transmission intensity of spectroscopic ellipsometry, and UVVIS analysis, the extinction coefficient $k(-)$ was converted to the absorption coefficient $\alpha\left(\mathrm{nm}^{-1}\right)$ by $\alpha=4 \pi k / \lambda$, with $\lambda(\mathrm{nm})$ being the wavelength of the light. The transmission intensity $I(-)$ was converted to the absorbance by $A(-)$ by $A=-\ln \left(I / I_{0}\right)$, with $I_{0}(-)$ the intensity of the incident beam before transmission. 


\subsection{Results and discussion}

\subsubsection{Influence of the counter-ion on the thermal stability of SPEEK}

Figure 6-2 shows the mass loss and evolved gases that are detected upon heating of $\mathrm{H}$-SPEEK, Na-SPEEK, $\mathrm{H}^{\star}$-SPEEK, and PEEK. In these spectra, the identical low mass loss below $200{ }^{\circ} \mathrm{C}$ is accompanied by the release of water and can be attributed to removal of absorbed water from the material. For H-SPEEK, mass loss associated with removal of water, $\mathrm{CO}_{2}$ and $\mathrm{SO}_{2}$ sets on at $250{ }^{\circ} \mathrm{C}$. There are two possible origins for the evolution of $\mathrm{SO}_{2}$ : the sulfonate group, or residual sulfuric acid. The presence of the latter has been proposed for SPEEK with high degrees of sulfonation [6]. Indeed, the release of $\mathrm{SO}_{2}$ takes place close to the boiling point of $\mathrm{H}_{2} \mathrm{SO}_{4}$ [23]. To verify this hypothesis, Na-SPEEK, for which this peak was absent, was back-converted to $\mathrm{H}^{*}$-SPEEK, using hydrogen chloride to avoid the sulfuric counter ion. The mass loss spectrum obtained for the $\mathrm{H}^{\star}$-form is strikingly similar to that of the original $\mathrm{H}$-form, thus rejecting the hypothesis that residual $\mathrm{H}_{2} \mathrm{SO}_{4}$ is the sulfur source in the $\mathrm{SO}_{2}$ formation. Hence, it can be concluded that the sulfonate group is the origin of the $\mathrm{SO}_{2}$, and that exchange of the proton by sodium prevents the reaction that produces the $\mathrm{SO}_{2}$. The exact mechanism will be discussed in more detail in the section on ${ }^{1} \mathrm{H}-\mathrm{NMR}$. The absence of this $\mathrm{SO}_{2}$-loss in the sodiumexchanged $\mathrm{Na}$-SPEEK is a direct evidence of the enhanced thermal stability of the Na-SPEEK over H-SPEEK.

Between 450 and $650{ }^{\circ} \mathrm{C}$, all SPEEK-forms show a strong mass loss, associated with the evolution of $\mathrm{CO}_{2}$ and $\mathrm{SO}_{2}$, followed by a release of aromatic compounds. The evolution of $\mathrm{SO}_{2}$ indicates that sulfonate groups were still present at these temperatures in both materials. For H-SPEEK, the release of $\mathrm{SO}_{2}$ in two distinct steps with onsets at $\sim 250{ }^{\circ} \mathrm{C}$ and $\sim 500{ }^{\circ} \mathrm{C}$ is an indication for the presence of sulfur in two different forms in the material.

Exchange of the $\mathrm{H}^{+}$by $\mathrm{Na}^{+}$suppresses the reaction responsible for the release of $\mathrm{SO}_{2}$ at $250{ }^{\circ} \mathrm{C}$. The sulfur that is not released at $250{ }^{\circ} \mathrm{C}$ is mostly 
released at $500{ }^{\circ} \mathrm{C}$, manifested by a higher mass loss at this temperature. In the past, the $\mathrm{SO}_{2}$ release from H-SPEEK was recorded in a single step at $300{ }^{\circ} \mathrm{C}$ [17]. The discrepancy with the SPEEK in this study is not fully clear; possible, it is a result of a difference in sulfonation degree $(84 \%$ in this study, unknown in [17]).
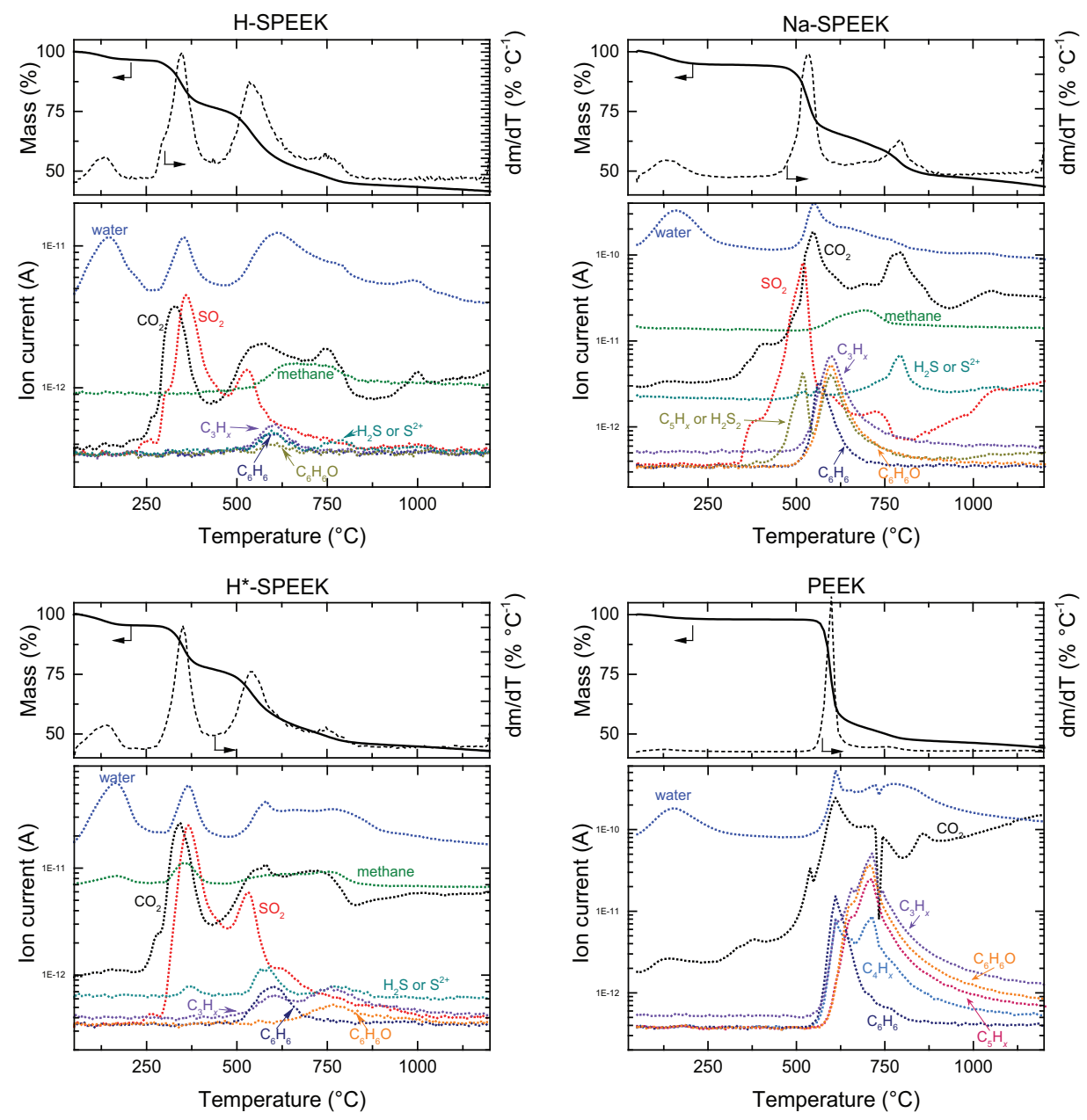

Figure 6-2: TGA-MS spectra of H-SPEEK (top left), Na-SPEEK (top right), $\mathrm{H}^{\star}$-SPEEK (bottom left) and PEEK (bottom right), all recorded with a heating rate of $20^{\circ} \mathrm{C} \mathrm{min-1}$ under a nitrogen atmosphere. 


\section{H-SPEEK}

before

heating

\section{MESA+}

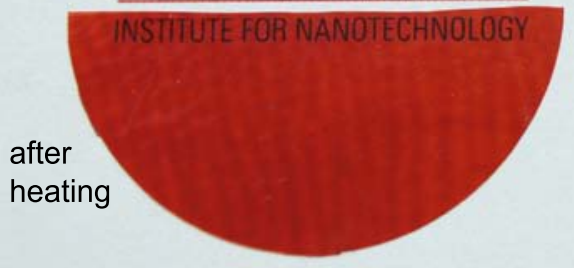

\section{Na-SPEEK}

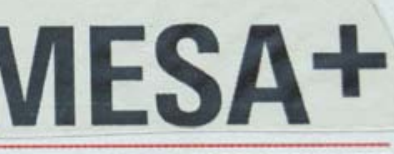

INSTITUTE FOR NANOTECHNOLOGY

Figure 6-3: Photos of H-SPEEK (left) and Na-SPEEK (right) before (top) and after heating (bottom) in nitrogen to $190{ }^{\circ} \mathrm{C}$ for 15 hours.

Around $750{ }^{\circ} \mathrm{C}$, a final mass loss step takes place that is accompanied by the release of $\mathrm{CO}_{2}$. A similar step is observed in the case of PEEK. This implies that the $\mathrm{CO}_{2}$-loss is due to degradation of the polymer backbone, and is independent on the sulfonation history of the polymer.

Figure 6-3 visualizes the differences between the proton and sodium forms after thermal treatment of both films. Here, the films are shown before and after heating to $190 \pm 10{ }^{\circ} \mathrm{C}$ for 15 hours. Before thermal treatment, both films are transparent, and the H-SPEEK has a yellowish appearance. After heating the material, the strong color change into red in the H-SPEEK confirms the substantial chemical changes in the material.

Although at this temperature the TGA results do not reveal significant mass changes of the material, nor the release of gaseous degradation products, the long dwell time can significantly increase the progress of the reaction [24]. The red color of the treated H-SPEEK is a manifestation of the development of one or more chromophoric groups below $\lambda=580 \mathrm{~nm}$. Most likely, an increase in the conjugation of the network due to thermal cross-linking is the cause for the increased absorption. After the thermal treatment, H-SPEEK has lost its flexibility and has turned into a brittle 
material. In contrast to the reversible properties that have been reported previously for short-term treatments [25], the color change after the longterm treatment is irreversible.

The thermally induced changes in the NMR-spectrum of SPEEK, shown in Figure 6-4, are another demonstration of the distinct characteristics of the proton and sodium form of SPEEK. The results and agree well to results previously reported in literature [26]. For correctly discerning the $\mathrm{H}_{\mathrm{A}}$, and $\mathrm{H}_{\mathrm{A}}$-protons, a $2 \mathrm{D}(1 \mathrm{H} \mathrm{COSY})$ spectrum was used (see Appendix, Figure 6-A8). As can be seen from the spectrum, the exchange of the sulfonate proton by a sodium ion results in a slight deshielding of the $\mathrm{H}_{\mathrm{E}}$-proton, resulting in a small downfield shift. A similar effect is seen for the $\mathrm{H}_{\mathrm{B}}$-protons. The sodium exchange did not influence any of the other peaks. For the sodium form, the thermal treatment step induced no changes at all in the material's structure. For H-SPEEK, definite changes are introduced by the thermal treatment, resulting in strong changes in the chemical environment of the protons. Although most peaks remain visible, strong peak broadening has occurred. Peak broadening can typically be a result of reduced mobility of the studied molecules and can therefore be an indication of crosslinking reactions.

As a single peak without overlap with other peaks, the $\mathrm{H}_{\mathrm{C}}$-peak is an ideal peak to study the effects of (de)sulfonation. Upon desulfonation, the removal of one sulfonate group results in the creation of four $\mathrm{H}_{\mathrm{C}}$-protons at the expense of the $\mathrm{H}_{\mathrm{C}}, \mathrm{H}_{\mathrm{D}}$, and $\mathrm{H}_{\mathrm{E}}$, peaks. Indeed, the ${ }^{1} \mathrm{H}-\mathrm{NMR}$ spectrum shows a significant increase in the $\mathrm{H}_{\mathrm{C}}$-peak, confirming the occurrence of desulfonation reactions. This conclusion is further supported by the decrease of the $\mathrm{H}_{\mathrm{A}}, \mathrm{H}_{\mathrm{B}}, \mathrm{H}_{\mathrm{D}}$, and $\mathrm{H}_{\mathrm{E}}$-peaks, and in line with spectra of SPEEK at lower sulfonation degrees [21]. The 2D (1H COSY) spectrum (see Appendix, Figure 6-A9 and Figure 6-A10) confirms the presence of three new groups of coupled protons with apparent downfield shifts from the base material, indicating the occurrence of side reactions during the desulfonation. 

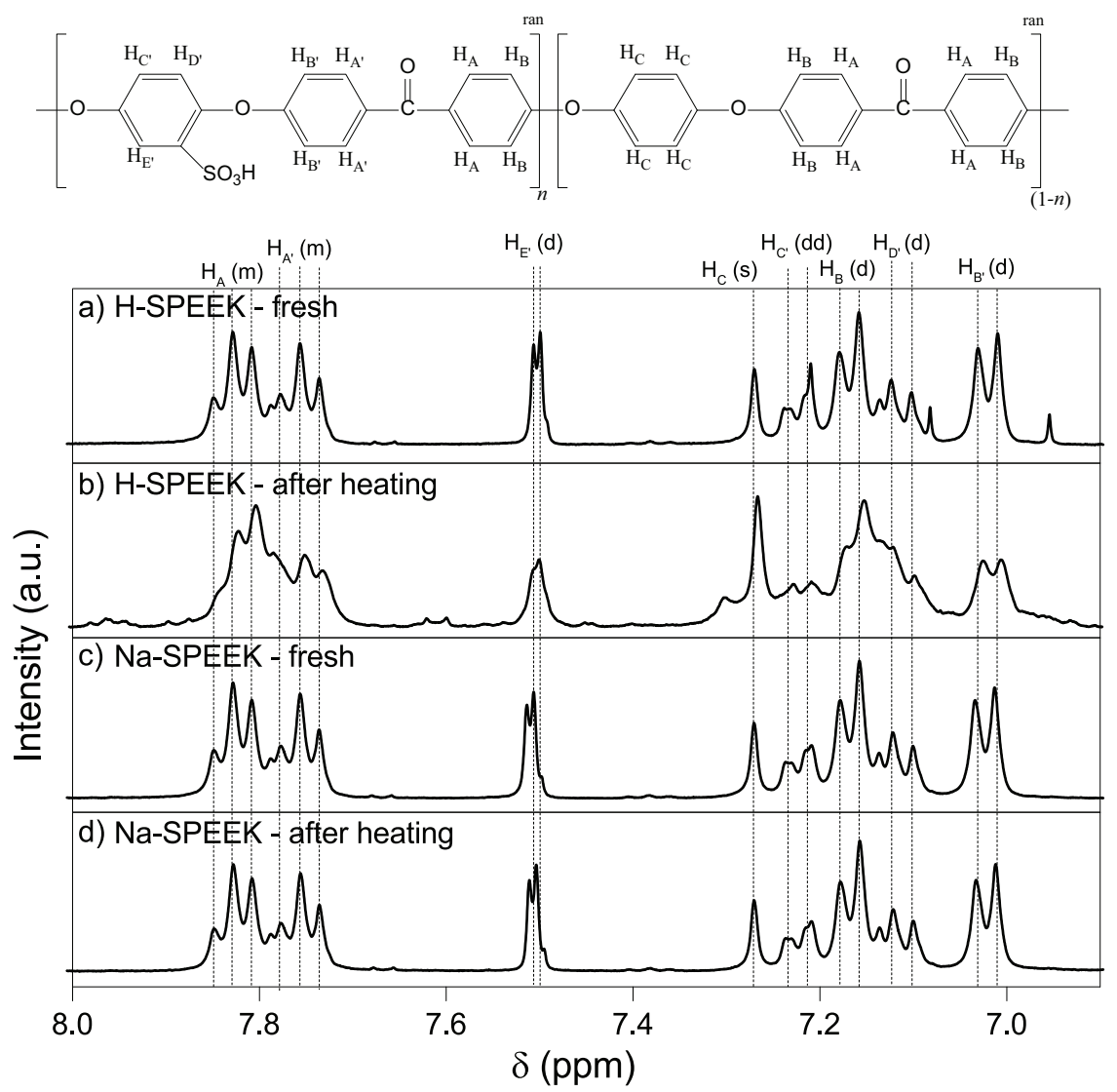

Figure 6-4: Top panel: 1H-NMR spectra of H-SPEEK and Na-SPEEK before and after thermal treatment at $190{ }^{\circ} \mathrm{C}$ for 15 hours. Assignments given at the top of the graph are for fresh H-SPEEK. Bottom panel: structural formula of H-SPEEK with proton assignment.

From the NMR-spectrum of SPEEK, the degree of sulfonation can be determined [21]. For the untreated H-SPEEK and both untreated and treated Na-SPEEK, this calculation could be applied accurately. For all three SPEEK-types, the degree of sulfonation was determined to be unchanged at $84 \%$, indicating no structural changes in these polymers. For the treated H-SPEEK, the apparent degree of sulfonation was calculated to be $65 \%$ after treating at $190{ }^{\circ} \mathrm{C}$ for $15 \mathrm{~h}$. Because some changes in the 140 
spectrum could not be assigned to specific groups, wrong groups can be included in the peak integration, and these values should be considered with caution. For the treatment at $163{ }^{\circ} \mathrm{C}$ at $15 \mathrm{~h}$, the loss of sulfonate groups from the material is supported by the detected release of $\mathrm{SO}_{2}$ in ICP-AES measurements (not shown here).

\subsubsection{Long-term stability of thin films}

Figure 6-5 shows the absorption spectra obtained by UV-VIS, by transmission mode ellipsometry, and reflectance mode ellipsometry.

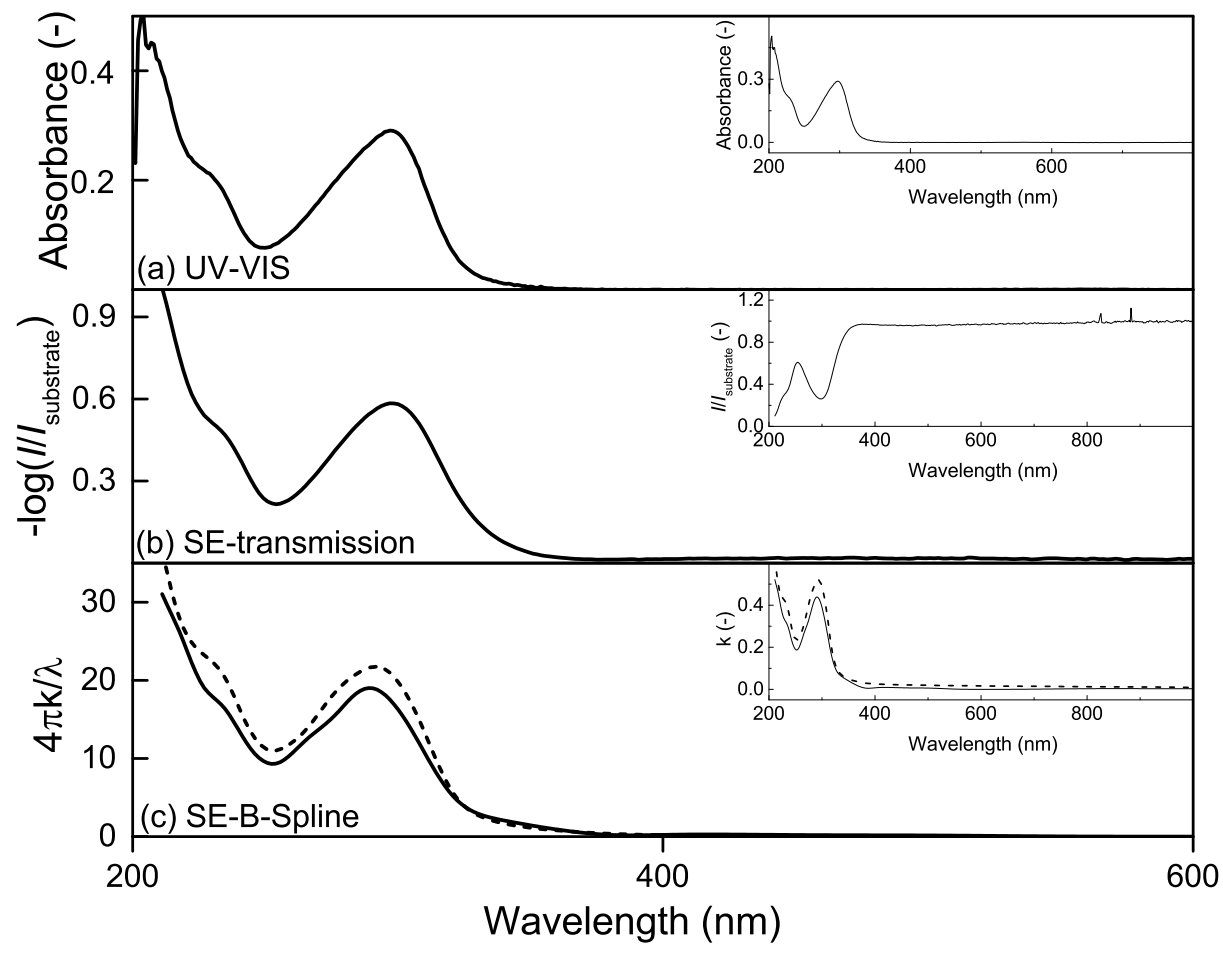

Figure 6-5: Absorption spectra of H-SPEEK (solid line) and PEEK (dashed line) determined by (a) UV-VIS on SPEEK dissolved in ethanol, (b) spectroscopic ellipsometry in transmission mode, and (c) spectroscopic ellipsometry B-spline modeling. All data were converted to a parameter that is linearly proportional to the absorbance. The inserts show the original data over the whole wavelength range. 
The close agreement between the spectra establishes ellipsometry as a suitable technique to study the changes in the thin supported films. This is in particular beneficial for polymers such as PEEK that have low solubility in common solvents, and are therefore difficult to study with, e.g., UVVIS. The close resemblance between the PEEK and H-SPEEK ellipsometry spectra indicate that the sulfonation of the polymer does not affect large changes in its light absorption properties.

The changes in the absorption spectrum of H-SPEEK upon prolonged exposure to a temperature of $163{ }^{\circ} \mathrm{C}$ are given in Figure 6-6. The red line corresponds to untreated $\mathrm{H}$-SPEEK and has the same shape as in Figure 6-5. The prolonged exposure to $163{ }^{\circ} \mathrm{C}$ for $15 \mathrm{~h}$ induced multiple changes in the absorption spectrum. The increase in absorbance at wavelengths higher than $320 \mathrm{~nm}$, and the slight decrease of the peak at $300 \mathrm{~nm}$, are in line with earlier observations made by temperature-controlled UV-VIS [25]. Notable is the development of two peaks at 250 and $260 \mathrm{~nm}$. The peak at $250 \mathrm{~nm}$ shows a progressive growth with increasing dwell times; the peak at $260 \mathrm{~nm}$ first appears but later disappears during the prolonged exposure to this temperature. The clear development of individual peaks corresponds to changes in the structure of SPEEK. Absorptions around 250 $\mathrm{nm}$ are generally associated with $n-\pi^{\star}$ transitions or with $\pi-\pi^{\star}$ transitions in conjugated systems [27]. It is therefore difficult to assign this peak specifically, as it can be due to non-bonding electrons of oxygen in either the sulfonate, the ether, or the carbonyl groups, or due to an increase in conjugation within the material because of thermal crosslinking. Treatment of H-SPEEK at temperatures of 183 and $193{ }^{\circ} \mathrm{C}$ (see Appendix, Figure 6-A11 and Figure 6-A12) resulted in similar, but more pronounced, trends. For $\mathrm{Na}$-SPEEK, treatment at $183{ }^{\circ} \mathrm{C}$ introduces only minor changes in the spectrum, indicating that the absence of the sulfonate proton prevents the thermal reactions from taking place (see Appendix, Figure 6-A11). 


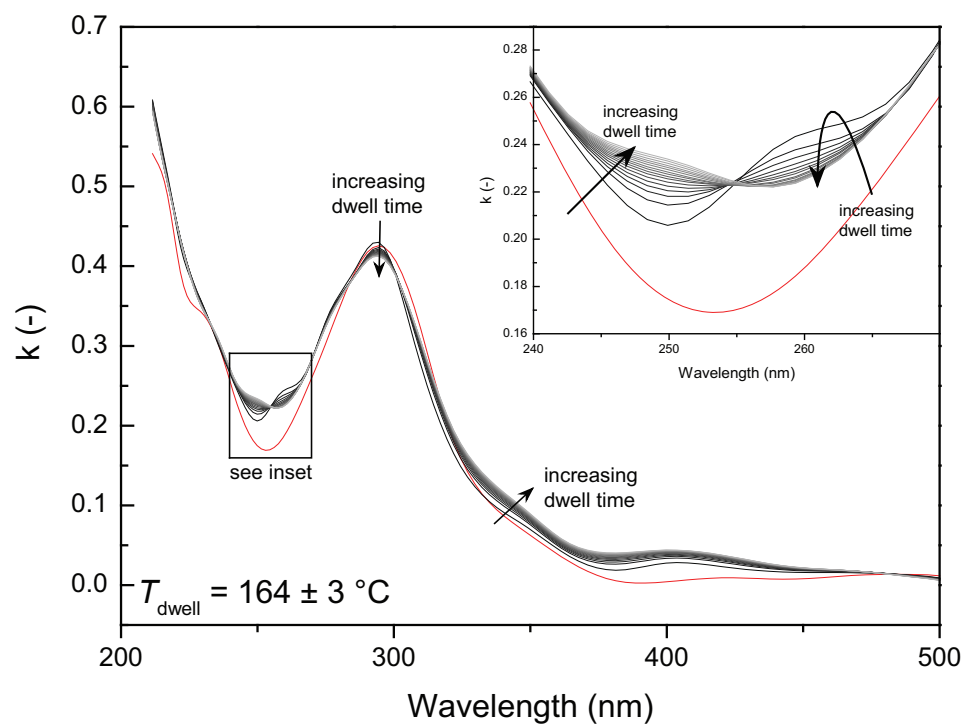

Figure 6-6: The absorption spectrum of H-SPEEK under nitrogen before thermal treatment (red) and after 0 (black) to 15 hours (light grey) of dwell at $164 \pm 3{ }^{\circ} \mathrm{C}$. The change between the untreated and the 0 -hour dwell samples is induced by the heating ramp.
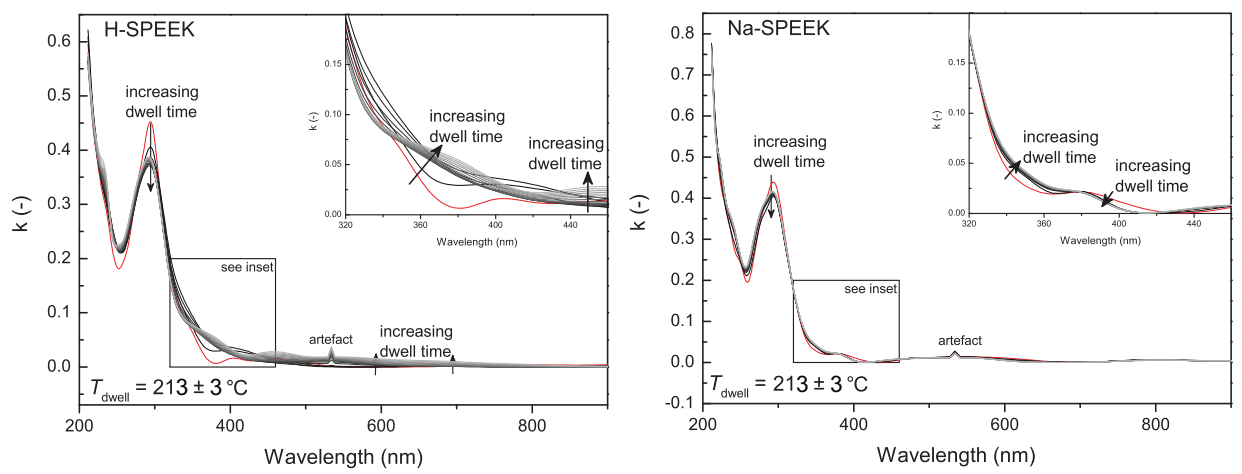

Figure 6-7: The absorption spectrum of H-SPEEK (left) and $\mathrm{Na}-$ SPEEK (right) under nitrogen before thermal treatment (red) and after 0 (black) to 15 hours (light grey) of dwelling at $213 \pm 3{ }^{\circ} \mathrm{C}$. The change between the untreated and the 0-hour dwell samples is induced by the heating ramp. 
At a treatment temperature of $220{ }^{\circ} \mathrm{C}$ (Figure 6-7) and higher (see Appendix, Figure 6-A13), the differences between the proton and sodium form are even more pronounced. Here, the region of interest is the wavelength range of $300 \mathrm{~nm}$ upwards, in which chromophoric behavior is typically limited to strongly conjugated structures [27]. For H-SPEEK, light absorption increases over nearly the full wavelength range, and strong changes take place around $\lambda=380 \mathrm{~nm}$. The increase in absorption is in line with the visual observations presented in Figure 6-3. For Na-SPEEK, the changes in the spectrum are limited to minor changes in the absorption in the 300-400 nm wavelength range.

\subsection{Conclusions}

The thermal stability of SPEEK (H-SPEEK) and its sodium-exchanged form (Na-SPEEK) has been studied at moderate temperatures of $150-250{ }^{\circ} \mathrm{C}$, in short heating rate experiments and for longer dwell times up to 15 hours. It is found that the thermal stability of SPEEK is strongly enhanced upon ion exchange of the sulfonate proton with a sodium ion. This exchange shifts the onset of the first mass loss (excluding drying) by $100 \backslash{ }^{\circ} \mathrm{C}$ to higher temperatures. This shift is attributed to the inhibited protodesulfonation reaction. Experiments in which the sodium form was back-converted to the proton form eliminate residual sulfuric acid as the cause for sulfur release at $250-350{ }^{\circ} \mathrm{C}$ [6]. In general, the obtained results are in good agreement to those reported in literature $[4,15,17]$. The absence of sulfonated solvents in our synthesis, and the fact that $\mathrm{H}_{2} \mathrm{SO}_{4}$ could be excluded as a sulfur source, is a strong indication for the involvement of the sulfonate groups for both mass losses. ${ }^{1} \mathrm{H}-\mathrm{NMR}$ data showed that the changes were mostly limited to the sulfonate group. This indicates the possibility of using specific thermal treatments to obtain SPEEK with a targeted degree of desulfonation. Because the second step of the desulfonation shows large overlap with the thermal decomposition, it is, however, not possible to fully desulfonate SPEEK into a PEEK film. 
For thin H-SPEEK films, during a dwell of 15 hours, irreversible changes could be recorded already at temperatures as low as $160{ }^{\circ} \mathrm{C}$. The results indicate that the structural integrity of H-SPEEK can be affected during moderate-temperature treatments, such as temperature-promoted crosslinking. For Na-SPEEK an improved thermal stability is observed up to temperatures of at least $210{ }^{\circ} \mathrm{C}$.

\subsection{Appendices}

\subsection{1. ${ }^{1} \mathrm{H}-\mathrm{COSY}$ NMR spectra}

Figure 6-A8 shows the ${ }^{1} \mathrm{H}$-COSY spectrum of fresh H-SPEEK for $\delta=6.9-8.0$. From the off-diagonal elements, the homonuclear correlation of protons can be determined. From the figure, the following peaks could be coupled:

- $\delta 7.17$ to $\delta 7.82$ (establishing that $\delta 7.82$ belongs to the $\mathrm{H}_{\mathrm{A}}$-proton);

- $\delta 7.02$ to $\delta 7.76$ (establishing that $\delta 7.76$ belongs to the $\mathrm{H}_{\mathrm{A}}$-proton);

- $\delta 7.22$ to $\delta 7.50$ (confirming the coupling between $\mathrm{H}_{\mathrm{C}}$ and $\mathrm{H}_{\mathrm{E}}$ );

- $\delta 7.22$ to $\delta 7.11$ (confirming the coupling between $\mathrm{H}_{\mathrm{C}^{\prime}}$ and $\mathrm{H}_{\mathrm{D}}$ );

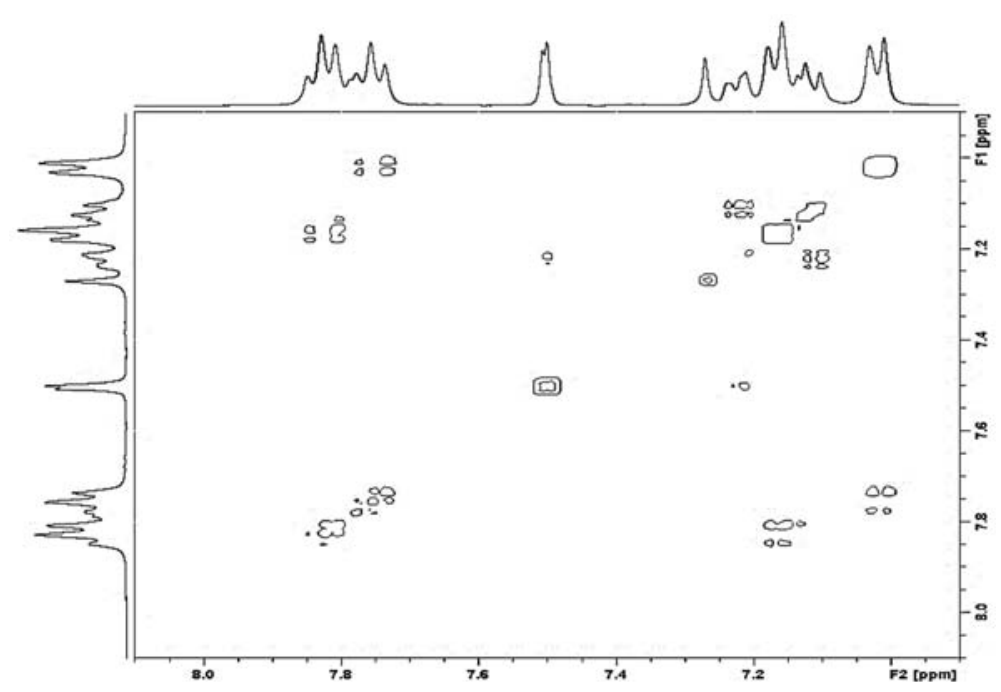

Figure 6-A8: ${ }^{1} \mathrm{H}$-COSY spectrum in $\mathrm{C}_{2} \mathrm{D}_{6} \mathrm{O}$ at $400 \mathrm{MHz}$ of fresh $\mathrm{H}-$ SPEEK. 
Figure 6-A9 shows the ${ }^{1} \mathrm{H}-\mathrm{COSY}$ spectrum of $\mathrm{H}-\mathrm{SPEEK}$ treated at 160 ${ }^{\circ} \mathrm{C}$ for 15 hours, for $\delta=6.9-8.1$. Again, the spectrum shows the correlation between the peaks as given above for the fresh SPEEK. However, in the spectrum, additional correlations can be found:

- $\delta 6.85$ to $\delta 7.55$

- $\delta 7.0$ to $\delta 7.7$ and to $\delta 7.95$

- $\delta 7.15$ to $\delta 8.03$

Figure 6-A10 shows the ${ }^{1} \mathrm{H}$-COSY spectrum of $\mathrm{H}$-SPEEK treated at 190 ${ }^{\circ} \mathrm{C}$ for 15 hours, for $\delta=6.9-8.1$. Please note that the H-SPEEK was treated in a different batch as the H-SPEEK given in the chapter, and that as a result, the treatment temperature may be slightly different. Again, the spectrum shows the correlation between the peaks as given above for the fresh SPEEK. However, in the spectrum, additional correlations can be found:

- $\delta 6.93$ to $\delta 7.6$

- $\delta 7.0$ to $\delta 7.7$ and to $\delta 7.95$

- $\delta 7.15$ to $\delta 8.03$

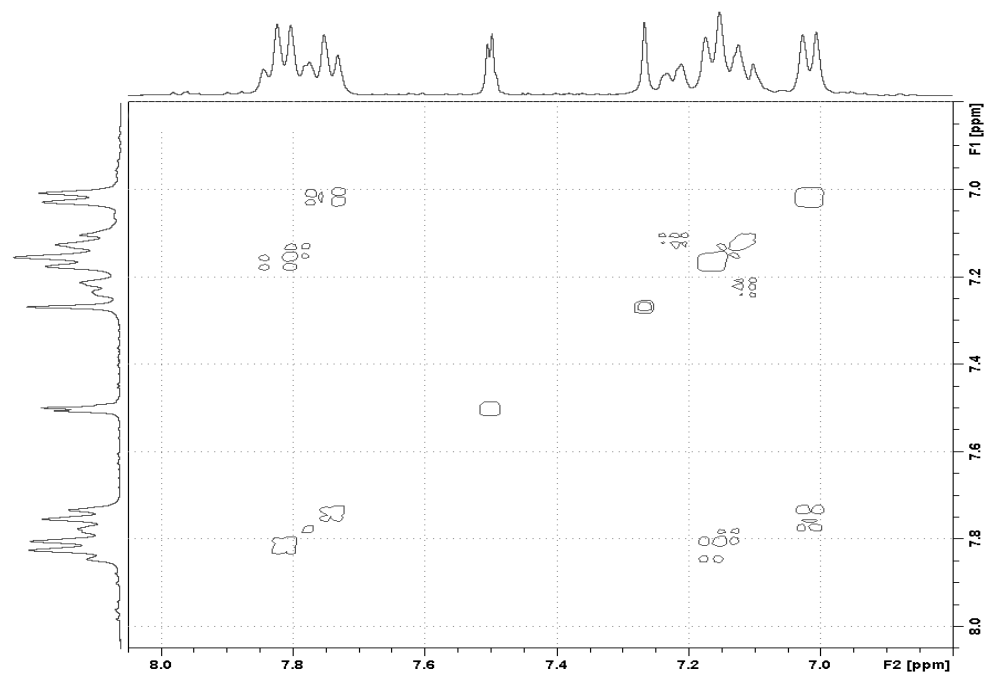

Figure 6-A9: ${ }^{1} \mathrm{H}$-COSY spectrum in $\mathrm{C}_{2} \mathrm{D}_{6} \mathrm{O}$ at $400 \mathrm{MHz}$ of $\mathrm{H}$-SPEEK treated at $160{ }^{\circ} \mathrm{C}$ for 15 hours. 


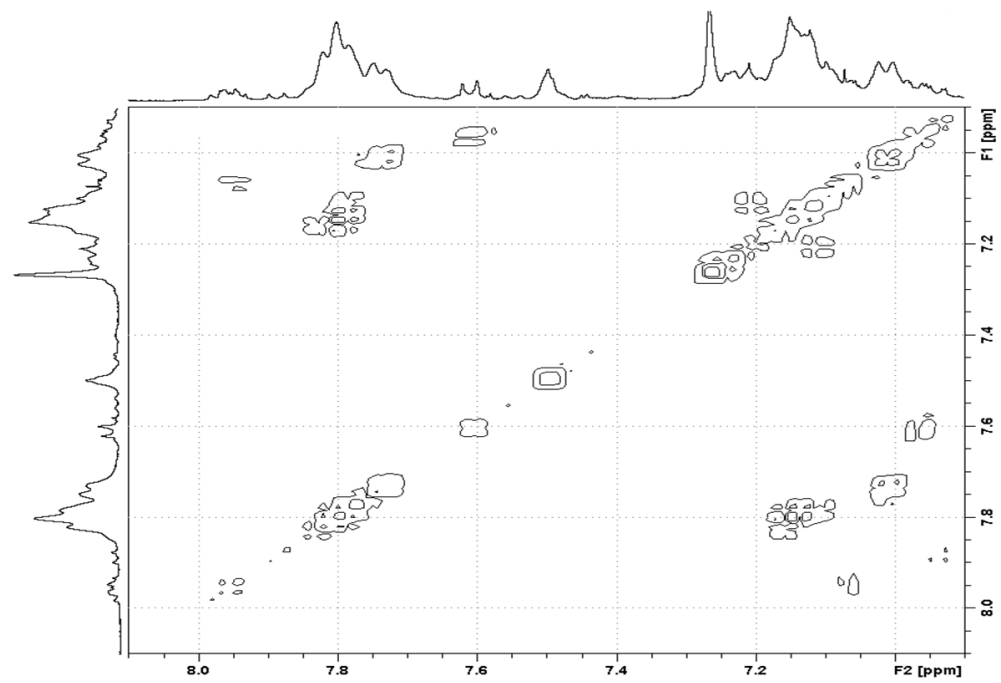

Figure 6-A10: ${ }^{1} \mathrm{H}$ COSY spectrum in $\mathrm{C}_{2} \mathrm{D}_{6} \mathrm{O}$ at $400 \mathrm{MHz}$ of $\mathrm{H}$-SPEEK treated at $190{ }^{\circ} \mathrm{C}$ for 15 hours. The chemical shift is not locked to the solvent peak.

Assigning these peaks to specific compounds is difficult, because of the numerous possible reactions that could occur in the material. The upfield shift of all these peaks is an indication of the increasing shielding of these protons. Furthermore, the correlation between the $\delta 7.0, \delta 7.67$ and $\delta 7.95$ indicates that these groups are part of the same structure.

\subsubsection{Absorption spectra H-SPEEK and Na-SPEEK}

In addition to the spectra already given in this chapter, the spectra in this appendix show the changes in the absorption of H-SPEEK and Na-SPEEK upon prolonged exposure to different temperatures between 180 and $250{ }^{\circ} \mathrm{C}$. Figure 6-A11 shows that the changes in H-SPEEK follow the same trend for treatment at 164 and $183{ }^{\circ} \mathrm{C}$. For the $183{ }^{\circ} \mathrm{C}$ treatment, the changes in the absorption peaks at $\sim 250 \mathrm{~nm}$ are stronger, and a significant absorption peak develops over the course of a 15-hour treatment. For NaSPEEK treated at the same temperatures, only minor changes are recorded. Figure 6-A12 shows that the changes in H-SPEEK at $193{ }^{\circ} \mathrm{C}$ are in line with those obtained at $183{ }^{\circ} \mathrm{C}$. No significant differences are seen between the spectra. 

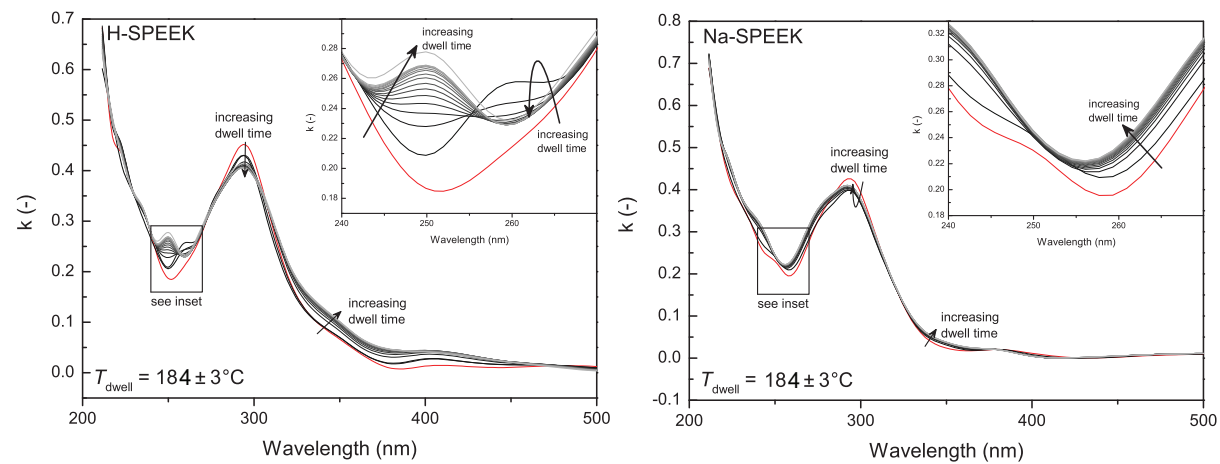

Figure 6-A11: The absorption spectrum of H-SPEEK and Na-SPEEK under nitrogen before thermal treatment (black) and after 0 to 15 hours (light grey) of dwell at $184 \pm 3{ }^{\circ} \mathrm{C}$. The change between the untreated and the 0 -hour dwell samples is induced by the heating ramp.

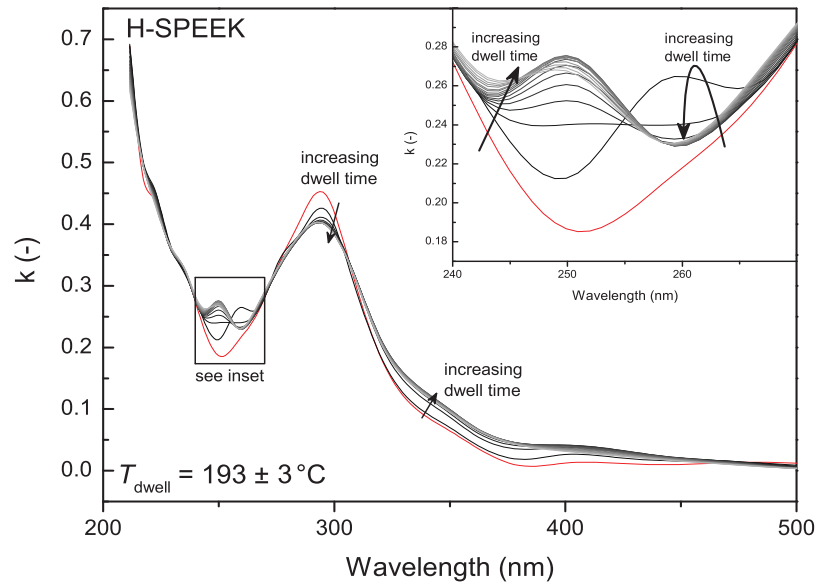

Figure 6-A12: The absorption spectrum of H-SPEEK under nitrogen before thermal treatment (black) and after 0 to 15 hours (light grey) of dwell at $193 \pm 3{ }^{\circ} \mathrm{C}$. The change between the untreated and the 0 hour dwell samples is induced by the heating ramp. 


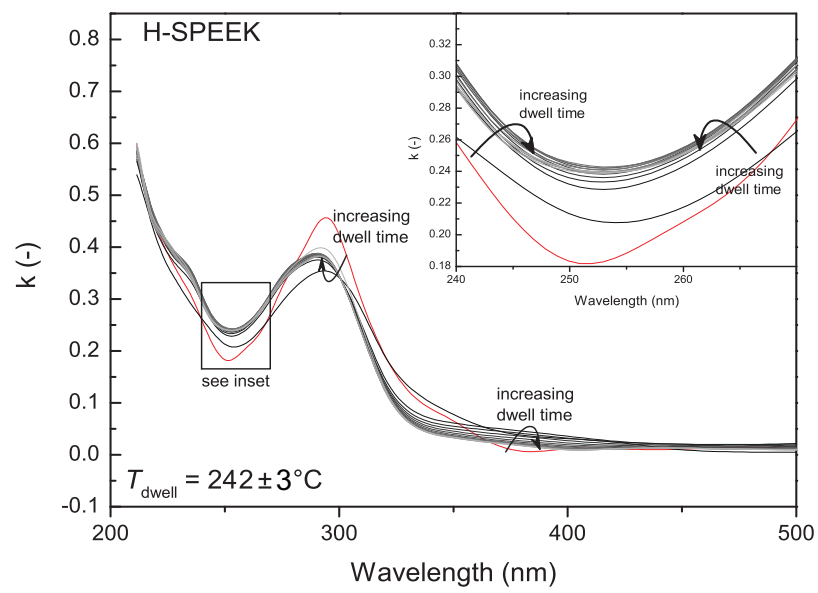

Figure 6-A13: The absorption spectrum of H-SPEEK under nitrogen before thermal treatment (black) and after 0 to 15 hours (light grey) of dwell at $242 \pm 3{ }^{\circ} \mathrm{C}$. The change between the untreated and the 0 hour dwell samples is induced by the heating ramp.

In addition to the figures in the chapter, Figure 6-A13 substantiates the pronounced differences in the absorption spectra of H-SPEEK when heating to temperatures higher than $210^{\circ} \mathrm{C}$.

\subsection{References}

1. He, T., Frank, M., Mulder, M.H.V. \& Wessling, M., 2008, Preparation and characterization of nanofiltration membranes by coating polyethersulfone hollow fibers with sulfonated poly(ether ether ketone) (SPEEK). J. Membr. Sci. 307, pp. 62-72. (doi:10.1016/j.memsci.2007.09.016)

2. Ba, C. \& Economy, J., 2010, Preparation and characterization of a neutrally charged antifouling nanofiltration membrane by coating a layer of sulfonated poly(ether ether ketone) on a positively charged nanofiltration membrane. $J$. Membr. Sci. 362, pp. 192-201. (doi:10.1016/j.memsci.2010.06.032)

3. Bowen, W.R., Doneva, T.A. \& Yin, H., 2002, Separation of humic acid from a model surface water with PSU / SPEEK blend UF / NF membranes. J. Membr. Sci. 206, pp. 417-429. (doi:10.1016/S0376-7388(01)00786-4)

4. Carbone, A., Pedicini, R., Portale, G., Longo, A., D’llario, L. \& Passalacqua, E., 2006, Sulphonated poly(ether ether ketone) membranes for fuel cell application: 
Thermal and structural characterisation. J. Power Sources 163, pp. 18-26. (doi:10.1016/j.jpowsour.2005.12.066)

5. Jörissen, L., Gogel, V., Kerres, J. \& Garche, J., 2002, New membranes for direct methanol fuel cells. J. Power Sources 105, pp. 267-273. (doi:10.1016/S03787753(01)00952-1)

6. Kaliaguine, S., Mikhailenko, S.., Wang, K.., Xing, P., Robertson, G. \& Guiver, M., 2003, Properties of SPEEK based PEMs for fuel cell application. Catal. Today 82, pp. 213-222. (doi:10.1016/S0920-5861(03)00235-9)

7. Giuseppin, M.L.F., Smits, P.J. \& Hofland, G.W., 2012, Subcritical gas assisted drying of biopolymer material. US2012/0316331 A1.

8. Jia, L., Xu, X., Zhang, H. \& Xu, J., 1996, Sulfonation of Polyetheretherketone and its effects on permeation behavior to nitrogen and water vapor. J. Appl. Polym. Sci. 60, pp. 1231-1237. (doi:10.1002/(SICI)1097-4628(19960523)60:8<1231::AIDAPP16>3.0.CO;2-4)

9. Sijbesma, H., Nymeijer, K., van Marwijk, R., Heijboer, R., Potreck, J. \& Wessling, M., 2008, Flue gas dehydration using polymer membranes. J. Membr. Sci.313, pp. 263-276. (doi:10.1016/j.memsci.2008.01.024)

10. Zhang, J. et al., 2006, High temperature PEM fuel cells. J. Power Sources 160, pp. 872-891. (doi:10.1016/j.jpowsour.2006.05.034)

11. Alberti, G., Casciola, M., Massinelli, L. \& Bauer, B., 2001, Polymeric proton conducting membranes for medium temperature fuel cells $\left(110-160^{\circ} \mathrm{C}\right)$. J. Membr. Sci. 185, pp. 73-81. (doi:10.1016/S0376-7388(00)00635-9)

12. Khan, A.L., Li, X. \& Vankelecom, I.F.J., 2011, Mixed-gas CO2/CH4 and CO2/N2 separation with sulfonated PEEK membranes. J. Membr. Sci. 372, pp. 8796. (doi:10.1016/j.memsci.2011.01.056)

13. Di Vona, M.L., Sgreccia, E., Licoccia, S., Alberti, G., Tortet, L. \& Knauth, P., 2009, Analysis of temperature-promoted and solvent-assisted cross-linking in sulfonated poly(ether ether ketone) (SPEEK) proton-conducting membranes. $J$. Phys. Chem. B 113, pp. 7505-12. (doi:10.1021/jp9006679)

14. Mikhailenko, S.D., Wang, K., Kaliaguine, S., Xing, P., Robertson, G.P. \& Guiver, M.D., 2004, Proton conducting membranes based on cross-linked sulfonated poly(ether ether ketone) (SPEEK). J. Membr. Sci. 233, pp. 93-99. (doi:10.1016/j.memsci.2004.01.004)

15. Maranesi, B., Hou, H., Polini, R., Sgreccia, E., Alberti, G., Narducci, R., Knauth, P. \& Di Vona, M.L., 2013, Cross-Linking of Sulfonated Poly(ether ether ketone) by Thermal Treatment: How Does the Reaction Occur? Fuel Cells 13, pp. 107117. (doi:10.1002/fuce.201200010)

16. Jin, X., Bishop, M.T., Ellis, T.S. \& Karasz, F.E., 1985, A sulphonated poly(aryl ether ketone). Br. Polym.J. 17, pp. 4-10. (doi:10.1002/pi.4980170102) 
17. Knauth, P., Hou, H., Bloch, E., Sgreccia, E., Vona, M.L. Di \& Di Vona, M.L., 2011, Thermogravimetric analysis of SPEEK membranes: Thermal stability, degree of sulfonation and cross-linking reaction. J. Anal. Appl. Pyrolysis 92, pp. 361-365. (doi:10.1016/j.jaap.2011.07.012)

18. Hou, H., Di Vona, M.L. \& Knauth, P., 2012, Building bridges: Crosslinking of sulfonated aromatic polymers-A review. J. Membr. Sci. 423-424, pp. 113-127. (doi:10.1016/j.memsci.2012.07.038)

19. Wanders, A.C.M. \& Cerfontain, H., 1967, Kinetics of the desulfonation of benzenesulfonic acid and the toluenesulfonic acids in aqueous sulfuric acid. Recl. des Trav. chiqmiques des Pays-Bas 86, pp. 1199-1216. (doi:10.1002/recl.19670861106)

20. Shibuya, N. \& Porter, R.S., 1992, Kinetics of PEEK Sulfonation in Concentrated Sulfuric Acid. Macromolecules 25, pp. 6495-6499. (doi:10.1021/ma00050a017)

21. Zaidi, S.M.., Mikhailenko, S.., Robertson, G.., Guiver, M.. \& Kaliaguine, S., 2000, Proton conducting composite membranes from polyether ether ketone and heteropolyacids for fuel cell applications. J. Membr. Sci. 173, pp. 17-34. (doi:10.1016/S0376-7388(00)00345-8)

22. Johs, B. \& Hale, J.S., 2008, Dielectric function representation by B-splines. Phys. Status Solidi 205, pp. 715-719. (doi:10.1002/pssa.200777754)

23. Lide, D.R., , editor 2007, Physical Constants of Organic Compounds. In CRC Handbook of Chemistry and Physics, Boca Raton, FL: Taylor and Francis.

24. Vyazovkin, S., Burnham, A.K., Criado, J.M., Pérez-Maqueda, L.A., Popescu, C. \& Sbirrazzuoli, N., 2011, ICTAC Kinetics Committee recommendations for performing kinetic computations on thermal analysis data. Thermochim. Acta 520, pp. 1-19. (doi:10.1016/j.tca.2011.03.034)

25. Jarumaneeroj, C., Tashiro, K. \& Chirachanchai, S., 2014, Shifting from Hydrogen Bond Network to $\pi-\pi$ Stacking: A Key Mechanism for Reversible Thermochromic Sulfonated Poly(Ether Ether Ketone). Macromol. Rapid Commun. 35, pp. 1397-1401. (doi:10.1002/marc.201400186)

26. Robertson, G.P., Mikhailenko, S.D., Wang, K., Xing, P., Guiver, M.D. \& Kaliaguine, S., 2003, Casting solvent interactions with sulfonated poly(ether ether ketone) during proton exchange membrane fabrication. J. Membr. Sci. 219, pp. 113-121. (doi:10.1016/S0376-7388(03)00193-5)

27. Pretsch, E., Bühlmann, P. \& Badertscher, M., 2009, Structure Determination of Organic Compounds. Tables of Spectral Data. 4th, revis. Heidelberg: Springer. ISBN: 9783540938095(doi:10.1007/978-3-540-93810-1) 



\section{Chapter 7}

\section{Thermal imidization kinetics of ultrathin films of hybrid poly(POSS-imide)s}

This chapter has been submitted for publication:

Raaijmakers, M.J.T., E.J. Kappert, A. Nijmeijer, N.E. Benes, Thermal imidization kinetics of ultrathin films of hybrid poly(POSS imide)s, submitted for publication 


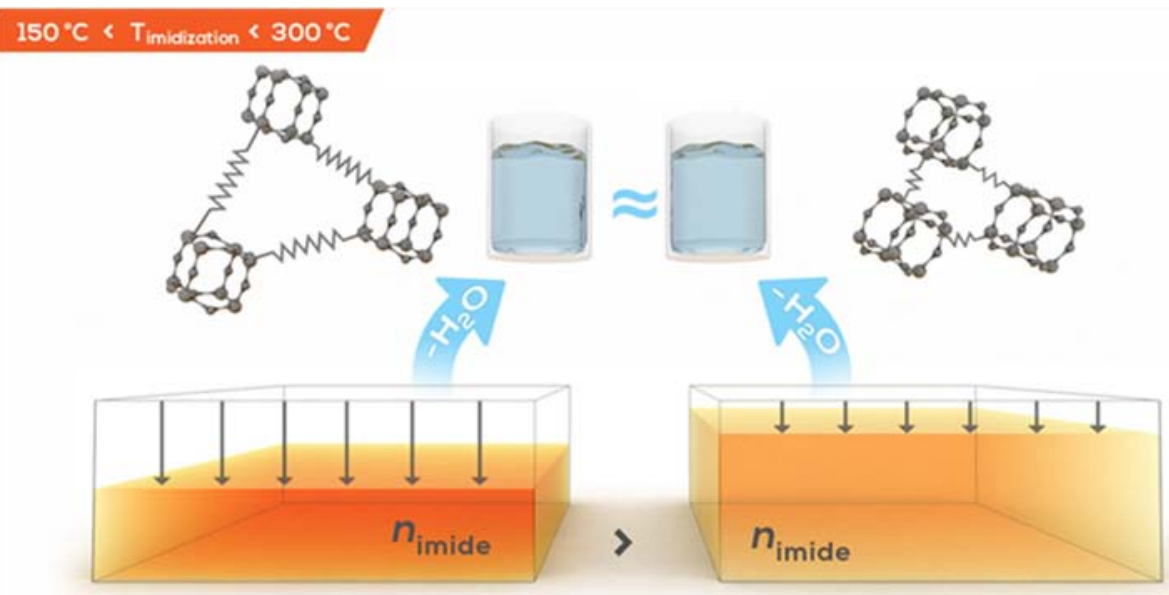

\section{Abstract}

In the thermal imidization of an alternating inorganic-organic hybrid network, there is an inverse relation between the length of the organic bridges and the extent of the dimensional reduction. The hybrid materials consist of polyhedral oligomeric silsesquioxanes that are covalently bridged by (amic acid) groups. During heat treatment, shrinkage of the materials occurs due to removal of physically bound water, imidization of the (amic acid) groups, and silanol condensation. For five different bridging groups, with different lengths, comparable mass reduction of the materials is observed. For the shorter bridging groups, the dimensional changes are hampered by the limited network mobility. Longer, more flexible, bridging groups allow for much more shrinkage. The imidization step can only be described by a decelerating reaction mechanism with an onset at $150{ }^{\circ} \mathrm{C}$ and shows a higher activation energy than in the case of entirely organic polyimides. The distinct imidization kinetics underline the hybrid materials characteristics of the hyper-cross-linked materials. 


\subsection{Introduction}

Hybrid network materials exhibit properties that are distinct from their individual organic and inorganic constituents. These unique properties are a result of the interplay between flexible organic bridges and rigid inorganic domains [1-3]. Due to their chemical and thermal stability, aromatic imides are relevant candidates for the organic component in hybrid polymers. Most of these hybrid polyimides are based on sol-gelderived silica-imide networks or polyhedral oligomeric silsesquioxanes (POSS)-derived materials [4,5]. These POSS-derived materials can consist of either a network of alternating POSS and imide groups [6-8] POSS cages that are covalently bound to oligomeric imides [9-13], or POSS cages that are tethered to a polyimide main chain as side or end group $[14,15]$.

To synthesize polyimide-based hybrid polymers, poly(amic acid) precursors are thermally processed to convert the amic acid groups to chemically and thermally robust imide groups. As compared to fully organic poly(amic acid)s, differences in the mobility of the functional groups in the hybrid material can strongly affect the imidization reaction kinetics and structural rearrangements [8]. A thermal processing strategy designed for an organic imide can therefore not simply be applied for its hybrid counterpart. Only a few studies report on the changes in the physical properties during thermal treatment of hybrid polyimides $[10,16,17]$. Often, only the properties before and after the imidization step are measured, and the mechanisms of the thermally activated processes remain a black box.

Optimization of the thermal treatment step is crucial for obtaining a fully imidized material without significant decomposition of the organic moieties. Thermal imidization of hybrid imides most often needs to be performed in the solid state, because of the limited solubility of the highly cross-linked networks. Solid-state thermal imidization has been studied ex situ by UV-VIS [18,19] infrared [19] and Raman spectroscopy [20]. In 
situ tracking of the imidization can be performed by TGA-MS [21], in-situ infrared spectroscopy [22], and interferometry [23-25]. The obtained data can be used to study the reaction kinetics. Past studies on reactions unanimously agree on a decelerating reactivity [20; 26-29]; firstorder reaction models [26-28] and diffusion models [29] have both been proposed. Most of these studies are performed on bulk materials, whereas in many applications the materials are used as thin films. It is well known that for ultra-thin films the length-scale confinement can affect the time scale of diffusion-limited processes and thus result in different apparent kinetics.

Here, we explore the co-current imidization and structural rearrangements of ultrathin POSS-based hybrid materials by a combination of timeresolved techniques. The changes to the materials chemistry in the bulk have been studied by means of TGA-MS, allowing for assignment of mass loss processes to specific chemical reactions. Thermo-ellipsometric analysis (TEA) has been applied to follow the changes in the layer thickness and refractive index during thermal treatment. To assess the influence of the organic moiety on the behavior of the hybrid material, the five different organic linking groups, given in Figure 7-1, have been studied. We conclude that the length of the dianhydride precursor is an important factor that influences network mobility during the imidization, resulting in lower density films for shorter bridges. 
<smiles>Nc1cc2cc3c(cc2c(=O)o1)C(=O)OC3=O</smiles>

PMDA<smiles>O=C1OC(=O)c2cc(-c3ccc4c(c3)C(=O)OC4=O)ccc21</smiles>

BPDA<smiles>O=C1OC(=O)c2cc(Oc3ccc4c(c3)C(=O)OC4=O)ccc21</smiles><smiles>CC(C)(c1ccc(Oc2ccc3c(c2)C(=O)OC3=O)cc1)c1ccc(Oc2ccc3c(c2)C(=O)OC3=O)cc1</smiles>

BPADA<smiles>O=C1OC(=O)c2cc(C(c3ccc4c(c3)C(=O)OC4=O)(C(F)(F)F)C(F)(F)F)ccc21</smiles>

Figure 7-1: Structural formulas of the dianhydrides used as a precursor for crosslinking the POSS-cages.

\subsection{Experimental section}

7.2.1. Synthesis of poly[POSS-(amic acid)]s by interfacial polymerization.

Synthesis of poly[POSS-(amic acid)]s by interfacial polymerization. Toluene (anhydrous $99.8 \mathrm{wt} \%$, Sigma-Aldrich), 4,4-(hexafluoroisopropylidene) diphthalic anhydride (6FDA, Sigma-Aldrich), pyromellitic dianhydride (PMDA, Sigma-Aldrich), 3,3',4,4'-biphenyl tetracarboxylic dianhydride (BPDA, Sigma-Aldrich), 4,4'-oxydiphthalic anhydride (ODPA, Sigma-Aldrich), 4,4'-(4,4'-isopropylidene diphenoxy) bis(phthalic anhydride) (BPADA, Sigma-Aldrich) and ammonium chloride-functionalized POSS (octa-ammonium POSS ${ }^{\circledR}$, Hybrid Plastics) and sodium hydroxide ( $\mathrm{NaOH}$, Sigma-Aldrich) were used as received. The POSS was dissolved in water. To partially convert the ammonium groups to reactive amine groups, the $\mathrm{pH}$ was adjusted to 9.9 using $1 \mathrm{M} \mathrm{NaOH}$. Bulk poly[POSS(amic acid)] was prepared by vigorously stirring a mixture of a $0.9 \mathrm{wt}-\%$ aqueous solution of octa-ammonium POSS and a $0.075 \mathrm{wt} \%$ dianhydride solution in toluene, which was filtered to remove any undissolved dianhydride. After reacting for several hours, toluene and water were removed from the poly[POSS-(amic acid)] by vacuum filtration using a Büchner funnel, followed by rinsing with acetone to remove residual reactants. 
Poly[POSS-(amic acid)] membranes were prepared by interfacial polymerization atop a $\gamma$-alumina coated $\alpha$-alumina discs. The $\alpha$-alumina discs were pre-wetted with the $0.9 \mathrm{wt}-\%$ aqueous POSS-solution for $15 \mathrm{~min}$ at $500 \mathrm{mbar}$ vacuum, followed by $30 \mathrm{~min}$ drying at room temperature. Subsequently, a solution of the dianhydride in toluene was poured onto the discs. After 5 minutes, the toluene was removed and the samples were rinsed with acetone.

\subsubsection{Characterization of thin films.}

Thermogravimetric analysis (TGA) was performed using an STA 449 F3 Jupiter® (Netzsch), equipped with a TG-only sample holder. Measurements were performed under $70 \mathrm{ml} \mathrm{min}^{-1} \mathrm{~N}_{2}$ flow, with a heating rate of $20{ }^{\circ} \mathrm{C} \mathrm{min}{ }^{-1}$, from 50 to $1200{ }^{\circ} \mathrm{C}$. Temperature calibration was done using melting standards. Measurements were run sample-temperature controlled. Sample masses were determined by an internal balance exactly 30 min after inserting the sample. Using a consistent residence time in the purge gas prior to measurement was found to be a crucial parameter to obtain reproducible TGA-graphs. Gases evolving during the thermosgravimetric analysis were transferred to a mass spectrometer (QMS 403D Aëolos®, Netzsch). TGA and MS start times were synchronized, but no correction was applied for the time offset caused by the transfer line time (estimated < $30 \mathrm{sec}$, systematic offset). First, a bar graph scan for $\mathrm{m} / \mathrm{z}=$ 1-100 amu was recorded for all poly(POSS-amic acid) samples in $\mathbf{N}_{2}$ atmosphere, to determine the evolving $\mathrm{m} / \mathrm{z}$-numbers (data not included here). The detected $\mathrm{m} / \mathrm{z}$-numbers were selected and recorded more accurately in multiple-ion-detection mode, with a dwell of 0.5 sec per $\mathrm{m} / \mathrm{z}$-value at a resolution of 50 .

\subsubsection{Kinetic analysis}

The samples that were designated for kinetic analysis were stored in vacuum at $30{ }^{\circ} \mathrm{C}$ for 24 hours prior to analysis, in order to remove any sorbed water. Measurements were performed under $70 \mathrm{ml} \mathrm{min} \operatorname{mon}^{-1}$, with heating rates $\beta$ of $5,10,15$, and $20{ }^{\circ} \mathrm{C} \mathrm{min}^{-1}$, from 50 to $1200{ }^{\circ} \mathrm{C}$. Blank 
corrections with an empty cup were carried out at every different heating rate. The mass loss was converted to the normalized conversion $(\alpha)$. Activation energies were determined following the modified advanced isoconversional method that allows for analyzing non-linear temperature programs and variation of the apparent activation energy with $\alpha$ [30-32]. The obtained activation energies were used as starting values for a multivariate analysis of the kinetics by a multistep parallel reaction model described by:

$$
\frac{\mathrm{d} \alpha_{i}}{\mathrm{~d} t}=A_{i} \exp \left[\frac{-E_{\mathrm{a}, i}}{R T(t)}\right] f_{i}(\alpha)
$$

Fitting of Equation 4-1 was performed by minimizing the residual sum of squares (RSS) between the data and the fit using the patternsearch algorithm in Matlab. The individual steps were fitted with 14 different reaction models Table 7-1, and the obtained RSS were used to determine the most accurate reaction model.

Table 7-1: Overview of possible reaction models, taken from [33]

\begin{tabular}{ll}
\hline Reaction model (name + abbreviation) & $\mathrm{f}(\alpha)$ \\
\hline Power law - P4 & $4 \alpha^{3 / 4}$ \\
Power law - P3 & $3 \alpha^{2 / 3}$ \\
Power law - P2 & $2 \alpha^{1 / 2}$ \\
Power law - P2/3 & $2 / 3 \alpha^{1 / 2}$ \\
Mampel (first order) - F1 & $1-\alpha$ \\
Avrami-Erofeev - A4 & $4(1-\alpha)[-\ln (1-\alpha)]^{3 / 4}$ \\
Avrami-Erofeev - A3 & $3(1-\alpha)[-\ln (1-\alpha)]^{2 / 3}$ \\
Avrami-Erofeev - A2 & $2(1-\alpha)[-\ln (1-\alpha)]^{1 / 2}$ \\
Contracting sphere - R3 & $3(1-\alpha)^{2 / 3}$ \\
Contracting cylinder - R2 & $2(1-\alpha)^{1 / 2}$ \\
One-dimensional diffusion - D1 & $1 / 2 \alpha^{-1}$ \\
Two-dimensional diffusion - D2 & {$[-\ln (1-\alpha)]^{-1}$} \\
Three-dimensional diffusion (Jander) - D3 & $3 / 2(1-\alpha)^{2 / 3}\left[1-(1-\alpha)^{1 / 3}\right]^{-1}$ \\
Three-dimensional diffusion (Ginstling-Brounshtein) D4 & $3 / 2\left[(1-\alpha)^{-1 / 3}-1\right]^{-1}$ \\
\hline
\end{tabular}


Using the selected reaction models, all steps were fitted simultaneously, with $A_{i}, E_{\mathrm{a}, i}$, and $w_{i}$ as fitting parameters for every individual step $i$, where the sum of the weights $w_{i}$ was set to 1 .

\subsubsection{Characterization of thin films by thermos-ellipsometric analysis (TEA)}

The thickness and refractive index of the poly[POSS-(amic acid)] membranes were measured as a function of time and temperature to track the progress of the thermal imidization. Measurements were performed on an M2000-X ellipsometer (J.A. Woollam Co.) equipped with a temperaturecontrolled hot-stage (HCS622, INSTEC), calibrated by the use of melting standards. Spectroscopic ellipsometry measurements were conducted in the full wavelength range of 210-1000 $\mathrm{nm}$. For room temperature measurements, spectra were recorded at a $65^{\circ}, 70^{\circ}$, and $75^{\circ}$ angle of incidence; measurements at elevated temperatures were performed under a single angle of incidence of $70^{\circ}$. During the experiments, the hot stage was continuously purged with ultrapure $\mathrm{N}_{2}$. Prior to the thermal treatment, the membrane was held under vacuum in the measurement cell for two hours at $100{ }^{\circ} \mathrm{C}$, followed by a 30 minute dwell at $50{ }^{\circ} \mathrm{C}$. Subsequently, the samples were heated to $300{ }^{\circ} \mathrm{C}$ at a heating rate of $5{ }^{\circ} \mathrm{C} \mathrm{min}^{-1}$. The sample was kept at $300{ }^{\circ} \mathrm{C}$ for at least 6 hours to ensure completion of the imidization process. After the dwell, the sample was cooled to room temperature at the fastest attainable cooling rate $\left(>50^{\circ} \mathrm{C} \mathrm{min}^{-1}\right)$.

\subsubsection{TEA data analysis}

CompleteEASE (v.4.86, J.A. Woollam Co.) was used for data analysis. The optical model used to model the membrane layer atop a $\gamma$-alumina coated $\alpha$-alumina disc is visualized in Figure 7-2. The layered optical model was constructed by first measuring the bare substrate, and subsequently measuring each individually applied layer. All layers are characterized by their thickness $\mathrm{d}$ and their refractive index $n(\lambda)$. The wavelength-dependency of $n$ is modeled by an optical dispersion. Because of light scattering below $\lambda=500 \mathrm{~nm}$, the wavelength range was limited to $500-1000 \mathrm{~nm}$. 


\section{SEM micrograph}

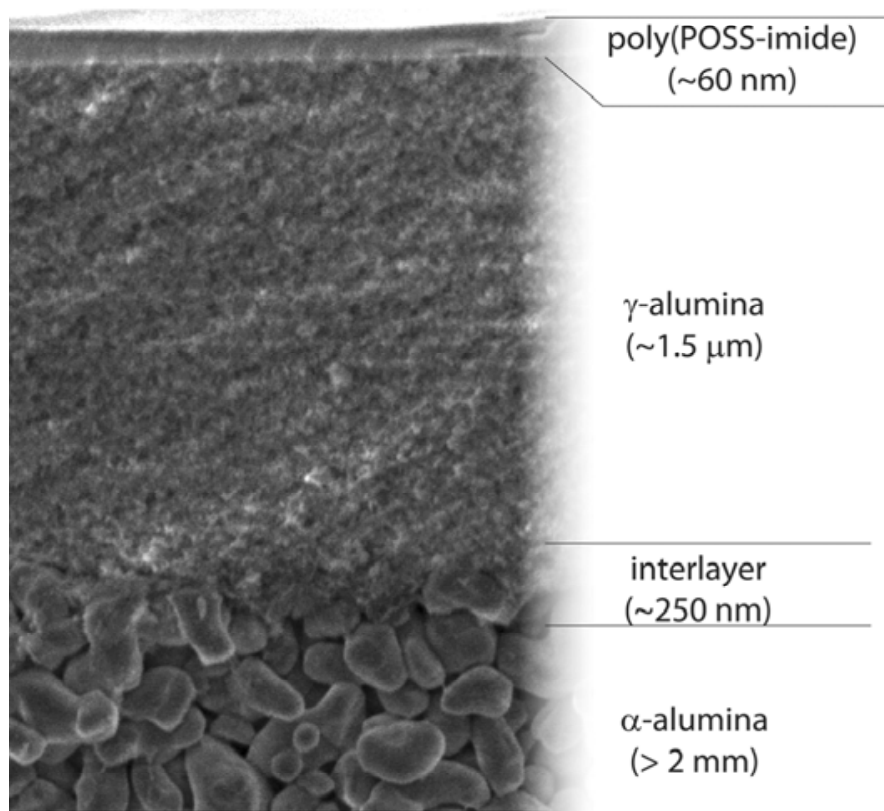

Layer assignment

Optical model

(fit parameter)

Cauchy $[d, n(A, B)]$

$\operatorname{EMA}\left(\Phi_{\text {void' }} d\right)$ of:

Cauchy $[n(A, B, C)]$

Void

Figure 7-2: Optical model of a poly(POSS-imide) layer atop a $\gamma$-alumina coated $\alpha$-alumina disc. The cross-section scanning electron micrograph of the membrane shows the distinct morphology of the dense poly(POSS-imide) layer, the $1.5 \mu \mathrm{m} \gamma$-alumina and the macroporous $\alpha$-alumina.

The $\alpha$-alumina disc was modeled by Bruggeman's Effective Medium Approximation (EMA) of alumina [34] and void $(n=1)$ with porosity $\Phi_{\text {void,substrate }}$ The roughness of the ceramic disc is modelled by a gradient in the porosity [35]; this layer is converted to an intermix layer between the $\alpha$-alumina substrate and the $\gamma$-alumina coating, to model infiltration of the coating layer into the substrate. The $\gamma$-alumina layer was as well modeled by an EMA of alumina and void $(n=1)$ with porosity $\Phi_{\text {void } \gamma \text {-alumina. }}$. The layer thickness and refractive index of the poly[POSS-(amic acid)] layers were modeled by a Cauchy optical dispersion, assuming transparency of the hybrid material in the wavelength range of 500-1000 nm. In the final fit, this thickness and optical dispersion were fit along the porosity of the $\gamma$-alumina layer and the porosity of the interlayer. Inclusion of the latter 
two is required to correct for the changes in the residual water content in the $\gamma$-alumina pores.

\subsection{Results and discussion}

\subsubsection{Imidization and thermal stability of the poly[POSS-(amic acid)] groups}

The conversion of amic acid groups to imide groups is associated with the release of water. Figure 7-3 displays the mass loss and the primary evolved gases upon heating for five different poly[POSS-(amic acid)]s. All five materials display a mass loss in four different mass steps, indicated by bold numerals (1, 2, 3, and 4) throughout the manuscript. Every step involves the loss of water from the material. The first three steps take place below $350{ }^{\circ} \mathrm{C}$, and are attributed to the removal of physically bound water (1), imidization (2), and dehydroxylation as a result of silanol condensation (3). A fourth step, recorded at temperatures exceeding $350{ }^{\circ} \mathrm{C}$, involves the thermal decomposition of the hybrid material (4). These four steps will be discussed in more detail.

The removal of physically bound water (1) occurs from room temperature to $\sim 250{ }^{\circ} \mathrm{C}$. The $\mathrm{CO}_{2}$ that is released during this step can originate from a decarboxylation reaction of either an unreacted carboxylic acid groups or a non-cyclized amic acid group. Also, $\mathrm{CO}_{2}$ may have been sorbed by the POSS-material, leading to $\mathrm{CO}_{2}$ release at low temperatures.

The imidization of the material (2) takes place in the temperature range $150-300{ }^{\circ} \mathrm{C}$, agreeing well with previous observations by infrared spectroscopy of the imidization temperature range of these hybrid polyimides [6]. Mainly water evolves during step 2. The water loss is higher than would be expected based on an imidization step alone. Because the drying overlaps with the imidization (2) step, the mass loss below $300{ }^{\circ} \mathrm{C}$ can be associated with both drying and imidization. For the ODPA and 6FDA-based samples, a small amount of organic components is 
detected as well. These components may be the result of the sublimation of unreacted organic groups.

It is unlikely that the water release in step 3 corresponds to a distinct second imidization step. Although the imidization is reported to take place by a two-step reaction (see, e.g., [27]), these steps are reported to directly follow upon each other. Such a step would be detected as a unimodal, nonGaussian peak, rather than a bimodal peak. We therefore hypothesize that the water release originates from a condensation reaction of silanol groups that were formed by the partial hydrolysis of POSS cages during synthesis. This is supported by silanol condensation observed in attenuated total reflection - Fourier-transform infrared spectroscopy (ATF-FTIR) measurements (see Figure 7-A9 and Figure 7-A10 in the Appendix).

The onset of the decomposition (4) at $\sim 350{ }^{\circ} \mathrm{C}$ is found at the same temperature for all the different organic bridges. This observation suggests that the weakest link is found in the POSS-precursor. Theoretically, the aliphatic propyl-chain connecting the POSS-cage to the amine group is expected to have the lowest thermal stability [36]. The detection of $\mathrm{C}_{3} \mathrm{H}_{x}$ components during the decomposition step in the TGA-MS analysis, at lower temperatures than any other evolved organic components, suggests that the propyl-group in the POSS-cage indeed forms the weakest link. Although the majority of the decomposition takes place between 350 and $650{ }^{\circ} \mathrm{C}$, a minor mass loss associated with release of $\mathrm{CO}_{2}$ and methane is found to continue up to $1200{ }^{\circ} \mathrm{C}$, indicating that organic groups are still present at these temperatures.

In Figure 7-3 (bottom right graph), the mass loss curve of the 5 different poly[POSS-(amic acid)]s are compared in the temperature range 50-400 ${ }^{\circ} \mathrm{C}$. The relative mass loss until $300{ }^{\circ} \mathrm{C}$, associated with the drying (1), imidization (2), and silanol condensation (3), is comparable for all the poly[POSS-(amic acid)]s. The similar extent of mass loss can be rationalized by the similar number of amic acid, unreacted amine, and silanol groups in all samples, apparent from XPS analysis in previous studies [37]. 

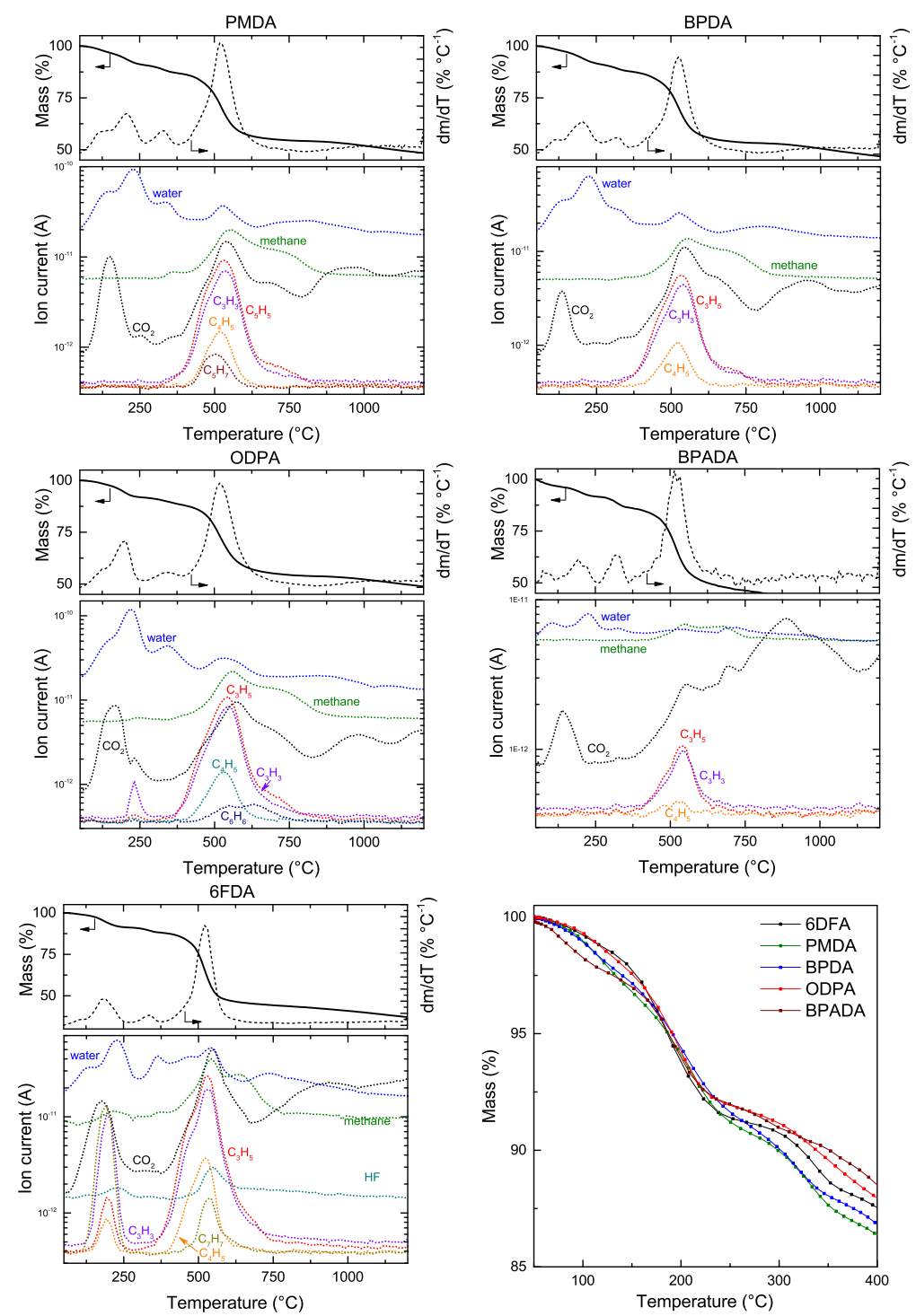

Figure 7-3: (All except bottom right graph) TGA-MS data: the relative mass and the first derivative thereof (top panels) and evolved gases (bottom panels) as a function of the temperature for poly[POSS(amic acid)]s prepared using the different dianhydrides. All samples were heated under $\mathrm{N}_{2}$ at $20{ }^{\circ} \mathrm{C} \mathrm{min}^{-1}$. (Bottom right graph) Comparison of the changes in sample mass as function of the temperature for the different linkers. 
Because the high molar mass of the POSS-cages dominates the mass of the polymer, the difference in mass of the organic bridges will only have a marginal influence on the differences in the molecular weight of the synthesized network. As a result, the relative amount of mass released by imidization and silanol condensation will be similar as well. Moreover, because the physisorbed water will mainly be present at the amic acid and amine groups, and because the number of these groups is similar for these materials, this amount will be comparable for all the materials. Therefore, the sum of the drying, imidization, and silanol condensation processes results in similar mass losses, irrespective of which organic bridging groups is considered.

\subsubsection{Imidization of thin layers}

Accurate determination of the film thickness and density during thermal imidization is required for understanding the mechanism of the imidization process in thin films. In particular, the role of the length of the organic bridging group on structural reorganizations is investigated. Figure 7-4 shows the relative changes in the thickness of the different poly[POSS-(amic acid)]s during heating under nitrogen.

Upon heating, the thicknesses of all the layers decrease. The stepwise shrinkage is in agreement with the stepwise mass loss. The large degree of shrinkage outweighs the contributions of the thermal expansion to the thickness. Only two distinct steps were recorded for the shrinkage: the drying step (1) recorded in the TGA-experiment has taken place during pretreatment of the film at $100{ }^{\circ} \mathrm{C}$ and is not recorded in this measurement. The onset of the first shrinkage is recorded at $125{ }^{\circ} \mathrm{C}$, and the process continues until $\sim 225^{\circ} \mathrm{C}$. A higher decrease in the thickness is recorded during further heating to $345{ }^{\circ} \mathrm{C}$, resulting from the concurrent imidization (2) and silanol condensation (3). At this temperature, the reaction driving the shrinkage is kinetically hampered, as is evident from the shrinkage that persists for multiple hours of dwelling at $345^{\circ} \mathrm{C}$. 


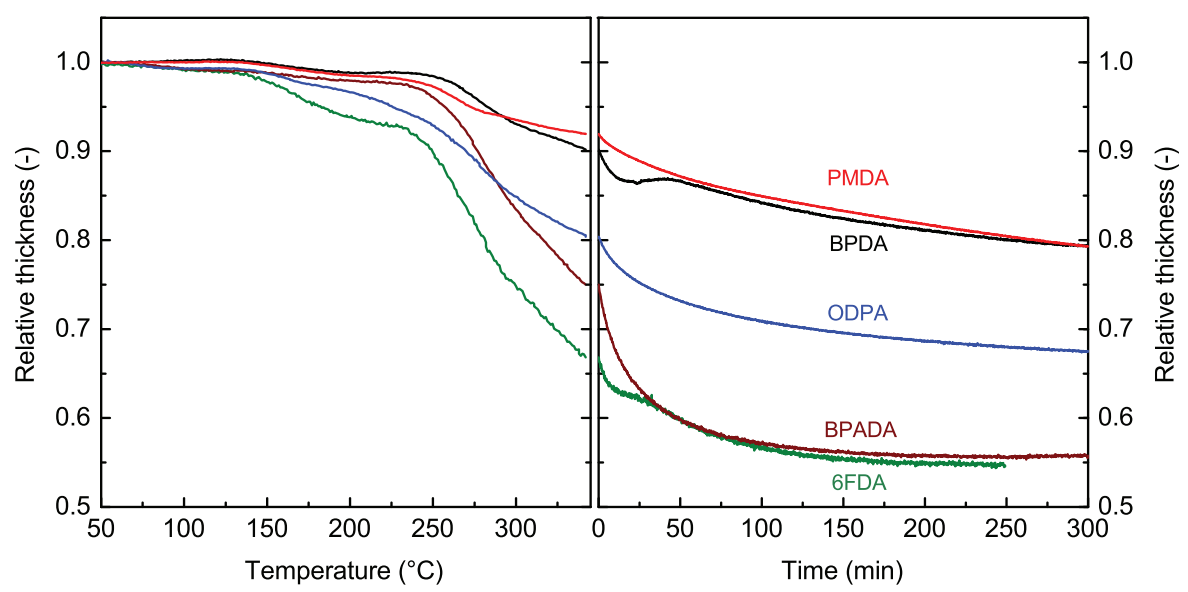

Figure 7-4: (left panel) Relative thickness during conversion of poly[POSS-(amic acid)]s to poly(POSS-imide)s as function of temperature, and (right panel) dwell time at $345{ }^{\circ} \mathrm{C}$ after heating from 50 to $345{ }^{\circ} \mathrm{C}$ at a heating rate of $5{ }^{\circ} \mathrm{C} \mathrm{min}$. The optical model is validated by a duplicate measurement of the ODPA based poly[POSS-(amic acid)] (not shown here).

The observation that the shrinkage rate decreases in time during the isothermal treatment is indicative for a decelerating type of reaction [38]. In particular for the layers prepared with short dianhydride bridges (PMDA, BPDA and ODPA), the thickness changes advance well beyond 10 hours of dwell time (not shown in graph). For the longer dianhydride bridges (BPADA, 6FDA) on the other hand, the changes in thickness stabilize within 4 hours of dwell time. The final relative thickness changes the most for 6FDA, followed by the others in the order 6FDA $\approx$ BPADA > ODPA > BPDA $\approx$ PMDA. The shrinkages are most pronounced for the longest bridging groups, because the larger spacing between the POSScages and higher flexibility of the long groups allows for larger and faster structural rearrangements.

The higher flexibility of the longer bridging groups is reflected in the linear thermal expansion coefficients that are higher for the longer bridges and lower for the short bridges. For solid-state reactions, decelerating reactions are typically described by a reaction-order or diffusion model. 
The strong dependency of the shrinkage on the length of the dianhydride bridge could indicate that diffusional limitations are the main reason for the decelerating rate [39].

The lower shrinkage displayed by the layers with the short bridging groups are indicative for a higher degree of free volume in the imidized material. This is confirmed by a stronger decrease of the refractive index of the materials with short bridging groups. Figure 7-5 shows the development of the relative refractive index of the layers upon heating. For all layers, the refractive index decreases upon heating. In agreement with the mass and thickness changes, the refractive index change occurs in a stepwise manner. The concurrent decrease in refractive index and thickness is a typical indication for the removal of a component from a matrix.

The relative refractive index changes differ significantly among the different layers. The relative changes in the refractive index are the largest for BPDA, followed by the others in the order BPDA > PMDA > BPADA $>6 \mathrm{FDA}>$ ODPA. The changes in the refractive index due to chemical changes are expected to be similar for the different bridging groups.

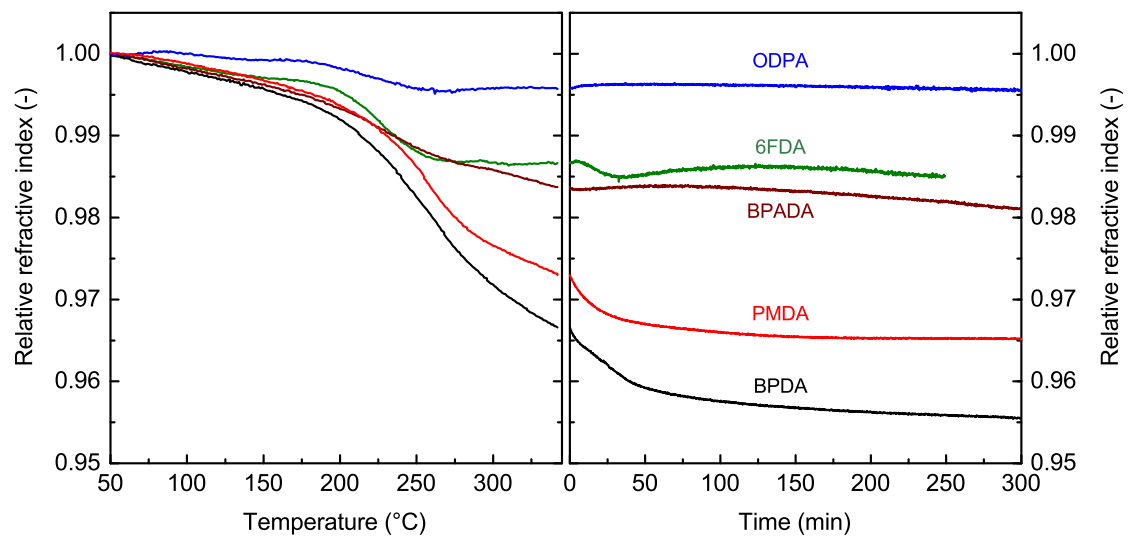

Figure 7-5: (Left panel) Relative refractive index at $632.8 \mathrm{~nm}$ wavelength of the poly[POSS-(amic acid)] as a function of the temperature and (right panel) the dwell time at $300{ }^{\circ} \mathrm{C}$ after heating from 50 to $300{ }^{\circ} \mathrm{C}$ at a heating rate of $5{ }^{\circ} \mathrm{C} \mathrm{min}^{-1}$. 
Therefore, the differences in the mobilities of the networks are the probable cause for the distinct changes in refractive indices observed for different bridging groups. For all networks, a similar amount of water is removed. Yet, for the more rigid networks of BPDA- and PMDA-based layers the shrinkage is less pronounced. This corresponds to a relatively high free volume in the imidized networks with the short bridging groups. This is further substantiated by in a higher change in their refractive index during the imidization step.

\subsubsection{Density change upon imidization}

The density of poly[POSS-(amic acid)] films changes during imidization because of shrinkage and water removal. Figure 7.6 shows a comparison of the changes in refractive index between the poly[POSS-(amic acid)]s and the poly(POSS-imide)s. All measurements are performed at $50{ }^{\circ} \mathrm{C}$, and therefore include any structural rearrangement occurring during the cooling step that follows the imidization.

The refractive indices of the amic acids are similar for the materials prepared with the 5 different precursors. A strong decrease in index was recorded for the short bridging groups PMDA and BPDA, whereas only a minor change was recorded for the BPADA, 6FDA and the ODPA samples.

Changes in the refractive index can occur due to chemical group conversion, removal of a component and densification. The changes in the refractive index due to imidization and water removal are similar, because all materials display a similar mass loss and number of amic acid and silanol groups. The significant differences in layer shrinkage can therefore be the only explanation for the differences in refractive index change upon imidization.

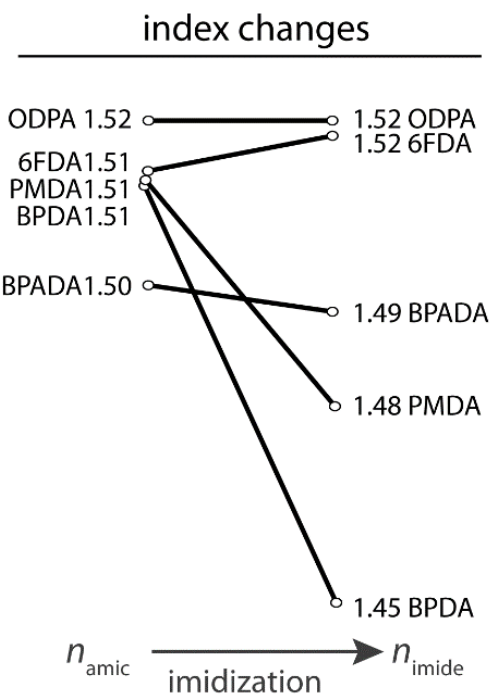

Figure 7-6: Changes in refractive index at $50{ }^{\circ} \mathrm{C}$ as a result of imidization, for 5 different dianhydride precursors. 
For the BPADA, the 6FDA, and - to a lesser extent - the ODPA-bridging group, the shrinkage is significant. For these materials, the overall changes in refractive index due to densification, chemical group conversion and water removal are negligible. For the PMDA and BPDA-bridging groups, however, only a minor shrinkage is observed as a result of the lower mobility of the network. The absence of densification upon removal of water and chemical group conversion results in the formation of void space. The additional free volume that is created in the PMDA and BPDA based materials therefore results in a decrease in refractive index.

\subsubsection{Kinetic analysis of the reactions by isoconversional and multivariate analyses}

As discussed in the previous sections, upon heating to $600{ }^{\circ} \mathrm{C}$ four distinct steps are considered for the thermal evolution of the mass of the poly[POSS-(amic acid)]s: drying (1), imidization (2), silanol condensation (3), and decomposition of the organic moiety (4). The imidization step (2) significantly overlaps with the drying step (1); in the kinetic analysis these steps will be considered as a single step during, referred to as step 1+2. Step $1+2$ is responsible for $\sim 16 \%$ of the weight loss, of which the imidization step may constitute only a smaller part. Step 3, responsible for $\sim 5 \%$ of the mass loss, is associated with water release from the condensation reactions of silanol groups that were formed by partial hydrolysis of POSS-cages during synthesis. Step 3 may partially overlap with the final stages of the imidization reaction (2), but the condensation reactions are anticipated to dominate the observed mass loss. Step $\mathbf{4}$ is associated with the decomposition of the hybrid materials.

Determination of the activation energy via an isoconversional analysis

Here, the reaction kinetics are analyzed for the poly(POSS-6FDA) material. The reaction kinetics are typically expressed by three parameters (the pre-exponential constant $A$, the reaction model $f(\alpha)$, and the activation energy $E_{\mathrm{a}}$ ) for every step $i$ (see Equation 4-1). First, the 170 
activation energy as a function of mass loss is determined without assuming a reaction model, by using a model-free isoconversional analysis method proposed in literature [30-32]. For this, the mass loss is converted to the normalized conversion $\alpha$. Drying and imidization $(1+2)$ are detected in the range $\alpha=0-0.16$, silanol condensation (3) is detected for $\alpha=0.16-0.21$, and decomposition (4) for $\alpha=0.21-1$. The results of this analysis, given in Figure 7-7, clearly indicate the existence of the three different steps. The combined step 1+2 and step 3 are associated with activation energies of $\sim 225 \mathrm{~kJ} \mathrm{~mol}^{-1}$ and $\sim 150 \mathrm{~kJ} \mathrm{~mol}^{-1}$, respectively. Step 4 shows an activation energy that gradually increases with conversion, from 225 to $400 \mathrm{~kJ} \mathrm{~mol}^{-1}$.

In the analysis of step $1+2$, the obtained value for the activation energy will be an effective average of the activation energies of removal of physisorbed water and imidization reactions. Possibly, imidization can only occur after the removal of the physisorbed water from the amic acid group.
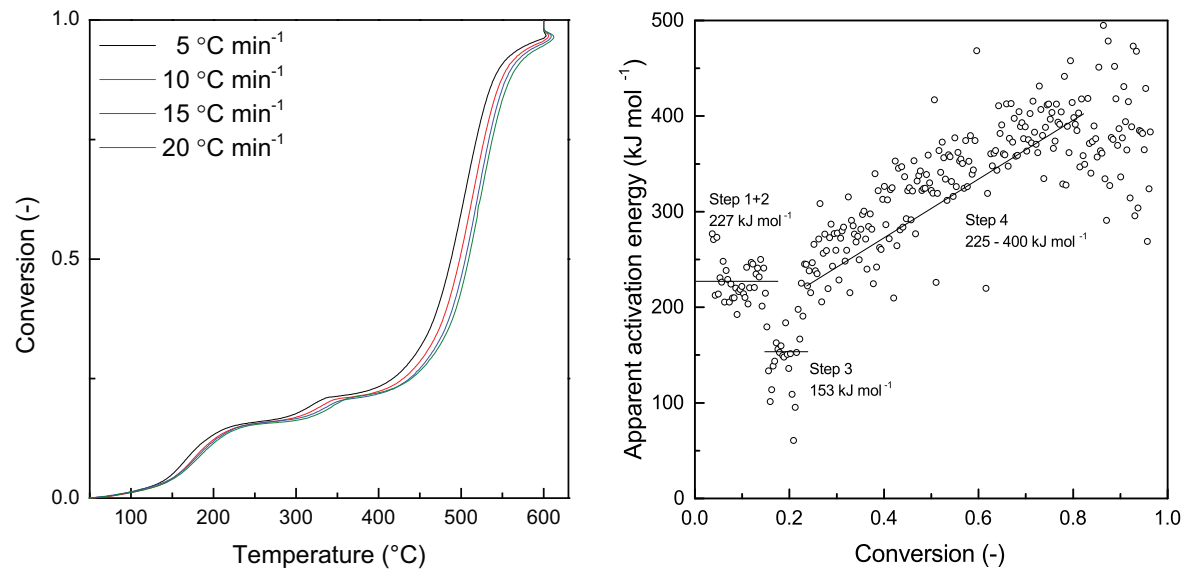

Figure 7-7. (left panel) Conversion of the mass loss of 6FDA-based poly[POSS-(amic acid)] as function of temperature, for heating rates $\beta=5,10,15$ and $20{ }^{\circ} \mathrm{C} \min ^{-1}$ under $\mathbf{N}_{2}$ atmosphere. (right panel) Apparent activation energy as function of conversion, determined by the isoconversional analysis of TGA-data for the thermal treatment of 6FDA based poly[POSS-(amic acid)]. 
The apparent activation energy determined in this study is significantly higher than the values typically obtained in previous imidization studies, which are in the order of $\sim 50$ to $100 \mathrm{~kJ} \mathrm{~mol}^{-1}[18,19,27-29]$. The use of a non-isothermal temperature program can be excluded as the cause of this difference [38], and the difference is too large to result solely from the assumption of a different reaction model [40].

As the differences cannot be attributed to modelling artefacts, it is concluded that the hybrid nature of the material strongly increases the activation energy of the imidization reaction. It has been suggested that the rotation of the amic acid carbon towards the amide group could be the rate-limiting step during the imidization reaction [41]. The rigid characteristics and the high degree of network interconnectivity of the POSS cage can hamper the rotational freedom of the amic acid groups.

\section{Determination of the kinetic triplet through a multivariate analysis of the kinetics}

The model-free values for the activation energy are subsequently used as input for a multivariate analysis of the kinetics, in which Equation 4-1 is integrated for the 3 different reaction steps $(1+2,3$, and 4$)$. In the fitting approach, all steps are first fitted independently in their own temperature range. For step $1+2$, this is the range $50-250{ }^{\circ} \mathrm{C}$, for step 3 this is the range $250-380{ }^{\circ} \mathrm{C}$, and for step 4 this is the range of temperatures of $380{ }^{\circ} \mathrm{C}$ and higher. The optimal fit parameters obtained for the individual reaction steps are subsequently combined and used as starting values for an overall fit of the data over the full temperature range. In this overall fit, the relative weight of the individual steps is included as a fit parameter as well.

\section{Fitting of the drying and imidization steps $(1+2)$}

For step $1+2$, when a single step reaction is fitted to the data in the range $\alpha=0.02-0.16$, none of the 14 reaction models given in Table 7-1 adequately capture the data. The reaction order model F1 and the diffusional models D2, D3, and D4 describe the shape of the curve better than the other 
models do. The inadequacy of the fit, when assuming a single reaction step, is in line with the previous suggestion that for imidization a diffusional term needs to be added to the commonly employed F1model [29]. Fitting the data by two reactions in parallel also does not capture the data accurately. To improve the fit, a distributed activation energy can be assumed. This approach has been shown adequate for a wide range of parallel reactions. ${ }^{42}$ By combining the D4 reaction model (best describing the data in the first fitting attempt) with a Weibull-distribution of the activation energy, the data can be fitted accurately. The mean activation energy of $\sim 225 \mathrm{~kJ} \mathrm{~mol}^{-1}$, obtained from the model fit, is in agreement with the value obtained by the isoconversional analysis. The suitability of the diffusional model can indicate that densification of the material limits the reaction rate, with progressing conversion.

\section{Fitting of the silanol condensation (3)}

For the silanol condensation (3), when a single step reaction is fitted to the data in the range $\alpha=0.16-0.21$, that the reaction-order model F1 most accurately describes the data. The corresponding activation energy is $\sim 150 \mathrm{~kJ} \mathrm{~mol}^{-1}$. The fit results are found to be completely independent of the starting values used for the fit. The suitability of the F1-model implies that the reactivity decreases due to a decrease in the concentration of reactive groups.

\section{Fitting of the decomposition (4)}

For the decomposition step (4), the strong dependency of the activation energy on the conversion hints at multiple processes taking place. A distributed activation energy is therefore required to properly fit the measured data. The onset of the decomposition processes is captured adequately by using a Weibull-distributed activation energy. This approach does not accurately capture the complete degradation process. Because only the onset of the decomposition is of interest in this study, no further attempts for optimizing a quantitative fit of the data are performed. 


\section{Overall fit of the reaction kinetics}

The values obtained for the pre-exponential constant, activation energy, and reaction model for the individual steps have been used as initial guess values for a fit of the data over the whole temperature and conversion ranges. In addition, the weights $w_{\mathrm{i}}$ of the individual steps is included as an extra fit parameter, for which $w_{4}$ is set equal to $1-w_{1+2}-\mathrm{w}_{3}$. The results of the overall fit are given in Figure 7-8, and the values corresponding to the obtained fit in Table 7-2. The obtained values are insensitive for the starting values, and do not deviate strongly from the values obtained for fitting the individual steps. This supports the appropriateness of the analysis of considering the individual steps. The high weight of reaction 1+2 over reaction 3 confirms the strong mass losses during the drying and imidization steps.

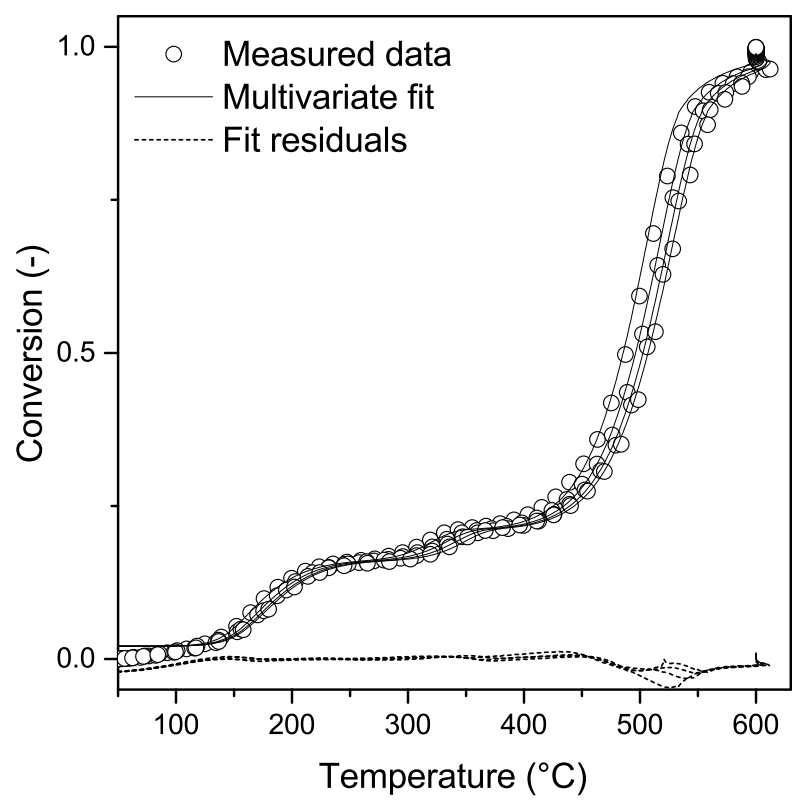

Figure 7-8: Multivariate fit for the thermal treatment of 6FDA based poly[POSS-(amic acid)] under $\mathbf{N}_{2}$ atmosphere. Symbols depict the experimental data, and solid lines represent the fit; dashed lines show the fit residuals. 
Table 7-2: Kinetic parameters for the thermal treatment of 6FDAbased poly[POSS-(amic acid)] under $\mathbf{N}_{2}$ atmosphere. Step 1 and 3 are fitted by a Weibull-distributed activation energy, step 2 was fitted by a F1-reaction model.

\begin{tabular}{llll}
\hline Conversion & Step 1 $(\boldsymbol{w}=0.141)$ & Step 2 $(\boldsymbol{w}=0.054)$ & Step 3 $(\boldsymbol{w}=0.785)$ \\
\hline$A\left(\mathrm{~min}^{-1}\right)$ & $2.62 \cdot 10^{24}$ & $5.12 \cdot 10^{12}$ & $3.77 \cdot 10^{18}$ \\
$E_{\mathrm{a}}$ threshold $\left(\mathrm{kJ} \mathrm{mol}^{-1}\right)$ & 200 & $\mathrm{n} / \mathrm{a}$ & 295 \\
$\beta(-)$ & 1.65 & $\mathrm{n} / \mathrm{a}$ & 3.29 \\
$\eta\left(\mathrm{kJ} \mathrm{mol}^{-1}\right)$ & 26.8 & $\mathrm{n} / \mathrm{a}$ & 4.9 \\
$E_{a}$ average $\left(\mathrm{kJ} \mathrm{mol}^{-1}\right)^{\mathrm{a}}$ & 224 & 151.4 & 299 \\
Reaction model & $\frac{3}{2}(1-\alpha)^{2 / 3}\left[1-(1-\alpha)^{1 / 3}\right]^{-1}$ & $1-\alpha$ & $\frac{3}{2}(1-\alpha)^{2 / 3}\left[1-(1-\alpha)^{1 / 3}\right]^{-1}$ \\
\hline
\end{tabular}

${ }^{\text {a }}$ The activation energy indicated for step 2 is the single activation energy used for the fit

\subsection{Conclusion}

Four steps were identified in the thermal processing of poly[POSS-(amic acid)]s: drying of physisorbed water (1), imidization (2), silanol condensation (3), and decomposition (4). The imidization was found to occur between 150 and $300{ }^{\circ} \mathrm{C}$, independent of the characteristics of the bridging group. Because of the comparatively low contribution of the organic bridging groups to the total mass of the material, the mass loss during all steps is similar. In contrast to the mass loss, the linking group does strongly influence the shrinkage, and hence the densification, that take place upon the imidization of the layer. The most pronounced shrinkage is found for the poly[POSS-(amic acid)]s with long bridges. For the short bridges, network densification is hampered by the rigidity of the bridges. Hence, shorter bridges results in hybrid polyimides with a significantly higher free volume, and thus a lower density.

A kinetic analysis of the imidization step reveals a very high value for activation energy, as compared to imidization of fully organic poly(amic acid)s. This is attributed to the high degree of interconnectivity and the rigidity of the POSS cages, impeding the rate-limiting rotation of the amic 
acid group. The appropriateness of a decelerating reaction model suggests that a decelerating reaction rate is caused by network densification.

The combination of TGA-MS and TEA provides unique insights into the structural rearrangements in the hybrid materials that can be used for further optimization of thermal treatments of hybrid organic-inorganic network materials.

\subsection{Appendices}

\subsubsection{Conversion processes during thermal imidization}

During the heat treatment of the poly[POSS-(amic acid)]s, reaction steps associated with drying and imidization (1+2), silanol condensation (3) and decomposition (4) are observed. Scheme S2 shows the reaction mechanism of step 2 and 3 that occur. During step 2 of the heat treatment process, mainly conversion of amic acid to imide groups occurs (blue).

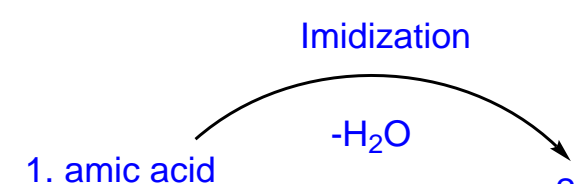

1. amic acid imide

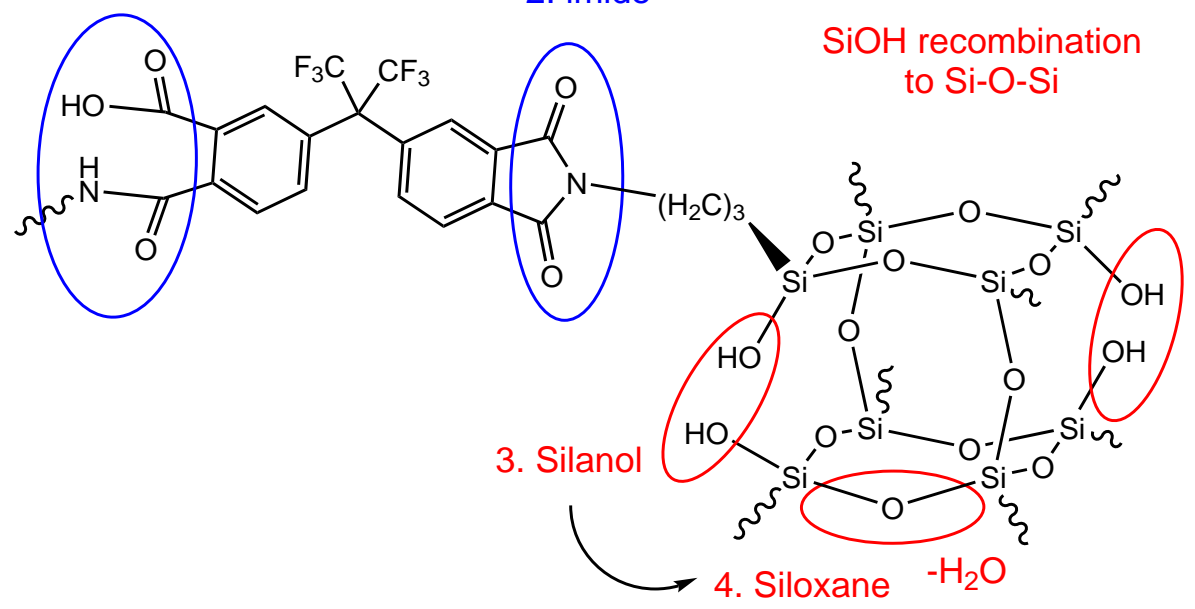

Figure 7-A9: Overview of the water loss originating from imidization and silanol condensation reactions. 
During step 3, additional water loss is observed that originates from recombination of silanol groups to form siloxane groups (red).

The silanol condensation reaction is observed from attenuated total reflection - Fourier transform infrared spectroscopy (ATR-FTIR) measurements of poly[POSS-(amic acid)] samples that were heat treated at different temperatures. Figure 7-A10 shows the relative intensity of infrared peaks that are characteristic for $\mathrm{Si}-\mathrm{O}$ bonds in a cage or ladder (i.e., a broken POSS cage) structure, and peaks that are characteristic for silanol groups. The peak at $3230 \mathrm{~cm}^{-1}$ could include vibrations from water present in the material. Although the scatter in the data makes a quantitative analysis difficult, the data shows a trend of increasing ladder and cage formation with increasing treatment temperatures, at the expense of silanol groups.
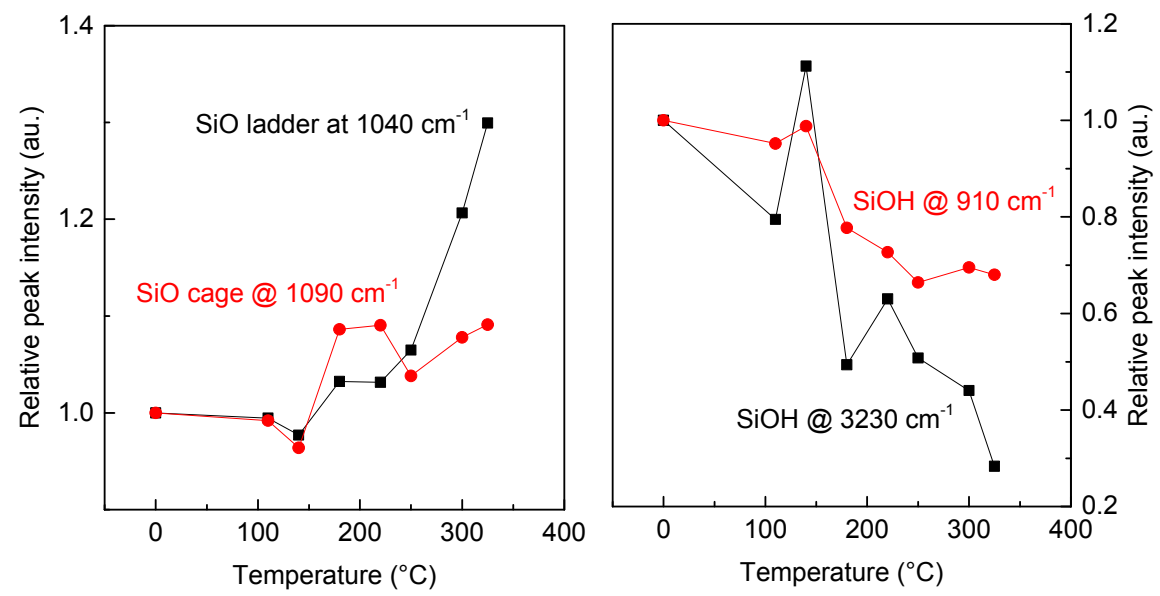

Figure 7-A10: (left panel) Relative intensity of the infrared peaks at 1040 and $1090 \mathrm{~cm}^{-1}$ for 6FDA-based samples, corresponding to a Si-OSi bond in ladder and cage configuration, respectively; (right panel) Relative intensity of the infrared peaks at 910 and $3230 \mathrm{~cm}^{-1}$, both corresponding to silanol groups. All infrared spectra were normalized with respect to the $\mathrm{CF}_{3}$ band at $1254 \mathrm{~cm}^{-1}$. All peak intensities are normalized with respect to their initial peak intensity. 


\subsection{References}

1. Pielichowski, K., Njuguna, J., Janowski, B. \& Pielichowski, J., 2006, Polyhedral oligomeric silsesquioxanes (POSS)-containing nanohybrid polymers. Adv. Polym. Sci. 201, pp. 225-296. (doi:10.1007/12_077)

2. Ruiz-Hitzky, E., Aranda, P., Darder, M. \& Ogawa, M., 2011, Hybrid and biohybrid silicate based materials: Molecular vs. block-assembling bottom-up processes. Chem. Soc. Rev. 40, pp. 801-828. (doi:10.1039/C0CS00052C)

3. Sanchez, C., Soler-Illia, G.J.D.A.A., Ribot, F., Lalot, T., Mayer, C.R. \& Cabuil, V., 2001, Designed hybrid organic-inorganic nanocomposites from functional nanobuilding blocks. Chem. Mater. 13, pp. 3061-3083. (doi:10.1021/cm011061e)

4. Beecroft, L.L., Johnen, N.A. \& Ober, C.K., 1997, Covalently linked, transparent silica-poly(imide) hybrids. Polym. Adv. Technol. 8, pp. 289-296. (doi:10.1002/(SICI)1099-1581(199705)8:5<289::AID-PAT648>3.0.CO;2-3)

5. Khalil, M., Saeed, S. \& Ahmad, Z., 2008, Mechanical and thermal properties of polyimide/silica hybrids with imide-modified silica network structures. J. Appl. Polym. Sci. 107, pp. 1257-1268. (doi:10.1002/app.27149)

6. Raaijmakers, M.J.T., Hempenius, M.A., Schön, P.M., Vancso, G.J., Nijmeijer, A., Wessling, M. \& Benes, N.E., 2014, Sieving of hot gases by hyper-cross-linked nanoscale-hybrid membranes. J. Am. Chem. Soc. 136, pp. 330-335. (doi:10.1021/ja410047u)

7. Asuncion, M.Z. \& Laine, R.M., 2007, Silsesquioxane barrier materials. Macromolecules 40, pp. 555-562. (doi:10.1021/ma062305p)

8. Choi, J., Tamaki, R., Kim, S.G. \& Laine, R.M., 2003, Organic/inorganic imide nanocomposites from aminophenylsilsesquioxanes. Chem. Mater. 15, pp. 33653375. (doi:10.1177/0954008310391825)

9. Devaraju, S., Vengatesan, M.R. \& Alagar, M., 2011, Studies on thermal and dielectric properties of ether linked cyclohexyl diamine (ELCD)-based polyimide POSS nanocomposites (POSS-PI). High Perform. Polym. 23, pp. 99-111.

10. Huang, J.C., He, C.B., Xiao, Y., Mya, K.Y., Dai, J. \& Siow, Y.P., 2003, Polyimide/POSS nanocomposites: Interfacial interaction, thermal properties and mechanical properties. Polymer (Guildf). 44, pp. 4491-4499. (doi:10.1016/S00323861(03)00434-8)

11. Leu, C.M., Chang, Y.T. \& Wei, K.H., 2003, Synthesis and Dielectric Properties of Polyimide-Tethered Polyhedral Oligomeric Silsesquioxane (POSS) Nanocomposites via Poss-diamine. Macromolecules 36, pp. 9122-9127. (doi:10.1021/ma034743r) 
12. Leu, C.M., Chang, Y.T. \& Wei, K.H., 2003, Polyimide-side-chain tethered polyhedral oligomeric silsesquioxane nanocomposites for low-dielectric film applications. Chem. Mater. 15, pp. 3721-3727. (doi:10.1021/cm030393b)

13. Seçkin, T., Köytepe, S. \& Adigüzel, H.I., 2008, Molecular design of POSS core star polyimides as a route to low-k dielectric materials. Mater. Chem. Phys. 112, pp. 1040-1046. (doi:10.1016/j.matchemphys.2008.07.017)

14. Wright, M.E., Petteys, B.J., Guenthner, A.J., Fallis, S., Yandek, G.R., Tomczak, S.J., Minton, T.K. \& Brunsvold, A., 2006, Chemical modification of fluorinated polyimides: New thermally curing hybrid polymers with POSS. Macromolecules 39, pp. 4710-4718. (doi:10.1021/ma060372d)

15. Monticelli, O., Fina, A., Ullah, A. \& Waghmare, P., 2009, Preparation, characterization, and properties of novel PSMA-POSS systems by reactive blending. Macromolecules 42, pp. 6614-6623. (doi:10.1021/ma900969b)

16. Wright, M.E., Schorzman, D.A., Feher, F.J. \& Jin, R.Z., 2003, Synthesis and thermal curing of aryl-ethynyl-terminated coPOSS imide oligomers: New inorganic/organic hybrid resins. Chem. Mater. 15, pp. 264-268. (doi:10.1021/cm020238h)

17. Pyun, E., Mathisen, R.J., Sung, C.S.P., Sook, C. \& Sung, P., 1989, Kinetics and Mechanisms for Thermal Imidization of a Polyamic Acid Studied by UltravioletVisible Spectroscopy. Macromolecules 22, pp. 1174-1183. (doi:10.1021/ma00193a031)

18. Dickinson, P.R. \& Sung, C.S.P., 1992, Kinetics and Mechanisms of Thermal Imidization Studies by UV-Visible and Fluorescence Spectroscopic Techniques. Macromolecules 25, pp. 3758-3768. (doi:10.1021/ma00040a023)

19. Seo, Y., Lee, S.M., Kim, D.Y. \& Kim, K.U., 1997, Kinetic Study of the Imidization of a Poly ( ester amic acid) by FT-Raman Spectroscopy. Macromolecules 9297, pp. 3747-3753. (doi:10.1021/ma961482v)

20. Kim, B.-H.H., Park, H.H. \& Moon, D.C., 2013, Degree of imidization for polyimide films investigated by evolved gas analysis-mass spectrometry. Thermochim. Acta 551, pp. 184-190. (doi:10.1016/j.tca.2012.10.029)

21. Kim, S.-K.K., Kim, H.-T.T. \& Park, J.-K.K., 1998, Effects of thermal curing on the structure of polyimide film. Polym. J. 30, pp. 229-233. (doi:10.1021/ma00013a009)

22. Ree, M., Shin, T.J., Park, Y.-H.H., Kim, S.I., Woo, S.H., Cho, C.K. \& Park, C.E., 1998, Residual stress and optical properties of fully rod-like poly(p-phenylene pyromellitimide) in thin films: Effects of soft-bake and thermal imidization history. J. Polym. Sci. Part B Polym. Phys. 36, pp. 1261-1273. (doi:10.1002/(SICI)1099-0488(199806)36:8<1261::AID-POLB1>3.0.CO;2-V) 
23. Kook, H.J. \& Kim, D., 2000, In situ measurements and analysis of imidization extent, thickness, and stress during the curing of polyimide films. J. Mater. Sci. 35, pp. 2949-2954. (doi:10.1023/A:1004722609188)

24. Shin, T.J. \& Ree, M., 2005, In situ infrared spectroscopy study on imidization reaction and imidization-induced refractive index and thickness variations in microscale thin films of a poly(amic ester). Langmuir 21, pp. 6081-6085. (doi:10.1021/la050470c)

25. Yilmaz, T., Güçlü, H., Özarslan, Ö., Yildiz, E., Kuyulu, A., Ekinci, E. \& Güngör, A., 1997, Kinetic Investigations of Formation of Polyimides Containing Arylene Sulfone Ether Linkages by Potentiometric Titration and Their Characterization. J. Polym. Sci. Part A Polym. Chem. 35, pp. 2981-2990. (doi:10.1002/(SICI)10990518(199710)35:14<2981::AID-POLA19>3.0.CO;2-F)

26. Seo, Y., 1997, Modeling of Imidization Kinetics. Polym. Eng. Sci. 37, pp. 1-5. (doi:10.1002/pen.11720)

27. Kim, Y.J., Glass, T.E., Lyle, G.D. \& Mcgrath, J.E., 1993, Kinetic and Mechanistic Investigations of the Formation of Polyimides under Homogeneous Conditions. Macromolecules 26, pp. 1344-1358. (doi:10.1021/ma00058a024)

28. Lu, H., Zhou, J. \& He, T., 2001, Diffusion-Limited Kinetics Modeling of OneStep Polyimide Formation. J. Appl. Polym. Sci. 79, pp. 2052-2059. (doi:10.1002/1097-4628(20010314)79:11<2052::AID-APP1014>3.0.CO;2-I)

29. Vyazovkin, S. \& Dollimore, D., 1996, Linear and Nonlinear Procedures in Isoconversional Computations of the Activation Energy of Nonisothermal Reactions in Solids. J. Chem. Inf. Comput. Sci. 36, pp. 42-45. (doi:10.1021/ci950062m)

30. Vyazovkin, S., 2001, Modification of the integral isoconversional method to account for variation in the activation energy. J. Comput. Chem. 22, pp. 178-183. (doi:10.1002/1096-987x(20010130)22:2<178::aid-jcc5>3.0.co;2-\%23)

31. Vyazovkin, S., 1997, Evaluation of activation energy of thermally stimulated solid-state reactions under arbitrary variation of temperature. J. Comput. Chem. 18, pp. 393-402. (doi:10.1002/(sici)1096-987x(199702)18:3<393::aid-jcc9>3.0.co;2-p)

32. Vyazovkin, S., Chrissafis, K., Di Lorenzo, M.L., Koga, N., Pijolat, M., Roduit, B., Sbirrazzuoli, N. \& Suñol, J.J., 2014, ICTAC Kinetics Committee recommendations for collecting experimental thermal analysis data for kinetic computations. Thermochim. Acta 590, pp. 1-23. (doi:10.1016/j.tca.2014.05.036)

33. Lichtenstein, T., 1979, Handbook of Thin Film Materials. Rochester, N.Y.: College of Engineering and Applied Science, University of Rochester.

34. Ogieglo, W., Wormeester, H., Wessling, M. \& Benes, N.E., 2012, Spectroscopic ellipsometry analysis of a thin film composite membrane consisting of polysulfone 
on a porous a-alumina support. ACS Appl. Mater. Interfaces 4, pp. 935-43. (doi:10.1021/am2015958)

35. Van Krevelen, D.W., 2009, Properties of Polymers: their correlation with chemical structure; their numerical estimation and predictino from additive group contributions. 4th edn. Amsterdam: Elsevier. ISBN: 9780080548197(doi:10.1016/B978-0-08054819-7.00004-2)

36. Raaijmakers, M.J.T., Wessling, M., Nijmeijer, A. \& Benes, N.E., 2014, Hybrid polyhedral oligomeric silsesquioxanes-imides with tailored intercage spacing for sieving of hot gases. Chem. Mater. 26, pp. 3660-3664. (doi:10.1021/cm500691e)

37. Vyazovkin, S., Burnham, A.K., Criado, J.M., Pérez-Maqueda, L.A., Popescu, C. \& Sbirrazzuoli, N., 2011, ICTAC Kinetics Committee recommendations for performing kinetic computations on thermal analysis data. Thermochim. Acta 520, pp. 1-19. (doi:10.1016/j.tca.2011.03.034)

38. Khawam, A. \& Flanagan, D.R., 2006, Solid-state kinetic models: basics and mathematical fundamentals. J. Phys. Chem. B 110, pp. 17315-17328. (doi:10.1021/jp062746a)

39. Lesnikovich, A.I. \& Levchik, S. V, 1983, A method of finding invariant values of kinetic parameters. J. Therm. Anal. 27, pp. 89-94. (doi:10.1007/BF01907324)

40. Ghosh, M.K. \& Mittal, K.L., 1996, Polyimides: fundamentals and applications. New York: CRC Press. ISBN: 978-0824794668

41. Burnham, A.K. \& Braun, R.L., 1999, Global Kinetic Analysis of Complex Materials. Energy E Fuels 13, pp. 1-22. (doi:10.1021/ef9800765) 



\section{Chapter 8 \\ Highly permeable and mechanically robust silicon carbide hollow fiber membranes}

This chapter had been adapted from:

De Wit, P., E.J. Kappert, T. Lohaus, M. Wessling, A. Nijmeijer, N.E. Benes, Highly permeable and mechanically robust silicon carbide hollow fiber membranes, J. Membr. Sci., 475, pp. 480-487, doi: 10.1016/j.memsci.2014.10.045 

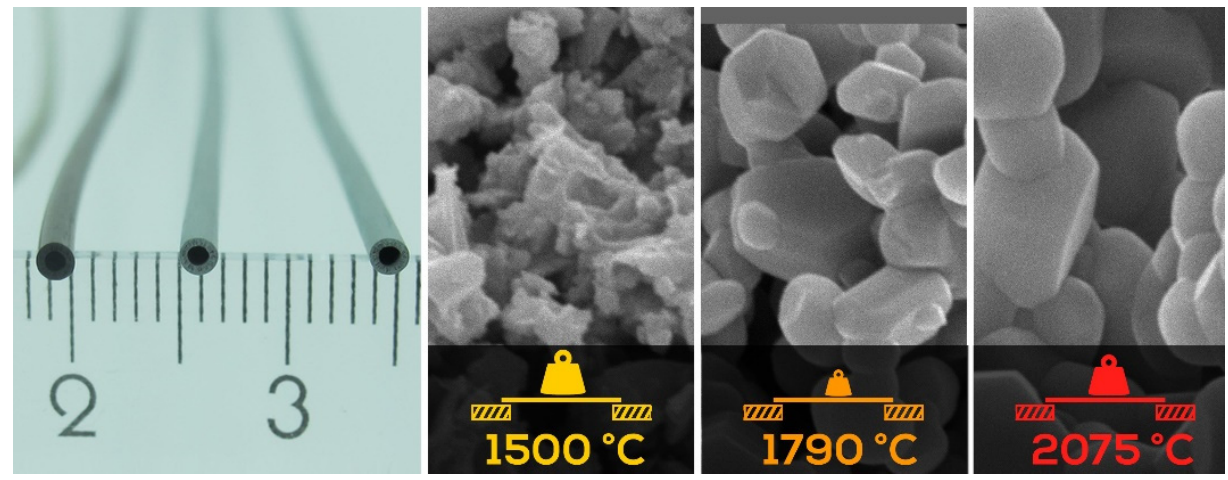

\section{Abstract}

Silicon carbide ( $\mathrm{SiC}$ ) membranes have shown large potential for applications in water treatment. Being able to make these membranes in a hollow fiber geometry allows for higher surface-to-volume ratios. This chapter presents a thermal treatment procedure that is tuned to produce porous silicon carbide hollow fiber membranes with sufficient mechanical strength. Thermal treatments up to $1500{ }^{\circ} \mathrm{C}$ in either nitrogen or argon resulted in relatively strong fibers that were still contaminated with residual carbon from the polymer binder. After treatment at a higher temperature of $1790{ }^{\circ} \mathrm{C}$, the mechanical strength decreased as a result of carbon removal, but after a treatment at even higher temperature of $2075{ }^{\circ} \mathrm{C}$ the $\mathrm{SiC}$-particles sinter together, resulting in fibers with mechanical strengths of 30-40 MPa and exceptionally high water permeabilities of $50,000 \mathrm{~L} \mathrm{~m}^{-2} \mathrm{~h}^{-1} \mathrm{bar}^{-1}$. Combined with the unique chemical and thermal resistance of silicon carbide, these properties make the fibers suitable for application in microfiltration or as a membrane support for application under demanding conditions. 


\subsection{Introduction}

The outstanding mechanical integrity and chemical stability of silicon carbide has resulted in its use in various applications in which the material has to resist harsh conditions. Examples are diesel particulate filters [1], catalyst carrier [2], and sensors that can be applied at extreme $\mathrm{pHs}$ [3]. Whereas silicon carbide has also been proposed for gas separation membranes [4-8], the application of silicon carbide membranes for liquid applications has received little attention in literature. In 2011, Hofs et al demonstrated the superb fouling resistance of silicon carbide membranes in the treatment of surface water [9]. Several companies claimed that this low-fouling behavior extents to the harsh conditions of oil/water separations [10-12].

Until now, silicon carbide membranes have been limited to flat [13], tubular $[4,14]$ and multichannel [5] geometries. All these geometries have a comparatively low surface-to-volume ratio in comparison with hollow fibers. The synthesis of inorganic hollow fibers has seen increasing attention in the last decade [15-18], but the few silicon carbide fibers that have been produced so far have showed an undesirable pore structure [19, 20] or poor mechanical stability [21].

This chapter presents a procedure for the fabrication of mechanically robust, porous silicon carbide hollow fibers via dry-wet spinning. The paper elaborates on the effects of the thermal treatment on the structure and properties of the obtained fibers, demonstrating that a felicitous thermal treatment is of key importance for the successful synthesis of highly permeable and mechanically robust silicon carbide hollow fibers.

\subsection{Experimental section}

\subsubsection{Materials}

$\alpha$-silicon carbide powders with a mean size of 0.4 and $0.6 \mu \mathrm{m}$ were supplied by Liqtech International AS (Denmark). Polyethersulfone (PES, Ultrason $^{\circledR}$ E6020P, BASF), N-methyl-2-pyrrolidone (NMP, <99.5\%, 
Sigma Aldrich) and de-ionized water (<18.2 $\mathrm{M} \Omega \mathrm{cm}^{-1}$, Milli-Q Advantage A10, Millipore) were used for drywet spinning. Prior to use, PES was dried overnight at $80{ }^{\circ} \mathrm{C}$; all other chemicals were used as received. Sintering was carried out in argon (4.5) or nitrogen (2.8) gas atmosphere (Praxair).

\subsubsection{Dry-wet spinning}

The spinning dope composition was based on prior work [22]. Silicon carbide powders were mixed in a 1:5 weight ratio $(0.4: 0.6 \mu \mathrm{m})$, added to NMP and treated ultrasonically for 30 minutes. PES was added in multiple steps to this mixture, allowing the PES to dissolve before the next amount was added. The resulting spinning mixture was composed of $36 \mathrm{wt}-\%$ of $\mathrm{SiC}, 50 \mathrm{wt}-\%$ of NMP and $14 \mathrm{wt}-\%$ of PES. After stirring overnight, vacuum was applied for 30 minutes and the mixture was left overnight to degas. For the dry-wet spinning, the mixture was forced through a spinneret by pressuring a stainless-steel vessel with nitrogen. The spinning conditions are given in Table 8-1; full details on the spinning setup can be found elsewhere [21]. After spinning, the fibers were stretched $\left(1 \mathrm{~cm} \mathrm{~m}^{-1}\right)$ and dried prior to sintering.

Table 8-1: Spinning conditions

\begin{tabular}{|c|c|}
\hline Condition & Value \\
\hline Bore liquid & $\mathrm{H}_{2} \mathrm{O}$ \\
\hline Coagulation bath & $\mathrm{H}_{2} \mathrm{O}$ \\
\hline Extrusion pressure & 2 bar \\
\hline Air gap & $3 \mathrm{~cm}$ \\
\hline Bore liquid flow rate & $7 \mathrm{ml} \mathrm{min}-1$ \\
\hline Spinneret diameter (OD/ID) & $2.0 / 0.8 \mathrm{~mm}$ \\
\hline
\end{tabular}

\subsubsection{Thermal treatment}

Thermal treatments up to $1500{ }^{\circ} \mathrm{C}$ were carried out in a STF $16 / 610$ tubular furnace (Carbolite) equipped with an alumina working tube. Samples were loaded onto $\mathrm{SiC}$ crucibles and thermally treated according to the programs given in Table 8-2. Prior to sintering, the system was 
evacuated and refilled with either argon or nitrogen three times, followed by sintering under a sweep flow of $100 \mathrm{ml} \mathrm{min}^{-1}$.

Table 8-2: Overview of the used sintering programs. For all experiments, a $5{ }^{\circ} \mathrm{C} \min ^{-1}$ heating rate was employed.

\begin{tabular}{lll}
\hline Name & Sintering & Atmosphere \\
\hline $300-\mathrm{N} 2$ & $0.5 \mathrm{~h}$ at $300{ }^{\circ} \mathrm{C}$ & Nitrogen \\
$1000-\mathrm{N} 2$ & $0.5 \mathrm{~h}$ at $300{ }^{\circ} \mathrm{C}, 3 \mathrm{~h}$ at $1000{ }^{\circ} \mathrm{C}$ & \\
$1500-\mathrm{N} 2$ & $0.5 \mathrm{~h}$ at $300{ }^{\circ} \mathrm{C}, 3 \mathrm{~h}$ at $1500{ }^{\circ} \mathrm{C}$ & \\
$300-\mathrm{Ar}$ & $0.5 \mathrm{~h}$ at $300{ }^{\circ} \mathrm{C}$ & Argon \\
$1000-\mathrm{Ar}$ & $0.5 \mathrm{~h}$ at $300{ }^{\circ} \mathrm{C}, 3 \mathrm{~h}$ at $1000{ }^{\circ} \mathrm{C}$ & \\
$1500-\mathrm{Ar}$ & $0.5 \mathrm{~h}$ at $300{ }^{\circ} \mathrm{C}, 3 \mathrm{~h}$ at $1500{ }^{\circ} \mathrm{C}$ & \\
$1790-\mathrm{Ar}^{\star}$ & $6 \mathrm{~h}$ at $1790{ }^{\circ} \mathrm{C}$ & \\
$2075-\mathrm{Ar}^{\star}$ & $0.75 \mathrm{~h}$ at $2075{ }^{\circ} \mathrm{C}$ & \\
\hline
\end{tabular}

* Samples sintered at Liqtech, Denmark. Samples were pre-sintered according to program 1500-Ar.

High-temperature sintering $\left(1500{ }^{\circ} \mathrm{C}-2075{ }^{\circ} \mathrm{C}\right)$ was carried out at Liqtech Industries A/S, Denmark, where the fibers were co-sintered with their production batches. All high-temperature sintering was carried out under argon; prior to shipping for high-temperature sintering, the samples were pre-sintered at $1500{ }^{\circ} \mathrm{C}$ for 2 hours in argon. Fiber mass $(m)$, length $(l)$ and diameter $(d)$ were determined per fiber prior to and after thermal treatment to allow for paired comparison.

\subsubsection{Characterization}

\section{SEM-EDS}

The cross section morphology, the wall thickness, and semi-quantitative elemental analysis of green and sintered fibers were obtained with a JSM6010LA scanning electron microscope equipped with an energy dispersive spectrometer (JEOL). To obtain a clean fracture, the green compacts were soaked in liquid nitrogen before fracturing. The samples were goldsputtered (13 mA, $3 \mathrm{~min}$ ) before SEM photos were taken. The EDS spectra were obtained from a cross-section of the non-sputtered fibers in lowvacuum mode. 


\section{TGA-MS}

Thermogravimetric analysis (TGA) was performed on a STA 449 F3 Jupiter $^{\circledR}$ (Netzch) fitted with a TG-only sample holder. Measurements were performed under $70 \mathrm{ml} \mathrm{min}{ }^{-1}$ argon at a heating rate of $20{ }^{\circ} \mathrm{C} \mathrm{min}{ }^{-1}$ from room temperature to $1500{ }^{\circ} \mathrm{C}$. Temperature correction by melting standard and a blank correction with an empty cup were carried out prior to the measurements. Small fragments of dried fibers were used as sample and their mass was determined externally.

Gases evolving during the thermogravimetric analysis were transferred to a mass spectrometer (MS, QMS 403 D Äeolos ${ }^{\circledR}$, Netzsch) by a glass capillary. TGA and MS start times were synchronized; no correction was applied for the time offset caused by the transfer line time (estimated $<30 \mathrm{sec}$, systematic offset). First, a bar graph scan for $m / z=1-100$ amu was performed to determine the evolving $m / z$-numbers (data not included here). The detected $m / z$-numbers $(2,12,14-18,20,2630,32,36,38,40$, $44,48-52,56,60-61,64,67-68)$ were selected and recorded more accurately in multiple-iondetection mode, with a dwell of $0.5 \mathrm{sec}$ per $\mathrm{m} / \mathrm{z}^{-}$ value and a resolution of 50 .

\section{Clean water permeation}

The clean water flux was measured using an OSMO Inspector 2 (Convergence, The Netherlands). Experiments were carried out in deadend mode under constant flux operation with three different flux settings for each fiber. Custom-made single-fiber modules were used made out of Plexiglass tubing and sealed with PUR435/PUR-N 2-component glue (Intercol, Germany). The permeate flow $\Phi_{\mathrm{V}}\left(\mathrm{L} \mathrm{h}^{-1}\right)$ was recorded as a function of the transmembrane pressure. The pressure drop over the fiber is assumed negligible. The permeability was calculated using equation 5-1, where $A$ is the effective membrane area.

$$
\Pi=\frac{\Phi_{\mathrm{V}}}{\left(P_{\text {feed }}-P_{\text {permeate }}\right) A}
$$




\section{Conductivity}

Electrical conductivity was measured using a home-built 4-probe conductivity meter. Current was applied at the outer probes that were 7 $\mathrm{cm}$ apart; the voltage drop was measured with two inner probes $3 \mathrm{~cm}$ apart. Measurements were performed at room temperature on three different spots at each fiber.

\section{Mercury intrusion porosimetry}

The volume of mercury intruded was measured as function of the pressure using a Poremaster PM-33-14 (Quantachrome $\left.{ }^{\circledR}\right)$. The helium density was measured using an AccuPyc II 1340 gas displacement analyzer (Micromeritics). Pressure $P$ and volume mercury intruded $V_{\mathrm{Hg}}$ were recorded, and data processing was performed using Matlab ${ }^{\circledR}$ [23]. The pore diameter corresponding to a certain pressure is calculated using Washburn's equation [24] (see the detailed calculation given in the Supplementary Information in reference [46]). The volume based pore size distribution is calculated via equation 5-2.

$$
D_{\mathrm{V}}(r)=\frac{d V_{\mathrm{Hg}}}{d P}\left|\frac{P^{2}}{2 \gamma \cos \theta}\right|
$$

The porosity is computed by combining apparent density measured using helium $\rho_{\mathrm{He}}$ and mercury $\rho_{\mathrm{Hg}}$ and calculated using equation 3 .

$$
\varepsilon=100\left(1-\frac{\rho_{\mathrm{Hg}}}{\rho_{\mathrm{He}}}\right)
$$

\section{Mechanical strength}

Mechanical testing (4-point bending test) was carried out according to ASTM C1161-02 [25] using a 5564A mechanical testing bench (Instron). Sintered fibers were cut to a length of $5 \mathrm{~cm}$ and tested with a crosshead speed of $2 \mathrm{~mm} \mathrm{~min}^{-1}$ at room temperature. 
The force and deflection curves were measured and subsequently the bending strength for sample $j$ was calculated using Equation 5-4,

$$
\sigma_{j}=\frac{16 F_{j} K d_{o, j}}{\pi\left(d_{o, j}^{4}-d_{i, j}^{4}\right)}
$$

where $F_{j}$ is the force at fracture, $K$ half the difference between outer and inner span $(5 \mathrm{~mm})$ and $d_{i, j}$ and $d_{o, j}$ are the inner and outer diameter of the hollow fiber $j$ at its fracture site. The error in the calculated bending strength was estimated using $\Delta F= \pm 0.5 \%, \Delta d_{i}=\Delta d_{o}=20 \mu \mathrm{m}$ and $\Delta K=$ $50 \mu \mathrm{m}$. For each fiber a minimum of 20 measurements were taken and the obtained bending strengths were fitted by a Weibull cumulative probability function, where the characteristic strength $\sigma_{o}$ and the shape parameter $m_{\text {shape }}$ are used as fitting parameters (full details can be found in the Supplementary Information in reference [46]).

\subsection{Results and discussion}

Figure 8-1 provides a set of pictures that show the fiber morphology before and after thermal treatments under argon at various temperatures. Figure 8-1B and Figure 8-1C display the fiber morphology of green hollow fibers after drying. Via dry-wet spinning prepared fibers consist of a PES network that is loaded with silicon carbide particles, with an asymmetric structure with finger-like voids at the lumen side and a sponge-like outer layer. This morphology is typical for inorganic fibers [15, 26]. Figure 8-1C shows the presence of $10 \mu \mathrm{m}$-sized particles dispersed throughout the fiber. A close-up of these particles (not shown here) indicated that the grains are presumably aggregates or agglomerates of smaller silicon carbide grains.

Figure 8-1D-F show that sintering at temperatures of 1500 to $2075{ }^{\circ} \mathrm{C}$ has no apparent effect on the morphology of the silicon carbide fibers. The finger-like voids and sponge-like structure are both preserved. At temperatures exceeding $1790{ }^{\circ} \mathrm{C}$, the sponge-like layer develops into a more open structure in which individual grains are clearly visible (see Figure 8-4 for close-up scanning electron micrographs). The minor 
changes in morphology are reflected in small differences in radial dimensions between the green and the sintered fibers.

Prior to sintering, the dried fibers had an outer diameter of $1.78 \mathrm{~mm} \pm 0.02 \mathrm{~mm}$. The shrinkage in radial $\left(d_{\text {sintered }} / d_{\text {green }}\right)$ and longitudinal $\left(l_{\text {sintered }} / l_{\text {green }}\right)$ directions as a result of sintering at $2075{ }^{\circ} \mathrm{C}$ was limited to $5 \%$ and $8 \%$, respectively (see the Supplementary Information in reference [46]). No difference was observed between sintering in argon or nitrogen atmospheres.

\subsubsection{Thermal treatment of the silicon carbide fibers}

The temperature dependency of the mass loss of a silicon carbide hollow fiber and the gases that evolve concurrently are shown in Figure 8-2 for heating under argon up to $1500{ }^{\circ} \mathrm{C}$ (left panel), and for a consecutive 8 hour dwell at $1500{ }^{\circ} \mathrm{C}$ (right panel). At lower temperatures $\left(25-250^{\circ} \mathrm{C}\right)$, a minor mass loss step is recorded that is accompanied by the release of water.

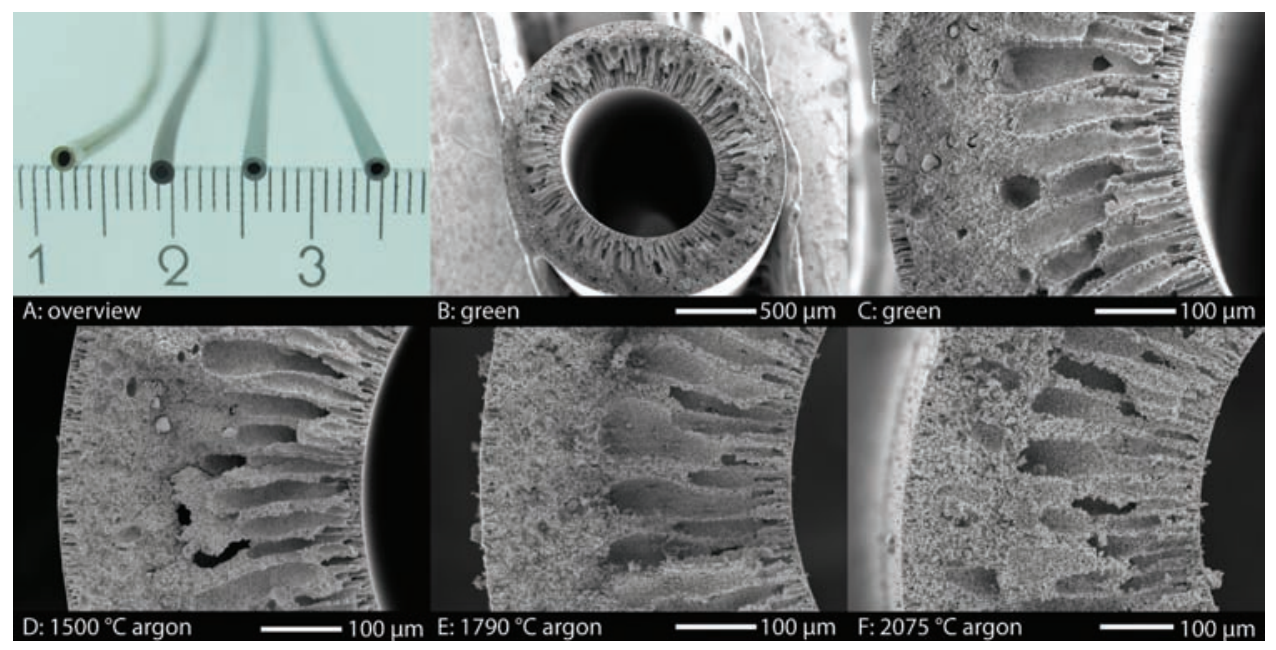

Figure 8-1: (A) Photograph of, from left to right, a green fiber, a fiber sintered at $1500{ }^{\circ} \mathrm{C}$, a fiber sintered at $1790{ }^{\circ} \mathrm{C}$, and a fiber sintered at $2075{ }^{\circ} \mathrm{C}$; and cross-sectional images of $(\mathrm{B})$ a green, (C) a green, (D) a fiber sintered at $1500{ }^{\circ} \mathrm{C},(\mathrm{E})$ a fiber sintered at $1790{ }^{\circ} \mathrm{C}$, and (F) a fiber sintered at $2075{ }^{\circ} \mathrm{C}$. All fibers shown here were sintered under argon. 

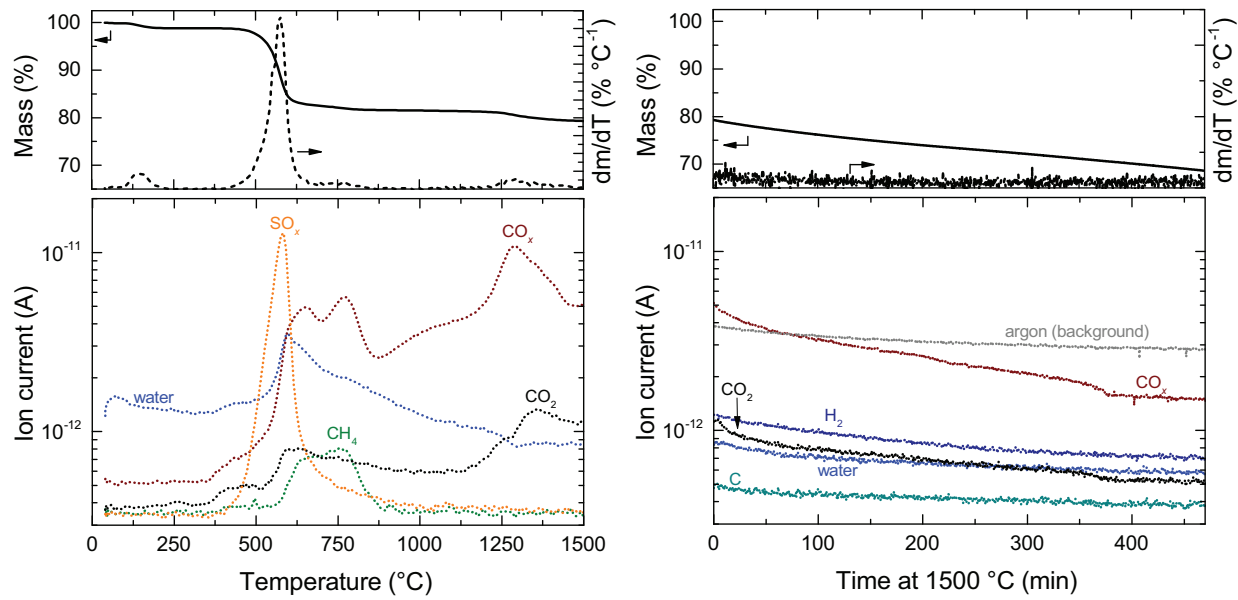

Figure 8-2: TGA-MS data of the thermal processing of SiC hollow fibres under argon with (left panel) a heating rate of $20{ }^{\circ} \mathrm{C} \mathrm{min}^{-1}$ followed by (right panel) a 8 hour dwell at $1500{ }^{\circ} \mathrm{C}$.

This mass loss is attributed to the continued drying of sorbed water from the $\mathrm{SiC}$ fibers. A second mass loss step is recorded at intermediate temperatures $\left(450-650{ }^{\circ} \mathrm{C}\right)$, where $\mathrm{SO}_{2}, \mathrm{CO}, \mathrm{CO}_{2}$ and water are the main gases emitted, followed by a minor mass loss concurring with release of methane, $\mathrm{CO}$ and $\mathrm{CO}_{2}$ at $750{ }^{\circ} \mathrm{C}$. This observed decomposition process matches closely to the reported decomposition of PES under an argon atmosphere [27-29], indicating that the presence of the silicon carbide in our hollow fibers has had no (apparent) effect on the decomposition process of the PES.

Further mass loss is recorded at temperatures exceeding $1150{ }^{\circ} \mathrm{C}$. This mass loss step continues up to $1500{ }^{\circ} \mathrm{C}$ and persists for a full 8-hour dwell period at this temperature. Mainly $\mathrm{CO}$ and $\mathrm{CO}_{2}$ evolve during this step. As the reaction atmosphere is free of oxygen, the formation of $\mathrm{CO}$ and $\mathrm{CO}_{2}$ is attributed to the following reaction $[30,31]$ :

$$
\mathrm{SiO}_{2}(\mathrm{~g})+3 \mathrm{C}(\mathrm{s}) \rightarrow \mathrm{SiC}(\mathrm{s})+2 \mathrm{CO}(\mathrm{g})
$$


The silica originates from impurities in the silicon carbide [32]. The production of $\mathrm{CO}_{2}$ would be the result of only two carbon atoms reacting with the silica. The reaction between silica and silicon carbide is reported to be inhibited at these temperatures in the presence of free carbon [33]. The rate of reaction 5-5 is controlled by the diffusion of CO through the $\mathrm{SiC}$ fiber wall [31]. Among the main parameters that influence the rate of this process are the porosity, tortuosity, and sample thickness of the material. In this respect, the fiber morphology — having a bore and large voids - would result in shorter times required for the thermal treatment than those required for a dense or mesoporous silicon carbide sample.

In Figure 8-3A, the mass of the fibers is shown after thermal treatment in nitrogen or argon. Because of the temperature limitations of the TGapparatus and tubular furnaces, temperature treatment at higher temperatures $\left(>1500^{\circ} \mathrm{C}\right)$ were performed in an industrial furnace, in which the fibers are co-fired along with the regular production. The results obtained up to $1500{ }^{\circ} \mathrm{C}$ are in excellent agreement with the previously discussed TG experiments.

However, at temperatures beyond $1500{ }^{\circ} \mathrm{C}$, a deviation from the mass loss trend is observed. At these temperatures, the fiber mass increases slowly with increasing sintering temperatures. Mass conservation dictates that this increase in mass results from reactions with gases in the atmosphere in the furnace. This cannot be the inert argon gas. It is known that the vapor pressure of silica is non-negligible at these temperatures, and that silica originating from the co-fired samples and/or the furnace can be deposited onto the samples. At the fiber, this silica can then react with the free carbon through reaction 5-5, yielding silicon carbide and carbon monoxide. At these high temperatures, an opposite reaction, in which silicon carbide reacts with the silica, can occur as well [32]. Either the resulting silicon oxide will be removed via the vapor phase, or it will disproportionate into silica and silicon at room temperature [34]. 
To test this hypothesis, the electrical conductivity of the silicon carbon fibers was measured after sintering. The electrical conductivity of amorphous carbon (up to $10^{6} \mathrm{~S} \mathrm{~m}^{-1}$ ) is multiple orders of magnitude higher than that of silicon carbide (down to $10^{-4} \mathrm{~S} \mathrm{~m}^{-1}$ under nitrogen atmosphere) or voids $[35,36]$. Hence, the deposition of silicon dioxide and the removal of carbon via reaction 5-5 should result in a sharp decline in the conductivity of the fibers. In Figure $8-3 \mathrm{~B}$, the electrical conductivity is given for sintered hollow fibers after various treatments under nitrogen and argon. The high electrical conductivity of the samples up to $1500{ }^{\circ} \mathrm{C}$ demonstrates that carbon is present and forms a percolative pathway through the material. Fitting of the data with Bruggeman's Effective Medium Approximation proved to be impossible, which demonstrated that the carbon is not present in the form of spherical inclusions, but more likely forms a film that surrounds the silicon carbide particles.

Above $1500{ }^{\circ} \mathrm{C}$, the large drop in conductivity indicates the removal of the carbon from the fibers. To verify the presence of carbon in the 1500-Ar fiber, and the absence of carbon in the 2075-Ar fiber, these fibers were measured with TGA under air. The TGA-runs give a clear indication for the presence of $13.5 \mathrm{wt}-\%$ residual carbon in the $1500-\mathrm{Ar}$ fiber, and the absence of residual carbon in the 2075-Ar fiber (see the Supplementary Information in reference [46]). 

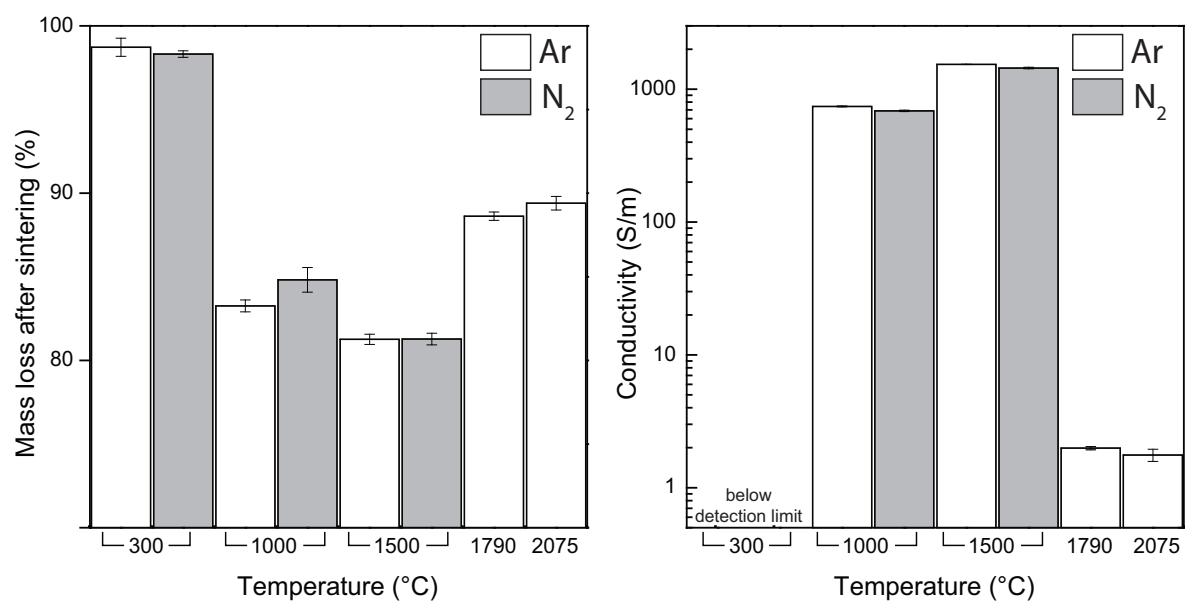

Figure 8-3: (A) Final mass after thermal treatment (with 95\% confidence interval) after sintering at certain temperatures and (B) conductivity after sintering at certain temperature. A full explanation of the thermal treatment steps is given in the text.

\subsubsection{Microstructure of the treated $\mathrm{SiC}$ fibers}

\section{Scanning Electron Micrographs}

Figure 8-4 shows the microstructure of the hollow fibers as a function of sintering temperature $\left(1500-2400{ }^{\circ} \mathrm{C}\right)$. The microstructures of the fibers sintered at $1500{ }^{\circ} \mathrm{C}$ (Figure $8-4 \mathrm{~A}$ and $\mathrm{B}$ ) reveal submicron silicon carbide particles, still bound together by the residual carbon. No significant sintering has taken place, which is as expected for the comparatively short holding time of 2 hours just above the sintering temperature $\left(T_{\text {Tamman }} \sim\right.$ $1250{ }^{\circ} \mathrm{C}$ ). At higher temperatures, sintering is evident from the significant grain growth that is a consequence of Ostwald ripening $\left(1790{ }^{\circ} \mathrm{C}\right.$ in Figure $8-4 \mathrm{C}$ and $2075{ }^{\circ} \mathrm{C}$ in Figure $\left.8-4 \mathrm{D}\right)$. The grains grow from loose grains, smaller than $0.5 \mu \mathrm{m}$ in size, to strongly necked particles of approximately $2 \mu \mathrm{m}$ at $2075{ }^{\circ} \mathrm{C}$, and form an interconnected pore structure with large-sized pores. This degree of grain growth agrees well with reported microstructures of synthesized $\mathrm{SiC}$ substrates at comparable temperatures without the use sintering additives $[1,4]$. 


\section{Pore-size distribution}

Figure 8-5 shows the volume-based pore size distribution of fibers sintered under argon. It can be seen that the median pore size increases with increasing sintering temperature. The green fiber shows an apparent median pore size of $125 \mathrm{~nm}$, consisting of both pores in the polymeric matrix and voids between the ceramic particles.

After sintering at $1500{ }^{\circ} \mathrm{C}$ many of the smaller pores disappear as the polymer is converted into elemental carbon - leaving only the voids between the ceramic particles. This results into a bell-shaped pore size distribution with a median pore size of $500 \mathrm{~nm}$. Still a considerable amount of residual carbon is present in this fiber, as a subsequent oxidation step further opens up pores in the $100-500 \mathrm{~nm}$ range (see the Supplementary Information in reference [46]).

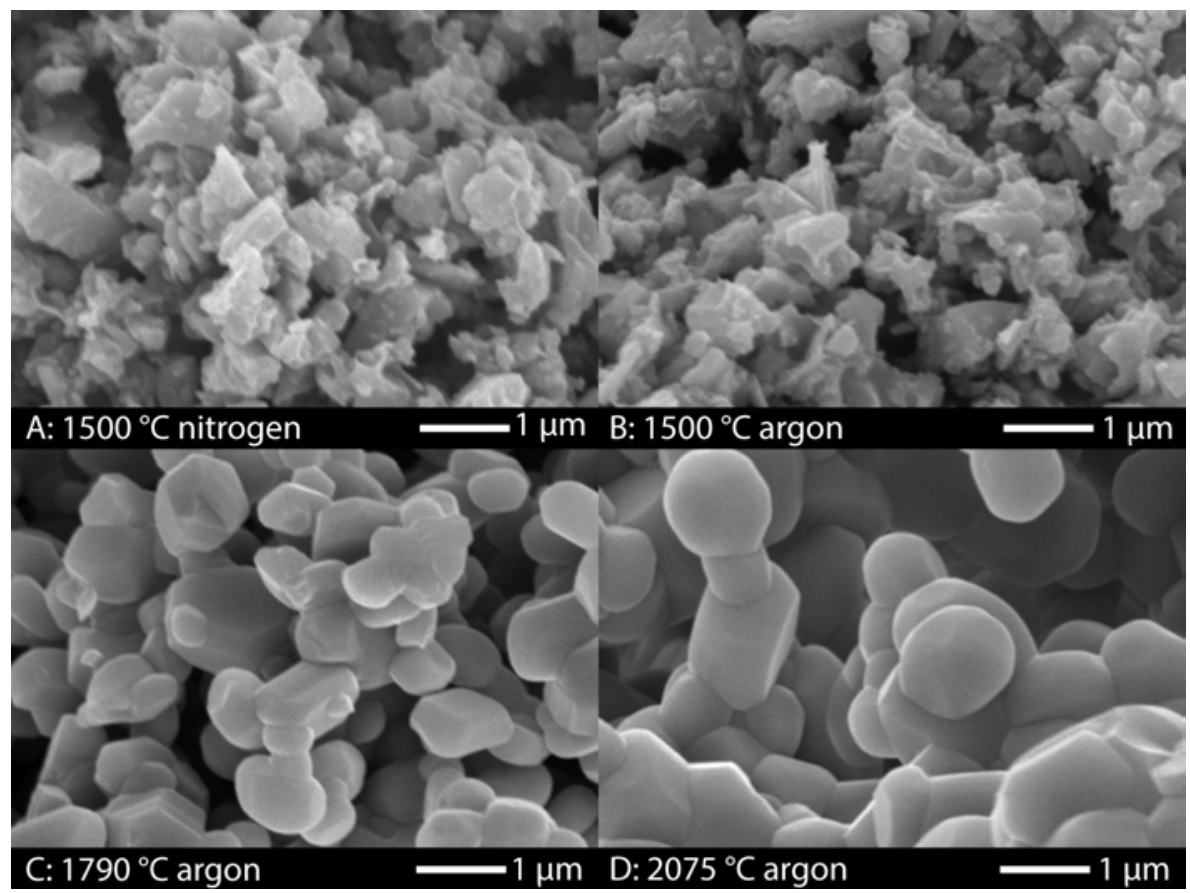

Figure 8-4: Cross section microstructure for sintered silicon carbide fibers. Details about the heat treatment can be found in Table 2.1500 ${ }^{\circ} \mathrm{C}$ sintered fibers in nitrogen (A) and argon (B). $1790{ }^{\circ} \mathrm{C}(\mathrm{C}), 2075^{\circ} \mathrm{C}$ (D) were sintered in argon atmosphere. 
At higher temperatures $\left(1790-2075{ }^{\circ} \mathrm{C}\right)$, a strong peak broadening of the pore size is observed, combined with a shift in the pore size to larger values $(>1000 \mathrm{~nm})$. The increase in pore size agrees well with the observed increase in particle size (Figure $8-4$ ). The change in pore size does not reflect strongly in the fibers' porosities (Table 8-3), as the porosity indicates there is no significant densification, even at high sintering temperatures.

Table 8-3: Porosity for green and sintered fibers, including standard error (details on the error analysis are given in the Supplementary Information in reference [46]).)

\begin{tabular}{lllll}
\hline Sample & Green & SiC1500Ar & SiC1790Ar & SiC2075Ar \\
Porosity & $62.8 \pm 9.7$ & $64.4 \pm 6.5$ & $70.0 \pm 4.7$ & $63.5 \pm 4.8$ \\
\hline
\end{tabular}

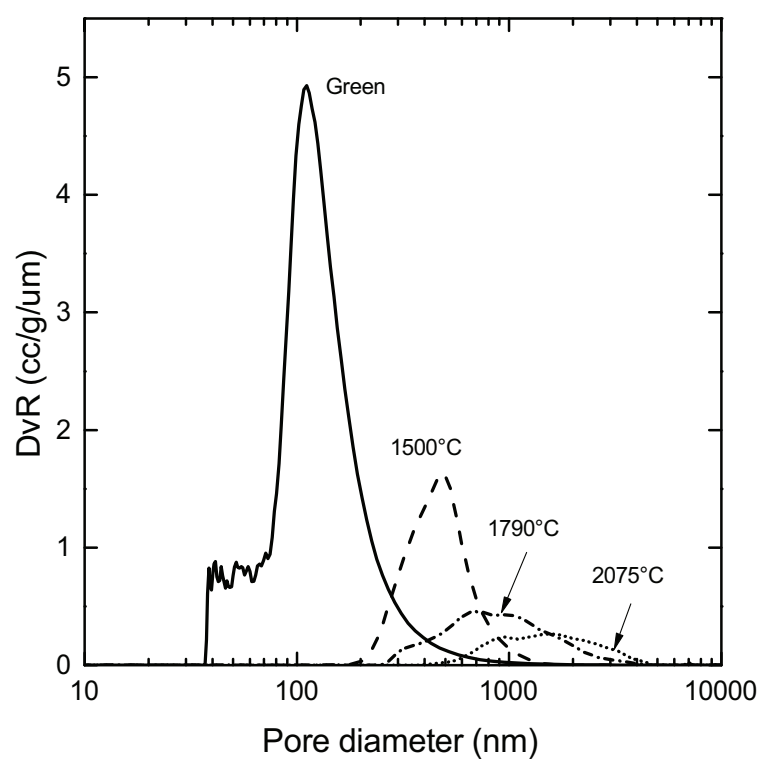

Figure 8-5: Volume-based pore size distribution by mercury intrusion for various sintering temperatures under argon atmosphere. 


\subsubsection{Properties of the SiC fibers \\ Mechanical strength}

Figure 8-6 shows the mechanical strength as a function of the sintering temperature and sintering atmosphere. The lower and upper error bars in the left panel indicate a cumulative probability of failure of $5 \%$ and $95 \%$, respectively. The right panel of Figure 8-6 demonstrates in detail how these values were obtained from a Weibull-fit of the cumulative probability of failure to the bending strength (see the detailed figures in the Supplementary Information in reference [46]).).

From the data, it can be concluded that there is no strong influence of the sintering atmosphere on the characteristic strength for the $1000{ }^{\circ} \mathrm{C}$ sintered sample. A large reduction in the strength is observed between the fibers sintered up to $1500{ }^{\circ} \mathrm{C}$ and at $1790{ }^{\circ} \mathrm{C}$. This loss of strength is attributed to the removal of residual carbon. As only minor neck formation has developed between the silicon carbide particles at $1500{ }^{\circ} \mathrm{C}$, the carbon is required to bind together the particles. Although an increased sintering temperature of $1790{ }^{\circ} \mathrm{C}$ increases the inherent strength of the SiC-network through neck formation, this increased strength is offset by the removal of the carbon. Only at the highest studied sintering temperature of $2075{ }^{\circ} \mathrm{C}$, progressive sintering of the silicon carbide particles led to a desired mechanical strength.

At first glance the mechanical strength of these silicon carbide fibers appears to be low in comparison with other reported ceramic hollow fibers [18,37-39]. These values, however, cannot be directly compared. In the present study, the bending strength was obtained via a 4-point bending test, resulting in a lower value for the mechanical strength as compared to the often-used 3-point bending test [40]. In addition, assessing the mechanical strength of a ceramic based on small sample numbers requires caution as sample-to-sample differences might introduce large errors. 


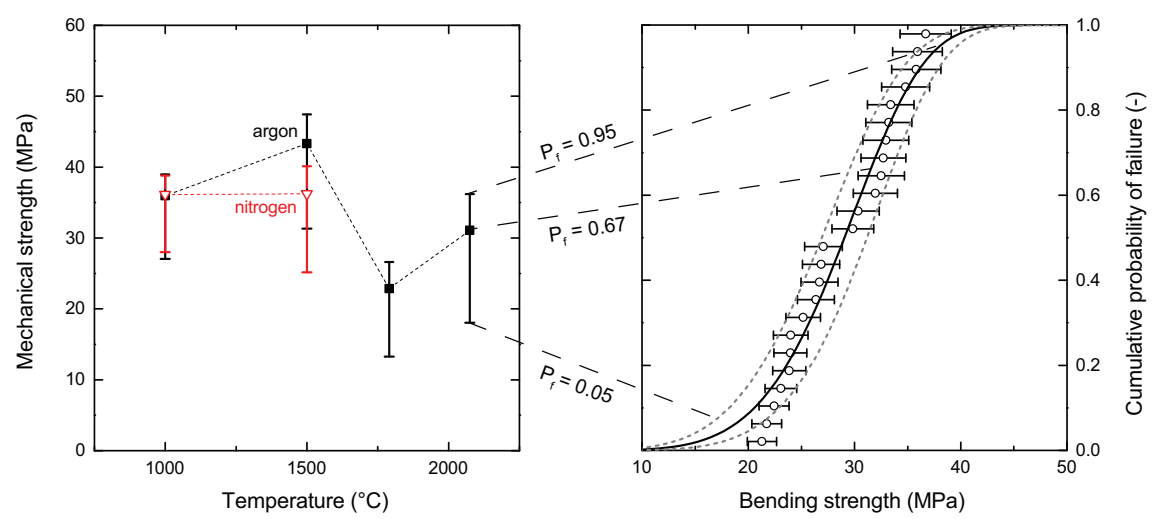

Figure 8-6: Summary of measured mechanical strengths at different temperature and atmosphere. In the left panel, the symbol (square for argon, triangle for nitrogen) denotes the characteristic strength $(\sigma 0)$ calculated from Weibull fitting. The lower error bar denotes the strength at which $5 \%$ of the fibers would fail. The upper error bar denotes strength at which $95 \%$ of the fibers would fail. The right panel shows the Weibull cumulative probability function for an 2075Ar sample, showing the measured mechanical strength per sample (were error bars denote measurement errors), fit and lower/upper boundaries.

Even though in this study a limited sample size of 24 fibers has been used [41-43], these results provide a better insight in the mechanical behavior than studies performed on limited sample sizes.

\section{Clean-water permeation}

Figure 8-7 shows the clean water permeability for fibers sintered at various temperatures. The fibers sintered at $1000{ }^{\circ} \mathrm{C}$ show a clean water permeability of approximately $500 \mathrm{~L} \mathrm{~m}^{-2} \mathrm{~h}^{-1}$ bar $^{-1}$ for both sintering atmospheres. After sintering at $1500{ }^{\circ} \mathrm{C}$ an increase in permeability to values in the order to $1000-1200 \mathrm{~L} \mathrm{~m}^{-2} \mathrm{~h}^{-1} \mathrm{bar}^{-1}$ is observed. The sintering atmosphere has little influence on the clean water permeability for these fibers. 


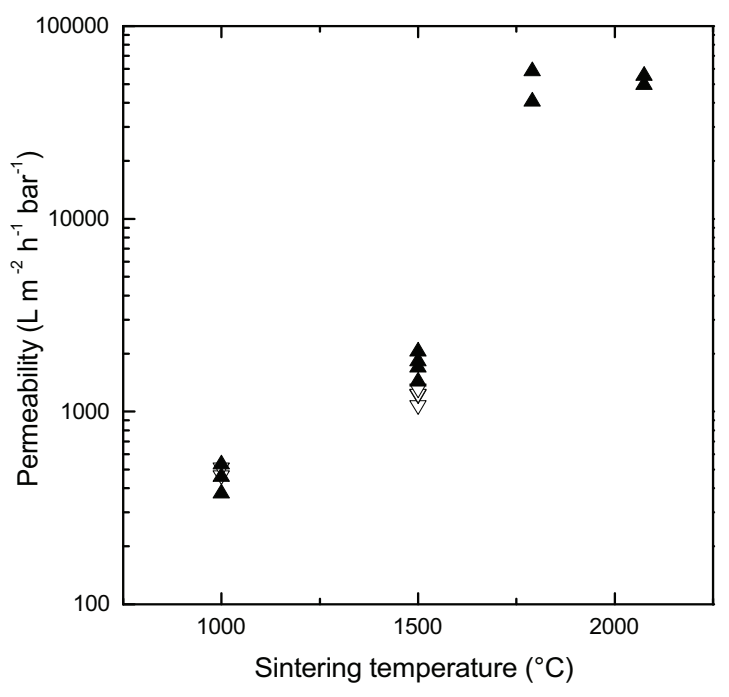

Figure 8-7: Clean water permeability for silicon carbide fibers sintered at various temperatures. The open symbols represent fibers sintered in a nitrogen atmosphere; the closed symbols represent the fibers sintered in an argon atmosphere. Each symbol represents a single fiber.

After high temperature sintering the clean water permeability increases more than tenfold to values in the order of $50,000 \mathrm{~L} \mathrm{~m}^{-2} \mathrm{~h}^{-1} \mathrm{bar}^{-1}$. Sintering at these high temperatures not only removed the residual carbon but also results in larger pores, yielding this increased clean water permeability. The observed clean water permeability of the fibers in this study (pore size $0.5-3 \mu \mathrm{m})$ is approximately a factor 50 higher than that reported for alumina (pore size 0.1-1.4 $\mu \mathrm{m}$ ) [44,45], a factor 5 higher than that reported for titanium (pore size 1-3 $\mu \mathrm{m}$ ) [39] and a factor 2 higher than that reported for silicon nitride hollow fibers (pore size 0.5-0.9 $\mu \mathrm{m}$ ) [37].

Burst pressure experiments were conducted up to a transmembrane pressure of 20 bar without rupture of the fiber, further substantiating the mechanical robustness of the fibers (details are given in the Supplementary Information in reference [46]). 


\subsection{Conclusions}

Porous silicon carbide hollow fiber membranes with outer diameters of $1.8 \mathrm{~mm}$ were prepared successfully by dry-wet spinning followed by a thermal treatment at various temperatures. Tuning of the microstructure by changing the sintering temperature allowed for the optimization of pore size and mechanical strength of the fibers. Although sintering at $1500{ }^{\circ} \mathrm{C}$ yielded mechanically stable fibers, the carbon residue of the polymeric binder effectively blocks the pores of the fiber, resulting in low water fluxes. The carbon binds the SiC-particles together, as is evident from the sharp decrease in mechanical strength when carbon is removed upon heating to $1790{ }^{\circ} \mathrm{C}$. Treatments at temperatures as high as $2075{ }^{\circ} \mathrm{C}$ are required to sufficiently sinter together the silicon carbide particles. The resulting fibers show exceptionally high clean-water fluxes in the order of $50,000 \mathrm{~L} \mathrm{~m}^{-2} \mathrm{~h}^{-1}$ at a differential pressure of $1 \mathrm{bar}$. With pore sizes in the order of microns, the membranes are directly applicable as a microfiltration membrane, or can be used as a substrate for UF or gas-separation membranes.

\subsection{Acknowledgements}

The authors would like to acknowledge LiqTech International A/S, Denmark for access to their high temperature furnaces. 


\subsection{References}

1. Thomé, T., Capelle, M., Thomé, L., Prenant, T. \& Néret, M., 2012, Thermal Oxidation of Sintered Silicon Carbide Used for Diesel Particulate Filter Walls. J. Ceram. Sci. Technol. 3, pp. 89-94. (doi:10.4416/JCST2012-00006)

2. Díaz, J.A., Calvo-Serrano, M., de la Osa, A.R., García-Minguillán, A.M., Romero, A., Giroir-Fendler, A. \& Valverde, J.L., 2014, $\beta$-silicon carbide as a catalyst support in the Fischer-Tropsch synthesis: Influence of the modification of the support by a pore agent and acidic treatment. Appl. Catal. A Gen. 475, pp. 82-89. (doi:10.1016/j.apcata.2014.01.021)

3. Rosso, M., Arafat, A., Schroën, K., Giesbers, M., Roper, C.S., Maboudian, R. \& Zuilhof, H., 2008, Covalent attachment of organic monolayers to silicon carbide surfaces. Langmuir 24, pp. 4007-12. (doi:10.1021/la704002y)

4. Suwanmethanond, V., Goo, E., Liu, P.K.T., Johnston, G., Sahimi, M. \& Tsotsis, T.T., 2000, Porous silicon carbide sintered substrates for high-temperature membranes. Ind. Eng. Chem. Res. 39, pp. 3264-3271. (doi:10.1021/ie0000156)

5. Deng, W., Yu, X., Sahimi, M. \& Tsotsis, T.T., 2014, Highly permeable porous silicon carbide support tubes for the preparation of nanoporous inorganic membranes. J. Membr. Sci. 451, pp. 192-204. (doi:10.1016/j.memsci.2013.09.059)

6. Chae, S., Kim, Y. \& Song, I., 2009, Porosity control of porous silicon carbide ceramics. J. Eur. Ceram. Soc. 29, pp. 2867-2872. (doi:10.1016/j.jeurceramsoc.2009.03.027)

7. Chen, F., Mourhatch, R., Tsotsis, T.T. \& Sahimi, M., 2008, Experimental studies and computer simulation of the preparation of nanoporous silicon-carbide membranes by chemical-vapor infiltration/chemical-vapor deposition techniques. Chem. Eng. Sci. 63, pp. 1460-1470. (doi:10.1016/j.ces.2007.12.001)

8. Elyassi, B., Deng, W., Sahimi, M. \& Tsotsis, T.T., 2013, On the use of porous and nonporous fillers in the fabrication of silicon carbide membranes. Ind. Eng. Chem. Res. 52, pp. 10269-10275. (doi:10.1021/ie401116b)

9. Hofs, B., Ogier, J., Vries, D., Beerendonk, E.F. \& Cornelissen, E.R., 2011, Comparison of ceramic and polymeric membrane permeability and fouling using surface water. Sep. Purif. Technol. 79, pp. 365-374. (doi:10.1016/j.seppur.2011.03.025)

10. Liqtech, 2012, Success for LiqTech ceramic membranes in oil \& gas trial. Filtr. Ind. Anal. 2012, pp. 4. (doi:10.1016/S1365-6937(12)70350-7)

11. Veolia Water Solutions and Technology, 2010, Veolia adds silicon carbide membranes to its CeraMem range. Membr. Technol. 2010, pp. 4. (doi:10.1016/S0958-2118(10)70102-6) 
12. Neufert, R., Moeller, M. \& Bakshi, A., 2013, Dead-end silicon carbide microfilters for liquid filtration. In Advances in Bioceramics and Porous Ceramics VI (eds R. Narayan P. Colombo S. Kirihar \& S. Widjaja), Hoboken, NJ, USA: John Wiley \& Sons, Inc. (doi:10.1002/9781118807811.ch10)

13. Lin, P. \& Tsai, D., 1997, Preparation and analysis of a silicon carbide composite membrane. J. Am. Ceram. Soc. 72, pp. 365-372. (doi:10.1111/j.11512916.1997.tb02839.x)

14. Facciotti, M., Boffa, V., Magnacca, G., Jørgensen, L.B., Kristensen, P.K., Farsi, A., König, K., Christensen, M.L. \& Yue, Y., 2014, Deposition of thin ultrafiltration membranes on commercial SiC microfiltration tubes. Ceram. Int. 40, pp. 32773285. (doi:10.1016/j.ceramint.2013.09.107)

15. Tan, X., Liu, S. \& Li, K., 2001, Preparation and characterization of inorganic hollow fiber membranes. J. Membr. Sci. 188, pp. 87-95. (doi:10.1016/S03767388(01)00369-6)

16. De Jong, J., Benes, N.., Koops, G.. \& Wessling, M., 2004, Towards single step production of multi-layer inorganic hollow fibers. J. Membr. Sci. 239, pp. 265-269. (doi:10.1016/j.memsci.2004.02.039)

17. Husain, S. \& Koros, W.J., 2009, Macrovoids in Hybrid Organic/Inorganic Hollow Fiber Membranes. Ind. Eng. Chem. Res. 48, pp. 2372-2379. (doi:10.1021/ie801008j)

18. Liu, S., Li, K. \& Hughes, R., 2003, Preparation of porous aluminium oxide $\left(\mathrm{Al}_{2} \mathrm{O}_{3}\right)$ hollow fibre membranes by a combined phase-inversion and sintering method. Ceram. Int. 29, pp. 875-881. (doi:10.1016/S0272-8842(03)00030-0)

19. Terpstra, R., Eijk, J. Van \& Feenstra, F., 1998, Method for the production of ceramic hollow fibres. US Pat. 5,707,584

20. Shin, D.-G., Kong, E.-B., Cho, K.-Y., Kwon, W.-T., Kim, Y., Kim, S.-R., Hong, J.-S. \& Riu, D.-H., 2013, Nano-Structure Control of SiC Hollow Fiber Prepared from Polycarbosilane. J. Korean Ceram. Soc. 50, pp. 301-307. (doi:10.4191/kcers.2013.50.4.301)

21. Luiten-Olieman, M.W.J., Raaijmakers, M.J.T., Winnubst, L., Bor, T.C., Wessling, M., Nijmeijer, A. \& Benes, N.E., 2012, Towards a generic method for inorganic porous hollow fibers preparation with shrinkage-controlled small radial dimensions, applied to $\mathrm{Al}_{2} \mathrm{O}_{3}, \mathrm{Ni}, \mathrm{SiC}$, stainless steel, and YSZ. J. Membr. Sci. 407408, pp. 155-163. (doi:10.1016/j.memsci.2012.03.030)

22. Luiten-Olieman, M., Winnubst, L., Nijmeijer, A., Wessling, M. \& Benes, N.E., 2011, Porous stainless steel hollow fiber membranes via dry-wet spinning. J. Membr. Sci. 370, pp. 124-130. (doi:10.1016/j.memsci.2011.01.004)

23. The MathWorks, 2012, MATLAB and Optimization Toolbox, Release 2012b. 
24. León, C., 1998, New perspectives in mercury porosimetry. Adv. Colloid Interface Sci. 66-77, pp. 341-372. (doi:10.1016/S0001-8686(98)00052-9)

25. ASTM, 2002, C1161-02 Standard Test Method for Flexural Strength of Advanced Ceramics at Ambient Temperature. ASTM Int. West Conshohocken, PA , pp. 1-21. (doi:10.1002/app.20134)

26. Kingsbury, B. \& Li, K., 2009, A morphological study of ceramic hollow fibre membranes. J. Membr. Sci. 328, pp. 134-140. (doi:10.1016/j.memsci.2008.11.050)

27. Gupta, Y. \& Chakraborty, A., 2004, Thermal and thermooxidative degradation of engineering thermoplastics and life estimation. J. Appl. Polym. Sci. 92, pp. 17371748.

28. Li, X.-G., Shao, H.-T., Bai, H., Huang, M.-R. \& Zhang, W., 2003, Highresolution thermogravimetry of polyethersulfone chips in four atmospheres. J. Appl. Polym. Sci.90, pp. 3631-3637. (doi:10.1002/app.13091)

29. Perng, L.-H., 2001, Comparison of thermal degradation characteristics of poly(arylene sulfone)s using thermogravimetric analysis/mass spectrometry. $J$. Appl. Polym. Sci. 81, pp. 2387-2398. (doi:10.1002/app.1679)

30. Baird, J.D. \& Taylor, J., 1958, Reaction between silica and carbon and the activity of silia in slag solution. Trans. Faraday Soc. 54, pp. 526-539. (doi:10.1039/TF9585400526)

31. Kaza, A., Matthewson, M.J., Niesz, D., Haber, R.L. \& Rossi, M.A., 2009, A Model of Gas-Phase Transport During the Initial Stages of Sintering of Silicon Carbide. J. Am. Ceram. Soc. 92, pp. 2517-2527. (doi:10.1111/j.1551-2916.2009.03252.x)

32. Rijswijk, W. \& Shanefield, D., 1990, Effects of carbon as a sintering aid in silicon carbide. J. Am. Ceram. Soc. 73, pp. 148-149. (doi:10.1111/j.11512916.1990.tb05109.x)

33. Malinge, A., Coupé, A., Le Petitcorps, Y. \& Pailler, R., 2012, Pressureless sintering of beta silicon carbide nanoparticles. J. Eur. Ceram. Soc. 32, pp. 4393-4400. (doi:10.1016/j.jeurceramsoc.2012.06.008)

34. Hertl, W. \& Pultz, W.W., 1967, Disproportination and Vaporization of Solid Silicon Monoxide. J. Am. Ceram. Soc. 50, pp. 278-381. (doi:10.1111/j.11512916.1967.tb15135.x)

35. Morgan, M., 1970, Conduction in amorphous carbon films. Thin Solid Films 7, pp. 313-323. (doi:10.1016/0040-6090(71)90049-6)

36. Prochazka, S., 1977, Sintered dense silicon carbide. US Pat. 4,004,934

37. Zhang, J.-W., Fang, H., Wang, J.-W., Hao, L.-Y., Xu, X. \& Chen, C.-S., 2014, Preparation and characterization of silicon nitride hollow fiber membranes for seawater desalination. J. Membr. Sci. 450, pp. 197-206. (doi:10.1016/j.memsci.2013.08.042) 
38. Zhang, X., Wang, D.K., Lopez, D.R.S. \& Diniz da Costa, J.C., 2014, Fabrication of nanostructured $\mathrm{TiO}_{2}$ hollow fiber photocatalytic membrane and application for wastewater treatment. Chem. Eng. J. 236, pp. 314-322. (doi:10.1016/j.cej.2013.09.059)

39. David, O., Gendel, Y. \& Wessling, M., 2014, Tubular macro-porous titanium membranes. J. Membr. Sci. 461, pp. 139-145. (doi:10.1016/j.memsci.2014.03.010)

40. Wachtman, J.B., Roger Cannon, W. \& John Matthewson, M., 1996, Mechanical properties of ceramics. 1st Ed. Hoboken, NJ, USA: John Wiley \& Sons, Inc. ISBN: 978-0-471-73581-6

41. Lu, C., Danzer, R. \& Fischer, F., 2002, Fracture statistics of brittle materials: Weibull or normal distribution. Phys. Rev. E 65, pp. 067102. (doi:10.1103/PhysRevE.65.067102)

42. Hoshide, T. \& Sugiyama, H., 2012, Numerical Analysis of Sample-Size Effect on Strength of Alumina. J. Mater. Eng. Perform. 22, pp. 1-8. (doi:10.1007/s11665-0120214-3)

43. Štubna, I., Šín, P., Trník, A. \& Vozár, L., 2014, Measuring the Flexural Strength of Ceramics at Elevated Temperatures-An Uncertainty Analysis. Meas. Sci. Rev. 14, pp. 35-40. (doi:10.2478/msr-2014-0006)

44. Lee, M., Wu, Z., Wang, R. \& Li, K., 2014, Micro-structured alumina hollow fibre membranes - Potential applications in wastewater treatment. J. Membr. Sci. 461, pp. 39-48. (doi:10.1016/j.memsci.2014.02.044)

45. Xu, G., Wang, K., Zhong, Z., Chen, C., Webley, P. a. \& Wang, H., 2014, SiC nanofiber reinforced porous ceramic hollow fiber membranes. J. Mater. Chem. A 2, pp. 5841. (doi:10.1039/c3ta15348g)

46. Online Supplementary Information for: de Wit, P., Kappert, E.J., Lohaus, T., Wessling, M., Nijmeijer, A., \& Benes, N.E., Highly permeable and mechanically robust silicon carbide hollow fiber membranes, J. Membr. Sci. 475, pp. 480-487, doi: 10.1016/j.memsci.2014.10.045 
Chapter 9

Reflections \& Perspectives 


\subsection{Reflections}

In the introduction, I defined the thermal processing of membranes as "the use of thermal energy to alter the chemistry and microstructure of a membrane layer". This chapter reflects on the thermal processing of membranes that was described in this thesis in two parts. First, the potential implications of the individual chapters on their respective fields are discussed; and secondly, the work is discussed from the broader perspective of the thermal processing of membranes in general.

\subsubsection{Reflections on the production of ceramic membranes}

An important factor hindering the application of both gas-separation and pervaporation inorganic membranes are the high capital costs for the membranes. Even though the lifetime and operational bandwidths of such membranes are much better than of other membranes, the initial investments will always form a barrier. For inorganic membranes, the costs are often dominated by the costs for the support and the module, and not by the costs for the selective layer itself [1].

An attractive development that has gained momentum over the last decade is the development of inorganic hollow fibers that are of interest for use as a membrane support because of their high surface-area-to-volume ratio [2]. In addition, potting of hollow fibers in modules is, at least in theory, straightforward. Many papers are devoted to the synthesis of inorganic hollow fibers from different materials [3-6]. Actual application of potting the fibers into a module is reported only sporadically [7], probably due to the difficulty of producing hollow fiber membranes with sufficient mechanical integrity. Until now, alumina membranes have been studied abundantly, and show satisfying mechanical properties. However, for some applications other materials may be more interesting. Silicon carbide is considered for different applications because of its low fouling behavior in oily environments [8]. Chapter 8 reports on the synthesis of silicon carbide hollow fibers with a mechanical strength that is sufficient for potting and permeation measurements. Silicon carbide fibers have been 
prepared before, but with only limited mechanical strength [3]. It has been demonstrated that a high-temperature furnace is indispensable for an optimized thermal treatment of silicon carbide hollow fibers, as temperatures well above $1700{ }^{\circ} \mathrm{C}$ are required for the successful sintering of this material.

A second method that has been suggested to decrease the support costs for inorganic and hybrid membranes is the replacement of the inorganic support by a polymeric support, opening up the possibility for spiralwound module designs. First steps towards polymeric support materials have been made by the deposition of hybrid inorganic layers onto a polymeric support through ETP-CVD [9,10], spin-coating [11], or immersion coating [12]. Because of the limited thermal stability of the polymeric support, the thermal processing of these layers has been carried out at lower temperatures than those used conventionally, or even has been avoided completely. These limitations may very well result in a lower selectivity of the hybrid membrane (see Section 9.1.2). The thermal treatment of an inorganic layer on a polymeric support was the original incentive behind Chapter 3. It soon turned out that the penetration of heat through the inorganic layer will always be too large, and will therefore always affect the support, making this route unsuccessful for synthesizing polymer-supported inorganic membranes.

Nonetheless, the rapid processing steps themselves may offer advantages in the production of membranes. Since the publication of Chapter 3, the rapid thermal processing method has been adopted and demonstrated for tubular supports $[13,14]$ and combined with the fast fabrication technique of ink-jet printing [15], and is under investigation at producers of inorganic membranes.

\subsubsection{Reflections on the processing of sol-gel-derived silica materials} Three chapters of this thesis have been dedicated to sol-gel-derived silica and organosilica. Sol-gel-derived silica materials have already been 
suggested for decades for gas-separation membranes [16-21]. Highperformance membranes of pure silica have been tailored for separations such as $\mathrm{H}_{2} / \mathrm{CO}_{2}$ or $\mathrm{CO}_{2} / \mathrm{CH}_{4}[18,19]$. Mixtures in which these separations are of interest typically contain water, and pure silica has been found to have limited hydrothermal stability [22,23]. Organosilica materials have been suggested as a hydrothermally stable alternative, but lack the high selectivities of the silica membranes [21,24,25]. In the field of pervaporation, where the size difference between the molecules in the mixture is often larger, the organosilica membranes do show sufficient selectivities [26,27]. In view of this thesis, an interesting question is: can thermal treatments ever help to overcome the limited selectivity displayed by organosilicas in the separation of small gases?

The answer is probably no. Higher treatment temperatures have been demonstrated to result in higher selectivities for (organo)silica materials, an effect which has commonly been attributed to the increased densification of the silica network through further dehydroxylation of the material [2831]. However, the limited stability of the organic moiety limits the maximum treatment temperature for organosilicas. In previous studies, the onset of decomposition of the organic moiety in BTESE-derived organosilica was given at $470{ }^{\circ} \mathrm{C}[20,32]$. In this thesis (Chapter 4), the extrapolated onset of methane release from BTESE-derived organosilica was found at $\sim 500{ }^{\circ} \mathrm{C}$ for heating at $20{ }^{\circ} \mathrm{C} \mathrm{min}$. The true onset for long(er) dwell times will be significantly lower, and can be questioned whether the organic moiety is stable at any temperature beyond $400{ }^{\circ} \mathrm{C}$ for longer periods of time. Nonetheless, in some studies the temperatures used to treat organosilica materials heavily exceed $400{ }^{\circ} \mathrm{C}[30,33]$. A slight decomposition of the organic moiety then seems inevitable, but is not necessarily a problem: as was demonstrated in Chapter 4, the decomposition of the organic moiety from BTESE follows a pathway starting with the scission of the carbon-carbon bonds in the material. The partially decomposed organosilica material that then remains can, in fact, 
resemble methylated silica [34] or carbon-templated silica membranes [35,36]. These membranes may still possess the hydrothermal stability that the pure silica membranes lack, but no tests of the hydrothermal stability of these partially decomposed hybrid membranes have been performed so far.

Based on the results that were obtained in Chapter 4, it can be concluded that full thermal dehydroxylation of BTESE-derived organosilica material is impossible without affecting the organic moiety. Therefore, an interesting approach, resembling the process of preparing ceviche, is the use of chemicals as a driving force instead of temperature. Care has to be taken to ensure that the hydroxyl-groups are (eventually) converted to a siloxane-bond [37], and are not only removed by grafting a species to it [38]. The feasibility of this approach was already demonstrated for organosilica materials, where a strongly acidic environment has been used to drive the densification through dehydroxylation of the material [39].

\subsubsection{Reflections on the analysis of the thermal processing of thin} films

Selective membrane layers are thin films that are constrained to substrates. It is known that thin films show a different susceptibility to phenomena such as ageing than bulk materials [40,41], and properties such as glass transitions can be different as well [42]. In addition, properties can be different between a freestanding and a supported layer [42,43]. Therefore, characterization of membranes is best carried out on thin films. Because of the availability of well-calibrated thermal analysis techniques such as TGA and DSC, the analysis of the thermal processing of materials is often performed on bulk material [44]. Other techniques are required to study phenomena on thin films, as techniques optimized for studying bulk behavior are typically insensitive to the small changes in thin films. In Chapter 6, the changes in H-SPEEK have been studied on thin films by spectroscopic ellipsometry. The results show that the onset of irreversible changes to the thin film takes places at temperatures of $160{ }^{\circ} \mathrm{C}$. The changes that have been detected in the light absorbance of the material are 
small, and detecting changes to the structure by non-optical techniques such as TGA and DSC is difficult or even impossible. Similarly, for the thermal treatment of poly[POSS-(amic acid)]s in Chapter 7, it has been found that mass loss and structural changes in the material take place simultaneously; however, it turns out to be impossible to use the mass loss data as a sole predictor for the changes in thickness and density of the material.

\subsection{Perspectives}

When executed properly, thermal processing can shape, strengthen, and functionalize a membrane. At the same time, carelessly performing a thermal treatment can result in broken, degraded, or not-functionalized membranes. The changes to the membrane structure that are caused by the thermal treatment will strongly determine the properties of the material. A fully optimized thermal treatment can be considered as a treatment that results in the membrane structure that achieves the best properties for the intended separation. In these perspectives, the focus will lie on identifying the pathways that will lead to the optimization of the thermal processing.

The question "when is a thermal treatment optimized?" then boils down to the question: "what is the optimal structure for a membrane, and how can this structure be achieved?" This can only be answered by firstly knowing all possible structures, followed by the construction of quantitative structure-property relations (QSPR) for all these structures - a tedious job $[45,46]$. This situation is far from the current situation, in which researchers (including myself, see, e.g., Chapter 3) often apply a limited number of thermal treatments to a material, study the outcome of the treatment on the properties, and indicate the best treatment from this dataset. In this approach, knowledge of the relation between structure and property is implicitly assumed. Rather, it would be recommendable to look at thermal treatments from a treatment-structure relation point-of-view. In turn, combining treatment-structure relation with a structure-property relation, allows for developing treatment-structure-property relations, thus 
coupling the effect of a treatment to the properties of an obtained membrane via the structure of the material.

In the next three sections, I will lay down my views on data acquisition, data analysis, and drawing conclusions based on these data. This section was written with the purpose of helping to identify and explain the key aspects of studying the thermal processing of membranes.

\subsubsection{Obtaining accurate data}

In 2014, a team of experts from the International Confederation for Thermal Analysis and Calorimetry (ICTAC) Kinetics Committee, led by Vyazovkin, published a manuscript with recommendations for collecting experimental thermal analysis data for use in studying reaction kinetics [44]. It is a must-read for anyone studying the kinetics of thermally stimulated reactions. Data intended for use in kinetic analysis has high quality demands, and is therefore suited for other types of analysis as well. To expand upon the ICTAC Kinetic Committee recommendations with my own experience on the thermal processing of membrane materials in specific, I want to summarize three important aspects of the study of thermally stimulated processes: sample temperature, instrument influences, and sample influences.

\section{Sample temperature}

The first parameter that should be known accurately is the temperature of the sample. An accurate reading of the sample temperature is not automatically guaranteed. Because of temperature gradients inside the heating chamber, the temperature of the sample is often different from that recorded by the instrument. Placing a thermocouple as close to the sample as possible is a first option to avoid measuring an inaccurate temperature. However, this is not always possible (especially when one measures on substrates with limited thermal conductivity). In that case, a temperature calibration can be performed. The introduction of Chapter 5 gives a short introduction of the different methods for performing such a calibration. 
Paying attention to thermal calibration is particularly important for instruments that are not dedicated to thermal analysis.

\section{Influences of instruments and substrates}

A common mistake made in thermal analysis is the measurement of properties of the instrument or substrate instead of those of the sample, such as measuring the buoyancy in a TGA-instrument instead of changes in the sample. Similar to performing a TGA-experiment, a blank run can be performed for other instruments as well.

For the analysis of thin layers, optical methods have proven to be a good addition to the thermal analysis toolbox, as the optical beam is easily directed into furnaces or heated cells. However, optical methods can be tricky to apply on a multilayered membrane. For optical techniques that require reflectance, the porous substrate can scatter off the light probe; and for optical techniques that rely on transmission of the optical beam, the substrate can interfere with the measurement signal. Apart from this, any results obtained are a convolution of changes in the substrate and in the thin film; accurately knowing the changes in the (optical) properties of the substrate is therefore required. For that reason, many optical analyses are carried out on ideal, non-porous substrates, such as a polished silicon wafer or a glass slide [47]. Nonetheless, studies on porous substrates may better reflect phenomena such as pore intrusion, and they allow for studying membranes in operandi.

For these studies, the ANOPORE membrane has been used [48], but these membranes are fragile and difficult to handle. In our own labs, a $\gamma$-alumina layer supported on a polished $\alpha$-alumina membrane is commonly employed as a substrate [49]. A disadvantage of these porous systems is the sorption of water during application of the membrane film. This water may be released during the thermal processing, and is then convoluted with the sample measurement. Data modeling is then required to obtain the desired results. Other issues are found in inhomogeneity of and 
scattering by the substrate. The development of a porous support material with a homogeneous pore distribution and good optical reflection (or transparency) could strongly aid the analysis of the thermal processing of thin membrane layers.

\section{Influences of the sample itself}

An often-overlooked parameter is the influence the sample itself has on its own measurement. Diffusion limitations in thin films can be different from those in the bulk of a material. Decreasing the sample size or film thickness until measurement curves superimpose can aid in detecting diffusional limitations [44]. Even if good care is taken with respect to sample size, it can still be debated whether the bulk material reflects the properties of the thin layer. It is long known that supported membranes can exhibit a different structure than their freestanding counterpart [50,51]. Probing the structure of the bulk can give a first insight into the material, especially when measurements on the thin layers are not easily accessible; however, to study the actual membrane properties, measurements on the thin films should never be avoided.

\subsubsection{Analysis of the obtained data}

In Chapter 4 and Chapter 7, we have seen that kinetic calculations can be powerful tools for studying thermally stimulated reactions in membrane materials. A good review on analyzing the kinetics of solid-state reactions was published in 2011 by (again) a delegation of the ICTAC Kinetics Committee [52]. Following these recommendations leads to a decent analysis of the solid-state reaction kinetics. Nonetheless, performing these calculations for membrane materials not always straightforward: often, the thermal processing of a membrane will display multiple reaction steps in series, in which every single step can consist of multiple parallel reactions and/or will be the result of an inhomogeneous starting material. The complete analysis of a multi-step reaction requires more knowledge and will take an extensive amount of work. On the other hand, obtaining insight in the mechanisms of multi-step reactions is rewarding, as the 216 
interplay between the different steps can lead to unexpected behavior of the material that, when known, allows for further tuning of the membrane properties.

For analyzing these multi-step reactions, there is not one single path to success. The best step is to start with obtaining the so-called 'model-free' activation energy $E_{\mathrm{a}}$ through an isoconversional method [52]. This activation energy can then be used for input in a multivariate analysis of the kinetics, in which the pre-exponential constant $A$ and the reaction model $f(\alpha)$ are determined. Combined, these three parameters form the kinetic triplet, and allow for the prediction of the conversion of a reaction under generic temperature-time programs. Although fitting the data would be expected to be a highly objective process, choices need to be made during the approach of the fitting. It has been demonstrated that in some cases, two apparently different equations are mathematically fully equivalent (i.e., taking an $n$-th order reaction model or a Gammadistributed activation energy [53]). In these cases, the investigator is 'free' to choose any of these equations, resulting in an identical quality of the fit. Prior knowledge of the reaction system can aid in choosing the parameters that best resemble the system. Alternatively, the physical realism of the model can be neglected, and the model can be constructed just to accurately fits data. Such models can be used for interpolation of the data; extrapolation from a model that fits well, but which is not based on a solid physical basis, potentially leads to grave errors.

\subsubsection{Drawing conclusions from thermal analysis data}

In the introductions of this section, treatment-structure-property relations have been put forward as the Holy Grail for studying thermally stimulated reactions. This section proposes three question that can be asked to verify the integrity of the data, its analysis, and the conclusion drawn. The same questions can aid in evaluating the quality of results obtained by others. 
Is that what has been measured that what had been intended to be measured?

These conclusions reflect on Section 9.2.1. At the end of the measurement, one should systematically check whether the measurement did not accidentally display a different process than that was intended to be measured. This is not always obvious. Simple errors, such as using a wrong gas flow, or accidentally diluting it with an inert gas in the instrument, leads to a completely different measurement atmosphere than expected. Performing duplicate measurements often allows for the detection of accidental mistakes, and should be performed not only for the difficult, but for the simple measurements as well. In addition, it should be checked whether the data was obtained with the right accuracy. Often, the temperatures used in thermal analysis are reported with a higher accuracy than practically possible - for instance, for dedicated TG-instruments calibrated by an expert in the field, the expected deviation in temperature is in the order of $1{ }^{\circ} \mathrm{C}[54,55]$. A higher accuracy can therefore not be expected for apparatuses that are not dedicated for thermal analysis. In reading manuscripts on thermal analysis, one should therefore be suspicious about data accuracy when it is higher than possibly could be expected, or when no details are given with respect to the use of blank measurements, temperature corrections, and other experimental details.

\section{Is that what has been measured a good indicator for membrane structure or properties?}

In studying membranes, the interesting properties are often the permeance through a layer, the selectivity for a specific separation, and the (long-term) stability of the material under operation conditions. In some cases, these properties can be calculated from structure parameters such as the porosity of the material, the pore size, or the layer thickness. Almost never are these measured during thermal processing, but for a good reason: direct measurement of the thermal development of the structure is often not possible or extremely difficult. Resorting to techniques that are well known 
allows for an easy thermal analysis, and instruments such as a TGA can be operated successfully without requiring too much experience. Nonetheless, a parameter such as mass loss does not always reflect the changes that one is interested in. Often, these results will give what in the practice of law would be called 'circumstantial evidence'. In those cases, it is important to link the studied phenomenon to the desired property via a chain of logical causality. Take for example the loss of water from silica. It may be coupled to the increased selectivity of the layer as a result of crosslinking on hydroxyl groups, but this conclusions rests on the assumptions that the phenomenon of water loss is (1) the result of dehydroxylation of the material, and (2) that the dehydroxylation in turn results in a densification of the material, and (3) that densification of the material increases the selectivity of the membrane. Often, based on an abundant amount of prior knowledge, these assumptions will be correct; nevertheless, keeping an open view to alternative insight helps avoiding incorrect interpretation of obtained data.

\section{Is that was has been measured been analyzed to the highest possible extent?}

Accurate experiments are often performed, without following these up by an exhaustive data analysis. Many times, only looking at the data from a different perspective will help in extracting more information from the data. The human eye is insensitive to derive this information from integral data (conversion vs time). Simply plotting the derivative of the data (rate vs time) makes it easy to see whether a change was due to one or more processes.

Performing a thermodynamic calculation or a kinetic analysis can be used to convert a qualitative description into a quantitative prediction. In some cases, storing all the data measured for a study in similar formats allows for performing a meta-analysis on the data. Such analyses are common in the field of medicine, where a combination of multiple datasets allows for detection of occurring phenomena with increased (statistical) accuracy. 
Lastly, it should be recommended to share all relevant measured data where possible. Small and seemingly insignificant processes may be used as others as a building block in their studies. In many cases, small deviations in measurements may only be artefacts; however, if such deviations are seen consistently across multiple studies, they can form the inspiration for new lines of research.

\subsection{References}

1. Pera-Titus, M. 2014 Porous inorganic membranes for $\mathrm{CO}_{2}$ capture: present and prospects. Chem. Rev. 114, 1413-92. (doi:10.1021/cr400237k)

2. Tan, X. \& Li, K. 2011 Inorganic hollow fibre membranes in catalytic processing. Curr. Opin. Chem. Eng. 1, 69-76. (doi:10.1016/j.coche.2011.08.004)

3. Luiten-olieman, M. W. J., Raaijmakers, M. J. T., Winnubst, L., Bor, T. C., Wessling, M., Nijmeijer, A. \& Benes, N. E. 2012 Towards a generic method for inorganic porous hollow fibers preparation with shrinkage-controlled small radial dimensions, applied to $\mathrm{Al} 2 \mathrm{O} 3, \mathrm{Ni}, \mathrm{SiC}$, stainless steel, and YSZ. J. Membr. Sci. 407-408, 155-163. (doi:10.1016/j.memsci.2012.03.030)

4. Liu, S., Li, K. \& Hughes, R. 2003 Preparation of porous aluminium oxide (Al2O3) hollow fibre membranes by a combined phase-inversion and sintering method. Ceram. Int. 29, 875-881. (doi:10.1016/S0272-8842(03)00030-0)

5. David, O., Gendel, Y. \& Wessling, M. 2014 Tubular macro-porous titanium membranes. J. Membr. Sci. 461, 139-145. (doi:10.1016/j.memsci.2014.03.010)

6. Zhang, X., Wang, D. K., Lopez, D. R. S. \& Diniz da Costa, J. C. 2014 Fabrication of nanostructured $\mathrm{TiO}_{2}$ hollow fiber photocatalytic membrane and application for wastewater treatment. Chem. Eng. J. 236, 314-322. (doi:10.1016/j.cej.2013.09.059)

7. Ebrahimi, M., Kerker, S., Daume, S., Geile, M., Ehlen, F., Unger, I., Schütz, S. \& Czermak, P. 2014 Innovative ceramic hollow fiber membranes for recycling/reuse of oilfield produced water. Desalin. Water Treat. (doi:10.1080/19443994.2014.947780)

8. Hofs, B., Ogier, J., Vries, D., Beerendonk, E. F. \& Cornelissen, E. R. 2011 Comparison of ceramic and polymeric membrane permeability and fouling using surface water. Sep. Purif. Technol. 79, 365-374. (doi:10.1016/j.seppur.2011.03.025)

9. Kreiter, R., Paradis, G. G., Vente, J. F. \& Castricum, H. L. 2011 WO2011145933A1.pdf.

10. Ngamou, P. H. T., Overbeek, J. P., Kreiter, R., van Veen, H. M., Vente, J. F., Wienk, I. M., Cuperus, P. F. \& Creatore, M. 2013 Plasma-deposited hybrid silica membranes with a controlled retention of organic bridges. J. Mater. Chem. A 1, 5567-5576. (doi:10.1039/c3ta00120b) 
11. Gong, G., Wang, J., Nagasawa, H., Kanezashi, M., Yoshioka, T. \& Tsuru, T. 2014 Synthesis and characterization of a layered-Hybrid membrane consisting of an organosilica separation layer on a polymeric nanofiltration membrane. $J$. Membr. Sci. 472, 19-28. (doi:10.1016/j.memsci.2014.08.030)

12. Jang, K.-S., Kim, H.-J., Johnson, J. R., Kim, W., Koros, W. J., Jones, C. W. \& Nair, S. 2011 Modified Mesoporous Silica Gas Separation Membranes on Polymeric Hollow Fibers. Chem. Mater. 23, 3025-3028. (doi:10.1021/cm200939d)

13. Wang, D. K., Motuzas, J., Costa, J. C. D. da \& Smart, S. 2013 Rapid thermal processing of tubular cobalt oxide silica membranes. Int. J. Hydrogen Energy 38, 7394-7399. (doi:10.1016/j.ijhydene.2013.04.052)

14. Wang, D. K., Diniz da Costa, J. C. \& Smart, S. 2014 Development of rapid thermal processing of tubular cobalt oxide silica membranes for gas separations. $J$. Membr. Sci. 456, 192-201. (doi:10.1016/j.memsci.2014.01.014)

15. Van Gestel, T., Hauler, F., Bram, M., Meulenberg, W. A. \& Buchkremer, H. P. 2014 Synthesis and characterization of hydrogen-selective sol-gel $\mathrm{SiO}_{2}$ membranes supported on ceramic and stainless steel supports. Sep. Purif. Technol. 121, 20-29. (doi:10.1016/j.seppur.2013.10.035)

16. Uhlhorn, R. J. R., Huis In 't Veld, M. H. B. J., Keizer, K. \& Burggraaf, A. J. 1989 High permselectivities of microporous silica-modified g-alumina membranes. $J$. Mater. Sci. Lett. 8, 1135-1138. (doi:10.1007/bf01730047)

17. De Lange, R. S. A., Hekkink, J. H. A., Keizer, K. \& Burggraaf, A. J. 1995 Formation and characterization of supported microporous ceramic membranes prepared by sol-gel modification techniques. J. Membr. Sci. 99, 57-75. (doi:10.1016/0376-7388(94)00206-E)

18. De Vos, R. M. \& Verweij, H. 1998 High-Selectivity, High-Flux Silica Membranes for Gas Separation. Science 279, 1710-1711. (doi:10.1126/science.279.5357.1710)

19. Tsai, C. Y., Tam, S. Y., Lu, Y. \& Brinker, C. J. 2000 Dual-layer asymmetric microporous silica membranes. J. Membr. Sci. 169, 255-268. (doi:10.1016/S03767388(99)00343-9)

20. Castricum, H. L., Sah, A., Kreiter, R., Blank, D. H. A., Vente, J. F. \& ten Elshof, J. E. 2008 Hybrid ceramic nanosieves: Stabilizing nanopores with organic links. Chem. Commun. (Cambridge, United Kingdom) , 1103-1105. (doi:10.1039/B718082A)

21. Kanezashi, M., Yada, K., Yoshioka, T. \& Tsuru, T. 2009 Design of silica network for development of highly permeable hydrogen separation membranes with hydrothermal stability. J. Am. Chem. Soc. 131, 414-415. (doi:10.1021/ja806762q)

22. Giessler, S., Jordan, L., Diniz da Costa, J. C. \& Lu, G. Q. (Max. 2003 Performance of hydrophobic and hydrophilic silica membrane reactors for the water gas shift reaction. Sep. Purif. Technol. 32, 255-264. (doi:10.1016/S1383-5866(03)00069-8) 
23. Imai, H., Morimoto, H., Tominaga, A. \& Hirashima, H. 1997 Structural Changes in Sol-Gel Derived $\mathrm{SiO}_{2}$ and $\mathrm{TiO}_{2}$ Films by Exposure to Water Vapor. J. Sol-Gel Sci. Technol. 10, 45-54.

24. Kanezashi, M., Kawano, M., Yoshioka, T. \& Tsuru, T. 2012 Organic-Inorganic Hybrid Silica Membranes with Controlled Silica Network Size for Propylene/Propane Separation. Ind. Eng. Chem. Res. 51, 944-953. (doi:10.1021/ie201606k)

25. Qureshi, H. F., Nijmeijer, A. \& Winnubst, L. 2013 Influence of sol-gel process parameters on the micro-structure and performance of hybrid silica membranes. J. Membr. Sci. 446, 19-25. (doi:10.1016/j.memsci.2013.06.024)

26. Castricum, H. L., Kreiter, R., van Veen, H. M., Blank, D. H. A., Vente, J. F. \& ten Elshof, J. E. 2008 High-performance hybrid pervaporation membranes with superious hydrothermal and acid stability. J. Membr. Sci. 324, 111-118. (doi:10.1016/j.memsci.2008.07.014)

27. Van Veen, H. M., Rietkerk, M. D. A., Shanahan, D. P., van Tuel, M. M. A., Kreiter, R., Castricum, H. L., ten Elshof, J. E. \& Vente, J. F. 2011 Pushing membrane stability boundaries with $\mathrm{HybSi}{ }^{\circledR}$ pervaporation membranes. J. Membr. Sci.380, 124-131. (doi:10.1016/j.memsci.2011.06.040)

28. Kanezashi, M., Shazwani, W. N., Yoshioka, T. \& Tsuru, T. 2012 Separation of propylene/propane binary mixtures by bis(triethoxysilyl) methane (BTESM)derived silica membranes fabricated at different calcination temperatures. J. Membr. Sci. 415-416, 478-485. (doi:10.1016/j.memsci.2012.05.034)

29. Wang, J., Kanezashi, M., Yoshioka, T. \& Tsuru, T. 2012 Effect of calcination temperature on the PV dehydration performance of alcohol aqueous solutions through BTESE-derived silica membranes. J. Membr. Sci. 415-416, 810-815. (doi:http://dx.doi.org/10.1016/j.memsci.2012.05.073)

30. Qi, H., Han, J., Xu, N. \& Bouwmeester, H. J. M. 2010 Hybrid OrganicInorganic Microporous Membranes with High Hydrothermal Stability for the Separation of Carbon Dioxide. ChemSusChem 3, 1375-1378. (doi:10.1002/cssc.201000242)

31. Vos, R. M. De \& Verweij, H. 1998 Improved performance of silica membranes for gas separation. J. Membr. Sci. 143, 37-51. (doi:10.1016/S0376-7388(97)00334-7)

32. Castricum, H. L., Sah, A., Kreiter, R., Blank, D. H. A., Vente, J. F. \& Ten Elshof, J. E. 2008 Hydrothermally stable molecular separation membranes from organically linked silica. J. Mater. Chem. 18, 2150-2158. (doi:10.1039/B801972J)

33. Qi, H., Han, J. \& Xu, N. 2011 Effect of calcination temperature on carbon dioxide separation properties of a novel microporous hybrid silica membrane. $J$. Membr. Sci. 382, 231-237. (doi:10.1016/j.memsci.2011.08.013) 
34. Castricum, H. L., Sah, A., Mittelmeijer-Hazeleger, M. C., Huiskes, C. \& Ten Elshof, J. E. 2007 Microporous structure and enhanced hydrophobicity in methylated $\mathrm{SiO}_{2}$ for molecular separation. J. Mater. Chem. 17, 1509-1517. (doi:10.1039/B610311A)

35. Duke, M. C., da Costa, J. C. D., Do, D. D., Gray, P. G. \& Lu, G. Q. 2006 Hydrothermally Robust Molecular Sieve Silica for Wet Gas Separation. Adv. Funct. Mater. 16, 1215-1220. (doi:10.1002/adfm.200500456)

36. Duke, M. 2004 Carbonised template molecular sieve silica membranes in fuel processing systems: permeation, hydrostability and regeneration. J. Membr. Sci. 241, 325-333. (doi:10.1016/j.memsci.2004.06.004)

37. McDaniel, M. P. 1982 Chemical dehydroxylation of silica., 1-5.

38. Jin, C., Luttmer, J. D., Smith, D. M. \& Ramos, T. A. 1997 Nanoporous Silica as an Ultralow-\&kappa; Dielectric. MRS Bull. 22, 39-42.

39. Wang, J., Gong, G., Kanezashi, M., Yoshioka, T., Ito, K. \& Tsuru, T. 2012 Poresize Tuning of Highly Selective Organic-Inorganic Hybrid Silica Membranes by Solid-phase Post-treatment at Low Temperature. Chem. Lett. 41, 1663-1665. (doi:10.1246/cl.2012.1663)

40. Huang, Y., Paul, D. R., March, R. V, Re, V., Recei, M. \& December, V. 2006 Physical Aging of Thin Glassy Polymer Films Monitored by Optical Properties. , 1554-1559.

41. Priestley, R. D. 2009 Physical aging of confined glasses. Soft Matter 5, 919. (doi:10.1039/b816482g)

42. Keddie, J. L., Jones, R. A. L. \& Cory, R. A. 1994 Interface and Surface Effects on the Glass-transition Temperature in Thin Polymer Films. Farady Discuss. 98, 219230. (doi:10.1039/FD9949800219)

43. Hu, M. S. \& Evans, A. G. 1989 The cracking and decohesion of thin films on ductile substrates. Acta Metall. 37, 917-925. (doi:10.1016/0001-6160(89)90018-7)

44. Vyazovkin, S., Chrissafis, K., Di Lorenzo, M. L., Koga, N., Pijolat, M., Roduit, B., Sbirrazzuoli, N. \& Suñol, J. J. 2014 ICTAC Kinetics Committee recommendations for collecting experimental thermal analysis data for kinetic computations. Thermochim. Acta 590, 1-23. (doi:10.1016/j.tca.2014.05.036)

45. Katritzky, A. R., Lobanov, V. S. \& Karelson, M. 1995 QSPR: The Correlation and Quantitative Prediction of Chemical and Physical Properties from Structure. Chem. Soc. Rev. 24, 279-287.

46. Le, T., Epa, V. C., Burden, F. R. \& Winkler, D. a 2012 Quantitative structureproperty relationship modeling of diverse materials properties. Chem. Rev. 112, 2889-919. (doi:10.1021/cr200066h)

47. Routh, A. F. 2013 Drying of thin colloidal films. Rep. Prog. Phys. 76, 046603. (doi:10.1088/0034-4885/76/4/046603) 
48. Cramera, C., Bindera, H., Schuberta, M., Rheinländera, B. \& Schmiedela, H. 1996 Optical Properties of Microconfined Liquid Crystals (only abstract). Mol. Cryst. Liq. Cryst. Sci. Technol. Sect. A. Mol. Cryst. Liq. Cryst. 282, 395-405. (doi:10.1080/10587259608037593)

49. Ogieglo, W., Wormeester, H., Wessling, M. \& Benes, N. E. 2012 Spectroscopic ellipsometry analysis of a thin film composite membrane consisting of polysulfone on a porous a-alumina support. ACS Appl. Mater. Interfaces 4, 935-43. (doi:10.1021/am2015958)

50. Leenaars, A. F. M., Keizer, K. \& Burggraaf, A. J. 1984 The preparation and characterization of alumina membranes with ultra-fine pores. 1. Microstructural investigations on non-supported membranes. J. Mater. Sci. 19, 1077-1088. (doi:10.1007/bf01120016)

51. Leenaars, A. F. M. \& Burggraaf, A. J. 1985 The preparation and characterization of alumina membranes with ultrafine pores. 2. The formation of supported membranes. J. Colloid Interface Sci. 105, 27-40. (doi:10.1016/0021-9797(85)903431)

52. Vyazovkin, S., Burnham, A. K., Criado, J. M., Pérez-Maqueda, L. A., Popescu, C. \& Sbirrazzuoli, N. 2011 ICTAC Kinetics Committee recommendations for performing kinetic computations on thermal analysis data. Thermochim. Acta 520, 1-19. (doi:10.1016/j.tca.2011.03.034)

53. Burnham, A. K. \& Braun, R. L. 1999 Global Kinetic Analysis of Complex Materials. Energy \& Fuels 13, 1-22. (doi:10.1021/ef9800765)

54. ASTM Standard E967-08 2014 Standard Test Method for Temperature Calibration of Differential Scanning Calorimeters and Differential Thermal Analyzers. , 1-4. (doi:10.1520/E0967-08R14.2)

55. Gallagher, P. K., Blaine, R., Charsley, E. L., Koga, N., Ozao, R., Sato, H., Sauerbrunn, S., Schultze, D. \& Yoshida, H. 2003 Magnetic temperature standars for TG. J. Therm. Anal. Calorim. 72, 1109-1116. (doi:10.1023/A:1025032013135) 


\section{Epilogue: Turn it on again?}

During the four years in which I have worked on this thesis, I have seen a variety of experiments being performed on a range of materials: from very simple, well-known materials to highly innovative materials that display exotic properties. For all these materials, very simple experiments still give a tremendous amount of insight into the materials. Often, the importance of these simple measurements is overlooked. In addition, a common mistake often seen is the one-on-one copying of a thermal processing step that was designed for different membranes of a 'similar' class. It is easy to see that this line of reasoning is prone to go wrong: if a novel material has different properties, it has, ipso facto, a different structure; and if the material has a different structure, chances are that it will respond differently to external stimuli. These mistakes can be easily prevented, by seeing materials for what they are and experiments for the value these add.

Techniques that may not have been readily accessible in the past can now be performed easily on large sample sets. Much can be learned from subjecting well-known materials to these analyses on a large scale. This allows for the expansion of the knowledge that we have on these materials. Revisiting these materials may lead to a further increased insight in the fundamental behavior of these 'simple' materials, which can aid in the development of new materials that have the desired properties.

Because of the tremendous adventures that can still be undertaken in the land of thermal processing, I would recommend to everyone that has a furnace, a hot plate, a TGA, a DSC, a TEA, or another thermal analysis instrument: Turn it on again!

Emiel Kappert, 2014 



\section{Dankwoord}

Allereerst bedank ik Karin. Naast alle hoogtepunten is het laatste jaar ook bijzonder druk geweest en heeft het jou minstens zoveel energie gekost als het mij gekost heeft. Toch ben je er altijd voor mij geweest; ik ben je daar bijzonder dankbaar voor. Het is voor mij zo vanzelfsprekend dat ik met je alle problemen die ik tegenkom kan bespreken, eventueel tot aan de kleinste details in een wetenschappelijke studie, dat ik vaak vergeet hoe bijzonder dat is. Ik kijk er naar uit om samen de wereld verder te verkennen!

Tijdens mijn promotieonderzoek mocht ik me gelukkig prijzen met twee promotoren van wie ik bijzonder veel heb geleerd. Arian, ik waardeer het hoe jij je industriële visie weet te combineren met theoretisch onderzoek. Het zorgt ervoor dat er altijd duidelijk gekeken wordt naar de latere toepassing, zonder dat de koers van het onderzoek van tevoren volledig vastligt. Ik waardeer je directe feedback en openheid en ben je dankbaar voor alle hulp en mogelijkheden die je me gedurende mijn promotietraject hebt geboden.

Nieck, van het begin af aan heb jij me geholpen koers te vinden in het onderzoek. Vaak door kleine bijsturingen die niet eens opvallen, maar achteraf vaak sterk hebben bijgedragen in het vinden van de juiste focus. Je hebt een scherp oog voor zowel de valkuilen als de mogelijkheden die in data zitten opgesloten, waardoor binnen het domein van jouw kamer ogenschijnlijke ruis plots een onverwachtse trend blijkt te zijn (en helaas weer terugviel in ruis zodra ik de deur uit was). Hoewel je weet dat we vaak grappen hebben gemaakt over jouw 'wezigheid', is het belangrijkste dat je er altijd bent wanneer dat nodig is. Bedankt!

In en om onze onderzoeksgroep heb ik met veel mensen samen mogen werken. Henny, jij bent en blijtt voor mij het wetenschappelijk geweten van onze groep. Voor jou geen quick wins, maar het uitwringen van een manuscript tot op de laatste punt en komma - en er dan nog wat dieper in duiken. Het samen werken aan het artikel dat ten grondslag lag aan 
hoofdstuk 4 en andere discussies was bijzonder leerzaam. Amy, I owe you many thanks. Although we had plenty of data for the research in the second chapter of this thesis, I often felt I would meet my nemesis in that part of the work. I am thankful for your help in puzzling out all the details in the beautiful world of fractures, bringing the work to a higher level.

Patrick, samen hebben we denk ik bijzonder efficiënt een paper geschreven op het gebied van siliciumcarbide. Ik laat het hier bij de constatering dat ik in eerdere dankwoorden correct heb geobserveerd dat de materiaalkunde jou niet vies is. Beata, thanks for introducing me in the wonderful world of SPEEK; without having any history in SPEEK, studying this polymer would be difficult (or easy, actually). Further help and learnings came from discussions with Mark, Kitty, Arie, Rob, Matthias, numerous fellow $\mathrm{PhDs}$, and many, many others. Thanks to all of you!

The work in this thesis has been funded by two parties. The project started with funding from the University of Twente - Inorganic Membranes Chair. This gave much freedom to develop directions without knowing the outcome in advance. It is, however, nice to discuss the research with others and to place it in a wider framework. Shortly after starting my research, I was lucky to join the Helmholtz Alliance MEM-BRAIN. I acknowledge the funding of this work by the Helmholttz Alliance MEMBRAIN, funded by the Initiative and Networking Fund of the Helmholtz Association. In addition, it was a very pleasant and instructive experience co-operating with all the partners in the project. In particular, I want to acknowledge Jürgen Malzbender for the co-operation in the research in Chapter 2 of this thesis.

Omdat warmtebehandelingen een groot deel van mijn onderzoek zijn, heb $\mathrm{ik}$ veel te danken aan Cindy. In het begin heb ik veel van je geleerd, met name op het gebied van TGA; later heb ik met veel plezier samen gepuzzeld aan het werkend en werkbaar krijgen van de MS. Ik vind het fijn dat ik altijd kon binnenlopen om te discussiëren over metingen en interpretatie. Dat was ook onmogelijk geweest zonder Frank: jouw 228 
kennisgebied is zo breed, dat je ogenschijnlijk elk probleem als eens tegen bent gekomen. Ik heb veel geleerd van het over jouw schouder meekijken en weet nu dat ik beter niet in de buurt kan zijn wanneer er een sorptiekolom geïnstalleerd moet worden. Mieke, jij hebt een groot aandeel in de veranderingen die de laboratoria van IM de laatste jaren hebben ondergaan. Het is knap om te zien hoe je altijd open blijft staan voor nieuwe inzichten. De verbeteringen in veiligheid en werkbaarheid maken het fijn om op onze labs te werken. Susanne, je staat altijd klaar om te helpen met bijzonder diverse vragen. Jouw hulp maakt zelfs de organisatorische facetten van het werk interessant.

Ik heb het geluk gehad gedurende mijn promotieonderzoek meerdere studenten te mogen begeleiden. Ronald en Casper, jullie bacheloronderzoeken waren de eerste die ik mocht begeleiden. Ik vond het een gave tijd en heb er veel van geleerd! Wouter, bedankt dat we samen ons hart op konden halen aan organische syntheses. Het is jammer dat we door de aanschaf van octakis(dibromoethyl)POSS waarschijnlijk ergens op een zwarte lijst zijn beland; bovenal is het jammer dat je er tussenuit geglipt bent, maar ik denk dat je een goede keuze hebt gemaakt. Denys, at the beginning I thought nanolayers may not be your cup of tea. With excessive force, you single-handedly introduced the fractures (with amazing chicken-shapes) that inspired the research underlying Chapter 2 of this thesis. I am thankful for the pleasant time, and happy that we still run into each other from time to time! Hier wil ik ook Louis van der Ham bedanken voor de mogelijkheid die ik heb gekregen Project CT te begeleiden. Dat waren bijzonder leerzame en leuke momenten!

Where some projects succeed, others fail. In research, sometimes you just have to try new routes, without knowing where you will end. It is therefore that I would like to thank Jan E., Gianni, Michael, Fresia, Timo, and Björn, with whom I had the pleasant experience to explore some new fields of study, alas only leading into cul-de-sacs. Met Barbara ben ik begonnen aan het onderzoeken van in-situ warmtebehandelingen van 
silica middels infrarood. Het was lastig, maar leerzaam. Helaas is het werk niet in dit proefschrift beland, maar ik wil je bedanken voor de fijne, leerzame samenwerking.

Aan een universiteit werken veel mensen direct in het onderzoek, maar er zijn ook veel mensen die op de achtergrond al dit werk mogelijk maken. Dit zijn de mensen van het facilitair bedrijf, de servicedesks, de universiteitsbibliotheek, de mensen van de schoonmaak die ons kantoor leefbaar houden. Ik ken jullie niet allemaal persoonlijk, maar ik dank jullie allemaal voor de hulp die jullie bieden! Antoinette wil ik graag persoonlijk bedanken voor de gezellige praatjes 's ochtends vroeg - hoewel ik het dan toch vaak afleg qua scherpte van geest...

Wetenschappers denken moeilijk. Soms kan het veel simpeler. Jonathan, Jolien en later Rob en z'n team van C4Real hebben veel geholpen moeilijke presentaties in simpele visuals te vangen. Dank!

In Nederland is een promovendus een ambtenaar. Koffie en collega's zijn daarom onontbeerlijk. Ik dank alle huidige en oud-collega's in de groep Anorganische Membranen (IM) / I thank all current and former colleagues in the Inorganic Membranes Group. Hier ook dank aan alle (oud)collega's van MST, SFI en andere groepen. Om het risico mensen te vergeten te verkleinen noem ik niet iedereen bij naam, maar ik ben jullie allemaal zeer dankbaar voor de fijne tijd en alle hulp wanneer het nodig was.

Een paar collega's wil ik in het specifiek bedanken. Vic, bedankt voor leuke discussies, soms over de inhoud, maar ook over hoe de wetenschap achter de schermen werkt (en zou moeten werken). Wojciech, we have been working together on many manuscripts, and I have learned a great deal in that time. However, above all, I value the fact that you are one of the few people I know who values the theoretical exercise of calculating the advantages of sending an ellipsometer into space in order to gain extra measurement time. 
These discussions would have been impossible without the help of Michiel, with whom I together formed the illustrious duo 'The Iels'. Ik kan me niet voorstellen hoe mijn $\mathrm{PhD}$ er had uitgezien als we geen aangrenzende bureaus hadden gehad. $\Sigma$ (feedback, comments en discussies) beschouwende, zijn jouw bijdragen aan dit proefschrift enorm. In het bijzonder wil ik van deze gelegenheid gebruik maken om je expliciet te bedanken voor de inspiratie voor het grafisch aperitiefje van Hoofdstuk 6.

Marcel, al sinds onze masterstudie voeren we samen experimenten uit en omdat we allebei andere invalshoeken hebben, loopt dat ook altijd bijzonder soepel en snel. Ik waardeer het inzicht dat je hebt in syntheses, waardoor je bijna intuïtief de juiste samenstelling voor een nieuw syntheserecept weet uit te voeren. Ik heb met plezier de fijne kneepjes afgekeken en hoop dat ik onderhand de details van de silicasynthese heb opgepikt! Bedankt voor alle hulp en discussies!

Jaren terug had ik het er met mijn moeder over dat ik ooit nog een boek wilde schrijven. De vraag was toen of het een wetenschappelijk boek of fictie zou worden. We hadden niet kunnen denken dat het een doctorsroman zou worden... Pap, mam en Jolien. Ik wil jullie bedanken voor jullie continue interesse in mijn werk. Jullie hebben niet alleen vanaf de zijlijn toegekeken, maar ook jullie hulp en mening gegeven op design, (soms) inhoud en het (Nederlandse) taalgebruik. Bedankt!

There are many people who were not directly involved with this thesis, but who have been an enormous support during these years. I thank you all, and hope we will find the time to keep visiting each other frequently!

PS. I recognize that many people find consolation in reading their name in the acknowledgment-section of a thesis. If I, in my attempt to keep this section shorter than the shortest chapter, by accident forgot to acknowledge you, or if you feel underacknowledged, feel free to expand this section: 


\section{Curriculum Vitae}

Emiel Kappert was born on the 10th of March 1986 in Hellendoorn, The Netherlands. In 2004, he obtained his vwo-diploma cum laude at Pius X College, Almelo. In the same year, he started his bachelor studies in Chemical Engineering at the University of Twente. During these years, he was active in multiple committees at D.B.V. DIOK and C.T.S.G. Alembic. At the latter, he served as the chairman of the board for two consecutive years. In 2008, he performed his bachelor thesis at the North-West University in Potchefstroom, South-Africa. In the same year, he finished his bachelor studies and started with the master Chemical Engineering at the University of Twente, in the track Chemistry and Technology of Materials. In 2009, he performed his three-month professional internship at Teijin Aramid, Arnhem, The Netherlands. In 2010, he graduated cum laude from the University of Twente on a master thesis entitled: rapid manufacturing of thin layer ceramic membranes.

Starting from November 2010, he has been working as a PhD candidate at the Inorganic Membranes group at the University of Twente, under the supervision of prof.dr.ir. Arian Nijmeijer and prof.dr.ir. Nieck E. Benes. $\mathrm{He}$ presented his research at multiple international conferences and workshops, including the International Conference on Membranes and Membrane Processes (ICOM, 2011) and the International Conference on Inorganic Membranes (ICIM-13, 2014). The latter presentation was awarded a best oral presentation prize. In 2012, he was member of the organizational committee of the ICIM-12 in Enschede, and in 2013, he served as guest editor of the Special Issue on Inorganic Membranes of the Journal of Separation and Purification Technology. 



\section{List of publications}

Per December 2014

\section{Peer-reviewed international journals}

E.J. Kappert, D. Pavlenko, J. Malzbender, A. Nijmeijer, N.E. Benes, P.A. Tsai, 2015, Formation and prevention of fractures in sol-gel derived thin films, Soft Matter, accepted for publication. http://dx.doi.org/10.1039/C4SM02085E

P. de Wit, E.J. Kappert, T. Lohaus, M. Wessling, A. Nijmeijer, N.E. Benes, 2015, Highly permeable and mechanically robust silicon carbide hollow fiber membranes, J. Membr. Sci., 475, pp. 480-487. http://dx.doi.org/10.1016/j.memsci.2014.10.045

E.J. Kappert, H.J.M. Bouwmeester, N.E. Benes, A. Nijmeijer, 2014, Kinetic Analysis of the Thermal Processing of Silica and Organosilica, J. Phys. Chem. B, 18(19), pp. 5270-5277. http://dx.doi.org/10.1021/jp502344k E.J. Kappert, A. Nijmeijer, N.E. Benes, 2012, Expeditious Calcination of Inorganic Membranes by an Instant Temperature Increment, Microporous Mesoporous Mater., 151, pp. 211-215. http://dx.doi.org/10.1016/j.micromeso.2011.10.034

S. Shukla, P. de Wit, M.W.J. Luiten-Olieman, E.J. Kappert, A. Nijmeijer, N.E. Benes, 2014, Synthesis of Porous Inorganic Hollow Fibers without Harmful Solvents, ChemSusChem, accepted for publication. http://dx.doi.org/10.1002/cssc.201402483

E.J. Kappert, M.J.T. Raaijmakers, W. Ogieglo, A. Nijmeijer, C. Huiskes, N.E. Benes, 2014, Temperature calibration procedure for thin film substrates for thermo-ellipsometric analysis using melting point standards, Thermochim. Acta, 601, pp. 29-32, doi: 10.1016/j.tca.2014.12.017 


\section{Selected oral presentations}

Kappert, E.J., H.J.M. Bouwmeester, A. Nijmeijer, N.E. Benes, Rigorous Kinetic Analysis of the Thermal Treatment of Silica and Hybrid Silica Membrane Materials, International Conference on Inorganic Membranes (ICIM), 2014, Brisbane, Australia. Awarded with an Oral Presentation Award.

Kappert, E.J., A. Nijmeijer, N.E. Benes, High-performance Inorganic Membranes Produced by Rapid Heat Treatments, International Conference on Membranes and Membrane Processes (ICOM), 2011, Amsterdam, The Netherlands. 


\section{Emiel J. Kappert Firing Membranes}

